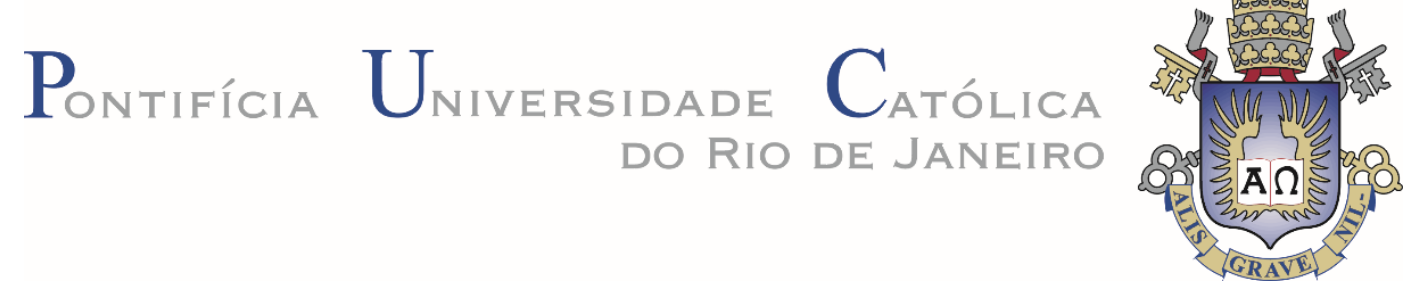

Andréa Ribeiro Carvalho De Castro

Efeitos do Uso da Realidade Aumentada sobre a Experiência do Consumidor no

Varejo e a sua Intenção de Compra

Tese de Doutorado

Tese apresentada ao Programa de Pós-graduação em Administração de Empresa da PUC-Rio como requisito parcial para obtenção do grau de Doutor em Administração de Empresas.

Orientador: Prof. Jorge Brantes Ferreira 


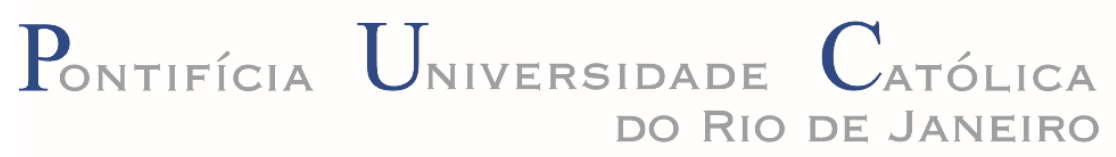

Andréa Ribeiro Carvalho De Castro

\section{Efeitos do Uso da Realidade Aumentada sobre a Experiência do Consumidor no Varejo e a sua Intenção de Compra}

Tese apresentada ao Programa de Pós-graduação em Administração de Empresa da PUC-Rio como requisito parcial para obtenção do grau de Doutor em Administração de Empresas. Aprovada pela Comissão Examinadora abaixo.

Prof. Jorge Brantes Ferreira

Orientador

Departamento de Administração - PUC-Rio

Profa. Angela Maria Cavalcanti da Rocha

Departamento de Administração - PUC-Rio

Prof. Marcus Wilcox

Hemais

Departamento de Administração - PUC-Rio

Prof. Angilberto Sabino de Freitas Universidade do Grande Rio

Profa. Paula Castro Pires de Souza Chimenti Universidade Federal do Rio de Janeiro

Profa. Ana Augusta Ferreira de Freitas

Universidade Estadual do Ceará

Rio de Janeiro, 14 de abril de 2020 
Todos os direitos reservados. É proibida a reprodução total ou parcial do trabalho sem autorização da universidade, do autor e do orientador.

\section{Andréa Ribeiro Carvalho de Castro}

Bacharel em Matemática com ênfase em Informática pela Universidade Estadual do Rio de Janeiro (1985). Mestre em Tecnologia da Informação pela Pontifícia Universidade Católica (1990). MBA em Marketing pelo IBMEC - Instituto Brasileiro de Mercado de Capitais (2005). Experiência Profissional - Área de Tecnologia da Informação (18 anos) e na área de Marketing (13 anos). Organizações/Empresas trabalhadas: Marinha do Brasil, Companhia Brasileira de Petróleo Ipiranga, Intelig Telecomunicações e Oi Telecomunicações.

Ficha Catalográfica

Castro, Andréa Ribeiro Carvalho de

Efeitos do uso da realidade aumentada sobre a experiência do consumidor no varejo e a sua intenção de compra / Andréa Ribeiro Carvalho de Castro ; orientador: Jorge Brantes Ferreira. - 2020.

188 f. : il. color. ; $30 \mathrm{~cm}$

Tese (doutorado)-Pontifícia Universidade Católica do Rio de Janeiro, Departamento de Administração, 2020.

Inclui bibliografia

1. Administração - Teses. 2. Realidade aumentada. 3. RA. 4. Realidade aumentada móvel. 5. Dispositivos móveis. 6. Experiências do usuário. I. Ferreira, Jorge Brantes. II. Pontifícia Universidade Católica do Rio de Janeiro. Departamento de Administração. III. Título. 


\section{Agradecimentos}

à minha mãe, Maria Teresa Reis Ribeiro e ao meu pai de coração, Aloysio Bastos Viannpelo apoio, estímulo, amor, carinho e por ceder gentilmente a casa deles para que eu pudesse ter um local adequado para os estudos. Sem isto, nada seria possível.

ao meu marido Phelipe e aos meus filhos, Isabela, Mariana e Rodrigo pelo incentivo e pela compreensão do meu tempo dedicado aos estudos.

ao Prof. Jorge Brantes, meu orientador, pelos seus ensinamentos, orientações e apoio ao longo dos últimos anos.

a CAPES e PUC-Rio, pelos auxílios concedidos que me permitiram realizar este trabalho. O presente trabalho foi realizado com apoio da Coordenação de Aperfeiçoamento de Pessoal de Nível Superior - Brasil (CAPES) - Código de Financiamento 001

a todos os professores do Doutorado de Administração da PUC-Rio, especialmente Prof. Angela Maria Cavalcanti da Rocha, Luis Fernando Hor-Meyll Alvares e Jorge Ferreira da Silva, pelos ensinamentos e orientações.

aos professores da graduação Luiz Paulo Moreira Lima e Alessandra Baiocchi Corrêa que me receberam com muito carinho em suas salas de aula para a realização do meu estágio em Docência.

aos funcionários do Departamento, pelo suporte dos membros da secretaria, especialmente a Teresa Campos, pela sua presteza e eficiência.

aos meus amigos da PUC-Rio, especialmente Elisa, Estefanie, Irene, Roberto e Tania, pelo companheirismo, pelas trocas de conhecimentos e experiências e pelas boas parceiras feitas em trabalhos e estudos.

ao amigo do doutorado Roberto Falcão por ter cedido o tempo de suas aulas na UFF para que eu pudesse fazer a coleta de dados com seus alunos.

a todos familiares e amigos, especialmente ao Jorge Carneiro e Patricia Freitas, que me ajudaram ou estimularam na realização da minha tese. 


\section{Resumo}

Castro, Andréa Ribeiro Carvalho de Castro; Ferreira, Jorge Brantes. Efeitos do Uso da Realidade Aumentada sobre a Experiência do Consumidor no Varejo e sua Intenção de Compra. Rio de Janeiro, 2020. 188p. Tese de Doutorado - Departamento de Administração, Pontifícia Universidade Católica do Rio de Janeiro.

Este estudo propõe fazer uma análise sobre o impacto da experiência de Realidade Aumentada (RA) aplicada no varejo online utilizando dispositivo móvel. Após a revisão de literatura feita sobre este tema, foi elaborado um modelo e foram formuladas hipóteses que permitissem investigar a relação entre a Experiência de Realidade Aumentada e a Intenção de Compra, sendo esta relação mediada por avaliações do consumidor, tais como, Certeza na Escolha, Satisfação do Usuário e a Emoção Positiva. Para testar o modelo, foi feito uma pesquisa com 201 consumidores. Os dados coletados foram analisados pelo método de modelagem de equações estruturais (SEM) e confirmaram a maioria das hipóteses formuladas, apresentando relações significativas dos construtos mediadores que ficam entre a Experiência de Realidade Aumentada e a Intenção de Compra. Os resultados indicam a importância da avaliação feita pelo consumidor sobre a Certeza na Escolha ao utilizar uma Experiência de Realidade Aumentada antes da Intenção de Compra. É oportuno mencionar que o construto Emoção Positiva também é um mediador significativo entre a Experiência de Realidade Aumentada e a Intenção de Compra, porém menos forte que a Certeza na Escolha. Estes resultados sugerem que os consumidores, após uma Experiência de Realidade Aumentada, são levados a avaliar os aspectos cognitivos e afetivos antes da decisão pela compra.

\section{Palavras-Chave}

Realidade Aumentada; RA; Realidade Aumentada Móvel; dispositivos móveis e experiências do usuário. 


\section{Abstract}

Castro, Andréa Ribeiro Carvalho de Castro; Ferreira, Jorge Brantes (Advisor). The implications of using Augmented Reality on the Retail Consumer Experience and the Purchase Intention associated. Rio de Janeiro, 2020. 188p. Doctoral Thesis - Departamento de Administração, Pontifícia Universidade Católica do Rio de Janeiro.

The purpose of this study is to analyze the impact of Augmented Reality (AR) experiences applied to online retails using a mobile device. After reviewing the literature on this topic, a model was elaborated, and hypotheses were formulated to investigate the relationship between the AR experience and the purchase intention. This relationship is mediated by consumer evaluations, such as certainty in the choice, user satisfaction, and positive emotions. To test the model, a survey was conducted with 201 consumers. The collected data were analyzed using the structural equation modeling method and confirmed most of the formulated hypotheses, presenting significant relationships between the mediating constructs with the AR experience and with the purchase intention. The results indicate the importance of the evaluation made by the consumer on the certainty of the choice when using an AR experience before the purchase intention. It is worth mentioning that the positive emotion construct is also a significant mediator between the AR experience and the purchase intention, but less strong than the certainty in the choice. These results suggest that consumers, after an AR Experience, are led to assess cognitive and affective aspects before purchase intention.

\section{Keywords}

Augmented reality; AR; mobile services; MAR; user experience and UX. 


\section{Sumário}

1 Introdução 15

$\begin{array}{ll}1.1 \text { Objetivos } & 17\end{array}$

$\begin{array}{ll}1.2 \text { Relevância do estudo } & 17\end{array}$

1.3 Delimitação da Tese 20

1.4 Questões a Investigar 21

1.5 Organização do Estudo 22

2 Revisão de Literatura $\quad 24$

2.1Estrutura da revisão 24

2.2 Conceituação 27

2.2.1 Realidade Aumentada $\quad 27$

2.2.2 Realidade Aumentada Móvel (MAR) 32

2.2.3 Provador Virtual (Virtual Try ou Virtual Fitting Room) 34

2.2.4 Tecnologia Interativa de Realidade Aumentada 35

2.2.5 Varejo Inteligente 38

2.2.6 Marketing Digital (via Mobile) 41

2.2.7 Marketing Experiencial $\quad 43$

2.2.8 Experiência de Realidade Aumentada dos Consumidores $\quad 47$

2.3 Teorias e Modelos Aplicados à Realidade Aumentada 48

2.3.1 Teoria da Difusão da Inovação (IDT) 49

2.3.2 Teoria do Fluxo 50

2.3.3 Teoria do Risco Percebido 51

2.3.4 Teoria de Efeitos de Mídia Interativa (TIME) 52

2.3.5 Modelo de Aceitação de Tecnologia (TAM) 53

2.3.6 Modelo de Aceitação de Compras Online (OSAM) 54

2.3.7 Modelo de Realidade Aumentada e Captura de Movimento 55

2.3.8 Modelo de Provador Virtual Online 55

2.3.9 Modelo para Aumentar a Intenção de Compra 56

2.3.10Modelo de Experiência de Produto Virtual (VPE) 56

2.3.11Modelos de Varejo Inteligente $\quad 57$

2.3.12Outros Modelos de Avaliação da Realidade Aumentada 59

2.4 Formulação do Modelo Conceitual e Hipóteses de Pesquisa 75

2.4.1 Modelo Proposto 77

2.4.2 Variável Dependente: Intenção de Compra 79 
2.4.3 Experiência de Varejo Inteligente $\quad 80$

2.4.3.1 Experiência de Realidade Aumentada 80

2.4.3.2 Vantagem Relativa $\quad 82$

2.4.3.3 Controle Percebido 82

2.4.3.4 Fruição percebida 83

2.4.3.5 Personalização 83

2.4.3.6 Realidade Aumentada Percebida 84

2.4.4 Mediadores entre Experiência de Realidade Aumentada
e Intenção de Compra

2.4.4.1 Certeza na escolha $\quad 85$

2.4.4.2 Satisfação do Usuário 87

2.4.4.3 Emoções Positivas 88

2.4.5 Modelos Alternativos Propostos $\quad 89$

2.4.5.1 Modelo Alternativo $1 \quad 90$

2.4.5.2 Modelo Alternativo $2 \quad 91$

3 Metodologia 93

3.1 Tipo de Pesquisa 94

3.2 Operacionalização das Variáveis 94

3.2.1 Definição Operacional das Variáveis 95

3.2.2 Procedimento de Adaptação das Escalas Utilizadas 100

3.2.3 Pré-teste do Instrumento de Pesquisa 101

3.3 População e Amostra 101

3.3.1 População 102

3.3.2 Amostra 102

3.4 Coleta de Dados 103

3.4.1 Instrumento de Coleta de Dados 103

3.4.2 Coleta de Dados 104

3.5 Análise de Dados 105

3.5.1 Validação e Confiabilidade 106

3.5.2 Análise Estatística 107

3.6 Limitações do Método 108

3.6.1 Limitações Relacionadas à Amostra 108

3.6.2 Limitações Relacionadas à Coleta de Dados 109 
4 Modelagem e Análise dos Dados 110

4.1 Caracterização da Amostra 110

4.2 Análises e Resultados $\quad 113$

4.2.1 Avaliação do Modelo de Mensuração 113

4.2.2 Validade e Confiabilidade dos Construtos 114

4.2.3 Análise do Modelo Estrutural 120

4.2.3.1 Normalidade dos Dados $\quad 120$

4.2.3.2 Ajuste do Modelo Proposto - Modelo \#1 121

4.2.3.3 Comparação com os Modelos Alternativos 126

4.2.3.3.1 Análise do Modelo Alternativo 1 - Modelo \#2 126

4.2.3.3.2 Análise do Modelo Alternativo 2 - Modelo \#3 128

4.2.3.3.3 Comparação dos Modelo \#1, \#2 e \#3 130

4.3 Discussão dos Resultados 133

4.3.1 Influência da Experiência de Realidade Aumentada
nos Construtos Mediadores

4.3.2 Influência dos Mediadores $\quad 136$

4.3.3 Influência da Satisfação do Usuário sobre a Intenção de Compra

4.3.4 Influência da Certeza na Escolha sobre a Intenção de Compra 140

4.3.5 Influência da Emoção Positiva sobre a Intenção de Compra 141

5 Conclusões e Recomendações 143

5.1 Resumo dos Resultados 143

5.2 Implicações Teóricas 147

5.3 Implicações Gerenciais $\quad 150$

5.4 Limitações 151

5.5 Sugestões de Pesquisas Futuras 152

6 Referências 154 


\section{Lista de Figuras}

Figura 2.1 - Gráfico Anual do Total de Artigos sobre Realidade Aumentada

Figura 2.2 - Realidade Mista

Figura 2.3 - Modelo de Efeitos de Mídia Interativa

Figura 2.4 - Modelo TAM Original 54

Figura 2.5 - Modelo de Experiência do Varejo Inteligente 58

Figura 2.6 - Modelo de Rese 60

Figura 2.7 - Modelo de Javornik 67

Figura 2.8 - Modelo de Poushneh e Vasquez-Parraga

Figura 2.9 - Modelo Proposto de Experiência Aumentada no Varejo Online

Figura 2.10 - Modelo Alternativo 1

Figura 2.11 - Modelo Alternativo 2 92

Figura 3.1 - Diagrama Metodológico 93

Figura 4.1 - Modelo Proposto do ARORM (Modelo \#1) 122

Figura 4.2 - Coeficientes Padronizados Estimados para o ARORM (Modelo \#1) 124

Figura 4.3 - Modelo Alternativo 1 (Modelo \#2) 127

Figura 4.4 - Modelo Alternativo 2 (Modelo \#3) 129

Figura 4.5 - Modelo ARORM Final 


\section{Lista de Tabelas}

Tabela 2.1: Quantidade de Artigos Selecionados

Tabela 2.2: Estudos Selecionados de Varejo Inteligente

com Realidade Aumentada

Tabela 2.3: Pesquisas de Aceitação dos Aplicativos

Realidade Aumentada

61

Tabela 2.4: Pesquisas de Aceitação dos Aplicativos de Realidade

Aumentada Complementar

Tabela 2.5: Resumo dos principais modelos e teorias

73

Tabela 3.1: Definição dos Construtos

95

Tabela 3.2: Operacionalização das Variáveis 96

Tabela 3.3: Variáveis Demográficas 99

Tabela 3.4: Perguntas Complementares para Análise dos Dados 99

Tabela 3.5: Construtos e os Itens Correspondentes no Questionário 100

Tabela 4.1: Característica da Amostra 111

Tabela 4.2: Perguntas Complementares $\quad 112$

Tabela 4.3: Avaliação dos Índices de Ajustes do Modelo

Mensuração Final

Tabela 4.4: Confiabilidade, Confiabilidade Composta e Variância Extraída da Média

Tabela 4.5: Cargas Fatoriais Padronizadas

Tabela 4.6: Comparativo entre Modelo Livre e Modelo Fixo

Tabela 4.7: Curtose dos Itens

Tabela 4.8: Avaliação dos Índices de Ajustes do Modelo Estrutural Proposto (Modelo \#1)

Tabela 4.9: Coeficientes Padronizados Estimados, Hipóteses e Significâncias para Modelo Estrutural Proposto

Tabela 4.10: Avaliação dos Índices de Ajustes do Modelo \#2 128

Tabela 4.11: Avaliação dos Índices de Ajustes do Modelo \#3 130

Tabela 4.12: Comparação dos Índices de Ajustes dos Modelos 130

Tabela 4.13: Coeficientes Padronizados Estimados e

Significância para os Modelos \#1, \#2 e \#3

Tabela 4.14: Resumo dos Resultados dos Testes de Hipóteses 


\section{Lista de Quadros}

Quadro 2.1 - Matriz De Tipologia De Valor Experiencial 46

Quadro 4.1 - Matriz de Correlação dos Construtos Estudados $\quad 115$

Quadro 4.2 - Matriz de Validade Discriminante 118 


\section{Lista de Siglas}

ARIT - Tecnologia Interativa de Realidade Aumentada

ARMC - Modelo de Realidade Aumentada e Captura de Movimento

ARORM - Modelo de Experiência Aumentada no Varejo Online

ECSI -Índice Europeu de Satisfação do Cliente

EDM - Modelo de não Confirmação de Expectativas

IAI - Inteligência Artificial

IDT - Teoria da Difusão da Inovação

ISSL - Modelo de Sucesso de Sistema de Informação

MAR - Realidade Aumentada Móvel

OSAM - Modelo de Aceitação de Compras Online

RA - Realidade Aumentada

RFID - Identificador de rádio frequência

RM - Realidade Mista

RV - Realidade Virtual

SEM - Modelo de Equação Estrutural

SRT - Experiência de Varejo Inteligente

TAM - Modelo de Aceitação de Tecnologia

TRA - Teoria da Ação Racionalizada

TIME - Teoria de Efeitos de Mídia Interativa

UTAUT - Teoria Unificada de Aceitação e Uso de Tecnologia

UX - Experiência do Usuário

VFR - Provador virtual

VPE - Experiência de Produto Virtual 
"O correr da vida embrulha tudo. A vida é assim: esquenta e esfria, aperta e daí afrouxa, sossega e depois desinquieta. O que ela quer da gente é coragem."

Guimaraes Rosa

"A esperança tem duas filhas lindas, a indignação e a coragem; a indignação nos ensina a não aceitar as coisas como estão; a coragem, a mudá-las."

Santo Agostinho 


\section{1 \\ INTRODUÇÃO}

A Realidade Aumentada (RA) é uma tecnologia que combina objetos reais com objetos virtuais gerados pelo computador em um ambiente real (AZUMA et al., 2001). Os analistas estimam que o setor de varejo será um dos mais impactados por essa tecnologia, já que esta possibilita maior aproximação entre os produtos oferecidos e seus consumidores. Segundo a MarketsandMarkets (2018), a estimativa da receita do mercado de tecnologia de Realidade Aumentada deve alcançar cerca de US\$ 60 bilhões em 2023. Esta receita é oito vezes maior do que a receita que foi prevista para 2019.

Este estudo propõe avaliar os efeitos do uso da tecnologia de Realidade Aumentada na experiência do consumidor e sua intenção de compra no varejo online via dispositivo móvel. Apesar das previsões de expansão do mercado da tecnologia de Realidade Aumentada, os estudos acadêmicos sobre o uso da Realidade Aumentada para o marketing experiencial ainda não foram suficientemente explorados. A literatura ressalta a importância da Realidade Aumentada para aprimorar a experiência de compra dos consumidores (CHEN et al., 2011; PEREIRA; SILVA; ALVES, 2011; WANG; LI, 2012; LEE; PARK, 2014). Os estudos existentes se limitaram a avaliar os aspectos utilitários das experiências com Realidade Aumentada. Huang e Liao (2015) notam que há uma carência de pesquisas que abordem as reações dos consumidores a essa tecnologia. É necessário avaliar se o consumidor se sente mais satisfeito, animado ou entusiasmado após uma experiência com Realidade Aumentada no varejo e se estes fatores podem aumentar a vontade do consumidor de fazer compras.

Além disso, o potencial da Realidade Aumentada no varejo online utilizando os dispositivos móveis (mobile commerce, ou m-commerce) não foi explorado em sua totalidade, como mencionado por Dacko (2017) em seu estudo sobre como e por que o uso de aplicativos de Realidade Aumentada Móvel (Mobile Augmented Reality - MAR) pode impactar no mercado de varejo. Os aplicativos de Realidade Aumentada Móvel são implementados nos dispositivos móveis (exemplos: smartphones, tablets ou óculos inteligentes). Dacko (2017) menciona que dados 
comportamentais sobre as experiências com aplicativos de Realidade Aumentada Móvel precisam ser examinados. Para isto, levam-se em consideração os fatores de avaliação do consumidor, tais como, satisfação do usuário, certeza na escolha e emoção positiva. A função da certeza na escolha é de permitir avaliar se o uso de uma experiência utilizando os recursos de Realidade Aumentada no varejo faz com que o consumidor tenha mais firmeza na escolha do produto a ser comprado.

Cada vez mais, as empresas estão preocupadas em criar experiências memoráveis aos seus clientes para fortalecer suas marcas e conquistar a lealdade deles. Com isto, ampliam-se as possibilidades e os desafios para se projetar experiências de marketing cada vez mais envolventes e prazerosas para os consumidores.

Espera-se que, nos próximos anos, profissionais e empresas desenvolvedoras de aplicativos para smartphones e tablets gerem uma enorme variedade de softwares utilizando a tecnologia de Realidade Aumentada. Esta tecnologia funciona com auxílio de recursos como o GPS e a câmera fotográfica, inserindo elementos virtuais - imagens, vídeos, textos etc. - para aprimorar a realidade que o usuário enxerga por meio de uma tela do celular. Porter e Heppelmann (2017), afirmaram que, no futuro próximo, a Realidade Aumentada será a nova interface homem-máquina. Essa interface é percebida como poderosa por preencher a lacuna entre o mundo físico e o digital, auxiliando as pessoas no aprimoramento de suas capacidades em compreender e aplicar informações no mundo real, usufruindo do novo conhecimento digital e dos recursos da máquina.

A interface de Realidade Aumentada permite ao usuário que o ambiente físico visto ao seu redor seja aprimorado por sobreposição digital de dados relevantes e orientado segundo a necessidade e o contexto adequado (PORTER; HEPPELMANN, 2017). Diversas áreas, tais como o Marketing, a Medicina, o Turismo, a Arquitetura, a Educação e os Jogos de Entretenimento, já buscam maneiras de explorar o uso de Realidade Aumentada em suas atividades para se beneficiarem dos recursos interativos que a tecnologia pode oferecer. 
$\mathrm{O}$ ambiente de compras e a experiência do consumidor no varejo podem ser transformados pela Realidade Aumentada, pois os estímulos visuais e sensoriais que ela proporciona podem ampliar contextos de compras e torná-los mais atraentes. Além disso, a Realidade Aumentada permite que os consumidores percebam e adquiram o prazer visual, bem como a estimulação sensorial de forma mais direta e imediata (FOGG, 2002; KIM; FORSYTHE, 2008a, b). É importante que os pesquisadores a considerem não apenas como uma tecnologia funcional, mas, sobretudo, como uma tecnologia persuasiva, capaz de formar, entregar e influenciar no valor experiencial (FOGG, 2002; MCCARTHY; WRIGHT, 2004).

A trajetória inicial da pesquisa investigou, de forma abrangente e atualizada, os estudos já realizados sobre o uso de Realidade Aumentada no marketing experiencial do varejo online. Após essa etapa, foi feita uma análise dedicada a entender os problemas, as inconsistências e as contradições detectadas por pesquisas anteriores, com a finalidade de contribuir com um estudo relevante sobre o tema.

\section{1}

\section{Objetivos}

O objetivo deste estudo é investigar como o uso da Realidade Aumentada em experiência do consumidor afeta a intenção de compra no varejo online via dispositivo móvel. Para isto, avalia-se como os efeitos da experiência de Realidade Aumentada - mediada por fatores de avaliação do consumidor estabelecidos após a experiência, tais como, certeza na escolha, emoção positiva e satisfação do usuário - afetam a intenção de compra no varejo online via dispositivo móvel.

\section{2 Relevância do estudo}

Para as áreas de pesquisa que abordam temas de inovação e marketing, este estudo contribuiu com a investigação em torno das avaliações do consumidor em relação aos aspectos utilitários e hedônicos de uma experiência com Realidade 
Aumentada, e os efeitos destas avaliações na intenção de compra no varejo online via dispositivo móvel. Estes efeitos, em conjunto, não foram encontrados em estudos anteriores. Foram avaliados fatores relacionados especificamente com a tecnologia estudada, assim como outros relacionados com a intenção de compra no varejo online via dispositivo móvel.

As primeiras pesquisas sobre Realidade Aumentada (por exemplo, LEE; FIORE; KIM, 2006; KIM; FORSYTHE, 2008a; CARMIGNIANI et al., 2011) examinaram percepções relacionadas às características e utilidades percebidas da tecnologia. As pesquisas mais recentes (por exemplo, JAVORNIK, 2016a; HILKEN et al., 2017, POUSHNEH; VASQUEZ-PARRAGA, 2017) evoluíram da avaliação de percepções técnicas a respeito da Realidade Aumentada para avaliações voltadas para suas aplicações no varejo.

Segundo Rese, Schreiber e Baier (2014), dada a importância da Realidade Aumentada no varejo, os estudos sobre a experiência de compra dos consumidores precisam ser aprimorados. As pesquisas empíricas sobre os efeitos do uso da Realidade Aumentada na decisão de compra online do consumidor ainda estão embrionárias (PANTANO; RESE; BAIER, 2017). Assim como Pantano, Rese e Baier (2017), Yadav e Pavlou (2014) também destacam a importância de Realidade Aumentada no futuro e afirmam que há uma escassez de pesquisas do comportamento do consumidor que envolvam aplicações desta tecnologia. $\mathrm{He}, \mathrm{Wu}$ e Li (2018) consideram que estudos futuros podem vir a examinar como a Realidade Aumentada afeta o prazer hedônico dos consumidores, a absorção de conhecimento e a recuperação da memória. De acordo com Javornik (2016b), dentre os efeitos não identificados em estudos sobre RA, ressaltam-se os elementos emocionais e hedônicos e os valores da experiência do usuário com o uso desta nova tecnologia. Segundo ela, há necessidade de avaliar se o comprometimento afetivo e o valor experiencial são mais relevantes e motivadores para os consumidores do que o compromisso racional, cognitivo e a busca de valores mais utilitários. Dado o potencial de criação de entretenimento pela Realidade Aumentada para o consumidor, Javornik et al. (2016) também salientam a necessidade de avaliar percepções diferentes entre as respostas cognitivas e afetivas nos diversos usos da tecnologia. 
Em vista disto, diversos estudos de Realidade Aumentada deram ênfase ao desempenho técnico das aplicações (por exemplo, BECK; CRIÉ, 2016; HILKEN et al., 2017; JAVORNIK, 2016a ; POUSHNEH, 2018; POUSHNEH; VASQUEZPARRAGA, 2017; YIM; CHU; SAUER, 2017), não avaliando o desempenho do uso desta tecnologia com relação à intenção de compra. Mais ainda, há uma carência de estudos que avaliem os efeitos utilitários e hedônicos envolvidos em experiências de Realidade Aumentada voltadas para a compra online via dispositivo móvel.

Apesar das pesquisas aprofundadas sobre teoria de Realidade Aumentada (SCHMALSTIEG; HOLLERER, 2016), serviços móveis (SAARIJÄRVI; MITRONEN; YRJÖLÄ, 2014) e valor do cliente experiencial (HUANG; HSU LIU, 2014; MATHWICK; MALHOTRA; RIGDON, 2001; SALO et al., 2013) terem mostrado o potencial da Realidade Aumentada Móvel (MAR), evidenciado pelos benefícios para clientes e varejistas, Dacko (2017), em sua revisão de literatura, verificou que ainda há muito a descrever e descobrir sobre a tecnologia de Realidade Aumentada Móvel (MAR) para permitir o varejo inteligente. Um varejo é considerado varejo inteligente quando faz uso de recursos tecnológicos para melhorar a qualidade das experiências de compras dos seus clientes. A pesquisa sobre a Realidade Aumentada dispositivo móvel está aumentando e é vista como uma área altamente relevante para pesquisas futuras, possivelmente pela onipresença dos smartphones (POUSTTCHI et al., 2015). Olsson et al. (2013) também consideraram que a experiência do usuário e as suas expectativas sobre os serviços da tecnologia da Realidade Aumentada Móvel receberam pouca atenção apesar da sua relevância. Este estudo deu especial atenção na avaliação de serviço desta tecnologia voltado para o varejo inteligente.

Da mesma forma, Roy et al. (2017), em seus estudos de tecnologia de varejo inteligente, ressaltam a necessidade de pesquisas futuras utilizando um modelo para tratar de uma tecnologia específica aplicada no varejo inteligente. No estudo de Roy et al. (2017), várias tecnologias de varejo inteligente, tais como Realidade Aumentada e RFID (Radio-Frequency IDentification) usado em etiquetas, foram testadas conjuntamente em um modelo para o varejo inteligente. As SRTs (smart retail technology) podem diferir de uma tecnologia para outra, em termos de 
atributos, tais como risco e interatividade, e de valor para o cliente, representado por construtos como conveniência e esforço. Assim sendo, este estudo vai contribuir com uma visão particular ao avaliar a experiência do cliente e sua influência na intenção de compra quando é utilizada uma tecnologia específica do varejo inteligente, a Realidade Aumentada Móvel.

A potencial ascensão dessa indústria nos próximos anos permitirá a construção mais aplicativos do varejo utilizando a tecnologia de Realidade Aumentada que poderão ser utilizando nos estudos acadêmicos. O mercado de Realidade Aumentada foi avaliado em US\$4,21 bilhões em 2017 e deve atingir US\$60,55 bilhões até 2023 (MARKETSANDMARKETS, 2018). Diversas empresas de tecnologia, como Google, Microsoft e Apple, estão desenvolvendo ferramentas que facilitarão o uso da Realidade Aumentada em dispositivos móveis para outras empresas. Apesar dos desafios na implantação das ferramentas, verificase que várias organizações como Amazon, Facebook, General Electric, Mayo Clinic e a Marinha dos EUA já estão implementando tecnologias de Realidade Aumentada em seus negócios, com impactos significativos no desempenho destas empresas (PORTER; HEPPELMANN, 2017).

A relevância empresarial deste estudo decorre da possibilidade de contribuir para o incentivo ao varejista na elaboração de novas experiencias de Realidade Aumentada com vista no aumento das compras. A tecnologia de Realidade Aumentada pode oferecer recursos que podem melhorar as experiências de compras online.

O presente estudo tem caráter original, pois propõe uma abordagem para avaliação da Realidade Aumentada Móvel no Marketing Experiencial, não tendo sido encontrada uma a abordagem similar a proposta na revisão de literatura.

\section{3}

\section{Delimitação da Tese}

O presente estudo apresenta uma delimitação na sua metodologia ao utilizar apenas uma aplicação de Realidade Aumentada no varejo online via dispositivo 
móvel. Este aplicativo escolhido contém uma única categoria de produto ofertada. Foi utilizado como recurso de apresentação das imagens sempre um mesmo tipo de dispositivo móvel com alta resolução de tela (um tablet) para garantir uma visão padronizada a todos os participantes.

Para garantir a homogeneidade da amostra, a coleta dos dados foi feita com consumidores do Rio de Janeiro e Niterói. A escolha destas duas cidades deve-se a conveniência do pesquisador em realizar a coleta nestes locais. O período da coleta de dados da amostra foi de junho de 2019 até agosto do mesmo ano.

Dentre a delimitação teórica, foram utilizadas as teorias e os modelos extraídos de artigos no período de 2012 até 2019 relacionados com a adoção e uso da nova tecnologia inteligente de Realidade Aumentada aplicada ao varejo. As teorias predominantes foram as relacionadas com varejo inteligente e marketing experiencial utilizando realidade aumentada.

\section{4 \\ Questões a Investigar}

As questões a investigar deste estudo foram definidas com base nas afirmações de estudos anteriores (JAVORNIK, 2016b; PANTANO; RESE; BAIER, 2017) sobre a necessidade de mais pesquisas que avaliem como as experiências de Realidade Aumentada afetam o comportamento do consumidor e como este comportamento pode afetar o processo decisório de compras online via dispositivo móvel. Javornik (2016b) sugere que novos estudos avaliem se o comprometimento afetivo é mais importante e motivador para os consumidores do que os fatores cognitivos.

Os fatores escolhidos para avaliar o comportamento do consumidor foram baseados nas análises dos estudos anteriores. São eles: satisfação do usuário (NOORDIN; ASHAARI; WOOK, 2017; ROY et al, 2017) , certeza na escolha (BECK; CRIÉ, 2016; LEMOINE; NOTEBAERT, 2011; OH; YOON; SHYU, 2008) e emoções positivas (MURRAY; HÄUBL, 2008; OLSSON et al., 2013). 
Esta pesquisa sobre Realidade Aumentada Móvel procura responder às questões a seguir:

1) A experiência da Realidade Aumentada no varejo online via dispositivo móvel tem efeito significativo sobre a certeza na escolha, emoção positiva e satisfação do usuário?

2) A certeza na escolha, emoção positiva e satisfação do usuário têm efeitos significativos sobre a intenção de compra no varejo online via dispositivo móvel dos consumidores, em um contexto de experiência da RA?

3) A certeza na escolha, emoção positiva e satisfação do usuário são mediadores dos efeitos da experiência da Realidade Aumentada sobre a intenção de compra no varejo online via dispositivo móvel?

\section{5}

\section{Organização do Estudo}

O estudo está organizado em cinco capítulos: Introdução, Revisão de Literatura, Metodologia, Resultados e Conclusão.

O primeiro capítulo apresenta o problema da pesquisa, seus objetivos e tece considerações sobre a relevância desse estudo na avaliação dos efeitos do uso da Realidade Aumentada sobre a experiência do consumidor no varejo e sobre a sua intenção de compra.

O segundo capítulo trata da revisão de literatura realizada sobre o tema, incluindo os modelos existentes e construtos utilizados nos últimos estudos sobre o assunto. Esta etapa termina com as apresentações de um modelo proposto, modelos alternativos e das hipóteses da pesquisa.

O terceiro capítulo aborda metodologia da pesquisa, definindo o tipo de pesquisa, a forma da coleta de dados, a população, o método de amostragem, os procedimentos para a elaboração da pesquisa, os métodos que são empregados na análise dos dados e as limitações do estudo decorrente da metodologia utilizada. 
O capítulo quatro apresenta os resultados do estudo. Estão contidos neste capítulo os dados do questionário, as análises estatísticas dos dados quantitativos e a discussão dos resultados. O estudo usa a modelagem de equações estruturais (SEM), sendo este método estatístico utilizado em diversas pesquisas que abordam este tema. São aplicados os testes do modelo de mensuração e dos diversos modelos estruturais considerados, além dos testes das hipóteses da pesquisa e das relações identificadas entre os construtos definidos.

O capítulo cinco apresenta as conclusões, resumindo os resultados encontrados e apresentando as conclusões relevantes do estudo, as limitações do estudo e suas contribuições teóricas e empresariais, além de sugestões de pesquisas futuras. Após a conclusão, são apresentados as referências bibliográficas e os apêndices com o layout do questionário e imagens sobre a tese. 


\section{2 REVISÃO DE LITERATURA}

Este capítulo tem como objetivo abordar os temas Marketing Experiencial no Varejo inteligente online, Realidade Aumentada, Intenção de Compra e suas interligações.

\section{1}

\section{Estrutura da revisão}

A estrutura dessa revisão foi organizada em quatro etapas. A primeira etapa apresenta as conceituações da Realidade Aumentada (AZUMA et al., 2001; CARMIGNIANI et al., 2011), da Realidade Aumentada Móvel (MAR) (AZUMA et al., 2004), do varejo inteligente (PANTANO; TIMMERMANS, 2014), do marketing experiencial (HASSENZAHL; ULLRICH, 2007) e de outros temas afins. Na etapa seguinte, são apresentados as teorias e os modelos já existentes que se relacionam com o tema do estudo e suas análises, com o objetivo de apontar as inconsistências, contradições ou problemas ainda não solucionados. No fim do capítulo, são mostrados o modelo conceitual, os construtos e as suas relações e, com base neste modelo, formuladas as hipóteses do estudo. Além do modelo principal, foram testados outros dois modelos alternativos.

Para a seleção dos artigos sobre esses temas, foram feitas pesquisas nos periódicos internacionais mais importantes classificados pelo JCR (Journal Citation Report) com o fator de impacto maior ou igual 1 e nos periódicos nacionais classificados pelo Qualis com as categorias A1, A2, B1 e B2. Os temas selecionados foram Marketing Experiencial, Realidade Aumentada, Intenção de Compras e Dispositivos Móveis e suas interligações dentro das áreas de Administração, Negócios e Tecnologia. Essa última área foi selecionada apenas quando relacionada a uma aplicação de Realidade Aumentada no varejo. Os estudos foram concentrados a partir de 2012 até abril de 2019 para garantir a atualidade do tema. Além disto, o gráfico anual de evolução de números de artigos publicados mostra poucos estudos anteriores a este período dada a inovação desta tecnologia. 
As explorações iniciais foram realizadas nas principais bases de dados: Web of Science, Scopus e Spell com período selecionado de 2012 até 2017. Foram também incorporados alguns estudos relevantes citados nos artigos selecionados na primeira etapa, ampliando a quantidade de artigos estudados. Vale ressaltar que alguns artigos seminais de marketing pertinentes ao tema do presente estudo e com datas anteriores ao período inicial selecionado entraram na revisão de literatura (por exemplo, AZUMA et al., 2001, 2004; BARNES; SCORNAVACCA, 2004; CARMIGNIANI et al., 2011; DAVIS, 1989; DAVIS; BAGOZZI; WARSHAW, 1992; HIRSCHMAN; HOLBROOK, 1982; HOLBROOK, 1994; HOFFMAN; NOVAK, 1996; KIM; FORSYTHE, 2008a, 2008b; PORTER; DONTHU, 2006; ROGERS, 2003). Nesta revisão foram encontrados os modelos de aceitação de tecnologia (TAM) (DAVIS, 1993), teoria unificada de aceitação e uso de tecnologia (UTAUT) (VENKATESH et al., 2003); teoria da difusão (IDT) (ROGERS, 2003), teoria do fluxo (CSIKSZENTMIHALYI, 1990; HOFFMAN; NOVAK, 1996); modelo de interação homem-computador (PANTANO; SERVIDIO, 2012), e teoria de efeitos de mídia interativa (BRYANT; OLIVER, 2009).

A figura 2.1 contém um gráfico com a quantidade de artigos publicados por ano obtidos das bases Web of Science e Scopus. Verificou-se um crescimento anual do número de artigos encontrados sobre Realidade Aumentada, a partir de 2012 até abril de 2019. Estes resultados corroboram a justificativa de que este assunto está em expansão e apontam para o fato de que a adoção e efeitos da Realidade Aumentada são campos de estudo que ainda possuem lacunas a serem preenchidas por novos estudos.

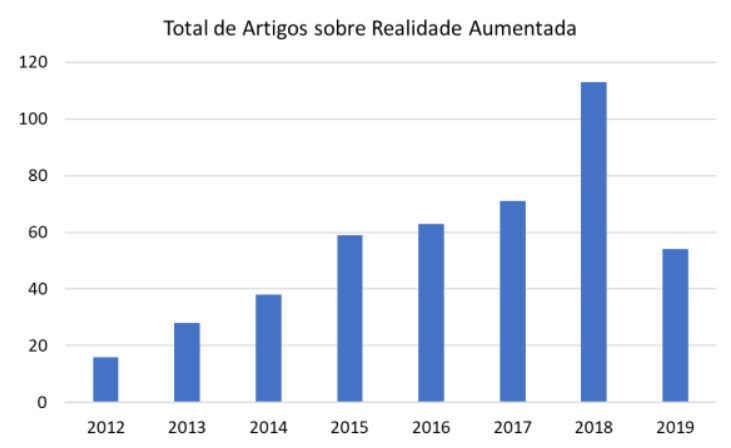

Figura 2.1 - Gráfico Anual do Total de Artigos sobre Realidade Aumentada Fonte: adaptação própria - dados obtidos da Web of Science e Scopus 
Mais evidências de que este tema não foi ainda devidamente explorado foram encontradas no artigo de revisão bibliométrica sobre o tema Realidade Aumentada feito por Alvarez, Castillo e Geldes (2017). Este artigo evidenciou que, no período de 1993 até 2011, as publicações feitas sobre este tema eram mais técnicas, como acontece normalmente nos primeiros anos de desenvolvimento de uma nova tecnologia. A partir de 2012, os estudos são focados na relação da tecnologia com pessoas e sua integração nas atividades diárias. Isso reforça mais ainda a oportunidade de estudos aplicados na área de administração de empresas.

Numa nova rodada de pesquisa na literatura feita em 2018, foram selecionados 88 artigos indicados pelo Mendeley que foram publicados em $2018 \mathrm{e}$ 2019. As indicações feitas pelo Mendeley foram baseadas na definição prévia dos temas de interesse deste estudo. Dos artigos sugeridos, 23 foram selecionados pela avaliação do conteúdo dos artigos apresentados em seus resumos e pelo critério definido para seleção de periódicos (fator de impacto maior ou igual a 1). Além dos artigos selecionados pelo Mendeley, foram pesquisadas novamente as bases Scopus e Web of Science os artigos publicados em 2018 até abril de 2019, das quais foram selecionados mais 17 artigos.

A tabela 2.1 contém os critérios aplicados (filtros) sobre as bases, a quantidade de artigos obtidos nas pesquisas e quantidade de artigos selecionados para a revisão de literatura. Após a obtenção dos artigos filtrados nas bases foram aplicados mais dois critérios para a selecionar os artigos para a revisão de literatura. O primeiro critério foi selecionar apenas os artigos de periódicos com fator de impacto maior ou igual 1 ou classificados pelo Qualis com as categorias A1, A2, B1 e B2. Após aplicação do filtro dos periódicos, foi realizado uma nova seleção de artigos a partir da avaliação dos artigos pelos seus resumos. Após a aplicação destes critérios, foram selecionados na fase inicial (fase 1) 116 artigos para a revisão e mais 41 artigos na segunda rodada (fase 2), totalizando 157 artigos.

Com base na classificação do fator de impacto do periódico, no número de citações do artigo e na relevância identificada pelo resumo, foi definida a prioridade de leitura dos artigos. 
Os critérios de seleção aplicados nas bases, além das palavras-chave e áreas mencionadas anteriormente, foram referentes ao período de 2012 até abril de 2019 e ao tipo do documento na forma de artigo. Desta pesquisa, foram encontrados poucos estudos sobre marketing experiencial utilizando a tecnologia de Realidade Aumentada Móvel (MAR). Na tabela 2.1 são apresentadas as palavras-chave utilizadas com a quantidade inicial e final de artigos selecionados para a revisão de literatura.

Tabela 2.1 - Quantidade de Artigos Selecionados

\begin{tabular}{|c|l|c|c|}
\hline Fase & Palavra-chave & Qtd artigos & Qtd artigos selec. \\
\hline & $\begin{array}{l}\text { augmented reality and (retail user experience or } \\
\text { interactive experience or experiential value or, } \\
\text { purchase intention or willingness to buy or } \\
\text { smartphone or mobile or cell phone or acceptance } \\
\text { modeling or acceptance model) }\end{array}$ & 422 & 116 \\
\hline $\mathbf{2}$ & purchase intention and augmented reality & 95 & 41 \\
\hline Total & & & $\mathbf{1 5 7}$ \\
\hline
\end{tabular}

Fonte: elaboração própria

\section{2 \\ Conceituação}

Nas seções a seguir serão apresentados os principais conceitos encontrados nos estudos sobre Realidade Aumentada, experiências de marketing, varejo inteligente e vendas online com dispositivos móveis. Estes conceitos foram obtidos na revisão de literatura.

\subsection{1}

\section{Realidade Aumentada}

A definição mais simples e disseminada sobre Realidade Aumentada augmented reality - (RA) no ambiente acadêmico foi dada por Azuma et al. (2001). Eles definiram a Realidade Aumentada como uma tecnologia que combina elementos reais e virtuais gerados pelo computador em um ambiente real. Ao longo 
dos anos, outros acadêmicos aprimoraram esta definição. Uma definição mais atual, também bem aceita, foi dada por Carmigniani et al. (2011). A Realidade Aumentada é uma visão direta ou indireta em tempo real de um ambiente real que foi aumentada pela adição de informações virtuais geradas por computador. A Realidade Aumentada é interativa e registrada em $3 \mathrm{D}$, além de combinar objetos reais e virtuais (CARMIGNIANI et al., 2011). Daponte (2014) acrescentou que a percepção sensorial de uma pessoa é enriquecida pela superposição de objetos virtuais 3D no ambiente do usuário. A sobreposição de conteúdos digitais em ambientes reais implementada na Realidade Aumentada permite que as pessoas processem de maneira simultânea o físico e o digital, tornando desnecessário a união mental dos dois.

Porter e Heppelmann (2017) ressaltam que o mundo físico é tridimensional, e que páginas e telas dos computadores, tablets e celulares são bidimensionais. Essa diferença dimensional, entre o real e o digital, limita substancialmente a exploração de informações atualmente disponíveis. Isto exige que as pessoas traduzam mentalmente as informações 2D disponíveis nas telas para o uso em um ambiente real em 3D. As características 3D da interface da Realidade Aumentada implementada, por exemplo, nos óculos inteligentes reduziram esta diferença. Os aplicativos de Realidade Aumentada são comumente utilizados em dispositivos móveis, tais como celulares e tablets, porém, cada vez mais, serão utilizados em dispositivos vestíveis, como por exemplo, os óculos inteligentes e monitores na cabeça (heads-up).

Azuma (2017) também previu esta possibilidade de que os sistemas vestíveis venham a substituir os smartphones. Segundo ele, as vantagens dos vestíveis em relação aos seus substitutos seriam a capacidade destes sistemas de fornecer exibição mais abrangente, de forma compacta e com a liberação das mãos. Estes monitores na cabeça requerem mais avanços tecnológicos e, por isto, ainda devem levar mais alguns anos para sua disseminação em massa.

Em contrapartida, o grande sucesso de uma experiência mais simples da tecnologia de Realidade Aumentada já foi evidenciado em 2016 pelo jogo Pokémon Go, tendo mais de 700 milhões de downloads e uma receita de cerca de 1 bilhão de dólares segundo a Tecmundo (2017). Isto pode evidenciar que o êxito desta 
tecnologia pode ser obtido mesmo sem ter todos os avanços tecnológicos esperados implementados em Realidade Aumentada (AZUMA, 2017).

Segundo Porter e Heppelmann (2017), as pessoas estão familiarizadas com aplicativos simples de entretenimento de Realidade Aumentada, como os filtros do Snapchat ou Instagram e o jogo Pokémon Go. No entanto, a Realidade Aumentada está sendo utilizada de forma mais abrangente nas configurações do consumidor e do business-to-business. Da mesma forma, Porter e Heppelmann (2017) afirmam que o uso disseminado da Realidade Aumentada poderá alterar o número de lojas físicas no varejo. A interação via Realidade Aumentada, embora ainda emergente, terá grande influência em vários setores que envolvem produtos personalizados e de controle complexo. Vale destacar que estas interações estão presentes em diversas áreas e, segundo Jamali et al. (2015), essa evolução deve-se ao aumento significativo do uso da Realidade Aumentada via dispositivos móveis, oferecendo um potencial elevado de treinamento e aprendizagem.

De acordo com Adhani e Rambli (2012), ao apresentar informações adicionais sobre produtos em termos de conteúdo virtual, o aplicativo de Realidade Aumentada pode influenciar os consumidores na decisão de compra. O consumidor pode fazer uso de sua imagem pessoal com informações adicionais de forma interativa tanto na loja física como virtual, criando modelos virtuais com os seus produtos preferidos.

Olsson et al. (2013) constataram que o valor de um aplicativo de Realidade Aumentada foi evidenciado pelo fornecimento de informações adicionais úteis e relevantes, associadas a lugares, pessoas, transportes e problemas momentâneos.

Segundo Huang e Liao (2015), essa tecnologia pode oferecer uma narrativa rica que aumenta o valor da experiência entregue. A aceitação de uma tecnologia é um dos aspectos mais importantes de estudo quando se deseja incorporar uma tecnologia em diversas áreas e, assim, levar a oportunidades de negócios.

Para Olsson et al. (2013), o conceito de Realidade Aumentada se relaciona com um conceito de realidade mista $(\mathrm{RM})$. A realidade mista refere-se à integração e fusão dos mundos real e virtual onde os objetos físicos e virtuais se complementam e interagem um com o outro (MILGRAM; KISHINO, 1994). A Realidade Aumentada geralmente é entendida como parte da realidade mista. A 
figura 2.2 mostra os tipos de Realidades (Aumentada, Virtual ou Mista) e os seus ambientes.

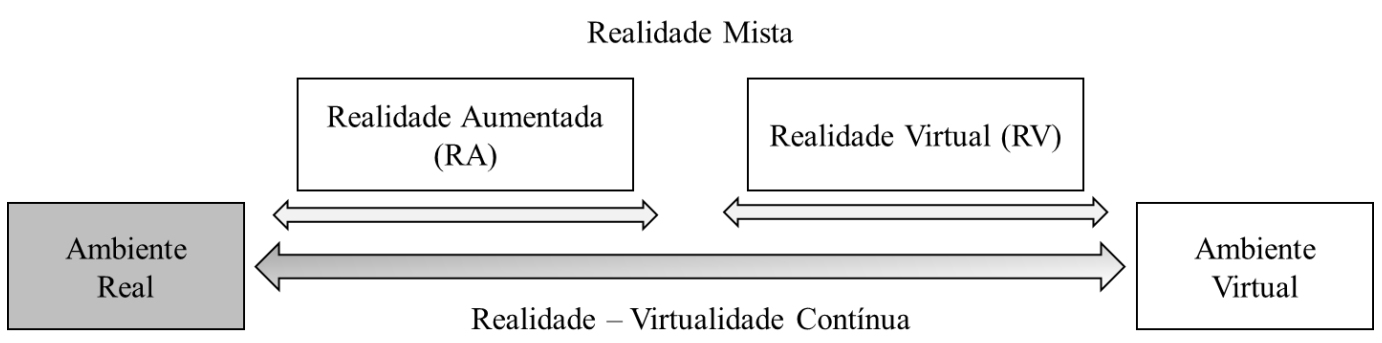

Figura 2.2 - Realidade Mista

Fonte: Adaptado de Milgram e Kishino (1994)

Os componentes necessários para o funcionamento desta tecnologia são: objeto real, objeto virtual (exemplo: imagens, textos ou vídeos), dispositivo de transmissão de imagem (exemplo: smartphone, tablets ou smartglass) e software de interpretação. Esta tecnologia explora hipertextualidade, conectividade, especificidade de localização, sincronização entre o real e o virtual e interatividade do computador-homem de forma portável ou vestível.

A realidade virtual (RV) difere da Realidade Aumentada (RA) pelo ambiente em que ambas se inserem. A Realidade Virtual substitui inteiramente a visão do mundo real ao criar um ambiente virtual com elementos virtuais. Diferentemente da Realidade Virtual, a Realidade Aumentada mantém a visão do mundo real, complementando este ambiente com elementos virtuais pertinentes ao contexto (AZUMA, 2017). Para o autor, a Realidade Aumentada tem mais potencial no mercado do que Realidade Virtual, pois melhora a compreensão e a interação do usuário com o mundo real. Embora a Realidade Aumentada tenha se mostrado uma tecnologia envolvente e promissora, Van Krevelen e Poelman (2010) apontaram algumas limitações na sua adoção, como a aceitação social e o desafio de persuadir as pessoas no seu uso. Isto se deve pela necessidade do engajamento do consumidor ao, por exemplo, ter que fazer download de um aplicativo no seu tablet ou smartphone para habilitar o uso de Realidade Aumentada. (ROSS; HARRISON, 2016).

Segundo Scholz e Duffy (2018), os estudos iniciais abordavam avaliações sobre as primeiras implementações de Realidade Aumentada no varejo, feitas com 
os provadores virtuais que fazem a sobreposição de roupas e calçados virtuais (por exemplo, PONCIN; MIMOUN, 2014). Já os estudos mais recentes têm avaliado os aplicativos de Realidade Aumentada implementados nos dispositivos móveis (por exemplo, HILKEN et al., 2017; POUSHNEH, 2018; POUSHNEH; VASQUEZPARRAGA, 2017; YIM; CHU; SAUER, 2017) que são destinados para um amplo público de consumidores (PORTER; HEPPELMANN, 2017). Para usos que influenciam a experiência do consumidor, além dos smartphones, um outro tipo de dispositivo móvel é utilizado, os tablets, por estes oferecem recursos de telas maiores, visualização melhor dos gráficos e bom poder de processamento nos aplicativos mais elaborados de Realidade Aumentada. Neste caso, como este tipo de dispositivo não é tão disseminado quanto os smartphones, os varejistas têm como prática fornecer os tablets em suas lojas para realização da experiência.

Para Azuma (2017), os aplicativos de Realidade Aumentada devem evoluir para os smartglasses, tais como o Meta 2, o HoloLens, da Microsoft, e o Smart Helmet, da DAQRI que apresentam visores transparentes e óticos, projetados para esta finalidade. Estes visores permitem a adição virtual do elemento numa visão direta, evitando distorções do usuário sobre o ambiente real. $\mathrm{O}$ aprimoramento desta característica de "transparência ótica" tem sido um desafio para os fabricantes destes óculos. Outro obstáculo é o aprimoramento da detecção de profundidade para tornar a imagem mais inteligente.

Além destes desafios tecnológicos, ressalta Azuma (2017), há também o grande desafio da criação de experiências de Realidade Aumentada que se conectem de forma significativa com o mundo real, pois elas necessitam de um sistema que entenda a semântica do ambiente, limitando assim, a sua utilidade e riqueza. Outro ponto importante é que ambos os aspectos tecnológico e criativo de aplicações úteis devem evoluir de forma integrada para o sucesso do Realidade Aumentada Móvel.

O estado atual de implementações de Realidade Aumentada mostra a adesão de marcas importantes do varejo, tais como IKEA, Wayfair e Sephora, que estão criando aplicativos Realidade Aumentada Móvel para os consumidores experimentarem "virtualmente" os produtos em seus corpos e em seus próprios espaços. Estas aplicações de Realidade Aumentada foram estudadas em diversos 
segmentos do varejo, como os de mobiliário (RESE; SCHREIBER; BAIER, 2014), óculos (HILKEN et al., 2017; POUSHNEH;VASQUEZ-PARRAGA, 2017; RESE et al., 2017), relógios (YIM; CHU; SAUER, 2017) e produtos e serviços de beleza (CENTRIC DIGITAL, 2017).

\subsection{2}

\section{Realidade Aumentada Móvel (MAR)}

Os dispositivos móveis inteligentes, smartphones, permitiram aos seus usuários uma maior mobilidade e portabilidade, não servindo apenas para conectar as pessoas por meio de chamadas, mensagens, redes sociais e e-mails, mas também como assistentes pessoais dos usuários, centro de mídia, recursos de trabalho, navegador, entretenimento, guia turístico, relógio, entre outros. O telefone celular é um dos poucos produtos de consumo que ganhou aceitação global em um período relativamente curto (BARNES; SCORNAVACCA, 2004). Para os profissionais de marketing, a adoção generalizada de telefones celulares representa uma boa oportunidade para alcançar e servir os consumidores a qualquer hora e lugar (GRANT; O'DONOHOE, 2007; ROACH, 2009; BARUTÇU, 2007).

Em termos de variáveis comportamentais, Grant e O'Donohoe (2007), em suas pesquisas, descobriram cinco fatores que motivam os consumidores jovens a utilizar os telefones celulares: (1) entretenimento conveniente; (2) estimulação social; (3) escapismo; (4) aprendizagem experiencial; e (5) obtenção de informações e conselhos. Eles acrescentam que a conveniência e a flexibilidade do marketing eletrônico podem ajudar a criar relacionamento e fidelidade de marca com consumidores de alto valor. Persaud e Azhar (2012) adicionam que o marketing móvel deve resultar em benefícios tangíveis para os consumidores em termos de conveniência, eficiência, flexibilidade e relevância.

Outro benefício importante advindo dos smartphones foi o de propiciar a introdução da Realidade Aumentada no mercado de massa. Embora a Realidade Aumentada seja normalmente considerada mais visual, os dispositivos móveis atuais também podem enriquecer com informações auditiva ou háptica (sinônimo de tátil). Assim, as marcas do varejo já são capazes de explorar novas experiências 
visuais e sensoriais para aproximar o público de seus produtos usando Realidade Aumentada por meio dos smartphones.

Benou e Vassilakis (2010) acrescentam que os aplicativos móveis de Realidade Aumentada (MAR) oferecem m-serviços que liberam cada vez mais os clientes de restrições de tempo e local, permitindo ganhos de benefícios adicionais além destes dois. Essa tecnologia de Realidade Aumentada Móvel (MAR) é habilitada por dispositivos de mídia móvel que combinam câmera, tela, localização/GPS, acelerômetro e bússola, capacidade de reconhecimento de imagem e acesso à internet, permitindo meios de interação entre usuário e sistema (AZUMA et al., 2004). A imersão da Realidade Aumentada Móvel no varejo pode ser feita tanto com os dispositivos móveis mais comuns, tais como smartphones ou tablets, quanto com os dispositivos vestíveis, tais como óculos inteligentes ou displays transparentes montados na cabeça (BILLINGHURST et al., 2015; HUANG et al., 2013).

Essas capacidades, por exemplo, quando usadas em negócios relativos ao turismo, tornam as experiências turísticas mais agradáveis, personalizadas e interessantes. Segundo Jung, Chung e Leue (2015), há uma relação importante entre a satisfação turística e a qualidade percebida das aplicações de Realidade Aumentada Móvel para prever as intenções do comportamento do turista. Assim, a Realidade Aumentada Móvel no turismo pode impulsionar compras não intencionais em viagens turísticas. No estudo sobre Realidade Aumentada Móvel de Wang e Li (2012), foram apresentados relatos de aumento da satisfação do uso dos smartphones pelos turistas em diversos contextos de viagens e situações. Portanto, vários pesquisadores concordam com a afirmação de que os smartphones permitem ubiquidade e onipresença, e seu contexto pode gerar boas oportunidades de compras, podendo a tecnologia de Realidade Aumentada se beneficiar mais ainda destes recursos para aprimorar a experiência do consumidor e aumentar seu interesse em comprar.

Para criar serviços Realidade Aumentada Móvel com sucesso para os consumidores, é primordial entender o que estes consumidores esperam dessa experiência de interação. Em relação aos varejistas, o sucesso da Realidade Aumentada Móvel dependerá do valor que esta tecnologia acrescentará ao negócio. 
(PANTANO; VIASSONE, 2014). Dacko (2017) encontrou, em sua revisão de literatura sobre aplicativos Realidade Aumentada Móvel para compras, várias evidências dos benefícios em potencial que estes aplicativos podem trazer para a criação de valor de varejistas e clientes.

Pelos aplicativos de Realidade Aumentada Móvel, pode-se apresentar as ofertas do varejo com informações adicionais e aprimoradas ao contexto, apoiando as decisões de compra do cliente. Ele também acrescenta que a surpresa dos elementos adicionados ao ambiente serve para entreter o consumidor, incentivá-lo as compras e cria o valor da novidade, que pode ser compartilhada em redes sociais. Além disso, outro aspecto relevante é que o varejista pode coletar mais informações sobre as preferências dos consumidores.

Segundo Ramakrishna et al. (2013), um problema associado à aplicação da Realidade Aumentada Móvel em relação ao comprador está na dificuldade ou na demora em aprender a utilizar este tipo de aplicativo. Para Dacto (2017), o fato desta tecnologia estar num estágio inicial de adoção faz com que ainda há muitos desafios e problemas que ainda precisam ser endereçados no desenvolvimento e implementação de aplicativos de Realidade Aumentada Móvel (DACKO, 2017; SCHOLZ; DUFFY, 2018).

\subsection{3 \\ Provador Virtual (Virtual Try ou Virtual Fitting Room)}

O provador virtual que usa a tecnologia de Realidade Aumentada é uma adaptação do conceito de provador das lojas físicas e tem como objetivo ajudar os consumidores a escolherem adequadamente os seus produtos em compras online. Este tipo de recurso auxilia, por exemplo, na escolha do tamanho correto de uma roupa, solucionando o problema do número elevado de devolução de roupas compradas online erradamente (NOORDIN; ASHAARI; WOOK, 2017). Na literatura foram encontrados diversos nomes para os provadores virtuais: espelhos mágicos (magic mirrors), sala de provador virtual (virtual fitting room) ou experimentação virtual (virtual try). Estas aplicações práticas de Realidade Aumentada em marketing começaram a aparecer no fim dos anos 2000 
(JAVORNIK et al., 2016) e proporcionaram novas oportunidades de engajamento do consumidor (SCHOLZ; SMITH, 2016).

Pesquisas apontam que o problema de devolução de compras erradas pelos consumidores para as lojas ocorre em torno de $35 \%$ do total das vendas online (BROOKS; BROOKS, 2014; JONSTRÖMER; RENTZHOG; ANÉR, 2012). Este o percentual de foi em torno de 30\% em 2019 (EXTRAGLOBO, 2019).

O uso dos provadores virtuais pelos varejistas ajuda a solucionar este problema, porém sua usabilidade e o envolvimento emocional dos consumidores com esta tecnologia ainda necessitam de aprimoramento (ANITAWATI; LAILA; NAGAMUCHI, 2008). Em relação à usabilidade dos provedores virtuais, verificase que algumas interfaces e imagens 3D apresentam resultados insatisfatórias quando sobrepostas aos corpos dos consumidores. Os desenvolvedores deste tipo de tecnologia também estão preocupados em produzir sistemas e produtos que sejam emocionalmente satisfatórios para o consumidor, o que poderia influenciá-lo na compra de determinado produto (NOORDIN; ASHAARI; WOOK, 2017).

\subsection{4 \\ Tecnologia Interativa de Realidade Aumentada}

Na literatura, a tecnologia de Realidade Aumentada também foi nomeada em diversos estudos, como Tecnologia Interativa de Realidade Aumentada (ARIT). Dentre os que adotaram o termo ARIT, podem-se citar os estudos de Huang (2018), Huang e Tseng (2015) e Dacko (2017), entre outros. Nesses estudos de ARIT, foram abordados os efeitos do emprego desta tecnologia em vários segmentos do varejo, tais como, produtos de beleza (DACKO, 2017), a decoração de ambientes (HUANG; TSENG, 2015) e outros.

Vale ressaltar que na Teoria de Difusão de Inovações de Rogers (2003), uma forma de resolver a incerteza sobre as consequências de uma inovação é experimentá-la para determinar sua utilidade, sendo esta experimentação frequentemente uma parte importante do processo de adoção. Para incentivar os consumidores a continuarem a usar esta tecnologia interativa, os varejistas devem fornecer vantagens relevantes, (GUO; BARNES, 2009; ROGERS, 2003), tais como 
benefícios e valores exclusivos (CHIOU; SHEN, 2012). Sendo assim, pode-se observar que a ARIT permite ao usuário uma experiência de simulação que o ajudará a assumir um comportamento de compra, motivando-o em função de seus valores utilitários e hedônicos.

As tendências atuais na aplicação da ARIT mostram que o foco da tecnologia interativa está se alterando, de usabilidade ou problemas de funcionalidade para oferecer aos consumidores uma experiência rica, estimulante e prazerosa (FOGG, 2002; GARRETT, 2010). Se as empresas pretendem transformar os visitantes iniciais em compradores online de repetição, a experiência de varejo online deve oferecer um valor único (SPIEGELMAN, 2000; HUANG; LIAO, 2015). As experiências de compras com uso da ARIT criam valor na forma de satisfação, prazer, divertimento e eficiência, com tudo isso aumentando a vontade dos consumidores de fazer compras online em uma experiência simulada de compras (KIM; FORSYTHE, 2008a, b). De acordo com Huang e Liao (2015), isso coincide com a perspectiva do paradigma de marketing de relacionamento de que os benefícios ou valores percebidos são os fatores mais críticos para os clientes.

As interações entre consumidores e a ARIT oferecem informações importantes e confiáveis que auxiliam os consumidores a tomar decisões de compra com mais precisão, ao mesmo tempo que recebem um valor experiencial mais diversificado (WON JEONG et al., 2009; MATHWICK; MALHOTRA; RIGDON, 2001). A ARIT permite que os consumidores experimentem um produto em um contexto específico (KIM; FORSYTHE, 2008a, b). Apesar da capacidade da ARIT de persuadir os consumidores a comprar produtos ou serviços, a pesquisa de Murray, Liang e Häubl (2010) mostram a ARIT como facilitadora das atividades online. As lojas online devem fazer uso dos efeitos produzidos pelo uso da ARIT para evocar as lembranças dos consumidores online e formar uma experiência exploratória de consumo (HUANG; TSENG, 2015). As circunstâncias agradáveis e memoráveis motivam os consumidores a reviver novamente aquelas experiências. Sendo assim, os varejistas online criam aplicações usando ARIT de acordo com estas perspectivas, enfatizando os recursos visuais de forma engajada e personalizada para a vendas online. Estes recursos visuais permitem maior imersão dos consumidores na experiência de compra online (HUANG; LIAO, 2015). 
Em relação às lojas físicas, Pantano (2014) observou que também houve aumento de interesse pelos varejistas, na última década, em utilizar aplicações com tecnologias novas para melhorar os pontos de venda. As condições experimentais das novas tecnologias digitais nas lojas podem atrair mais clientes para visitar o ponto de venda e aumentar, eventualmente, as vendas. Os varejistas estão se voltando para essas tecnologias para impulsionar as vendas, o relacionamento com clientes e melhorar a experiência de compra, conforme observado por Bodhani (2013). Além disso, os desenvolvimentos de novas tecnologias e estratégias de marketing de canais cruzados têm aproximado as atmosferas das lojas físicas e online (MANTRALA; KRAFFT, 2010; SHANKAR et al., 2011; PANTANO; VIASSONE, 2014). Bodhani (2012) investigou também como as tecnologias digitais podem reinventar as lojas de varejo e concluiu que as lojas se tornarão um lugar para a experiência da marca e de novas tecnologias. Outros pesquisadores também avaliaram o efeito de algumas dessas tecnologias nos contextos de varejo (PANTANO; NACCARATO, 2010; PANTANO; SERVIDIO, 2012; CLODFELTER, 2010), mas não sobre a ambiência da loja (BODHANI, 2012; PONCIN; MIMOUN, 2014).

Poncin e Mimoun (2014) concentraram sua pesquisa sobre o uso de duas novas tecnologias em lojas físicas, um espelho mágico com Realidade Aumentada e um terminal de jogos interativos. Os resultados mostraram um efeito positivo de ambas as tecnologias sobre as percepções holísticas da atmosfera da loja. O Espelho Mágico com Realidade Aumentada ofereceu benefícios positivos mais fortes do que os jogos interativos. Os resultados também indicaram que uso destas tecnologias possibilitou experiências de compra aprimoradas, aumentando o nível de satisfação e as intenções de recomendação. Poncin e Mimoun (2014) ainda enfatizam a importância que os gerentes de lojas devem dar a estes recursos tecnológicos em busca da melhoria da satisfação de clientes.

Assim como apontado por Kim, Fiore e Lee (2007), Poncin e Mimoun (2014) também observaram que os entrevistados expostos a maior nível de interatividade expressaram níveis mais elevados de prazer em suas compras. 


\subsection{5 \\ Varejo Inteligente}

A Realidade Aumentada é considerada um tipo de tecnologia inteligente que agrega valor aos varejistas ao influenciar o engajamento do cliente (PANTANO, 2009), bem como as decisões de compra (PANTANO; TIMMERMANS, 2014). Segundo eles, a concepção de varejo inteligente está no uso de uma plataforma com tecnologia inteligente pelos varejistas e seus clientes, com o objetivo de reinventar e reforçar a economia de serviços, e de melhorar a qualidade das experiências de compras, sendo esta plataforma considerada uma facilitadora de inovação.

Para Pantano e Timmermans (2014), uma configuração de varejo inteligente pode ser uma boa maneira para uma empresa gerar maior valor para os clientes e para negócios. O uso da Realidade Aumentada é cada vez mais reconhecido como tendo potencial para criar valor tanto para clientes como para varejistas (HUANG; LIAO, 2015; PANTANO; TIMMERMANS, 2014) em ambientes de varejo inteligente (DI RIENZO et al., 2015). O grande potencial destas tecnologias está na possibilidade de proporcionar experiências mais aprimoradas ao consumidor, fornecendo serviços superiores e personalizados (HOFFMAN; NOVAK, 2015; WÜNDERLICH; WANGENHEIM; BITNER, 2013). Contudo, há uma preocupação enorme sobre a capacidade dos compradores de lidar corretamente com estes serviços tecnológicos mais sofisticados (ROY et al., 2017). Outro ponto a ser considerado está na possibilidade de que os consumidores estejam mais interessados nos benefícios que estes serviços tecnológicos proporcionam, do que propriamente na sofisticação dos recursos disponíveis (BURKE, 2002).

A proposta de Roy et al. (2017), baseada em Gretzel et al. (2015a), é de que o varejo inteligente deve apoiar os usuários com recomendações pertinentes no processo de escolha durante a jornada de compras. Além disto, deve apoiá-los para melhorar as experiências dos clientes, tanto nas lojas físicas quanto virtuais, oferecendo, a partir de sua localização e interação, informações relevantes. Esta tecnologia pode afetar o comportamento do consumidor na loja (PANTANO; NACCARATO, 2010; BHARADWAJ; NAYLOR; TER HOFSTEDE, 2009), aumentando o apelo das compras (NEWSOM; COLLIER; OLSEN, 2009; 
LILJANDER et al., 2006) e a satisfação do cliente (PANTANO; NACCARATO, 2010; BHARADWAJ; NAYLOR; TER HOFSTEDE, 2009).

Assim sendo, ao orquestrar experiências imersivas por meio de tecnologias inteligentes, uma empresa pode criar um nível mais profundo de satisfação do cliente e, ao mesmo tempo, aumentar o volume de vendas (KENT et al., 2018). As aplicações de varejo inteligentes que fazem uso de Realidade Aumentada Móvel (MAR) para compras podem criar experiências agradáveis para os clientes, com a possibilidade de gerar níveis altos de satisfação e lealdade. Isto ocorre principalmente quando o conteúdo personalizado combina perfeitamente com as necessidades específicas do cliente. Na medida em que os aplicativos de compras de Realidade Aumentada Móvel podem proporcionar uma experiência perfeita de compras integradas em vários canais, os revendedores inteligentes podem obter vantagens competitivas em relação aos seus concorrentes menos integrados (SHANKAR et al., 2010).

As configurações de varejo estão sendo desafiadas a tornarem-se mais inteligentes e a proporcionarem maior valor tanto aos consumidores quanto aos varejistas, observa Dacko (2017). Ele também reconhece o aumento do potencial do varejo inteligente ao fazer uso de aplicações de Realidade Aumentada Móvel (MAR). Em sua pesquisa, Dacko (2017) procura descrever e descobrir como e por que os aplicativos de Realidade Aumentada Móvel contribuem para configurações de varejo inteligentes, criando valor adicional aos clientes, além de beneficiar os varejistas.

Dacko (2017) destaca cinco benefícios com exemplos de varejo inteligente utilizando a Realidade Aumentada que são apresentados a seguir.

1. Melhora as taxas de conversão. As tecnologias de Realidade Aumentada podem melhorar as taxas de conversão para ofertas que vão de roupas até maquiagem. Alguns varejistas, como a JC Penney e a Bloomingdale's, estão testando o uso de "provadores virtuais", que permitem que os clientes experimentem virtualmente roupas por meio de uma tela (GAIOSHKO, 2014). Varejistas do ramo de beleza planejam oferecer aos clientes uma nova maneira de experimentar a maquiagem com a ajuda de um "espelho antienvelhecimento 3D criado em Realidade Aumentada 3D" (MARTÍNEZ et al., 2014). 
2. Redução das taxas de devolução de produtos. Um dos principais desafios logísticos e de custos que os varejistas enfrentam refere-se à devolução de produtos, especialmente quando a mercadoria é grande e/ou pesada. $\mathrm{O}$ custo do transporte desse tipo de item pode exceder, às vezes, o custo dos próprios itens. A tecnologia de Realidade Aumentada pode ser implementada para reduzir esses custos para os varejistas e reduzir as taxas de devolução. No ramo do varejo de mobiliário, a Realidade Aumentada pode permitir que os consumidores interajam com produtos frequentemente caros para verificar a aparência ou a composição visual em suas casas (LU; SMITH, 2007; OH; YOON; SHYU, 2008; OLSSON et al., 2013). Pensando nisso, o revendedor de móveis IKEA criou um "Catálogo de Realidade Aumentada" em 2013. O aplicativo de compras MAR permite, por exemplo, medir as dimensões de uma sala real por meio de do uso da câmera de um smartphone e, em seguida, incluir imagens virtuais de seus móveis dentro da sala para que os clientes possam avaliar a combinação dos dois (BAIER; RESE; SCHREIBER, 2016). Esta aplicação no varejo de móveis também é mencionada em vários estudos (LU; SMITH, 2007; OH; YOON; SHYU, 2008; OLSSON et al., 2013; RESE; SCHREIBER; BAIER, 2014)

3. Visualização virtual dos estoques do varejo estático. Um dos maiores desafios enfrentados por muitos varejistas de lojas físicas é o gerenciamento de inventário nas prateleiras e a falta de interação com os produtos nessas prateleiras. A Lowe's, empresa americana do varejo no ramo de construção, introduziu o aplicativo de Realidade Aumentada para facilitar a localização dos seus produtos e a sua compra pelos clientes.

4. Atração de pessoas circulando dentro loja. Os aplicativos de Realidade Aumentada Móvel podem facilitar conexões mais fortes de consumidores com os produtos antes da compra desses produtos (SINGH; SINGH, 2013). Por exemplo, a Blippar, uma empresa de desenvolvimento de aplicações de Realidade Aumentada, é capaz de mostrar informações relevantes sobre um item básico como, por exemplo, uma maçã. Pelo "blipping" numa maçã, o cliente é capaz de conhecer o tipo de maçã, receitas com maçã, a proveniência da maçã e muito mais. Esse conteúdo específico pode auxiliar na criação de uma conexão entre o cliente, o produto e o revendedor, na medida em que o produto está associado a um 
revendedor inteligente específico. Portanto, os varejistas inteligentes podem usar este tipo de conteúdo para envolver os consumidores, ligando a compra de um produto (como por exemplo uma simples maçã) à sua loja, além de gerar mais espaço nas lojas pelo uso de informações virtuais.

5. Oferecimento de avaliações personalizadas pré-compra. À medida que os clientes se tornam mais exigentes, eles esperam cada vez mais que os produtos e serviços atendam às suas necessidades específicas. Algumas marcas de calçados, como Deichmann e Converse, usam aplicativos de Realidade Aumentada Móvel para oferecer compras personalizadas aos clientes. Por estes aplicativos, os clientes podem escolher diferentes modelos de tênis e sapatos de um catálogo e depois, praticamente, "experimentá-los". Há outros ramos de negócio que também fazem uso desta tecnologia, como é caso da joalheria De Beers Company e a empresa de cosméticos Shiseido, que introduziram aplicativos MAR para os clientes experimentarem virtualmente diferentes modelos de produtos de joias e cosméticos, respectivamente, na pré-compra.

Os esforços de varejo para dinamizar os estoques das lojas, aumentar o ritmo e oferecer avaliações personalizadas de pré-compra são atraentes para os clientes e geram maior valor no processo de compras. Isto inclui o julgamento, a personalização, a escolha, a variedade de produtos, as informações completas e as demonstrações para aumentar a certeza do comprador (DACKO, 2017). Portanto, esses esforços beneficiam tanto os consumidores que ficam mais confiantes em suas escolhas de compra, quanto aos varejistas que conseguem obter os benefícios do aumento de taxa de conversão e redução de taxa de retorno, entre outros citados anteriormente.

\subsection{6 \\ Marketing Digital (via Mobile)}

O mobile shopper marketing (marketing de compradores móveis) engloba o planejamento e a execução de todas as atividades de marketing em mobile que influenciam um comprador em seu caminho da compra, incluindo também o consumo, a recompra e as recomendações (SHANKAR et al., 2016). Willems et al. 
(2017) também enfatizam que as tecnologias utilizadas no varejo podem afetar a experiência de compra dos clientes durante toda a jornada de compra, englobando o estágio de pré-compra, onde ocorre conhecimento do produto, pesquisa de informações e avaliação das opções e os estágios de compra e pós-compra (HOYER; STOKBURGER-SAUER, 2012)

A tecnologia móvel é cada vez mais atraente porque oferece acesso flexível e onipresente à Internet, convertendo assim o comércio eletrônico tradicional em comércio móvel (m-commerce) (SCHARL; DICKINGER; MURPHY, 2005). De acordo com Shankar et al. (2016), a compra pelo dispositivo portátil conectado permite que o usuário realize diversas atividades e tome decisões em movimento. As compras móveis combinam duas ideias muito importantes: a interatividade e a instantaneidade. O dispositivo móvel provê informações instantâneas que pode acelerar ou abandonar o planejamento de uma compra.

Outro ponto relevante sobre os dispositivos móveis é a crescente confiança alcançada pelas aplicações desenvolvidas. Giovannini et al. (2015) sugerem que a confiança verificada nos contextos online e a facilidade de uso têm efeitos significativos na formação da confiança no uso do móvel e na atitude e intenção dos consumidores de comprar via dispositivos móveis. Shankar et al. (2016) discutem e levantam questões relacionadas aos compradores sobre a transformação nos estágios da jornada de compra, que necessitam de aprofundamento, tais como, motivação, procura, descoberta, considerações, escolhas e pós-compras com o uso da tecnologia móvel. Eles destacam ainda a conveniência e a economia como sendo os principais motivadores do uso do celular em compras.

Já nas questões da tecnologia móvel, eles abordam a convergência e wearables (vestíveis). As tecnologias wearables diferem dos smartphones e tablets pelas mãos livres. Um dispositivo móvel de mão exige atenção completa durante o uso, já os wearables permitem multitarefas. Os smartglasses (óculos inteligentes), um dispositivo wearable, podem ser usados enquanto se caminha, fala ou durante várias atividades regulares, facilitando a combinação com uso da Realidade Aumentada (SHANKAR et al., 2016).

Apesar destas facilidades e benefícios citados, Shankar et al. (2016) levantam a questão de se investigar melhor como a Realidade Aumentada irá remodelar a 
experiência de compra móvel. Kannan (2017) também evidenciou esta necessidade de aprofundamento dos estudos sobre o impacto da Realidade Aumentada no planejamento do marketing digital, acrescentando a importância de pesquisas sobre o tema com vistas à possibilidade de aumento do customer equity (valor do cliente).

\subsection{7 Marketing Experiencial}

As empresas não apenas vendem produtos ou prestam serviços aos clientes, mas também aumentam memórias e experiências agradáveis. As empresas de sucesso criam consumidores leais criando experiências memoráveis (YUAN; WU, 2008).

A Experiência do Usuário (user experience - UX) no marketing experiencial aborda, de forma ampla, a interação do usuário com um produto. A Experiência do Usuário se move além da usabilidade para mais emocionalmente criar relações atraentes entre o usuário e o produto (DESMET; PORCELIJN; VAN DIJK, 2007). Sendo assim, a experiência é algo mais envolvente entre o usuário e o produto.

A Experiência do Usuário (UX) também foi definida por Hassenzahl e Ullrich (2007) como a consequência do estado interno de um usuário - predisposições, expectativas, necessidades, motivação, humor, etc. -, as características do projeto da experiência - complexidade, propósito, usabilidade, funcionalidade - e o meio ambiente dentro do qual ocorre a interação. Segundo Olsson et al. (2013), a maioria das definições de Experiência do Usuário inclui o uso esperado como um elemento essencial.

Para criar sucesso e produtos envolventes, a Experiência do Usuário deve ser levada em consideração nas fases iniciais dos processos de projeto de forma sistêmica, pesquisando as expectativas dos potenciais usuários. Essas expectativas influenciam as percepções dos usuários sobre a capacidade e a qualidade do produto. Se um produto supera as expectativas pós-uso, isto provavelmente resultará na sua satisfação (LINDGAARD; DUDEK, 2003), e em caso contrário é provável que o usuário se sinta insatisfeito (OLIVER, 1977). 
A utilidade do uso da Realidade Aumentada no marketing experiencial para o consumidor é permitir que ele teste os produtos e serviços, levando a maior certeza na sua compra e melhorando as informações para sua tomada de decisão. Desta forma, o uso da Realidade Aumentada pode aprimorar a experiência de compra. Muito embora os métodos tradicionais de venda do varejo, como as promoções e a ambientação nas lojas, possam ser fundamentais para alcançar a satisfação do cliente (BÄCKSTRÖM; JOHANSSON, 2006; GREWAL; LEVY; KUMAR, 2009), as experiências do consumidor fazendo uso de aplicativos de compras com Realidade Aumentada também podem desempenhar um papel importante na decisão e na satisfação do cliente.

Dacko (2017) relata que as experiências favoráveis de aplicativos de compra que usam Realidade Aumentada Móvel podem gerar decisões satisfatórias para o consumidor. Os benefícios oferecidos destes aplicativos de compras integrados nos diversos canais do varejo proporcionam uma experiência de compras mais aprimorada e isto pode trazer uma vantagem competitiva para os varejistas em relação aos seus concorrentes menos integrados (SHANKAR et al., 2010).

Uma boa experiência pode diminuir o sentimento de dúvidas dos clientes sobre suas escolhas, encurtando o ciclo de vendas (PORTER; HEPPELMANN, 2017). Sendo assim, a criação de experiências imersivas com os recursos de uma tecnologia inteligente pode proporcionar, ao mesmo tempo, benefícios para o cliente, com uma boa compra, e para o varejista, com o aumento de vendas (Kent et al., 2018).

Vários estudos (por exemplo, DACKO, 2017; HUANG; LIAO, 2015; OLSSON et al., 2013) foram realizados para compreender a criação de valor advinda de experiências do consumidor no varejo. Dacko (2017) em seu estudo sobre Realidade Aumentada Móvel procurou entender como esta tecnologia pode contribuir para o valor da experiência, avaliando as perspectivas da experiência do cliente sobre a criação de valor. A aceitação Realidade Aumentada Móvel pelos varejistas dependerá do reconhecimento de que a tecnologia agregará valor ao negócio. Dacko (2017) baseou-se nos estudos de Holbrook (1999) sobre o valor percebido pelo consumidor e na visão matricial de tipo de valores experienciais 
definida por Mathwick, Malhotra e Rigdon (2001) para classificar o valor da experiência do cliente.

Holbrook (1999) definiu os tipos de valores percebidos experienciais para prever o comportamento de compra e obtenção de vantagens competitivas sustentáveis em três eixos: (1) intrínsecos ou extrínsecos, (2) orientados para si ou para outros e (3) ativos ou reativos. Foram relatados por Hirschman e Holbrook (1982) que os consumidores procuram frequentemente prazer e diversão em uma atividade de compra ao invés de resultados extrínsecos. A matriz de Mathwick, Malhotra e Rigdon (2001), baseada no estudo de Holbrook (1999), apresenta quatro quadrantes, contendo a combinação do tipo de valor extrínseco-intrínseco com o tipo de valor ativo-reativo.

Segue-se a descrição dos valores que compõem cada quadrante da matriz:

1) Valor intrínseco-ativo - captura o valor em "divertimento" ou valor relacionado ao prazer intrínseco de comprar e/ou fazer compras como uma forma de escapismo.

2) Valor intrínseco-reativo - captura o valor em "estética" ou valor relacionado ao apelo visual de uma oferta do varejo e/ou apelo do entretenimento.

3) Valor extrínseco-ativo - captura o retorno de investimento do consumidor ou valor econômico da compra.

4) Valor extrínseco-reativo - captura o valor da excelência de serviço.

Segue a matriz do estudo de Dacko (2017) com a tipologia de valor experiencial de Mathwick, Malhotra e Rigdon (2001) e as categorias do Google Play. Além disto, em cada quadrante é apresentada a distribuição percentual da quantidade de aplicativos por categoria do Google Play. Para fazer o estudo, Dacko (2017) utilizou a categoria do Google Play para classificar os aplicativos disponíveis de MAR, em seguida avaliou o nível de uso dos aplicativos pelos consumidores, os benefícios experimentais oferecidos avaliados pelos consumidores e as consequências no varejo. O quadro 2.1 expõe a matriz de tipologia de valor experiencial elaborada por Mathwick, Malhotra e Rigdon (2001). 
Quadro 2.1 - Matriz de Tipologia de Valor Experiencial de Mathwick, Malhotra e Rigdon (2001)

\begin{tabular}{|c|c|}
\hline $\begin{array}{l}\text { Valor intrínseco - valor Ativo } \\
\text { (Divertimento) } \\
\text { Ações e aventuras, fliperama, cartas, } \\
\text { criativos, quebra-cabeça, social e } \\
\text { esportes - } 50 \% \\
\text { Entretenimento - } 25 \% \\
\text { Livros, educação e bibliotecas - } 13 \% \\
\text { Outros - } 12 \%\end{array}$ & $\begin{array}{l}\text { Valor intrínseco - valor reativo } \\
\text { (Estética) } \\
\text { Shopping, estilo de vida - } 29 \% \\
\text { Entretenimento - } 25 \% \\
\text { Comunicação, vídeo e mídia, jornais e } \\
\text { revistas e fotografias - } 16 \% \\
\text { Livros, educação e bibliotecas - } 8 \% \\
\text { Outros - } 22 \%\end{array}$ \\
\hline $\begin{array}{l}\text { Valor extrínseco - valor Ativo } \\
\text { (CROI - retorno de investimento do } \\
\text { consumidor) } \\
\text { Shopping e estilo de vida }-67 \% \\
\text { Negócios e Finanças }-12 \% \\
\text { Viagens }-11 \% \\
\text { Outros }-10 \%\end{array}$ & $\begin{array}{l}\text { Valor extrínseco - valor reativo } \\
\text { Excelência de serviço } \\
\text { Viagens - } 69 \% \\
\text { Shopping e estilo de vida }-12 \% \\
\text { Produtividade, ferramentas e transportes } \\
-9 \% \\
\text { Outros }-10 \%\end{array}$ \\
\hline
\end{tabular}

Fonte: adaptado de Dacko (2017)

O resultado da avaliação de Dacko (2017) sobre os aplicativos de compras de Realidade Aumentada Móvel indicou que a percepção dos usuários sobre o fornecimento de serviço de excelência e entretenimento não é tão forte em relação aos outros benefícios experienciais percebidos. Os usuários percebem os aplicativos como possíveis fornecedores de alto valor extrínseco (como por exemplo, mais valor de compra), sendo este tipo de benefício mais valorizado por eles. Este resultado contraria os resultados dos estudos de Hirschman e Holbrook (1982) sobre a motivação frequente nas atividades de compra ser mais intrínseca (prazer e diversão) do que extrínseca (utilidade).

Já Mathwick, Malhotra e Rigdon (2001) haviam sugerido que o valor experiencial auxilia os varejistas a criarem e gerenciarem relacionamentos entre consumidores e fornecedores de serviços. Assim, o valor que os consumidores recebem como resultado de experiência favorável com o fornecedor de serviços motiva a criação de uma relação sustentável com esse fornecedor (HUANG; LIAO, 2015).

Olsson et al. (2013) abordaram a experiência de usuários antes do uso real dos serviços de MAR, dando relevância à experiência antecipada. A inspiração e a surpresa estão relacionadas tanto com a estimulação quanto com a evocação, enquanto a cativação e a brincadeira referem-se principalmente à estimulação. Tais 
expectativas emocionais são importantes a se considerar para exceder as expectativas pragmáticas do usuário e fornecer valor emocional adicional e uma experiência prazerosa.

Alguns pesquisadores ressaltam a necessidade de medir o valor percebido experimentado por meio de uma experiência completa pela importância atribuída à previsão do comportamento de compras e a obtenção de vantagens competitivas sustentáveis (PONCIN; MIMOUN, 2014). Apesar desta percepção, de que a experiência do usuário pode se tornar mais atraente e interessante com o uso da Realidade Aumentada e dos estudos iniciais já realizados, os pesquisadores destacam que ainda é preciso ter mais compreensão sobre essas percepções, como por exemplo em relação aos elementos emocionais e hedônicos percebidos pelos usuários na experiência de Realidade Aumentada.

\subsection{8 \\ Experiência de Realidade Aumentada dos Consumidores}

Os estudos acadêmicos sobre as experiências de Realidade Aumentada dos consumidores são recentes, e apesar de ainda serem considerados escassos, tiveram um aumento relevante nos últimos anos. Segundo Scholz e Duffy (2018), os estudos iniciais foram mais conceituais (por exemplo, HUANG; HSU LIU, 2014; JAVORNIK, 2016b; RESE; SCHREIBER; BAIER, 2014; SCHOLZ; SMITH, 2016) e os mais recentes abordaram estudos experienciais, tecendo considerações e achados importantes sobre a experiência do usuário utilizando aplicações de Realidade Aumentada (por exemplo, BECK; CRIÉ, 2016; HILKEN et al., 2017; HOPP; GANGADHARBATLA, 2016; JAVORNIK, 2016b; PONCIN; MIMOUN, 2014; POUSHNEH, 2018; POUSHNEH; VASQUEZ-PARRAGA， 2017; YAOYUNEYONG et al., 2016).

Para entender melhor o conceito de Experiência do Usuário, Poushneh e Vasquez-Parraga (2017) se basearam no conceito apresentado por Hassenzahl e Tractinsky (2006) de que a Experiência do Usuário é um estado interno do indivíduo, em que este pode perceber as características do produto experimentado e seu contexto de uso. Os estados internos dos usuários, juntamente com os valores 
utilitários e hedônicos percebidos, são apontados como direcionadores das atitudes e reações dos consumidores a respeito da Realidade Aumentada (por exemplo, HILKEN et al., 2017; YIM; CHU; SAUER, 2017). Muitos destes estudos foram realizados dentro de universidades com apenas estudantes ou em laboratórios, fora dos contextos nos quais os aplicativos de Realidade Aumentada são realmente usados (SCHOLZ; DUFFY, 2018). No entanto, alguns destes estudos examinaram o uso de Realidade Aumentada em situações reais (por exemplo, DACKO, 2017; PONCIN; MIMOUN, 2014; OLSSON et al., 2013).

Em relação aos estudos sobre experiências do consumidor com Realidade Aumentada, Rauschnabel, Brem e Iven (2015) observaram que os consumidores tendem a adotar óculos com Realidade Aumentada, como por exemplo o Google Glass, pela obtenção de benefícios sociais ou status. Já em relação aos jogos de Realidade Aumentada, como por exemplo o Pokémon Go, eles observaram que os benefícios emocionais, como a diversão, e os aspectos hedônicos têm mais impacto que os benefícios sociais na atitude em relação à Realidade Aumentada.

Segundo Javornik (2016a), dependendo do tipo de aplicação de Realidade Aumentada, os consumidores podem ter motivações diferentes em relação à adoção da tecnologia. Rese et al. (2017), por exemplo, sugerem que ambos os aspectos utilitários e hedônicos são motivadores do uso de aplicativos de compras com Realidade Aumentada, porém a dominância dos aspectos utilitários é maior do que a dos aspectos hedônicos. Os resultados de outras pesquisas sobre aplicativos de compras com Realidade Aumentada (DACKO, 2017; OLSSON et al., 2013) indicaram que os benefícios mais importantes procurados pelos usuários estavam relacionados com os aspectos utilitários (por exemplo, tomar decisões de compra mais eficientes e confiantes).

\section{3}

\section{Teorias e Modelos Aplicados à Realidade Aumentada}

Esta seção apresenta as principais teorias e modelos de adoção aplicados a esta nova tecnologia encontrados na revisão de literatura. Desta forma, foi possível realizar uma análise destas teorias e modelos encontrados. Esta análise tem por 
finalidade propor modelos que visem novas descobertas, contribuindo, assim, com o aprimoramento dos estudos sobre Realidade Aumentada e sua influência na intenção de compras online via mobile.

\subsection{1}

\section{Teoria da Difusão da Inovação (IDT)}

O processo de difusão e adoção de inovações tem sido foco de muitos estudos ao longo dos últimos anos, sendo Rogers (2003) o pesquisador mais destacado. Suas obras, em especial o livro Diffusion of Innovations, contribuíram significativamente para a compreensão da dinâmica do processo de difusão de inovações. As definições de Rogers (2003) são baseadas nas percepções da inovação em si, e não nas percepções de uso do produto. As inovações se difundem pela decisão das pessoas em adotá-las. O processo de adoção segue os estágios de conhecimento e consciência da inovação, formação da atitude, decisão de aceitar ou rejeitar, implementação da nova ideia e confirmação da decisão. Segundo ele, a difusão se manifesta de formas diferentes em várias culturas e campos e é altamente sujeita ao tipo de adotante e ao processo de inovação-decisão subjacente.

Ainda em relação à adoção, Rogers (2003) explica que, além dos atributos percebidos de inovação, tais como vantagem relativa, compatibilidade com valores e crenças, complexidade, experimentação e observabilidade, há outras variáveis que podem afetar a velocidade com que uma inovação é adotada por membros de um sistema social (taxa de adoção). Ele cita o tipo de decisão de inovação, a natureza dos canais de comunicação que difundem a inovação, a natureza do sistema social e a extensão dos esforços dos agentes de mudança na difusão inovação como outras variáveis que podem afetar a taxa de adoção. Rogers não aborda, na sua teoria, aspectos emocionais que também podem influenciar as pessoas na adoção de uma inovação. Ele ressalta que a auto sustentação de uma inovação depende da amplitude da adoção e que há um ponto no qual uma inovação alcança a massa crítica. Em relação às categorias de adotantes, ele classifica em inovadores, adotantes iniciais, maioria precoce, maioria tardia e retardatários. 


\subsection{2 Teoria do Fluxo}

Csikszentmihalyi (1990) introduziu a teoria do fluxo, descrevendo o fluxo (flow) como um estado de imersão, absorção e foco de uma pessoa em uma atividade desafiadora, fazendo com que nada mais ao redor desperte o interesse. A teoria do fluxo foi bem difundida dentro da psicologia. Hoffman e Novak (1996) logo observaram o potencial desta teoria aplicada ao varejo online, percebendo que o ambiente digital pode gerar fluxo, levando a navegação e finalizando com uma possível compra. O fluxo apresentou significância nas intenções de compra online no estudo feito por Huang (2012) e Hausman e Siekpe (2009). A aplicação do fluxo nos estudos de compras usando Realidade Aumentada foi feita mais recentemente por Javornik (2016a) e os resultados mostraram que o fluxo media os efeitos do "Realidade Aumentada percebida" nas respostas efetivas e intenções comportamentais dos consumidores. Pela "Realidade Aumentada percebida", os consumidores avaliam os recursos implementados pela tecnologia de Realidade Aumentada. Este estudo mostrou que a Realidade Aumentada age como tecnologia imersiva, principalmente pela sua característica da "Realidade Aumentada percebida". Isto é corroborado com outras descobertas na área de marketing sobre a imersão do consumidor em ambientes tecnológicos, em que os efeitos de interatividade, tele presença e vivacidade em comportamento exploratório podem afetar a atitude com relação à marca e à intenção de compra (AGARWAL; KARAHANNA, 2000; FAIOLA et al., 2013; HOFFMAN; NOVAK, 1996; KOUFARIS, 2002; MATHWICK; RIGDON, 2004; NAH et al., 2010; VAN NOORT; VOORVELD; VAN REIJMERSDAL, 2012).

A forma original do fluxo foi descrita por Csikszentmihalyi e Csikszentmihalyi (1975) contendo nove dimensões, porém estudos mais novos adaptaram com sucesso este construto com menos dimensões (DOMINA; LEE; MACGILLIVRAY, 2012). Alguns pesquisadores, por exemplo, conceituaram o fluxo como sendo um construto multidimensional que mede a imersão, curiosidade, fruição e controle (NEL et al., 1999; WEBSTER; TREVINO; RYAN, 1993). Já Koufaris (2002) mediu o fluxo por meio de 3 construtos (Fruição Percebida, Controle Percebido e Concentração), sendo utilizado desta forma por Domina, Lee 
e Macgillivray (2012). O motivo para uso destas três dimensões em estudos do varejo online é que essas dimensões podem ser mais apropriadas para este contexto do que, por exemplo, o interesse intrínseco (HOFFMAN; NOVAK, 2009). A fruição percebida, que avalia o prazer percebido pelo indivíduo, é importante neste contexto, particularmente em casos como o da tecnologia de Realidade Aumentada, pois, quando, por exemplo, os usuários estão se divertindo, eles são mais propensos a ficarem focados e terem atitude positiva em relação a intenção de aceitação da nova tecnologia (LI; HUANG, 2009).

\subsection{3}

\section{Teoria do Risco Percebido}

A Teoria do Risco Percebido (BAUER, 1960; COX, 1967) propõe que o risco percebido é uma função que engloba a quantia que está envolvida na possível compra, a importância da função do produto e a posição subjetiva do consumidor em relação a seus sentimentos de certeza sobre os benefícios da compra $(\mathrm{BLOCH}$; RICHINS, 1983). O comportamento do consumidor na Teoria do Risco Percebido considera que "qualquer ação de um consumidor produzirá consequências que ele não pode antecipar com algo que se aproxime da certeza" (BAUER; COX, 1967, p. 24).

A teoria foi aplicada em alguns estudos (YU, 2009; NOORDIN; ASHAARI; WOOK, 2017) para examinar a percepção e a redução de risco da tomada de decisão do consumidor em compras online de vestuário. Cox (1967) sugere que uma estratégia para redução de riscos na tomada de decisão poderia ser obtida pela aquisição de mais informações durante o processo de compra para aumentar a certeza do consumidor. Como a tecnologia de Realidade Aumentada tem como característica principal aumentar a realidade com informações e objetos virtuais, seu uso poderia ajudar os consumidores a avaliarem melhor os riscos de uma compra. 


\subsection{4 Teoria de Efeitos de Mídia Interativa (TIME)}

A Teoria de Efeitos de Mídia Interativa (Theory of Interactive Media Effects - TIME) foi desenvolvida por Sundar et al. (2015) para aprofundar o conhecimento sobre o impacto das características de mídia nos resultados afetivos, cognitivos e comportamentais do consumidor. Segundo eles, ao concentrar os estudos apenas nas percepções do consumidor, que estão relacionadas com as habilidades dos usuários e suas observações, estes estudos podem negligenciar os resultados do efeito de uma tecnologia no comportamento do consumidor. Dentre as características de mídia de uma tecnologia, a interatividade é considerada uma das mais importantes para ambientes mediados por computador (EVELAND, 2003; FORTIN; DHOLAKIA, 2005; HOFFMAN; NOVAK, 1996; LIU; SHRUM, 2002). Isto porque a interatividade tem apresentado efeitos significativos nas respostas do consumidor relacionadas a suas experiências e suas emoções, como por exemplo, o prazer (GAO; RAU; SALVENDY, 2009; HOFFMAN; NOVAK, 2009).

No uso de uma tecnologia, o usuário capta as possibilidades de interações que a tecnologia oferece ou deixa de oferecer, gerando um correlato psicológico. Sundar et al. (2015) apresentaram o exemplo de uma tela de um computador com diversos botões disponíveis. Os vários botões podem dar a percepção ao usuário de que ele tem várias escolhas e com isto pode ter a percepção de controle sobre o conteúdo apresentado na tela, gerando um correlato psicológico. Os correlatos psicológicos podem funcionar como mediadores para as cognições, a afetividade e o comportamento subsequentes. Assim Sundar et al. (2015) definem que os recursos tecnológicos geram ações dos usuários, provocando correlatos psicológicos e estes são traduzidos em experiências imersivas que geram respostas afetivas, cognitivas e comportamentais. A figura 2.3 apresenta o modelo TIME proposto por Sundar et al. (2015).

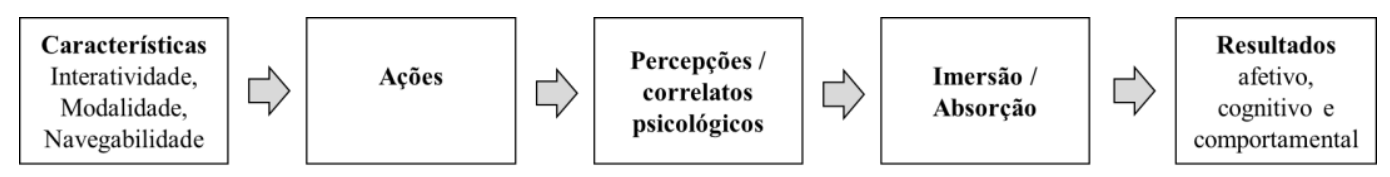

Figura 2.3 - Modelo de Efeitos de Mídia Interativa Fonte: adaptado de Sundar et al. (2015) 


\subsection{5}

\section{Modelo de Aceitação de Tecnologia (TAM)}

Davis, Bagozzi e Warshaw (1989) propuseram o modelo de aceitação e tecnologia (Technology Acceptance Model - TAM), baseado na Teoria da Ação Racionalizada (Theory of Reasoned Action - TRA) de Ajzen e Fishbein (1980) para explicar a relação entre as crenças internas dos usuários, utilidade percebida (Perceived Usefulness - PU) e facilidade de uso percebida (Perceived Easy of Use - PEOU), suas atitudes, intenções e comportamento de uso do computador e tecnologias afins. O TRA de Ajzen e Fishbein (1980) aborda aspectos psicológicos relacionados ao comportamento humano, como, por exemplo, a atitude de um indivíduo ser um antecedente da sua intenção, que por sua vez antecede ao seu comportamento futuro. OTAM é considerado um modelo parcimonioso para prever a aceitação e uso da tecnologia pelos usuários, sendo disseminado e utilizado em vários estudos em diversos países ao longo dos anos (VENKATESH, 2000).

Os autores do TAM (DAVIS; BAGOZZI; WARSHAW, 1989) testaram o modelo de adoção e uso de uma tecnologia sem o construto atitude em ambientes de livre escolha dos indivíduos. O resultado dos testes mostrou que o modelo se comportou bem com ou sem a atitude. Já em ambiente de uso mandatório de uma tecnologia (por exemplo, organizações e empresas), a atitude apresentou relevância (JACKSON; CHOW; LEITCH, 1997).

O modelo TAM proposto por Davis, Bagozzi e Warshaw (1989), apresentado na figura 2.4, é considerado como um modelo parcimonioso e robusto. Este modelo serviu de base para diversos estudos de adoção e uso de RA, apresentando resultados satisfatórios (DOMINA; LEE; MACGILLIVRAY, 2012; HUANG; LIAO, 2015; KIM; FORSYTHE, 2008a; KIM; HYUN, 2016, LEE; FIORE; KIM, 2006, SPREER; KALLWEIT, 2014; RESE et al., 2017). Alguns destes autores acrescentaram ao TAM original algumas variáveis externas, como por exemplo, divertimento percebido, fruição percebida, inovatividade ou informações valiosas percebidas, para testá-lo no contexto de Realidade Aumentada. 


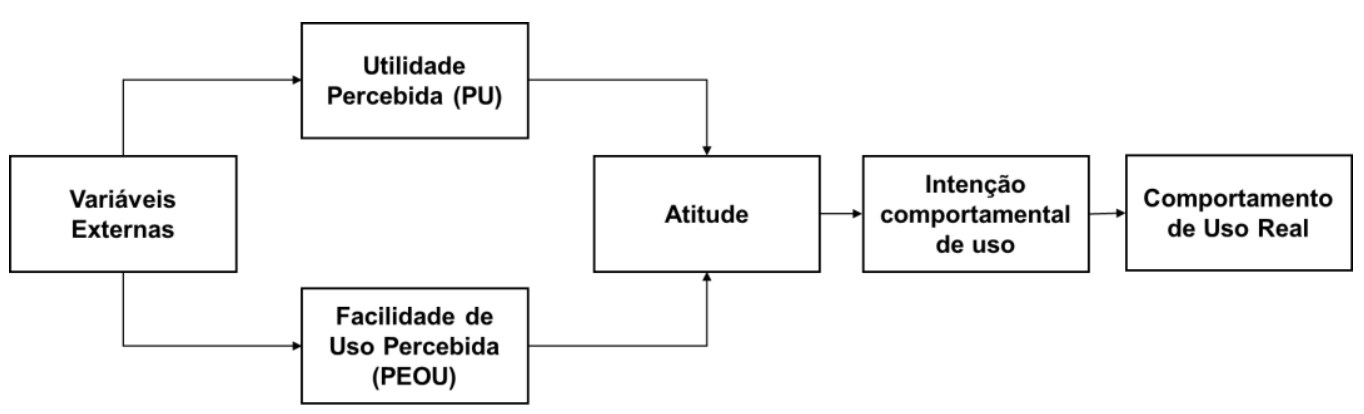

Figura 2.4 - Modelo TAM Original (DAVIS; BAGOZZI; WARSHAW, 1989)

Fonte: adaptado de (YOUSAFZAI; FOXALL; PALLISTER,2007)

\subsection{6 \\ Modelo de Aceitação de Compras Online (OSAM)}

O Modelo de Aceitação de Compras Online (Online Shopping Acceptance Model -OSAM) foi proposto por Zhou, Dai e Zhang (2007) com objetivo de contribuir com explicações e entendimento sobre a aceitação das compras online pelos consumidores. Ele foi desenvolvido com base no TAM e em outras teorias do varejo e marketing (NOORDIN; ASHAARI; WOOK, 2017). Zhou, Dai e Zhang (2007) observaram que a aceitação do consumidor de compras online difere de um produto para outro.

Alguns pesquisadores verificaram que os consumidores percebiam riscos diferentes, dependendo do produto associado à compra (BHATNAGAR; GHOSE, 2004; BHATNAGAR; MISRA; RAO, 2000; PIRES; STANTON; ECKFORD, 2004). Zhou, Dai e Zhang (2007) analisaram no modelo OSAM o impacto na intenção do consumidor de compras online em relação ao resultado percebido, da orientação para compras, da experiência online, da motivação no shopping, da satisfação e de informações demográficas de consumidores (idade, educação e experiência na Internet).

Noordin, Ashaari e Wook (2017) analisaram que alguns aspectos, tais como usabilidade e emoção profunda, não estavam presentes no modelo e que estes poderiam ser importantes para a avaliação da aceitação das compras via provador virtual. O modelo OSAM, por ser um modelo abrangente de compras online, não 
contém características específicas da RA, como a interatividade ou a Realidade Aumentada Percebida.

\subsection{7}

\section{Modelo de Realidade Aumentada e Captura de Movimento}

O modelo de Realidade Aumentada e Captura de Movimento (Augmented Reality and Motion Capture - ARMC) foi proposto por Kang (2014), que utilizou como base a Teoria da Expectativa (Prospect Theory) e o Modelo de Decisão do Consumidor, que contém a hierarquia valor-atitude-comportamento. A Teoria da Expectativa aborda o comportamento humano e suas decisões diante de incertezas. Já o Modelo de Decisão do Consumidor avalia os valores que afetam seu comportamento.

O modelo ARMC apresenta seis construtos que são: valor monetário, valor da conveniência, valor emocional, valor do produto/serviço, valor social e expectativa e desempenho hedônico (NOORDIN; ASHAARI; WOOK, 2017). O modelo ARMC, apesar de ser específico para Realidade Aumentada, não inclui a característica importante de interatividade ou Realidade Aumentada Percebida.

\subsection{8 Modelo de Provador Virtual Online}

O Modelo de Provador Virtual Online (Online Virtual Fitting Room Model) proposto por Huang e Qin (2011) agrega o risco percebido em compras online com uso de provadores virtuais (VFR) ao modelo de Teoria Unificada de Aceitação e Uso de Tecnologia (Unified Theory of Acceptance and Use of Technology UTAUT) (VENKATESH; THONG; XU, 2012).

Este modelo contém sete construtos que são expectativa de desempenho, expectativa de esforço, influência social, condições facilitadoras, preocupação com privacidade, preocupação de segurança e risco percebido. Com exceção das condições facilitadoras, os demais construtos apresentaram relevância em relação à intenção dos usuários em usarem os provadores virtuais. Outra descoberta do 
modelo foi que a preocupação com privacidade e segurança, assim como o risco percebido, são fatores importantes na determinação da intenção de uso (NOORDIN; ASHAARI; WOOK, 2017).

\subsection{9}

\section{Modelo para Aumentar a Intenção de Compra}

Schwartz (2011) desenvolveu o modelo para Aumentar a Intenção de Compra (Augmenting Purchase Intent Model) para examinar o impacto da Tecnologia de Interatividade de Imagem (IIT) ou Realidade Aumentada na atitude e intenção de compra dos usuários. Este modelo examina se os construtos IIT, tele presença, atitude e conhecimento podem afetar a atitude e a intenção de compra.

Segundo Noordin, Ashaari e Wook (2017), o resultado do modelo indicou que o uso do IIT afetou de forma significativa a atitude dos consumidores e a sua intenção de compra, porém o conhecimento do produto não apresentou significância. Este modelo precisa ser testado em outros estudos para avaliar se o resultado apresentado de significância do IIT na intenção é mantido em outros contextos de RA.

\subsubsection{0} Modelo de Experiência de Produto Virtual (VPE)

O Modelo de Experiência do Produto Virtual (Virtual Product Experience - VPE) foi proposto por Yu (2009) baseado no Modelo de Aceitação de Tecnologia (TAM) e na Teoria do Risco Percebido. O VPE foi desenvolvido para compreender o efeito da satisfação do usuário, pela visualização do seu corpo numa experiência virtual de RA, em relação à atitude e à intenção de compra. Este modelo contém os construtos risco de desempenho do produto, satisfação corporal, utilidade percebida, fruição percebida da experiência do produto virtual e a atitude em relação ao produto.

O resultado do estudo empírico do VPE revelou que a satisfação corporal representa um fator importante na intenção de compras (NOORDIN; ASHAARI; 
WOOK, 2017). A satisfação na usabilidade não foi testada no modelo. Este modelo foi criado para a experimentação virtual de produtos no corpo humano, não sendo aplicado, por exemplo, na experimentação virtual de móveis.

\subsubsection{1}

\section{Modelos de Varejo Inteligente}

A revisão de literatura sobre varejo inteligente feita por Roy et al. (2017) apontou diversos estudos e modelos propostos (por exemplo, BHATTACHARYA, 2015, KANG; MUN; JOHNSON, 2015, KIM; YOON, 2014; MÜLLER-SEITZ et al., 2009). Dentre os estudos do varejo inteligente, foram encontrados alguns estudos com a tecnologia de Realidade Aumentada, conforme apresentado na Tabela 2.2 (HUANG; LIAO, 2015; HUANG; HSU LIU, 2014; RESE; SCHREIBER; BAIER, 2014).

Tabela 2.2 - Estudos Selecionados de Varejo Inteligente com Realidade Aumentada.

\begin{tabular}{|c|c|c|c|}
\hline Autor(es) & Objetivo & Métodos & Descobertas \\
\hline $\begin{array}{l}\text { Huang e } \\
\text { Liao (2015) }\end{array}$ & $\begin{array}{l}\text { Examinar se a } \\
\text { presença, a riqueza } \\
\text { da mídia e as } \\
\text { experiências } \\
\text { narrativas afetam o } \\
\text { valor experiencial }\end{array}$ & $\begin{array}{l}344 \\
\text { respondent } \\
\text { es }(\mathrm{SEM})\end{array}$ & $\begin{array}{l}\text { Os resultados revelam que a percepção das } \\
\text { narrativas afeta significativamente todas as } \\
\text { quatro dimensões do valor experiencial } \\
\text { (estética, divertimento, ROI do consumidor e } \\
\text { excelência do serviço). A riqueza e a } \\
\text { presença na mídia afetam apenas as } \\
\text { sensações estéticas e excelência do serviço). }\end{array}$ \\
\hline $\begin{array}{lr}\text { Huang } & \text { e } \\
\text { Hsu } & \text { Liu } \\
(2014) & \end{array}$ & $\begin{array}{l}\text { Examinar o papel } \\
\text { da presença na } \\
\text { adoção de } \\
\text { tecnologia } \\
\text { interativa de } \\
\text { Realidade } \\
\text { Aumentada. }\end{array}$ & $\begin{array}{l}220 \\
\text { respondent } \\
\text { es (SEM) }\end{array}$ & $\begin{array}{l}\text { A utilidade percebida e o divertimento } \\
\text { percebido influenciam o papel da presença } \\
\text { em comportamentos de relacionamento } \\
\text { sustentável. A inovatividade percebida pelo } \\
\text { cliente foi moderada nessa relação. }\end{array}$ \\
\hline $\begin{array}{l}\text { Rese, } \\
\text { Schreiber e } \\
\text { Baier (2014) }\end{array}$ & $\begin{array}{l}\text { Investiga a } \\
\text { aceitação da } \\
\text { tecnologia de } \\
\text { Realidade } \\
\text { Aumentada no } \\
\text { ponto de vendas } \\
\text { usando uma } \\
\text { análise de revisões } \\
\text { on-line }\end{array}$ & $\begin{array}{l}\text { Experimen } \\
\text { to } \\
\text { em } \\
\text { laboratório } \\
275 \\
\text { respondent } \\
\text { es } \\
\text { Técnica de } \\
\text { incidente } \\
\text { crítico }\end{array}$ & $\begin{array}{l}\text { Embora a utilidade percebida e a facilidade } \\
\text { de uso tenham influenciado } \\
\text { significativamente a aceitação do cliente, as } \\
\text { variáveis externas de informatividade } \\
\text { percebida e fruição percebida não } \\
\text { influenciaram a aceitação do cliente. Os } \\
\text { autores mostram que as revisões on-line } \\
\text { podem ser usadas para examinar a aceitação } \\
\text { de tecnologia da Realidade Aumentada. }\end{array}$ \\
\hline
\end{tabular}

Fonte: adaptado de Roy et al. (2017)

Com base nos principais modelos estudados, Roy et al. (2017) desenvolveram um modelo de varejo inteligente para avaliar as consequências da 
experiência inteligente do consumidor na tecnologia (intenções comportamentais e boca a boca), no consumidor (eficácia de compras e o bem-estar) e no varejista (adesão à loja do varejo). Eles examinaram os fatores que deveriam compor a experiência dos clientes e, a partir desta análise, propuseram o construto multidimensional "experiência inteligente do varejo" composto pela vantagem relativa (TRUMAN; SANDOE; RIFKIN, 2003; WUENDERLICH et al., 2015); controle percebido (ABI GHANEM; MANDER, 2014); interatividade percebida (SCARDAMALIA; BEREITER，2014; WÜNDERLICH; WANGENHEIM; BITNER , 2013); fruição percebida (GRETZEL et al., 2015a, 2015b) e personalização (NEUHOFER; BUHALIS; LADKIN, 2015; PANTANO; TIMMERMANS, 2014).

Os resultados deste modelo indicaram que a satisfação do cliente pode aumentar a intenção de compra e as divulgações boca-a-boca e o risco percebido pode reduzir a intenção de compra e as divulgações boca-a-boca. Da mesma forma, a satisfação e o risco podem afetar a eficácia de compras, o bem-estar do consumidor e a adesão à loja do varejo. A figura 2.5 contém o modelo proposto por Roy et al. (2017) de experiência do varejo inteligente.

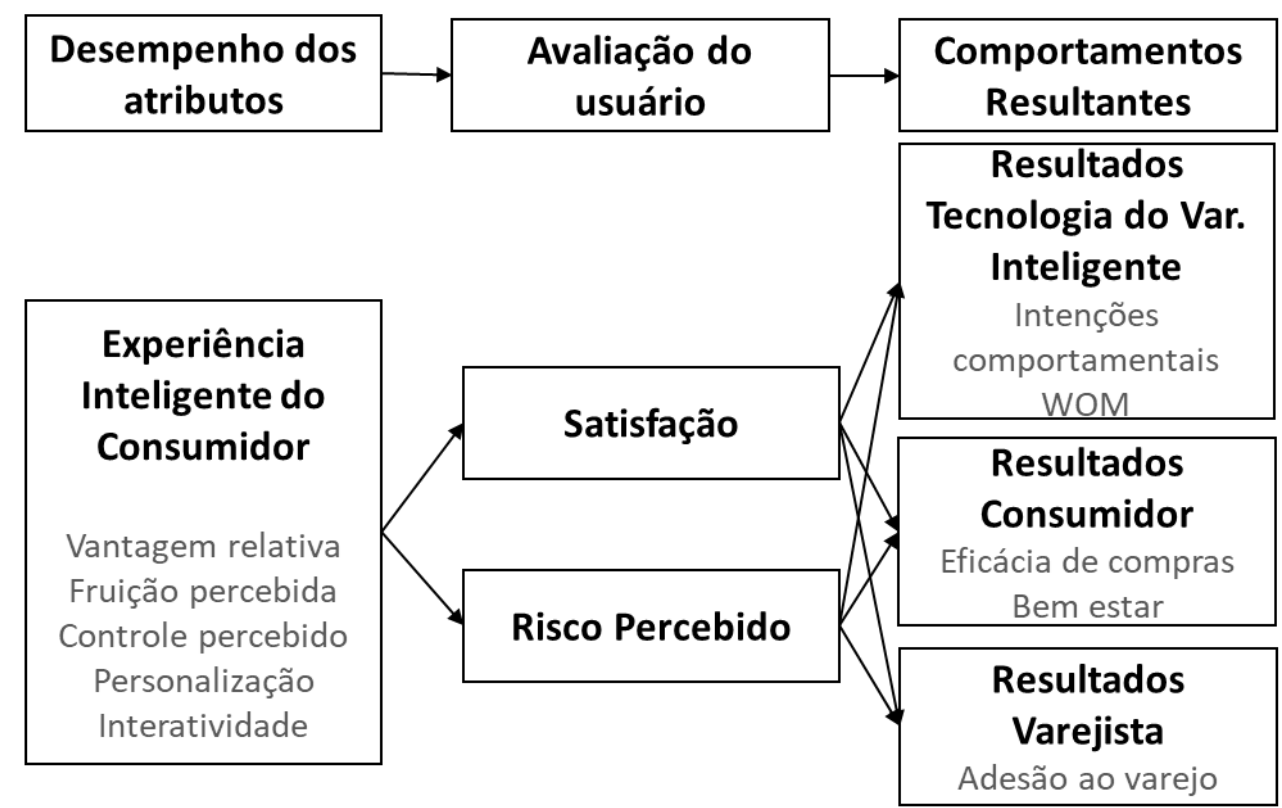

Figura 2.5 - Modelo de Experiência do Varejo Inteligente

Fonte: adaptado de Roy et al. (2017) 


\subsubsection{2 \\ Outros Modelos de Avaliação da Realidade Aumentada}

Foram encontrados diversos modelos na literatura para avaliar o uso da tecnologia interativa de Realidade Aumentada em contextos variados.

Ahn, Ryu e Han (2004) utilizaram o modelo TAM na investigação da aceitação e uso da tecnologia da informação (TI), incluindo a teoria da difusão da inovação e a teoria da ação fundamentada. Este modelo defende que as percepções ou crenças sobre a inovação são fundamentais para o desenvolvimento de atitudes que podem resultar na intenção comportamental de uso que, por sua vez, podem resultar no uso real. Já a atitude é diretamente afetada pela facilidade de uso e pela utilidade do sistema (DAVIS, 1989). Os estudos subsequentes ao de Davis (1989) sugerem que o modelo TAM produz resultados consistentes sobre o comportamento de aceitação dos usuários em relação à tecnologia. Legris, Ingham e Collerette (2003) reiteram o poder do modelo ao afirmarem, em seu estudo de meta-análises de modelos, que o TAM explica em torno de $40 \%$ da variância da intenção comportamental de usar (BI) em sistemas de TI inovadores. Em contrapartida, o modelo TAM foi criticado devido à sua simplicidade por não focar em antecedentes de design e implementação, bem como comportamento e experiência humana (BENBASAT; BARKI, 2007). Assim ao longo dos anos, o modelo TAM foi estendido com outras variáveis (VENKATESH; DAVIS, 2000; VENKATESH; BALA, 2008).

Rese et al. (2017) apresentaram um panorama dos estudos relevantes encontrados na literatura sobre a aceitação de aplicações de Realidade Aumentada no Varejo. Esta meta-análise serviu de base para o trabalho deles sobre Realidade Aumentada, desenvolvido na Alemanha. Um dos objetivos deste trabalho foi identificar variáveis externas para serem acrescentadas ao modelo TAM. A seleção das variáveis foi baseada na meta-análise realizada. As variáveis escolhidas foram: a provisão de informações adicionais sobre produtos, serviços ou o ambiente da loja, e a experiências estimulantes e agradáveis (OLSSON et al., 2013). A realização dos testes foi aplicada a quatro experimentos distintos de aplicativos Realidade Aumentada para apoiar a generalização dos resultados, os modelos e a 
abordagem de medição. As respostas aos testes indicam que o peso relativo dos aspectos hedônicos e utilitários varia de acordo com os diferentes tipos de aplicativos de Realidade Aumentada utilizados. Os resultados mostram que o modelo TAM é robusto e satisfatório. Mesmo assim, eles sugerem que novas pesquisas sejam aprimoradas e replicadas para outros ambientes. A figura 2.6 ilustra o modelo proposto por Rese et al. (2017).

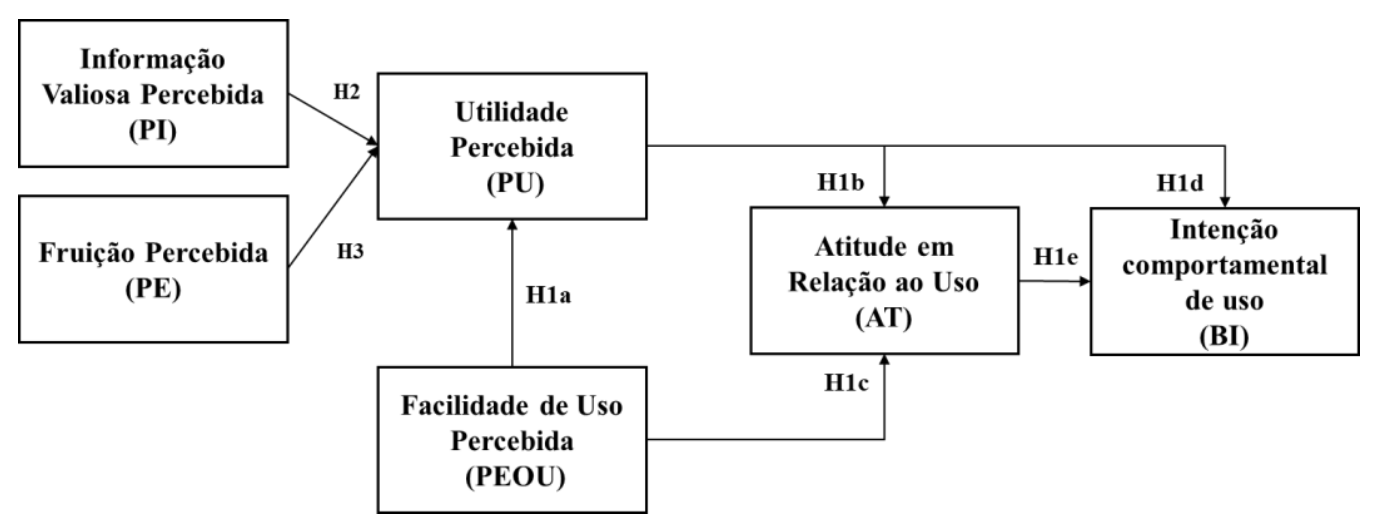

Figura 2.6 - Modelo de Rese et al. (2017) adaptado

Diversos pesquisadores, da mesma forma que Rese et al. (2017), testaram o TAM com adaptações para os seus contextos de estudo, como por exemplo Wixom e Todd (2005). Eles combinaram modelos de satisfação do usuário com o modelo TAM, acrescentando variáveis como qualidade do sistema e qualidade da informação, baseados em orientações específicas para a concepção de sistemas de TI.

Já no contexto do marketing de varejo, a "gamificação" e o design estético foram considerados importantes em diversos trabalhos (POUSTTCHI; HUFENBACH, 2014). No que diz respeito aos aspectos hedônicos no uso TAM para Realidade Aumentada, a maioria dos estudos incluiu, como elemento a ser investigado, a fruição percebida (perceived enjoyment) e/ou o divertimento (playfulness). Em contraste, o foco em aspectos utilitários de aplicativos de RA, tais como as informações valiosas percebidas (PI) ou a qualidade da informação, foram 
pouco explorados. Outro ponto pouco explorado foi o uso de vários aplicativos para estudos comparativos.

A exceção de Stoyanova et al. (2015) e Javornik (2016a), quase todas as pesquisas foram concentradas em um único aplicativo (RESE et al., 2017). A tabela 2.3 contém as pesquisas realizadas de aceitação dos aplicativos de Realidade Aumentada. Conforme mostrado na Tabela, e de acordo com Rauschnabel e Ro (2016), a maioria dos estudos utilizaram o modelo TAM por considerarem este modelo claro, estruturado e robusto.

Tabela 2.3 - Pesquisas de Aceitação dos Aplicativos Realidade Aumentada (continua)

\begin{tabular}{|c|c|c|c|c|c|}
\hline Estudo & Aplicação & Modelo & Construtos & $\begin{array}{l}\text { Coleta de } \\
\text { Dados }\end{array}$ & Método \\
\hline $\begin{array}{l}\text { Lee, Fiore } \\
\text { Kim } \\
(2006)\end{array}$ & $\begin{array}{l}\text { Provador virtual } \\
\text { de roupas } \\
\text { (modelo } \\
\text { rotativo) }\end{array}$ & TAM & $\begin{array}{l}\text { Orientação de compras } \\
\text { hedônica e utilitária, } \\
\text { nível de tecnologia de } \\
\text { interatividade de } \\
\text { imagem, PU, PEOU, } \\
\text { PE, AT, BI }\end{array}$ & $\begin{array}{l}\text { Pesquisa } \\
\text { com } 208 \\
\text { estudantes }\end{array}$ & SEM \\
\hline $\begin{array}{l}\text { Lee e } \\
\text { Chung } \\
(2008) \\
\end{array}$ & $\begin{array}{l}\text { Shopping mall } \\
\text { virtual }\end{array}$ & - & $\begin{array}{l}\text { Conveniência, PE, } \\
\text { garantia de qualidade, } \\
\text { satisfação do cliente }\end{array}$ & $\begin{array}{l}\text { Pesquisa } \\
\text { com } 102 \\
\text { estudantes }\end{array}$ & PLS \\
\hline $\begin{array}{l}\text { Oh, Yoon } \\
\text { e Shyu } \\
(2008)\end{array}$ & $\begin{array}{l}\text { VRIS protótipo } \\
\text { (visualização de } \\
\text { móveis em um } \\
\text { showroom } \\
\text { virtual em 3D) }\end{array}$ & -- & $\begin{array}{l}\text { Prazer, excitação, } \\
\text { atitude de produto, } \\
\text { intenção de compra, } \\
\text { certeza na escolha, } \\
\text { gozo de tomada de } \\
\text { decisão, PEOU, PU, } \\
\text { satisfação, certeza na } \\
\text { decisão }\end{array}$ & $\begin{array}{l}\text { Pesquisa } \\
\text { com } 92 \\
\text { estudantes }\end{array}$ & \\
\hline $\begin{array}{l}\text { Kim e } \\
\text { Forsythe } \\
\text { (2008a) }\end{array}$ & $\begin{array}{l}\text { Provador virtual } \\
\text { de roupas }\end{array}$ & TAM & $\begin{array}{l}\text { Ansiedade tecnológica, } \\
\text { inovatividade, PEOU, } \\
\text { PU, PE, BI, avaliação } \\
\text { pós-uso }\end{array}$ & $\begin{array}{l}\text { Pesquisa } \\
\text { com } 491 \\
\text { comprador } \\
\text { es online }\end{array}$ & SEM \\
\hline $\begin{array}{l}\text { Domina, } \\
\text { Lee e } \\
\text { Macgillivr } \\
\text { ay (2012) }\end{array}$ & $\begin{array}{l}\text { Mundo Virtual } \\
\text { (sites de moda) }\end{array}$ & $\begin{array}{l}\text { Teoria do } \\
\text { Fluxo e } \\
\text { TAM }\end{array}$ & $\begin{array}{l}\text { PE, controle percebido, } \\
\text { concentração } \\
\text { percebida, PEOU, } \\
\text { inovatividade do } \\
\text { consumidor (busca de } \\
\text { novidade, julgamento } \\
\text { independente), } \\
\text { intenção de comprar }\end{array}$ & $\begin{array}{l}\text { Pesquisa } \\
\text { com } 119 \\
\text { estudantes }\end{array}$ & SEM \\
\hline $\begin{array}{l}\text { Pantano e } \\
\text { Servidio } \\
(\mathbf{2 0 1 2})\end{array}$ & $\begin{array}{l}\text { Loja 3D } \\
\text { imersiva }\end{array}$ & $\begin{array}{l}\text { Modelo } \\
\text { de } \\
\text { interação } \\
\text { homem- } \\
\text { computa } \\
\text { dor }\end{array}$ & $\begin{array}{l}\text { Percepção da loja, } \\
\text { PEOU, PU, PE, } \\
\text { satisfação do } \\
\text { consumidor }\end{array}$ & $\begin{array}{l}\text { Pesquisa } \\
\text { com } 150 \\
\text { estudantes }\end{array}$ & SEM \\
\hline
\end{tabular}




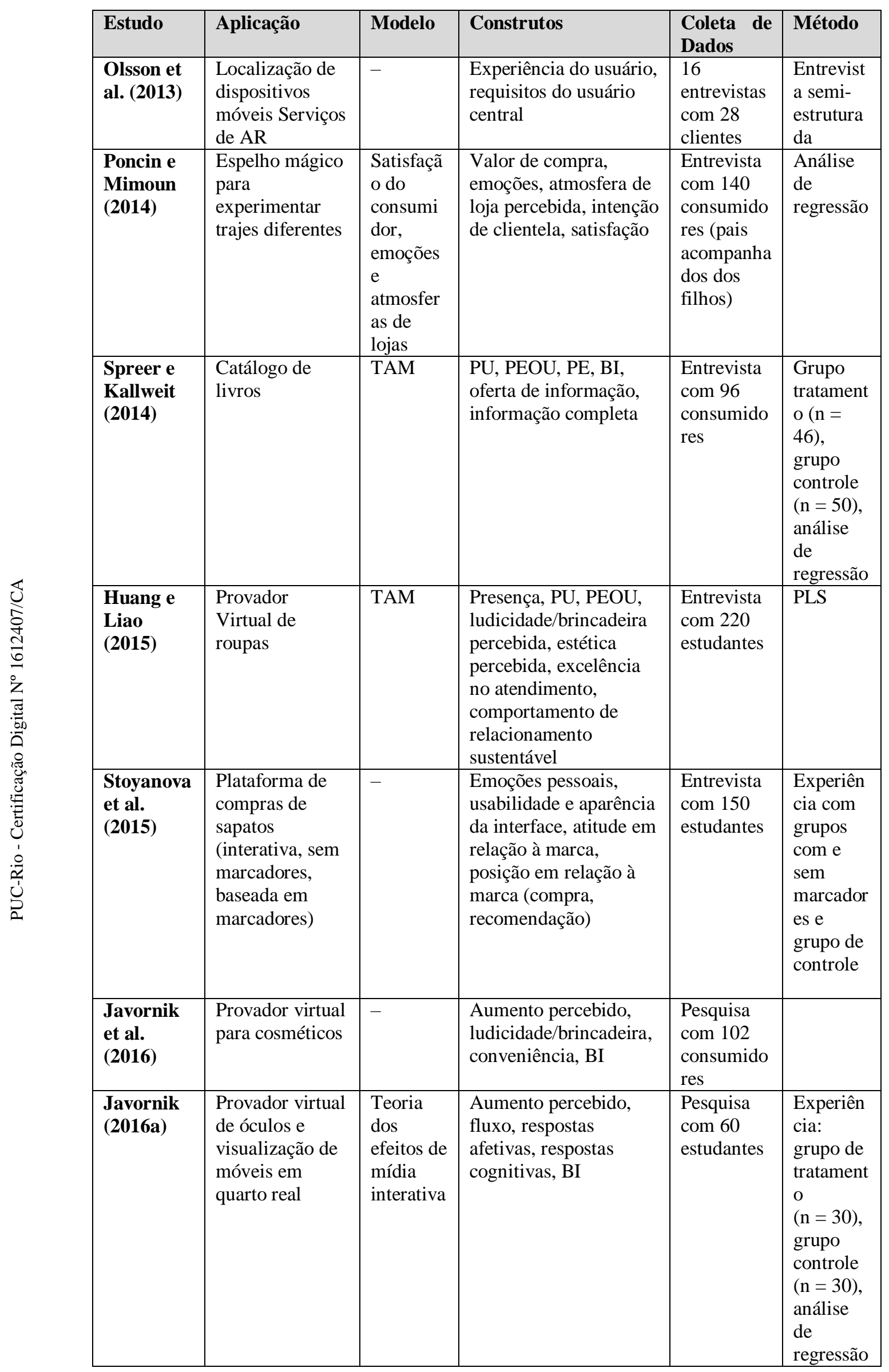




\begin{tabular}{|l|l|l|l|l|l|}
\hline Estudo & Aplicação & Modelo & Construtos & $\begin{array}{l}\text { Coleta de } \\
\text { Dados }\end{array}$ & Método \\
\hline $\begin{array}{l}\text { Kim e } \\
\text { Hyun } \\
\mathbf{2 0 1 6 )}\end{array}$ & $\begin{array}{l}\text { OVJET } \\
\text { (navegação) }\end{array}$ & TAM & $\begin{array}{l}\text { Qualidade do sistema, } \\
\text { qualidade da } \\
\text { informação, qualidade } \\
\text { do serviço, tele } \\
\text { presença, BI }\end{array}$ & $\begin{array}{l}\text { Pesquisa } \\
\text { com 114 } \\
\text { alunos }\end{array}$ & PLS \\
& & & & \\
\hline
\end{tabular}

Fonte: adaptada de Rese et al. (2017)

concluída

No estudo de Olsson et al. (2013), os aplicativos de Realidade Aumentada foram testados para avaliar o divertimento (playfulness) e as experiências momentâneas de entretenimento (entertaining). Para eles, além das aplicações Realidade Aumentada fornecerem informações digitais adicionais, elas também oferecem experiências hedônicas como, prazer e estimulação. Os resultados do estudo mostraram que as percepções de Olsson et al. (2013) parecem fazer sentido, uma vez que as variáveis testadas apresentaram significância. Uma tecnologia inovadora percebida como algo divertido satisfaz as necessidades dos consumidores de escapismo, diversão, prazeres estéticos ou liberação emocional (DUCOFFE, 1996).

A inclusão das variáveis fruição do uso do sistema e informações valiosas percebidas também foram identificados como fatores relevantes na influência da atitude dos usuários em relação ao comércio eletrônico e móvel (CHEN; TAN, 2004; CHEN; WELLS, 1999; HAUSMAN; SIEPKE, 2009). Ambos os fatores foram avaliados em estudos empíricos e apresentaram influência positiva na atitude em relação ao site ou dispositivo móvel (HAUSMAN; SIEPKE, 2009, PANTANO; NACCARATO, 2010, PANTANO; SERVIDIO, 2012). Isto corrobora a convicção de outros estudos de que a inclusão da fruição percebida (perceived enjoyment - PE) no modelo TAM parece influenciar a atitude, e consequentemente a intenção de uso de um sistema (CHILDERS et al., 2001; DAVIS; BAGOZZI; WARSHAW, 1992; VAN DER HEIJDEN, 2004). Já para Huang e Liao (2015), o divertimento (playfulness) avaliado foi considerado como uma característica secundária em relação à experiência de compra online criada pela ARIT.

Outra consideração feita sobre as aplicações de Realidade Aumentada no marketing e no varejo por Rese et al. (2017) refere-se à influência mais forte da utilidade percebida do que a da facilidade de uso na aceitação desta tecnologia. Já em relação à influência dos aspectos hedônicos e dos utilitários na experiência do 
consumidor com RA, segundo Javornik (2016b), os estudos anteriores mostram que os aspectos hedônicos se sobrepõem aos aspectos utilitários, principalmente no estágio inicial de uso desta tecnologia. Estas descobertas, de acordo com o seu estudo, precisariam ser testadas empiricamente em estudos futuros. Javornik (2016b) sugere que seja incluído uma variável moderadora (por exemplo: estágio de processo de decisão) nos modelos de RA. Esta variável moderadora serviria para validar o estágio inicial de engajamento com a ferramenta onde a "utilidade hedônica" seria encontrada. A "utilidade hedônica", assim chamada por Javornik (2016b), ocorre quando os aspectos hedônicos percebidos confundem a avaliação correta da utilidade e normalmente ocorrem no estágio inicial da jornada de compra. A variável serviria também para validar a "utilidade funcional" mais fortemente observada no estágio de decisão.

$\mathrm{Na}$ avaliação sobre a inclusão nos modelos do construto informações valiosas percebidas, que representa as informações acrescentadas sobre o produto pela tecnologia de RA, este construto serviria para medir se estas informações satisfazem as necessidades de informações dos clientes na tomada de decisão de compra (Chen; Tan, 2004).

Outra variável sugerida nos estudos sobre o uso de tecnologia interativa de Realidade Aumentada (ARIT) é o nível de inovação de um consumidor, que classifica a sua capacidade cognitiva associada às inovações tecnológicas. De acordo com Huang e Liao (2015), que integram o modelo de aceitação de tecnologia e os conceitos de valor experiencial, os consumidores online com alta inovação cognitiva dão mais ênfase a utilidade, estética e excelência do serviço oferecida pela tecnologia interativa de Realidade Aumentada. Em contrapartida, aqueles com baixa inovação cognitiva se concentram em brincadeira e facilidade de uso.

No estudo sobre a vontade dos consumidores em continuar usando a tecnologia interativa feito por Varadarajan et al. (2010), o nível de inovação do consumidor também foi considerado relevante. Isto também é corroborado nas descobertas feitas por Kim e Forsythe (2008a) e Simon e Usunier (2007) de que as intenções de uso futuro e as características dos consumidores têm um efeito positivo significativo sobre o uso contínuo de tecnologia interativa por parte dos consumidores (KIM; FORSYTHE, 2008a; SIMON; USUNIER, 2007). 
Uma revisão de literatura feita por Wu et al. (2011) sobre gerenciamento de informações e comércio eletrônico destaca uma série de teorias que são frequentemente usadas ou estendidas com outras variáveis para investigar a adoção pelo consumidor de serviços via plataformas móveis. As principais teorias incluem o modelo de aceitação de tecnologia (TAM) de Davis, Bagozzi e Warshaw (1989), o modelo de sucesso do sistema de informação (ISSL) (DELONE; MCLEAN, 2003), o modelo de não confirmação de expectativas (OLIVER, 1980), as dimensões da confiança (KIM; HALEY; KOO, 2009) , as teorias culturais, como as dimensões culturais da Hofstede (2004), os modelos de avaliação da qualidade do serviço, como SERVQUAL e E-QUAL (KAYNAMA; BLACK, 2000) e o índice europeu de satisfação do cliente (ECSI) (CASSEL; EKLÖF, 2001). Desses, o TAM tem sido o mais utilizado e ampliado com o objetivo de examinar as questões da adoção de serviços em dispositivos móveis (m-service). Em alguns estudos de $m$-service foi englobada a construção ou cultura de confiança. Esta perspectiva inclui variáveis relacionadas à confiança ou relacionadas à cultura ou à fruição percebida como medidas intrínsecas (LEE; CHUNG, 2008; LI; YEH; 2010; LIN, 2011).

Nos estudos sobre a aceitação do consumidor pela tecnologia para dispositivos móveis, a fruição percebida tem sido frequentemente usada como um antecedente importante para a adoção da tecnologia móvel (HO CHEONG; PARK, 2005; KIM; FIORE; LEE, 2007; KAO, 2009; LU; SU, 2009; WANG; LI, 2012). A fruição percebida aparece como uma variável importante tanto nos modelos de Realidade Aumentada quanto nos modelos que tratam de dispositivos móveis.

A pesquisa feita por Chung, Han e Joun (2015) utilizando um aplicativo usado no Turismo com tecnologia de Realidade Aumentada mostraram que, quando um indivíduo estava em um estado de espírito pronto para usar uma tecnologia, essa prontidão afetava a utilidade percebida. Já o recurso visual e as condições facilitadoras afetavam a facilidade de uso percebida e, por fim, a utilidade percebida. Para concluir, a utilidade percebida e a facilidade de uso afetavam, por meio da atitude, a intenção de uso da Realidade Aumentada nas viagens turísticas.

Outro ponto importante verificado nos estudos sobre Realidade Aumentada envolve a população estudada nas pesquisas. A maioria dos estudos utilizou em 
seus experimentos estudantes universitários, que são, geralmente, jovens. O resultado pode ser diferente para um grupo etário mais velho, como ressaltam Chong (2013) e Gurtner, Reinhardt e Soyer (2014). Outra preocupação dos estudos refere-se ao contexto cultural, que pode variar em relação à adoção de aplicativos de Realidade Aumentada (CHOI et al., 2014; LEE; CHUNG; JUNG, 2015). Vários autores recomendam a realização de estudos replicados em contextos e culturas diferentes para avaliar as relações e validar as estimativas de seus modelos (LEE; KOZAR; LARSEN, 2003; RESE et al., 2017).

Por sua vez, estudos envolvendo a avaliação sistemática de aplicações de Realidade Aumentada em aplicativos móveis foram pouco desenvolvidos. Estes estudos poderão contribuir na concepção de novas aplicativos móveis (HOEHLE; VENKATESH, 2015).

Com base na TIME de Sander (2015), Javornik (2016a) propôs a criação de um modelo para examinar o efeito do uso de aplicações de Realidade Aumentada em experiência do consumidor em relação às respostas afetivas, cognitivas e intenções comportamentais. A característica da Realidade Aumentada percebida (objetos/informações acrescentados à realidade) que a tecnologia de Realidade Aumentada oferece é um recurso muito importante e, apesar da aparente semelhança com a interatividade, a Realidade Aumentada tem recursos especiais e relevantes para os estudos que a interatividade, por si só, não oferece.

Sendo assim, Javornik (2016a) decidiu adotar o construto Realidade Aumentada percebida para avaliar se a inclusão de objetos e informações acrescentados à realidade pode levar a uma imersão mais intensa na experiência de compra, propiciando respostas afetivas e cognitivas. Os resultados da pesquisa apontam que a Realidade Aumentada percebida foi relevante e que este construto e seus itens de medição podem ser usados para avaliar o valor das ferramentas de Realidade Aumentada e os seus efeitos no comportamento do consumidor. Neste estudo, foi confirmado que os consumidores ficam mais imersos no fluxo quando percebem aumento visual intenso. A figura 2.7 apresenta o modelo proposto por Javornik (2016a) para avaliar a experiência de compra utilizando RA. 


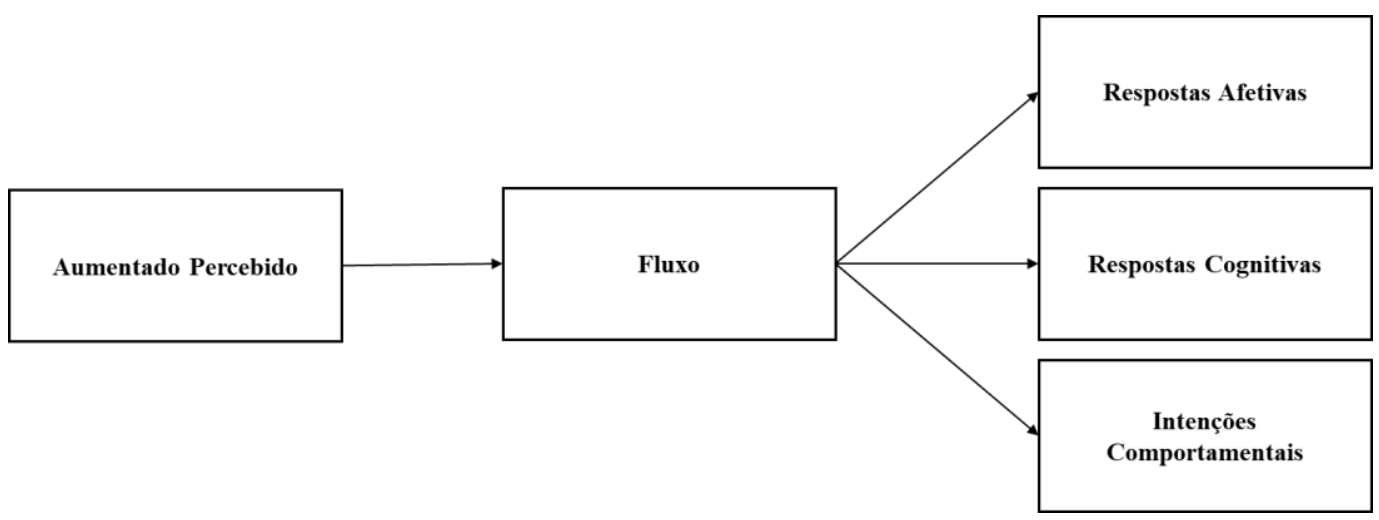

Figura 2.7 - Modelo de Javornik (2016a) adaptado

Além dos principais estudos selecionados por Rese et al. (2017) em sua revisão (tabela 2.3), o presente estudo encontrou mais alguns estudos relevantes sobre RA. A tabela 2.4 contém a lista de pesquisas adicionais relevantes com Realidade Aumentada que foram encontradas na revisão de literatura não mencionadas por Rese et al. (2017).

Tabela 2.4 - Pesquisas de Aceitação dos Aplicativos de Realidade Aumentada Complementar (continua)

\begin{tabular}{|c|c|c|c|c|c|}
\hline Estudo & Aplicação & Modelo & Construtos & $\begin{array}{l}\text { Coleta de } \\
\text { Dados }\end{array}$ & Método \\
\hline $\begin{array}{l}\text { Beck e } \\
\text { Crié } \\
(\mathbf{2 0 1 6})\end{array}$ & $\begin{array}{l}\text { VFR - } \\
\text { Salas de } \\
\text { adaptação } \\
\text { Virtual }\end{array}$ & $\begin{array}{l}\text { Motivações } \\
\text { intrínseca e } \\
\text { extrínseca }\end{array}$ & $\begin{array}{l}\text { Curiosidade } \\
\text { específica percentual } \\
\text { (PSC) sobre o } \\
\text { produto, Intenção de } \\
\text { patrocinar, intenção } \\
\text { de compra }\end{array}$ & $\begin{array}{l}228 \text { jovens da } \\
\text { Universidade } \\
\text { Europeia }\end{array}$ & $\begin{array}{l}\text { Dois } \\
\text { experimento } \\
\text { s (online } e \\
\text { Offline): } \\
\text { catálogo } \\
\text { eletrônico e } \\
\text { provador } \\
\text { virtual - } \\
\text { Mancova }\end{array}$ \\
\hline $\begin{array}{l}\text { Dacko } \\
(2017)\end{array}$ & $\begin{array}{l}\text { Pesquisas } \\
\text { para } \\
\text { examinar } \\
\text { os } \\
\text { benefícios } \\
\text { do uso de } \\
\text { aplicativos } \\
\text { Realidade } \\
\text { Aumentad } \\
\text { a para os } \\
\text { consumido } \\
\text { res e } \\
\text { varejistas }\end{array}$ & $\begin{array}{l}\text { Valores } \\
\text { experiencias } \\
\text { de } \\
\text { Mathwick, } \\
\text { Malhotra e } \\
\text { Rigdon } \\
\text { (2001) }\end{array}$ & $\begin{array}{l}\text { Valores } \\
\text { experimentais } \\
\text { consumidor } \\
\text { (Brincadeira } \\
\text { percebida, estética, } \\
\text { excelência de serviço } \\
\text { e ROI) e valores dos } \\
\text { varejistas e intenções } \\
\text { comportamentais, }\end{array}$ & $\begin{array}{l}\text { Pesquisa de } \\
\text { triagem com } \\
21.467 \\
\text { usuários para } \\
\text { selecionar os } \\
\text { usuários de } \\
\text { Realidade } \\
\text { Aumentada. } \\
\text { Amostra de } \\
9452 \text { usuários } \\
\text { em compras de } \\
\text { aplicativos de } \\
\text { Realidade } \\
\text { Aumentada } \\
\text { Móvel no }\end{array}$ & $\begin{array}{l}\text { Categorizaç } \\
\text { ão dos } \\
\text { aplicativos } \\
\text { de } \\
\text { Realidade } \\
\text { Aumentada } \\
\text { Móvel } \\
\text { dentro dos } \\
\text { quadrantes } \\
\text { do valor } \\
\text { experiencial } \\
\text {. }\end{array}$ \\
\hline
\end{tabular}




\begin{tabular}{|c|c|c|c|c|c|}
\hline Estudo & Aplicação & Modelo & Construtos & $\begin{array}{l}\text { Coleta de } \\
\text { Dados }\end{array}$ & Método \\
\hline & & & & $\begin{array}{l}\text { Google play } \\
\text { nos EUA. }\end{array}$ & \\
\hline $\begin{array}{l}\text { Hilken } \\
\text { et al. } \\
\text { (2017) }\end{array}$ & $\begin{array}{l}\text { Avaliação } \\
\text { de } \\
\text { aplicativos } \\
\text { com } \\
\text { espelhos } \\
\text { virtuais } \\
\text { (óculos e } \\
\text { maquiage } \\
\text { m) }\end{array}$ & $\begin{array}{l}\text { Teoria da } \\
\text { cognição } \\
\text { situada }\end{array}$ & $\begin{array}{l}\text { Variáveis de serviços } \\
\text { de Realidade } \\
\text { Aumentada (controle } \\
\text { e incorporação do } \\
\text { ambiente), presença } \\
\text { espacial (mediador) } \\
\text { valores percebidos da } \\
\text { experiência (utilitário } \\
\text { e hedônico), conforto } \\
\text { na decisão), estilo de } \\
\text { processamento e } \\
\text { consciência da } \\
\text { prática de } \\
\text { privacidade } \\
\text { (moderadores) e } \\
\text { intenção } \\
\text { comportamental } \\
\text { (compra e WOM) }\end{array}$ & $\begin{array}{l}\text { Pesquisa com } \\
176 \\
\text { participantes } \\
\text { de uma } \\
\text { universidade } \\
\text { pública. }\end{array}$ & $\begin{array}{l}\text { Análise de } \\
\text { regressão }\end{array}$ \\
\hline $\begin{array}{l}\text { Pantan } \\
\text { o, Rese } \\
\text { e Baier } \\
\text { (2017) }\end{array}$ & $\begin{array}{l}\text { Provador } \\
\text { virtual de } \\
\text { óculos }\end{array}$ & TAM & $\begin{array}{l}\text { Construtos do TAM, } \\
\text { divertimento e mais } \\
\text { os construtos de } \\
\text { características de } \\
\text { Realidade } \\
\text { Aumentada } \\
\text { (qualidade da } \\
\text { informação e estética, } \\
\text { interatividade e } \\
\text { tempo de resposta) }\end{array}$ & $\begin{array}{l}\text { Pesquisa com } \\
318 \\
\text { participantes } \\
\text { da Itália e } \\
\text { Alemanha }\end{array}$ & SEM \\
\hline $\begin{array}{l}\text { Poush } \\
\text { neh e } \\
\text { Vasqu } \\
\text { ez- } \\
\text { Parrag } \\
\text { a } \\
(\mathbf{2 0 1 7})\end{array}$ & $\begin{array}{l}\text { Provador } \\
\text { virtual de } \\
\text { óculos }\end{array}$ & $\begin{array}{l}\text { Modelo } \\
\text { proposto de } \\
\text { experiência } \\
\text { do usuário e } \\
\text { Realidade } \\
\text { Aumentada }\end{array}$ & $\begin{array}{l}\text { Experiência do } \\
\text { usuário, Realidade } \\
\text { Aumentada, vontade } \\
\text { de comprar, } \\
\text { satisfação do usuário, } \\
\text { controle de } \\
\text { privacidade e trade- } \\
\text { off entre preço e valor } \\
\text { (moderadores) }\end{array}$ & $\begin{array}{l}\text { Pesquisa com } \\
99 \\
\text { participantes } \\
\text { de uma cidade } \\
\text { metropolitana } \\
\text { do sul dos } \\
\text { EUA. }\end{array}$ & SEM \\
\hline
\end{tabular}




\begin{tabular}{|c|c|c|c|c|c|}
\hline Estudo & Aplicação & Modelo & Construtos & $\begin{array}{l}\text { Coleta de } \\
\text { Dados }\end{array}$ & Método \\
\hline $\begin{array}{l}\text { Yim, } \\
\text { Chu e } \\
\text { Sauer } \\
(2017)\end{array}$ & $\begin{array}{l}\text { Provador } \\
\text { virtual de } \\
\text { óculos e } \\
\text { relógios }\end{array}$ & $\begin{array}{l}\text { Mecanismos } \\
\text { funcionais } \\
\text { de Realidade } \\
\text { Aumentada } \\
\text { e } \\
\text { experiências } \\
\text { imersivas }\end{array}$ & $\begin{array}{l}\text { Interatividade, } \\
\text { vivacidade, imersão, } \\
\text { previa experiência, } \\
\text { novidade, utilidade, } \\
\text { divertimento, atitude } \\
\text { e intenção de compra }\end{array}$ & $\begin{array}{l}\text { Pesquisa com } \\
133 \\
\text { participantes } \\
\text { (óculos) e } 115 \\
\text { participantes } \\
\text { (relógios) }\end{array}$ & $\begin{array}{l}\text { Dois } \\
\text { estudos } \\
\text { comparativo } \\
\text { s entre web } \\
\text { convencion } \\
\text { al e RA }\end{array}$ \\
\hline $\begin{array}{l}\text { Brito, } \\
\text { Stoyan } \\
\text { ova e } \\
\text { Coelho } \\
(2018)\end{array}$ & $\begin{array}{l}\text { Três tipos } \\
\text { de } \\
\text { interface } \\
\text { do site de } \\
\text { compra de } \\
\text { tênis } \\
\text { Converse }\end{array}$ & $\begin{array}{l}\text { Teorias de } \\
\text { transferência } \\
\text {, propagação } \\
\text { de ativação e } \\
\text { interação } \\
\text { humano- } \\
\text { computador }\end{array}$ & $\begin{array}{l}\text { Tipos de interfaces, } \\
\text { resposta emocional, } \\
\text { atitude em relação à } \\
\text { marca, resposta sobre } \\
\text { recomendação da } \\
\text { marca, risco } \\
\text { percebido, } \\
\text { usabilidade, liderança } \\
\text { de opinião e traços } \\
\text { emocionais positivos }\end{array}$ & $\begin{array}{l}\text { Participantes } \\
150 \\
\text { consumidores }\end{array}$ & $\begin{array}{l}\text { Experiment } \\
\text { o } \\
\text { Laboratorial } \\
\text { - Ancova - } \\
\text { Anova e } \\
\text { Manova }\end{array}$ \\
\hline $\begin{array}{l}\text { Forou } \\
\text { di et al. } \\
(2018)\end{array}$ & $\begin{array}{l}\text { Pesquisa } \\
\text { com os } \\
\text { clientes de } \\
\text { uma loja } \\
\text { de alto } \\
\text { padrão em } \\
\text { Londres }\end{array}$ & $\begin{array}{l}\text { Experiência } \\
\text { do cliente }\end{array}$ & $\begin{array}{l}\text { Comprometimento na } \\
\text { aprendizagem, } \\
\text { intenção } \\
\text { comportamental, } \\
\text { dinâmicas do cliente } \\
\text { (consciência, } \\
\text { interesse) e } \\
\text { experiência do cliente } \\
\text { (hedônica e } \\
\text { reconhecimento) }\end{array}$ & $\begin{array}{l}\text { Pesquisa com } \\
\text { amostra de } \\
\text { conveniência } \\
\text { de } 330 \\
\text { consumidores } \\
\text { do varejo } \\
\text { online em } \\
\text { Londres }\end{array}$ & SEM \\
\hline
\end{tabular}

Fonte: própria

concluída

Beck e Crié (2016) testaram se o maior oferecimento de informações do produto obtidos via provadores virtuais (VFR), em relação ao catálogo eletrônico, pode influenciar na incerteza e consequentemente na percepção de risco percebido. Eles destacam que a curiosidade específica do produto e a intenção de patrocinar a marca são geradas tanto no contexto online quanto offline. Outro destaque é que o uso dos provadores virtuais, mediado pela curiosidade específica perceptual e pelas intenções de patrocínio, aumenta a intenção de compra. Desta forma, o provador virtual pode ser usado para melhorar a experiência de compra online, contribuindo para maior lealdade do cliente, além de também influenciar positivamente em visitas a lojas reais pelos clientes. Beck e Crié (2016) sugerem que novos estudos avaliem a influência da novidade em relação a curiosidade no decorrer do tempo.

Dacko (2017) realizou uma pesquisa com os usuários de aplicativos Realidade Aumentada Móvel (MAR) nos Estados Unidos para avaliar a percepção 
de uso, benefícios experimentais oferecidos e as contribuições destes aplicativos para criação de valor adicional para os clientes e para geração de benefícios para os varejistas. Sua descoberta aponta para uma satisfação alta do usuário, assim como um aumento na percepção de uso, trazendo benefícios, tanto para o consumidor, quanto para o varejista. Para o autor, é esperado que a Realidade Aumentada proporcione experiências de compras mais eficientes e divertidas, informações mais completas e decisões mais precisas, resultando em comportamentos positivos. Além disso, os varejistas que oferecerem aplicativos de Realidade Aumentada Móvel podem ser mais bem avaliados pelos consumidores, podendo ainda provocar mudanças no comportamento do consumidor.

Na pesquisa de Hilken et al. (2017), o sentimento de presença espacial na Experiência de Realidade Aumentada atua como um mediador, podendo gerar uma decisão mais confortável para o cliente. Outro destaque apontado por eles refere-se ao tipo das informações aumentadas (verbais ou visuais) em relação à percepção de valor utilitário. Os clientes têm mais disposição de processar as informações verbais do que visuais. Outro achado refere-se à preocupação com a privacidade, que é atenuada por uma decisão mais confortável.

Pantano et al. (2017) investigaram a influência do uso de Realidade Aumentada no varejo online sobre o comportamento do consumidor em dois ambientes culturais distintos. Tanto os participantes da Itália quanto os da Alemanha apresentaram atitude positiva em relação ao uso de provadores virtuais para experimentar os óculos.

Poushneh e Vasquez-Parraga (2017) testaram os efeitos da Realidade Aumentada, via o construto Realidade Aumentada, na experiência do usuário de varejo e sua subsequente influência na disposição do usuário em comprar e sua satisfação. A disposição de comprar do usuário (UWB) se refere à tendência dos consumidores de adquirirem produtos no futuro e prever o comportamento real de compra (MORRISON, 1979). A abordagem da pesquisa de Poushneh e VasquezParraga (2017) foi avaliar como as características do produto observadas via Realidade Aumentada podem afetar positivamente as atitudes e as intenções comportamentais dos consumidores, usando o aplicativo de Ray-Ban. As 
características de alto nível de qualidade de aumento, informatividade, interatividade e utilidade indicaram maior influência na satisfação do usuário.

Os resultados do estudo revelaram que uma experiência do usuário enriquecida por Realidade Aumentada é considerada pelos usuários mais divertida e estes enxergam o potencial da ferramenta pelo acréscimo das informações virtuais. Os usuários desta experiência ficaram mais satisfeitos e tiveram mais disposição do usuário em comprar. Além disto, os consumidores ficaram motivados a baixar aplicativos de Realidade Aumentada para obter as promoções com informações aprimoradas. Em relação aos moderadores trade-off de preço e valor e informações sobre privacidade, estes não moderam os efeitos da Realidade Aumentada na experiência do usuário. A figura 2.8 retrata o modelo de Realidade Aumentada proposto no estudo de Poushneh e Vasquez-Parraga (2017).

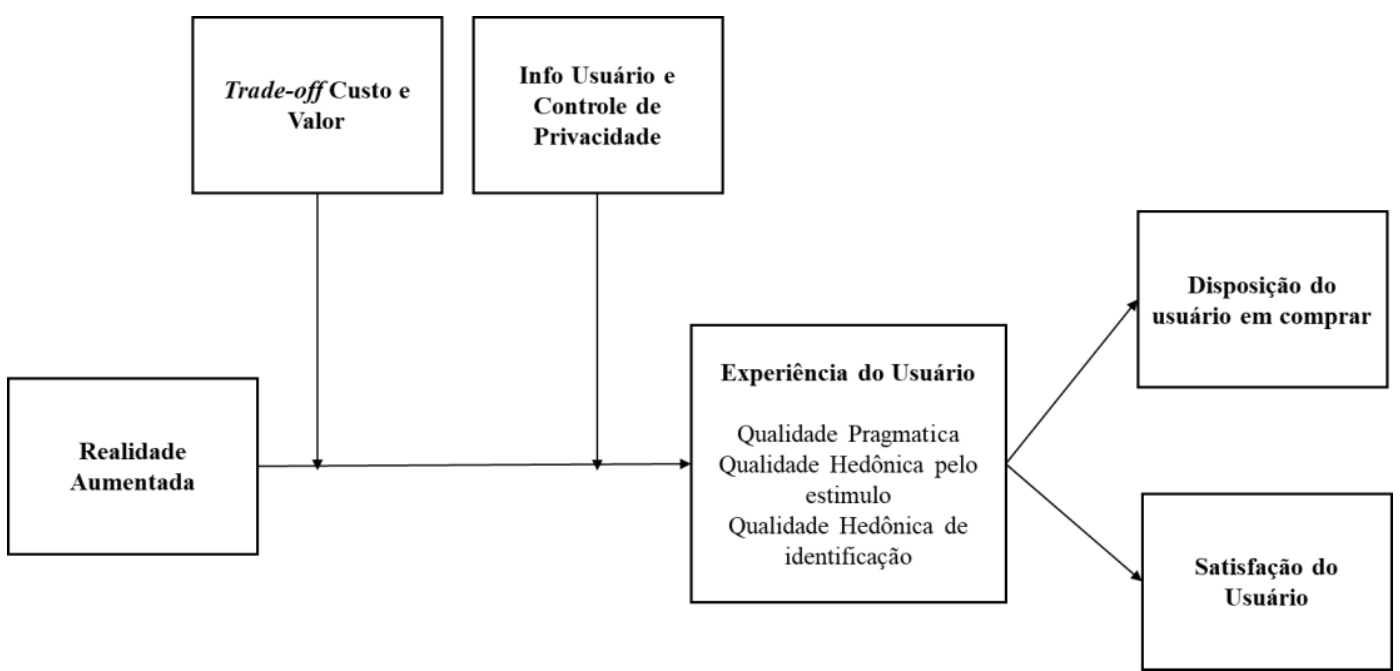

Figura 2.8 - Modelo de Poushneh eVasquez-Parraga (2017)

Yim, Chu e Sauer (2017) comparam o ambiente Web convencional com o de Realidade Aumentada em dois estudos. O estudo 1 avaliou a eficácia de Realidade Aumentada e seus resultados indicaram que as apresentações de produtos com Realidade Aumentada, em geral, têm efeitos superiores comparados aos do ambiente convencional em relação à novidade, imersão, entretenimento, utilidade, atitude e também a intenção de compra. Os resultados do estudo 2, que compara o processo de avaliação dos produtos pelos consumidores nos dois ambientes, 
mostraram que a imersão é mediadora da relação entre interatividade/vivacidade e os construtos utilidade e prazer no ambiente de Realidade Aumentada.

Para avaliar o desempenho dos tipos de interfaces no ambiente online, Brito, Stoyanova e Coelho (2018) fizeram um estudo experimental que comparava três interfaces de aplicativos de compras online. Eles compararam duas interfaces com Realidade Aumentada sendo uma com marcador (M) e outra sem marcador (RA) e uma interface interativa Convencional (CI). A interface de Realidade Aumentada com marcador (M) é a mais comum pela simplicidade de implementação. A interface com Realidade Aumentada com marcador (M) é baseada em um ícone, como o QR Code, para ser apontado para a câmera e reconhecido pelo aplicativo. O ícone serve como uma referência espacial para incluir o objeto virtual no ambiente real. Já a Realidade Aumentada sem marcador (RA) permite o reconhecimento pelos computadores de informações de contraste e padrão sem marca especial, ou seja, usa as próprias imagens reais 3D como marcadores utilizando técnicas baseadas em arestas. Este tipo de interface, embora mais complexo, proporciona uma maior imersão no ambiente (BRITO; STOYANOVA; COELHO, 2018).

Pelos resultados deste estudo, as respostas, emocional e interativa, e a avaliação da marca são maiores nas interfaces com marcador (M) e sem marcador (RA) do que na interativa convencional (CI). Por outro lado, o resultado da usabilidade é o oposto, pois a usabilidade é considerada maior em CI do que $\mathrm{M} \mathrm{e}$ RA. Não foram encontrados efeitos nas variáveis psicológicas nas interfaces Realidade Aumentada M. O tipo de interface, sofisticada ou simples, não afetou a intenção de compra, porém a sua recomendação melhorou, tanto para M como RA. As três interfaces foram mediadas pela familiaridade da marca, risco percebido, liderança de opinião e traços emocionais positivos, apresentando efeitos distintos.

Foroudi et al. (2018) utilizaram uma pesquisa inicial explicativa para compreender o fenômeno envolvendo a utilização de tecnologias inteligentes no varejo em experiências dos clientes e suas intenções comportamentais. $\mathrm{O}$ foco da pesquisa foi dar suporte aos acadêmicos e executivos de varejo na melhor compreensão do conceito da dinâmica da experiência do cliente utilizando tecnologias inteligentes relacionados ao compromisso com a aprendizagem e às 
intenções comportamentais dos clientes. Os resultados revelaram que tanto a disposição quanto a capacidade de aprender impulsionaram a participação dos clientes na adoção de tecnologias inteligentes no varejo. Entretanto, o compromisso de aprender e a probabilidade subjetiva de adoção de um comportamento (intenção comportamental) em um ambiente de varejo pelos clientes não apresentaram relação com intenção comportamental do cliente. A possível explicação para este resultado pode estar relacionada com a faixa etária, entre 18 e 39 anos, da maioria dos participantes, que já estariam familiarizados com estas tecnologias.

Segue uma tabela que contém o resumo dos principais modelos e teorias encontrados na revisão de literatura feita sobre Realidade Aumentada.

Tabela 2.5 - Resumo dos principais modelos e teorias

(continua)

\begin{tabular}{|c|c|c|}
\hline Teoria/Modelo & Autor/Referência & Comentários \\
\hline $\begin{array}{l}\text { Teoria da Difusão e } \\
\text { Inovação (IDT) - } \\
\text { Diffusion of } \\
\text { Innovations }\end{array}$ & Rogers (2003) & $\begin{array}{l}\text { Esta teoria contribui para compreensão da } \\
\text { dinâmica do processo de difusão de } \\
\text { inovações. Os aspectos emocionais não foram } \\
\text { abordados nesta teoria. O presente estudo } \\
\text { utilizou o construto Vantagem Relativa desta } \\
\text { teoria. }\end{array}$ \\
\hline Teoria do Fluxo & $\begin{array}{l}\text { Csikszentmihalyi } \\
\text { (1990) }\end{array}$ & $\begin{array}{l}\text { Teoria que surgiu na área de Psicologia. O } \\
\text { fluxo é definido como o estado de imersão, } \\
\text { absorção e foco de uma pessoa em uma } \\
\text { atividade desafiadora. O presente estudo } \\
\text { utilizou o construto Fruição Percebida e } \\
\text { Controle Percebido desta teoria. }\end{array}$ \\
\hline $\begin{array}{l}\text { Teoria do Risco } \\
\text { Percebido }\end{array}$ & $\begin{array}{l}\text { Bauer (1960) e } \\
\text { Cox (1967) }\end{array}$ & $\begin{array}{l}\text { A teoria do Risco pode ser utilizada em } \\
\text { estudo para avaliar como a tecnologia de } \\
\text { Realidade Aumentada, com o recurso de } \\
\text { acrescentar informações e objetos virtuais ao } \\
\text { ambiente real, pode ajudar os consumidores a } \\
\text { avaliarem melhor os riscos de uma compra. }\end{array}$ \\
\hline $\begin{array}{l}\text { Teoria do Efeito de } \\
\text { Mídia Interativa } \\
\text { (Theory of Interactive } \\
\text { Media Effects - } \\
\text { TIME) }\end{array}$ & $\begin{array}{l}\text { Sundar et al. } \\
(2015)\end{array}$ & $\begin{array}{l}\text { Os recursos tecnológicos geram ações dos } \\
\text { usuários, provocando correlatos psicológicos } \\
\text { e estes são traduzidos em experiências } \\
\text { imersivas que geram respostas afetivas, } \\
\text { cognitivas e comportamentais. Este modelo } \\
\text { serviu de base para o modelo de Javornick } \\
\text { (2016a) }\end{array}$ \\
\hline $\begin{array}{l}\text { Modelo de Aceitação } \\
\text { de Tecnologia } \\
\text { (Technology } \\
\text { Acceptance Model } \\
\text { TAM) - baseado na } \\
\text { Teoria da Ação } \\
\text { Racionalizada } \\
\text { (Theory of Reasoned } \\
\text { Action - TRA) de }\end{array}$ & $\begin{array}{l}\text { Davis, Bagozzi e } \\
\text { Warshaw (1989) }\end{array}$ & $\begin{array}{l}\text { Diversos estudos (DOMINA; LEE; } \\
\text { MACGILLIVRAY, 2012; HUANG; LIAO, } \\
\text { 2015; KIM; FORSYTHE, 2008a; KIM; } \\
\text { HYUN, 2016; LEE; FIORE; KIM, 2006; } \\
\text { RESE; SCHREIBER; BAIER, 2014; RESE et } \\
\text { al., 2017; SPREER; KALLWEIT, 2014) } \\
\text { sobre Realidade Aumentada utilizaram o } \\
\text { modelo TAM com variáveis externas } \\
\text { (divertimento percebido, fruição percebida, }\end{array}$ \\
\hline
\end{tabular}




\begin{tabular}{|c|c|c|}
\hline Teoria/Modelo & Autor/Referência & Comentários \\
\hline $\begin{array}{l}\text { Ajzen e Fishbein } \\
\text { (1980) }\end{array}$ & & $\begin{array}{l}\text { inovatividade ou informações valiosas } \\
\text { percebidas). Nenhum destes estudos utilizou } \\
\text { como variável externa o construto Realidade } \\
\text { Aumentada Percebida. }\end{array}$ \\
\hline $\begin{array}{l}\text { Modelo de Aceitação } \\
\text { de Compra online } \\
\text { (Online Shopping } \\
\text { Acceptance Model - } \\
\text { OSAM) - baseado no } \\
\text { TAM e outras teorias } \\
\text { do varejo e marketing } \\
\text { (NOORDIN; } \\
\text { ASHAARI; WOOK, } \\
\text { 2017) }\end{array}$ & $\begin{array}{l}\text { Zhou, Dai e } \\
\text { Zhang (2007) }\end{array}$ & $\begin{array}{l}\text { O modelo OSAM, por ser um modelo } \\
\text { abrangente de compras online, não contém } \\
\text { características específicas da Realidade } \\
\text { Aumentada, como a interatividade ou a } \\
\text { Realidade Aumentada Percebida. }\end{array}$ \\
\hline $\begin{array}{l}\text { Modelo de Realidade } \\
\text { Aumentada e Captura } \\
\text { de Movimento } \\
\text { (ARMC) }\end{array}$ & Kang (2014) & $\begin{array}{l}\text { O modelo ARMC, apesar de ser específico } \\
\text { para Realidade Aumentada, não inclui no } \\
\text { modelo o construto Realidade Aumentada } \\
\text { Percebida. }\end{array}$ \\
\hline $\begin{array}{l}\text { Modelo de Provador } \\
\text { Virtual Online } \\
\text { (Online Virtual } \\
\text { Fitting Room Model) }\end{array}$ & $\begin{array}{l}\text { Huang e Qin } \\
(2011)\end{array}$ & $\begin{array}{l}\text { O modelo agrega o risco percebido em } \\
\text { compras online com uso de provadores } \\
\text { virtuais (VFR) ao modelo UTAUT (Unified } \\
\text { Theory of Acceptance and Use of } \\
\text { Technology) (VENKATESH; THONG; XU, } \\
\text { 2012). Não foram avaliados os aspectos } \\
\text { emocionais e não contém a Realidade } \\
\text { Aumentada Percebida. }\end{array}$ \\
\hline $\begin{array}{l}\text { Modelo para } \\
\text { Aumentar a Intenção } \\
\text { de Compra } \\
\text { (Augmenting } \\
\text { Purchase Intent } \\
\text { Model) }\end{array}$ & Schwartz (2011) & $\begin{array}{l}\text { O modelo examinou o impacto da Tecnologia } \\
\text { de Interatividade de Imagem (IIT) na atitude e } \\
\text { intenção de compra dos usuários. Não foram } \\
\text { avaliados os aspectos emocionais no modelo. }\end{array}$ \\
\hline $\begin{array}{l}\text { Modelo de } \\
\text { Experiência de } \\
\text { Produto Virtual } \\
\text { (Virtual Product } \\
\text { Experience VPE) } \\
\text { baseado no TAM e } \\
\text { na Teoria do Risco } \\
\text { Percebido. }\end{array}$ & Yu (2009) & $\begin{array}{l}\text { Este modelo foi criado para a experimentação } \\
\text { virtual de produtos no corpo humano. Não } \\
\text { foram avaliados os aspectos emocionais e não } \\
\text { contém a Realidade Aumentada Percebida. }\end{array}$ \\
\hline $\begin{array}{l}\text { Modelo de } \\
\text { Motivações } \\
\text { intrínsecas e } \\
\text { extrínsecas }\end{array}$ & $\begin{array}{l}\text { Mathwick, } \\
\text { Malhotra e } \\
\text { Rigdon (2001) } \\
\text { para classificar o } \\
\text { valor da } \\
\text { experiência do } \\
\text { cliente }\end{array}$ & $\begin{array}{l}\text { Dacko (2017) baseou-se nos estudos de } \\
\text { Holbrook (1999) sobre o valor percebido pelo } \\
\text { consumidor e na visão matricial de tipo de } \\
\text { valores experienciais definida por Mathwick, } \\
\text { Malhotra e Rigdon (2001) para classificar o } \\
\text { valor da experiência nos aplicativos de } \\
\text { compras de Realidade Aumentada Móvel } \\
\text { pelos seus clientes }\end{array}$ \\
\hline
\end{tabular}




\begin{tabular}{|c|c|c|}
\hline Teoria/Modelo & Autor/Referência & Comentários \\
\hline $\begin{array}{l}\text { Modelos de Varejo } \\
\text { Inteligente }\end{array}$ & $\begin{array}{l}\text { Modelos de } \\
\text { Varejo Inteligente } \\
\text { que avaliaram a } \\
\text { Realidade } \\
\text { Aumentada } \\
\text { (HUANG; LIAO, } \\
\text { 2015; HUANG; } \\
\text { HSU LIU, 2014; } \\
\text { RESE; } \\
\text { SCHREIBER; } \\
\text { BAIER, 2014, } \\
\text { ROY et al., 2017) }\end{array}$ & $\begin{array}{l}\text { O estudo presente foi baseado no modelo de } \\
\text { Roy et al. (2017). O modelo Roy avaliou as } \\
\text { consequências da experiência inteligente do } \\
\text { consumidor para a tecnologia, consumidor e } \\
\text { o varejista. } \\
\text { Este modelo não contém o construto } \\
\text { Realidade Aumentada Percebida, pois } \\
\text { engloba outras tecnologias além da Realidade } \\
\text { Aumentada. }\end{array}$ \\
\hline $\begin{array}{l}\text { Modelo de RA para } \\
\text { provador virtual }\end{array}$ & $\begin{array}{l}\text { Poushneh e } \\
\text { Vasquez-Parraga } \\
\text { (2017) }\end{array}$ & $\begin{array}{l}\text { Estudo avaliou os efeitos da Realidade } \\
\text { Aumentada, via construto Realidade } \\
\text { Aumentada Percebida, na experiência do } \\
\text { usuário de varejo e sua subsequente } \\
\text { influência na disposição do usuário em } \\
\text { comprar e sua satisfação. Este modelo serviu } \\
\text { de base para o estudo presente. }\end{array}$ \\
\hline $\begin{array}{l}\text { Modelo de } \\
\text { Experiência de RA } \\
\text { - Baseado na Teoria } \\
\text { do Efeito de Mídia } \\
\text { Interativa (TIME) de } \\
\text { Sundar et al. (2015) }\end{array}$ & Javornik (2016a) & $\begin{array}{l}\text { Baseado no modelo de TIME Sundar et al. } \\
\text { (2015), este modelo avaliou as respostas } \\
\text { cognitivas, afetivas e intenção } \\
\text { comportamental. } \\
\text { O modelo contém o construto Realidade } \\
\text { Aumentada Percebida. Este modelo serviu de } \\
\text { base para o estudo presente. }\end{array}$ \\
\hline
\end{tabular}

\section{4 \\ Formulação do Modelo Conceitual e Hipóteses de Pesquisa}

A partir da revisão de literatura, foram encontrados modelos e teorias utilizados em estudos sobre Realidade Aumentada, tais como, o modelo TAM com variações (por exemplo, DOMINA; LEE; MACGILLIVRAY, 2012; HUANG; LIAO, 2015; KIM; FORSYTHE, 2008a; KIM; HYUN, 2016; LEE; FIORE; KIM, 2006; RESE; SCHREIBER; BAIER, 2014; RESE et al., 2017; SPREER; KALLWEIT, 2014), a teoria do fluxo (DOMINA; LEE; MACGILLIVRAY, 2012), o modelo de interação homem-computador (PANTANO; SERVIDIO, 2012), a teoria de efeitos de mídia interativa (JAVORNIK, 2016a), motivações intrínsecas e extrínsecas (BECK; CRIÉ, 2016), os efeitos da novidade e crenças de autoeficácia (HOPP; GANGADHARBATLA, 2016), o modelo de aceitação de compras online (ZHOU; DAI; ZHANG, 2017), o modelo de provador virtual online (HUANG; QIN, 2011), o modelo de Realidade Aumentada e captura de movimento (KANG, 2014), o modelo de intenção de compras aumentada (SCHWARTZ, 2011) e outros 
modelos propostos (PONCIN; MIMOUN, 2011; POUSHNEH; VASQUEZPARRAGA, 2017; YIM; CHU; SAUER, 2017).

Na revisão de literatura para o tema varejo inteligente foram encontrados modelos e teorias sobre varejo inteligente, tais como, aplicações do modelo TAM (por exemplo, HUANG; LIAO, 2015; RESE; SCHREIBER; BAIER, 2014), a importância do valor experiencial (HUANG; HSU LIU, 2014), a teoria da difusão (BHATTACHARYA, 2015; KANG, 2014; ROY et al., 2017), a teoria dos efeitos da mídia interativa (SUNDAR et al., 2015) e o modelo de interação homemcomputador (PANTANO; SERVIDIO, 2012).

Conforme a revisão de Rese et al. (2017), há muitas pesquisas sobre Realidade Aumentada utilizando o modelo TAM com foco na avaliação da tecnologia e poucas pesquisas focadas em avaliar os benefícios da experiência para o marketing no varejo. Em sintonia com Rese et al. (2017), o presente estudo também verificou que o modelo TAM foi aplicado em várias pesquisas de Realidade Aumentada e que este apresentou resultados satisfatórios na avaliação da eficácia e benefícios da tecnologia. As experiências de difusão de uma nova tecnologia requerem estudos preliminares que examinem a aceitação da tecnologia. Em seguida, há necessidade de novas pesquisas voltadas ao uso da tecnologia com vista a extensão dos benefícios a outras áreas. Vale ressaltar que a avaliação da tecnologia pode ir além das decisões de adoção (ROGERS, 2003).

Segundo Pantano e Priporas (2016), a maior concentração de estudos anteriores está na aceitação dos novos sistemas em função da atitude e uso (BLÁZQUEZ, 2014; GAO et al., 2013; PANTANO; VIASSONE, 2014), sem levar em consideração a influência das inovações tecnológicas na experiência do consumidor sob uma perspectiva cognitiva.

Portanto, como este trabalho visa avaliar os aspectos afetivos e cognitivos de uma experiência do consumidor no varejo online utilizando a tecnologia de Realidade Aumentada via dispositivo móvel e não somente a adoção de uma nova tecnologia em relação ao uso e atitude, não adotaremos o modelo TAM.

Baseado nas observações feitas com o referencial teórico, o presente estudo propõe contribuir com um modelo original de Realidade Aumentada que avalie não somente os aspectos técnicos da ferramenta, mas também avalie os aspectos 
hedônicos percebidos pelo consumidor em uma experiência que objetiva influenciar sua intenção de compra no varejo online. Embora o potencial da Realidade Aumentada para melhorar as experiências do cliente no varejo online seja reconhecido, estes aspectos ainda não foram suficientemente explorados.

\subsection{1 Modelo Proposto}

A figura 2.9 ilustra o modelo proposto contendo os construtos e as hipóteses do estudo. A descrição dos construtos, hipóteses e suas justificativas é apresentada a seguir. O modelo foi batizado de ARORM (Augmented Reality in Online Retail Model) - Modelo de Experiência Aumentada no Varejo Online. Para representar a experiência do consumidor, foi utilizado o construto de segunda ordem chamado de Experiência de Realidade Aumentada, adaptado do construto SRT de Roy et al. (2017). A Experiência de Realidade Aumentada engloba um conjunto de dimensões que avaliam os aspectos percebidos pelo consumidor sobre a tecnologia de Realidade Aumentada que possam afetar a intenção de compra. Além disto, foram avaliados alguns fatores considerados importantes para a decisão da compra que podem mediar a relação entre a Experiência de Realidade Aumentada e a intenção de compras.

Vários estudos reconhecem que os clientes avaliam suas experiências por meio de aspectos utilitários e hedônicos e de benefícios observados (BAUER et al., 2006; BABIN et al., 2005). Os clientes percebem os aspectos utilitários da experiência no primeiro momento da experiência e em seguida, verificam o prazer da experiência. (HILKEN et al., 2017). Com bases nestes estudos, os fatores (certeza na escolha, satisfação do usuário e emoções positivas) relevantes para a decisão da compra foram testados como mediadores entre a Experiência de Realidade Aumentada e a intenção de compra. 


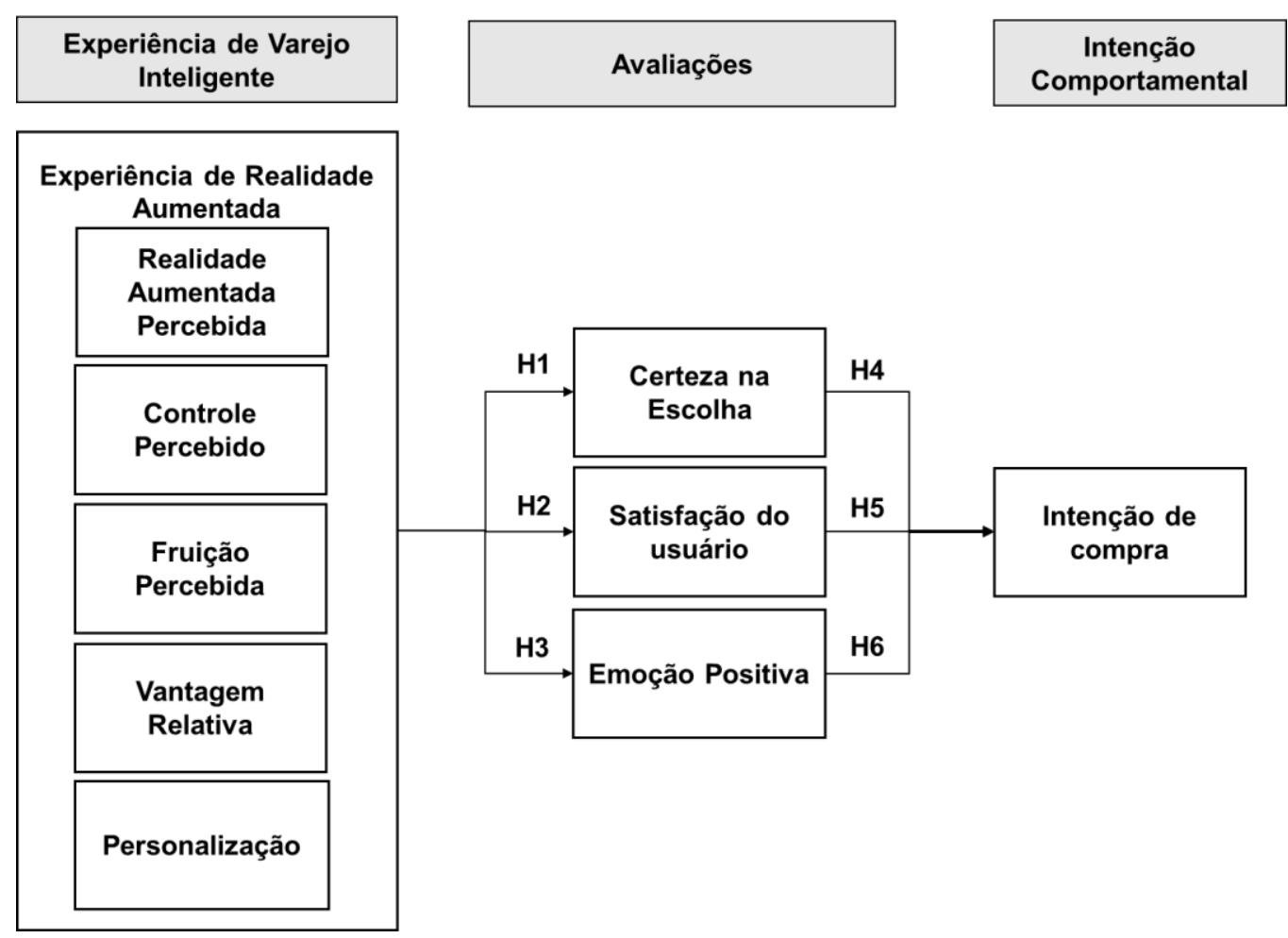

Figura 2.9 - Modelo Proposto de Experiência Aumentada no Varejo Online

Estudos recentes de Realidade Aumentada têm avaliado os efeitos desta tecnologia nas decisões do consumidor por meio da experiência do usuário no varejo. Vários destes estudos apontam para relações significativas entre a experiência e as avaliações dos usuários que levam a intenção da compra (JAVORNIK, 2016a; POUSHNEH; VASQUEZ-PARRAGA, 2017; ROY et al., 2017). A relação entre a experiência de Realidade Aumentada e a intenção comportamental foi utilizada nos estudos de Poushneh e Vasquez-Parraga (2017), Roy et al. (2017) e no estudo de Javornik (2016a), onde os autores avaliaram a relação entre fluxo e a intenção comportamental. Todos mostraram que as relações entre experiência ou fluxo e a intenção de compra são consistentes. Grande parte dos estudos mostra que os consumidores ampliam seu comportamento exploratório (SWAMINATHAN, 2003), certeza na escolha (LEMOINE; NOTEBAERT, 2011), imersão (WANG et al., 2007), emoções positivas (MURRAY; HÄUBL, 2008), intenção de compra (SENECAL; NANTEL, 2004) e satisfação com o varejo online (VIOT; BRESSOLLES, 2012) na presença de um provador virtual que usa a tecnologia de Realidade Aumentada (BECK; CRIÉ, 2016). 
Roy et al. (2017) sugeriram novos estudos do modelo de SRT aplicados às tecnologias específicas com o objetivo de avaliar se os resultados comportamentais apresentam diferença em relação ao modelo de SRT geral. Seguindo esta sugestão dada de avaliar uma tecnologia específica, o presente estudo avaliou se a certeza na escolha, a emoção positiva e satisfação do usuário são mediadores da relação entre a experiência de Realidade Aumentada e a intenção de compra.

\subsection{2 \\ Variável Dependente: Intenção de Compra}

Uma das características peculiares do modelo proposto refere-se à variável dependente que foi avaliada. Este modelo testou os efeitos das avaliações e experiências do consumidor especificamente na intenção de compra online via dispositivo móvel. O uso exclusivo desta variável dependente foi encontrado em poucos estudos de Realidade Aumentada (BECK; CRIÉ, 2016; YIM; CHU; SAUER, 2017). Beck e Crié (2016) examinaram a influência da curiosidade e intenção da clientela (patronage) na variável intenção de compra, Yim, Chu e Sauer (2017) investigaram como as características da mídia funcionam para influenciar a intenção de compra e Poushneh e Vasquez-Parraga (2017) exploraram a influência da qualidade da Experiência de Realidade Aumentada especificamente na disposição para compra.

A maioria dos modelos estudados de Experiência de Realidade Aumentada no varejo avalia a intenção de compra dentro da intenção comportamental que agrega outras variáveis, tais como, intenção de divulgação (WOW-World-ofmouth) e intenção de retorno ao aplicativo ou loja (por exemplo, HILKEN et al., 2017, DOMINA; LEE; MACGILLIVRAY, 2012; JAVORNIK, 2016a; HUANG; LIAO, 2015; HYUN, 2016; KIM; FORSYTHE, 2008a; KIM; FIORE; LEE, 2007; PANTANO et al., 2017; RESE; SCHREIBER; BAIER, 2014; SPREER; KALLWEIT, 2014 ) ou mesmo outra variável de comportamento, como, por exemplo, a manutenção de relacionamento sustentável (HUANG; LIAO, 2015; DACKO, 2017) ou a atitude em relação à marca (BRITO; STOYANOVA; COELHO, 2018). 
Assim como foi feito neste estudo que avaliou a intenção de compra online via dispositivo móvel, o construto Intenção de Compra foi adotado em outros estudos para avaliar a intenção de compra online via dispositivo móvel (MERLE; SENECAL; ST-ONGE, 2012; YIM; CHU; SAUER, 2017).

\subsection{3}

\section{Experiência de Varejo Inteligente}

A experiência de Realidade Aumentada no varejo é uma experiência de varejo inteligente (SRT - smart retail technology) na qual o consumidor usa a tecnologia de Realidade Aumentada. A experiência de Realidade Aumentada é composta de vários elementos tais como vantagem relativa, controle percebido, Realidade Aumentada percebida, fruição percebida e personalização.

\subsubsection{1 \\ Experiência de Realidade Aumentada}

O modelo de Roy et al. (2017) examina a experiência inteligente do consumidor e seus resultados para a tecnologia inteligente, o consumidor e o varejista, não destacando em particular a intenção de compra pelo consumidor. Eles apresentaram um construto original chamado Experiência Inteligente no Varejo, baseado nas pesquisas anteriores que discutiram vários elementos que retratam o cerne da experiência inteligente do cliente. Esses elementos incluem vantagem relativa, controle percebido, interatividade percebida, fruição percebida e personalização. Sendo assim, eles conceituaram esse construto original como reflexivo de segunda ordem, constituído de cinco dimensões: Vantagem Relativa, Fruição Percebida, Personalização, Controle Percebido e Interatividade, como uma forma de representar a experiência do cliente. Esta experiência compreende a interação direta com a tecnologia inteligente dos clientes e os elementos cognitivos, afetivos e comportamentais (PALMER, 2010; VAN NOORT; VOORVELD; VAN REIJMERSDAL, 2012). O novo construto enriquece a literatura, melhorando a compreensão das experiências dos clientes com a tecnologia inteligente. 
O presente estudo também examinou os fatores que constituem a experiência inteligente do cliente, porém como tratou de uma tecnologia específica, a dimensão Interatividade do construto Experiência Inteligente do Varejo foi substituída pela dimensão Realidade Aumentada Percebida. Esta dimensão também já foi utilizada como um construto não inserido dentro da Experiência do Usuário (UX) nos estudos de Javornik (2016a) e Poushneh e Vasquez-Parraga (2017) em pesquisas que tratavam da avaliação de experiência dos consumidores com Realidade Aumentada. Já Schwartz (2011) utilizou um construto semelhante, que avalia a Tecnologia Interativa de Imagem (IIT - Image Interactivity Technology), no seu modelo de intenção de compra aumentada. Esta tecnologia, que permite uma forma de experimentação virtual pela criação de modelos 3D aumentando o contexto de compras online, tem características similares com a tecnologia de Realidade Aumentada. Em ambos os estudos, os construtos de Realidade Aumentada e Tecnologia Interativa de Imagem, que permitem avaliar os recursos oferecidos pela tecnologia, apresentaram resultados satisfatórios. Sendo assim, a sugestão de substituir a Interatividade pela Realidade Aumentada Percebida pareceu ser uma escolha adequada. Vale observar que esta mudança no construto experiência inteligente do consumidor ainda não foi encontrada na literatura.

Sendo assim, o construto de experiência enriquecida de Realidade Aumentada que foi testado no modelo proposto é um construto de segunda ordem que engloba os construtos Vantagem Relativa, Controle Percebido, Fruição Percebida, Personalização e Realidade Aumentada Percebida. O conceito de UX (experiência do usuário) usada por Poushneh e Vasquez-Parraga (2017) para testar o modelo de Realidade Aumentada é holístico e subjetivo (MCCARTHY; WRIGHT, 2004) e varia ao longo do tempo (LAW et al., 2009). Estas características também são observadas no construto Experiência de Realidade Aumentada que foi testado. A experiência do usuário pode ser definida como os aspectos percebidos pelo usuário sobre um produto interativo, tais como, a maneira pessoal de sentir o produto, o entendimento de seu funcionamento, os propósitos e o contexto de uso (ALBEN, 1996). 


\subsubsection{2 Vantagem Relativa}

A vantagem relativa (relative advantage) é um dos atributos percebidos pelas pessoas em relação à adoção de uma inovação (ROGERS, 2003). Este atributo refere-se ao grau em que uma inovação é percebida como sendo melhor do que as ideias anteriores. Aplicado ao contexto de novas tecnologias de varejo inteligente, a vantagem relativa refere-se ao grau em que a nova tecnologia é percebida como melhor do que outras tecnologias existentes (LU et al., 2015; WEI; LOWRY; SEEDORF, 2015), avaliando não só em termos tecnológicos como também de conveniência, qualidade e função (ROY et al., 2017). O atributo é claramente caracterizado por comparações. A vantagem relativa também avalia a relação existente entre os benefícios esperados e os custos de adoção (ROGER, 2003).

\subsubsection{3}

\section{Controle Percebido}

O controle percebido (perceived control) refere-se à "percepção das pessoas de facilidade ou dificuldade em realizar o comportamento de interesse" (AJZEN, 1991, p. 183). As pessoas tendem a ficar mais entusiasmadas, interessadas e atentas à tarefa em execução, quando elas têm um maior controle percebido (KAMIS; STERN; LADIK, 2010). Esta constatação é reforçada no estudo de Roy et al. (2017), no qual eles assinalam que ter um alto grau de controle sobre uma tecnologia de varejo inteligente leva os consumidores a demonstrarem maior interesse e atenção na atividade envolvida. O controle percebido também é usado para medir o construto fluxo (flow) em vários estudos sobre compras no ambiente virtual (HOOKER; WASKO; PARADICE, 2009; HUA; HAUGHTON, 2008; DOMINA; LEE; MACGILLIVRAY, 2012). 


\subsubsection{4 Fruição percebida}

A fruição percebida (perceived enjoyment - PE) é um aspecto afetivo que está relacionado com o prazer ou divertimento percebidos pelos consumidores no uso da tecnologia inteligente do varejo (CHOI et al., 2014). Na definição contida no dicionário da língua portuguesa de Michaelis (2008), fruir significa desfrutar ou usufruir. A palavra fruição é o termo em português com a definição mais aderente ao conceito de perceived enjoyment. A fruição percebida refere-se ao quanto a atividade de usar uma tecnologia é percebida como agradável por causa própria, independentemente de quaisquer consequências de desempenho resultantes do seu uso (VENKATESH, 2000). Este construto agrega o lado emocional às outras partes funcionais existentes na Experiência de Realidade Aumentada. Em contraste com a utilidade percebida e a facilidade de uso percebida no modelo de aceitação de tecnologia (TAM), que dependem dos benefícios extrínsecos gerados pelo uso da tecnologia, a fruição percebida representa os benefícios intrínsecos que os clientes adquirem da experiência de usar a tecnologia, além do seu valor instrumental (DAVIS; BAGOZZI; WARSHAW, 1992; KIM; FIORE; LEE, 2007).

\subsubsection{5 Personalização}

A personalização (personalization) refere-se à capacidade de oferecer serviços personalizados ou customizados ao consumidor (NEUHOFER; BUHALIS; LADKIN, 2015) em experiências utilizando recursos tecnológicos. Os consumidores esperam cada vez mais experiências personalizadas propiciadas pelos recursos disponíveis na tecnologia da informação (GRETZEL et al., 2015a). Estes serviços personalizados são normalmente baseados em avaliações constantes das preferências dos consumidores (GUPTA; VAJIC, 2000). A tecnologia de Realidade Aumentada possibilita a implementação de serviços personalizados nas experiências de varejo inteligente (HOFFMAN; NOVAK, 2015; WÜNDERLICH; WANGENHEIM; BITNER, 2013). 


\subsubsection{6 Realidade Aumentada Percebida}

A Realidade Aumentada Percebida (perceived augmented) é uma percepção cognitiva que se refere à avaliação subjetiva e geral dos recursos exclusivos da tecnologia de Realidade Aumentada (SCARDAMALIA; BEREITER, 2014). Este construto foi incluído no construto experiência inteligente do consumidor, que, juntamente com os demais construtos apresentados anteriormente, integrou a Experiência de Realidade Aumentada. Esta configuração do construto experiência inteligente do cliente contendo o construto Realidade Aumentada Percebida não foi encontrada em outros estudos. É esperado que a inclusão deste construto permita uma melhor compreensão das novas percepções relacionadas às respostas dos consumidores em relação aos recursos virtuais acrescentados por meio desta tecnologia. A inclusão de objetos ou informações virtuais é proposto como uma característica única da Realidade Aumentada (PREECE; ROGERS; SHARP, 2015), enquanto a sua percepção de inclusão está relacionada com aspectos psicológicos, seguindo os caminhos do modelo TIME. Enquanto as características são apresentadas como variáveis independentes, o modelo TIME destaca o papel ativo do consumidor e investiga diferentes tipos de respostas, não sugerindo uma abordagem determinista.

Foi questionado por pesquisadores se este construto de Realidade Aumentada deve ser considerado como um tipo especial de interatividade ou pertencer a uma categoria nova (JAVORNIK, 2016a; SUNDAR et al., 2015). A interatividade está associada aos recursos e funções oferecidos numa tecnologia para os usuários, permitindo que eles tomem ações e iniciem interações com o meio. Partindo do princípio de que o aumento (objetos acrescentados) da Realidade Aumentada reage e interage com o ambiente físico que o circunda em tempo real e que a interatividade se refere à interação entre o meio e o usuário ou à interação entre os diferentes usuários conectados por um dispositivo (SUNDAR et al., 2015), o conceito de interatividade não contempla o espaço circundante.

Desta forma, ainda de acordo com Javornik (2016a), o construto Realidade Aumentada Percebida não pode ser considerado como um tipo de interatividade. Isto porque a interatividade não envolve o ambiente externo na interação. Neste 
estudo, pretende-se testar empiricamente se os consumidores percebem ou não nos aplicativos de Realidade Aumentada do varejo o aumento da realidade pelos objetos virtuais acrescentados ao ambiente.

\subsection{4}

Mediadores entre Experiência de Realidade Aumentada e Intenção de Compra

As compras online de Realidade Aumentada simulam, pela experiência virtual, o uso do produto e levam os consumidores a identificar benefícios e o valor do produto com precisão e eficiência (HUANG; HSU LIU, 2014). Holbrook (1994) destacou que a experiência está intimamente relacionada ao valor do produto, sendo este valor percebido pelo consumidor após o uso do produto ou serviço (MATHWICK; MALHOTRA; RIGDON, 2001). A relação entre a avaliação dos benefícios percebidos (HIRSCHMAN; HOLBROOK, 1982; HAVLENA; HOLBROOK, 1986; HOFFMAN; NOVAK, 1996) e a intenção de compra (SIMONSON; CARMON; O’CURRY, 1994; D’ASTOUS; JACOB, 2002; DIELS; WIEBACH; HILDEBRANDT, 2013) foi encontrada em diversos estudos de marketing (CARPENTER; MOORE, 2009; MAGNI; TAYLOR; VENKATESH, 2010; KIM; FIORE; LEE, 2007; BERNARDO; MARIMON; DEL MAR ALONSO-ALMEIDA, 2012).

A avaliação sobre a Experiência de Realidade Aumentada pelos consumidores neste estudo foi mediadora entre o resultado da experiência inteligente do consumidor e a intenção de compras. Ressalta-se nesta avaliação da experiência os aspectos de certeza na escolha, a satisfação do usuário e a emoção positiva.

\subsubsection{1}

Certeza na escolha

A certeza na escolha (choice confidance) determina o quanto um indivíduo se sente firme para escolher um produto. A inclusão de informações virtuais na Realidade Aumentada no contexto imediato dos consumidores foi apontada em 
diversas pesquisas como um fator que pode reduzir a incerteza sobre uma compra potencial (BECK; CRIÉ, 2016; JAVORNIK, 2016a; OH; YOON; SHYU, 2008; POUSHNEH, 2018; POUSHNEH; VASQUEZ-PARRAGA, 2017; YIM; CHU; SAUER, 2017).

Desta forma, vale avaliar se a redução da incerteza pela Experiência de Realidade Aumentada poderia aumentar a certeza na escolha do produto pelo consumidor. Alguns estudos de m-service englobam a construção ou cultura de confiança em seus modelos de aceitação. Algumas perspectivas incluem a confiança como uma medida intrínseca (LEE; CHUNG., 2008; LI; YEH, 2010; LIN, 2011; PONCIN; MIMOUN, 2014). A certeza da escolha pode ser reforçada por informações adicionais que auxiliam os indivíduos a diferenciarem as alternativas disponíveis (ANDREWS, 2013; YOON; SIMONSON, 2008). Assim sendo, foi testada a hipótese a seguir para verificar se a experiência inteligente influencia a certeza na escolha percebida pelo consumidor.

H1: A Experiência de Realidade Aumentada tem efeito direto e positivo sobre a certeza na escolha percebida pelo consumidor durante a compra no varejo online via dispositivo móvel.

Segundo Yim, Chu e Sauer (2017), num primeiro estágio pré-compra, o papel principal da Realidade Aumentada é atrair a atenção ou estimular a curiosidade para despertar o interesse dos consumidores na experimentação. Cabe aos pesquisadores investigarem a relação entre a confiança obtida pela experimentação virtual antes da compra do produto e a intenção de visitar as lojas físicas ou virtuais de varejo para efetuar a compra. Assim sendo, foi testada a hipótese a seguir para verificar se a certeza na escolha percebida pelo consumidor tem influência na intenção de compra no varejo online via dispositivo móvel.

H4: A certeza na escolha percebida tem efeito direto e positivo sobre a intenção de compra no varejo online via dispositivo móvel. 


\subsubsection{2 \\ Satisfação do Usuário}

A satisfação é definida como uma avaliação, um julgamento, do usuário. Uma avaliação é condicionada pela existência de um parâmetro de comparação (CHAUVEL, 1999). A satisfação do usuário em relação à Experiência de Realidade Aumentada está condicionada aos resultados da avaliação e impressão do consumidor no desempenho desta tecnologia em relação ao uso anterior no varejo online sem este recurso. A satisfação também pode ser definida como uma espécie de sentimento de prazer durante ou após o uso da tecnologia pelos consumidores (NOORDIN; ASHAARI; WOOK, 2017). Desta forma, a hipótese formulada avaliou se a experiência inteligente do consumidor influencia a satisfação do consumidor.

\section{H2: A Experiência de Realidade Aumentada tem efeito direto e positivo} sobre a satisfação do usuário.

Diversos estudos mostraram que a satisfação do cliente parece ser essencial para alavancar mais visitas dos clientes as lojas, recompras e recomendações a outras pessoas (GUPTA; KIM, 2010; TO; LIAO; LIN, 2007; ROSE et al., 2012). Rose et al. (2012) concluíram, em seus estudos no contexto do varejo, que a satisfação do cliente é determinada por estados experiencias cognitivos e afetivos, resultando em aumento nas intenções de recompra. Ressaltando esta relação, estudos sobre Realidade Aumentada mostraram que, quanto maior a satisfação do cliente, maior é sua a intenção de compra (NOORDIN; ASHAARI; WOOK, 2017; ROY et al., 2017; PONCIN; MIMOUN, 2014). As descobertas de Roy et al. (2017) mostram que uma experiência inteligente satisfatória aumenta as intenções de compra do consumidor e sua intenção de divulgar via boca-a-boca. Assim sendo, foi testada a hipótese a seguir para verificar se a satisfação percebida pelo consumidor tem influência na intenção de compra no varejo online via dispositivo móvel.

H5: A satisfação tem efeito direto e positivo sobre a intenção de compra pelo consumidor no varejo online via dispositivo móvel. 


\subsubsection{3 Emoções Positivas}

As experiências de compra online via Realidade Aumentada superam as experiências de serviços online atuais, uma vez que possibilitam a experimentação virtual do produto, inclusive com visão de 360 graus. A experimentação virtual via Realidade Aumentada fornece a percepção de valor utilitário e hedônico, oferecendo aos clientes uma sensação de conforto em uma etapa fundamental da tomada de decisão (HILKEN et al., 2017). A conexão emocional com os clientes (KUMAR; PANSARI, 2016) e o conforto propiciado (SPAKE et al., 2003) são as principais preocupações gerenciais. Empresas se empenham em projetar ambientes de compra que produzam efeitos emocionais específicos no comprador e que levem ao aumento da intenção de compra (PONCIN; MIMOUN, 2014).

A Realidade Aumentada via dispositivo móvel (MAR) possui um grande potencial de facilitar a experiência e gerar emoções positivas nos usuários (OLSSON et al., 2013). Segundo Noordin, Ashaari, Wook (2017), a implementação de experiências com provadores virtuais deve visar o envolvimento emocional dos consumidores. A experiência de compra de acordo com o tipo de produto pode afetar de forma diferente a emoção do consumidor on-line (HUANG, 2003). Zhou, Dai e Zhang (2007) também ressaltam que a emoção nas compras on-line pode ser influenciada pelas experiências do consumidor, variando de acordo com a categoria de produto (ZHOU; DAI; ZHANG, 2007). As informações anteriores dão suporte para propor a hipótese relativa a se a experiência inteligente do consumidor afeta as emoções positivas percebidas pelo consumidor.

H3: A Experiência de Realidade Aumentada tem efeito direto e positivo sobre a emoção positiva percebida pelo consumidor para a compra no varejo online via dispositivo móvel.

Poncim e Mimoun (2014) observaram o papel mediador de valores de compras e emoções positivas entre a atmosfera no cenário do varejo e a satisfação do usuário em um evento experiencial de Realidade Aumentada. Este resultado é interessante para entender o papel da atmosfera nas lojas e nas compras. Schmitt (2000) também ressalta a importância dos valores emocionais, quando destaca que 
os valores sensoriais, emocionais, cognitivos, comportamentais e relacionais fornecidos nas experiências substituem os valores utilitários. Nos estudos sobre compra online de produtos, foi identificado que sentimentos são fatores importantes envolvidos no processo decisório dos clientes (CILLEY, 2016; LIM et al., 2016; NOORDIN; ASHAARI; WOOK, 2017; OVERMARS; POELS, 2015; TANNER; RAYMOND, 2012; WALLACE, 2015). As pesquisas anteriores sobre Realidade Aumentada reconhecem que as emoções influenciam positivamente as compras futuras (BRITO; STOYANOVA; COELHO, 2018; PONCIN; MIMOUN, 2014). Com base nas informações, foi testada a hipótese a seguir para verificar se as emoções positivas percebidas pelo consumidor têm influência na intenção de compra no varejo online via dispositivo móvel.

H6: A emoção positiva tem efeito direto e positivo sobre a intenção de compra no varejo online via dispositivo móvel.

\subsection{5 Modelos Alternativos Propostos}

Além do modelo principal, foram testados dois modelos alternativos retratados nas figuras 2.10 e 2.11. Estes dois modelos foram baseados no modelo principal (figura 2.9) e apresentam pequenas modificações. Estas modificações servem para testar a permanência de construtos e suas relações presentes no modelo principal. O modelo alternativo 1 avaliou se a mediação é total, como apresentado no modelo principal, ou parcial. Para isto, foi incluído no modelo o efeito direto entre a Experiência de Realidade Aumentada e a Intenção de Compra. O modelo alternativo 2 testou apenas dois construtos mediadores: um deles avaliou um valor utilitário e outro um valor hedônico. 


\subsubsection{1}

\section{Modelo Alternativo 1}

A mediação envolve comparar o efeito direto entre dois construtos com o efeito indireto obtido com inclusão de um terceiro construto no meio dos dois construtos. Uma mediação pode ser classificada como total ou parcial. A mediação total é encontrada quando o efeito direto se torna não significativo na presença do efeito indireto, enquanto a mediação parcial ocorre quando o efeito direto é reduzido, mas ainda significativo (HAIR et al., 2010). O modelo Alternativo 1 foi elaborado com os mesmos construtos e relações do modelo principal, porém foi acrescentada a relação direta entre Experiência de Realidade Aumentada e a Intenção de Compra. Este modelo permite avaliar se a mediação entre a Experiência de Realidade Aumentada e a Intenção de Compra é total ou parcial. Desta forma, o modelo alternativo testou a hipótese de que a Experiência de Realidade Aumentada afeta diretamente a Intenção de Compra. A partir deste teste, espera-se avaliar se a mediação é total ou parcial entre a Experiência de Realidade Aumentada e a Intenção de compra. A figura 2.10 contém o modelo alternativo 1 que foi testado no estudo.

Neste caso, foi acrescentado ao modelo a hipótese H7.

H7: A Experiência de Realidade Aumentada tem efeito direto e positivo sobre a intenção de compra no varejo online via dispositivo móvel. 


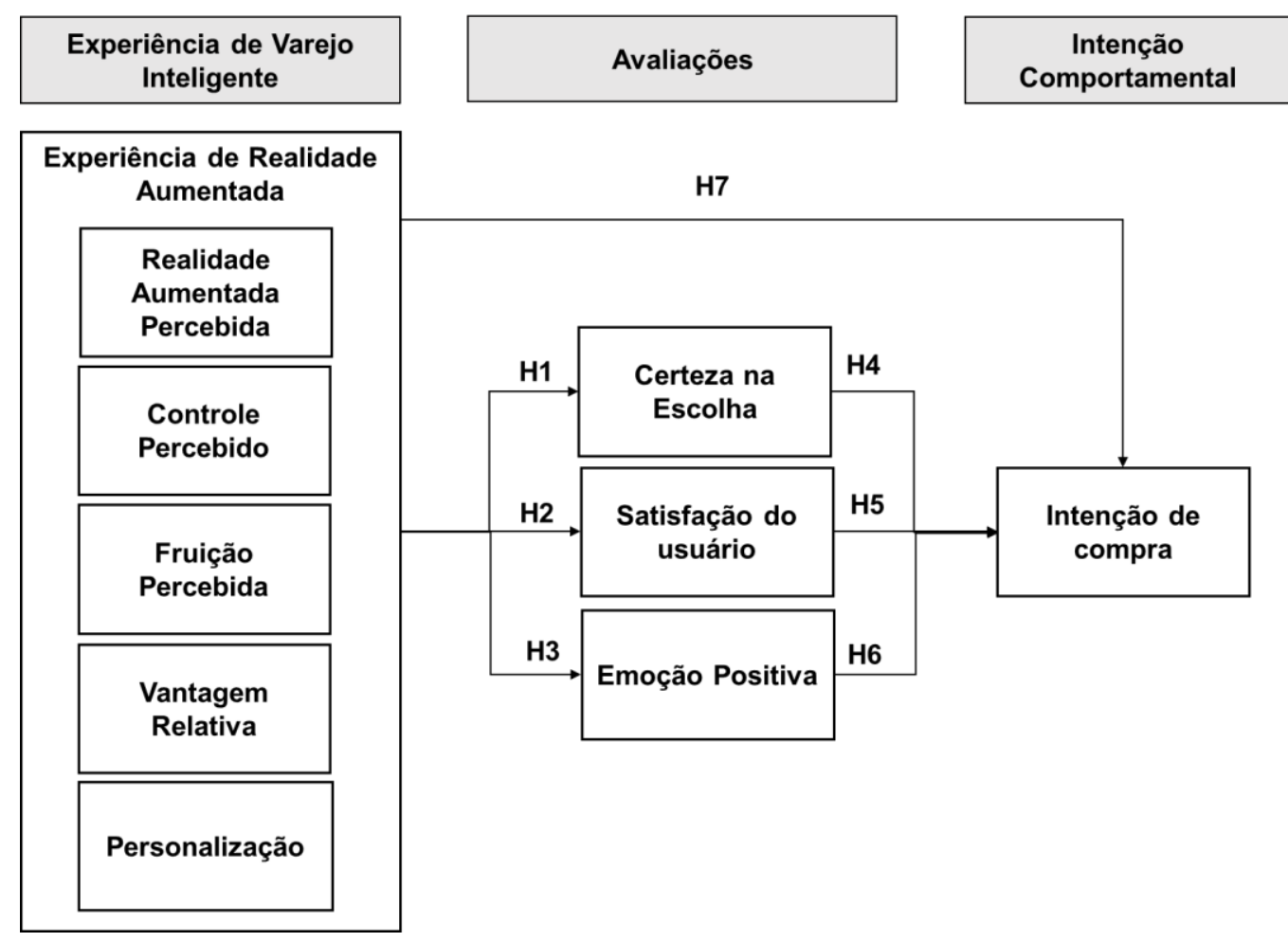

Figura 2.10-Modelo Alternativo 1

\subsubsection{2 \\ Modelo Alternativo 2}

O modelo alternativo 2 examinou apenas dois construtos mediadores entre a Experiência de Realidade Aumentada e a Intenção de Compra. Os construtos mediadores foram Certeza na Escolha que avalia um valor utilitário e a Emoção Positiva que avalia valores hedônicos. Estes dois construtos foram encontrados em diversos estudos sobre experiências com provadores virtuais e Intenção de Compra, apresentando resultados significativos entre estas relações (LEMOINE; NOTEBAERT, 2011; MURRAY; HÄUBL, 2008; SENECAL; NANTEL, 2004).

No estudo de Roy et al. (2017), o construto Satisfação do Usuário apresentou resultado satisfatório como um dos mediadores entre a Experiência de Varejo Inteligente e a Intenção de Compra. Não obstante, outros estudos que trataram da Experiência de Realidade Aumentada no varejo online, tais como os de Hilken et al. (2017), Beck e Crié (2016), Yim, Chu e Sauer (2017) e Javornick et al.(2016a), Javornick et al.(2016b) elaboraram modelos com a variável dependente Intenção de Compra, mas não utilizaram o construto Satisfação do Usuário em seus 
modelos. Como estes modelos de Experiência de Realidade Aumentada foram satisfatórios sem o construto Satisfação do Usuário, optou-se por testar um modelo alternativo sem este construto. Vale relembrar que a Satisfação do Usuário já foi inserido no modelo principal.

A figura 2.11 apresenta o modelo alternativo 2 .

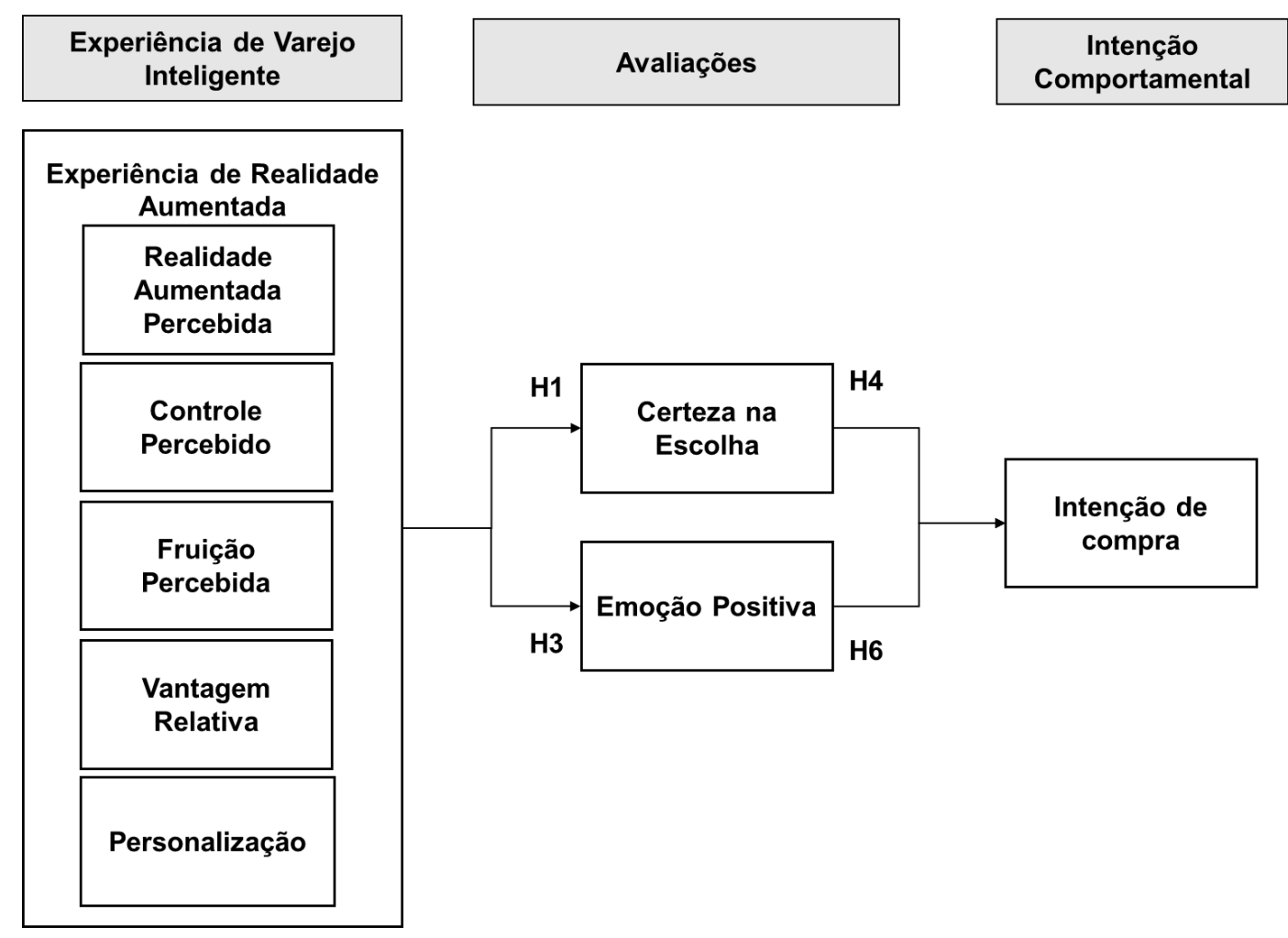

Figura 2.11 - Modelo Alternativo 


\section{3 \\ Metodologia}

A metodologia apresentada neste capítulo abrange o tipo de pesquisa, as descrições das variáveis operacionais medidas, determinação da amostra e população, método e os instrumentos de coleta de dados e os procedimentos utilizados para tratar e analisar os dados. Para finalizar o capítulo, são apresentadas as limitações da metodologia.

Conforme já definido, o objetivo deste estudo é investigar como o uso da Realidade Aumentada durante a experiência de compra do consumidor afeta a intenção de compra no varejo online via dispositivo móvel. Para isto, foi avaliado como os efeitos da experiência de Realidade Aumentada - mediada por fatores de avaliação do consumidor estabelecidos após a experiência, tais como, satisfação, certeza na escolha, a e emoção positiva - afetam a intenção de compra no varejo online via dispositivo móvel.

A figura 3.1 contém o diagrama metodológico com as etapas, estratégias e detalhamento das atividades.

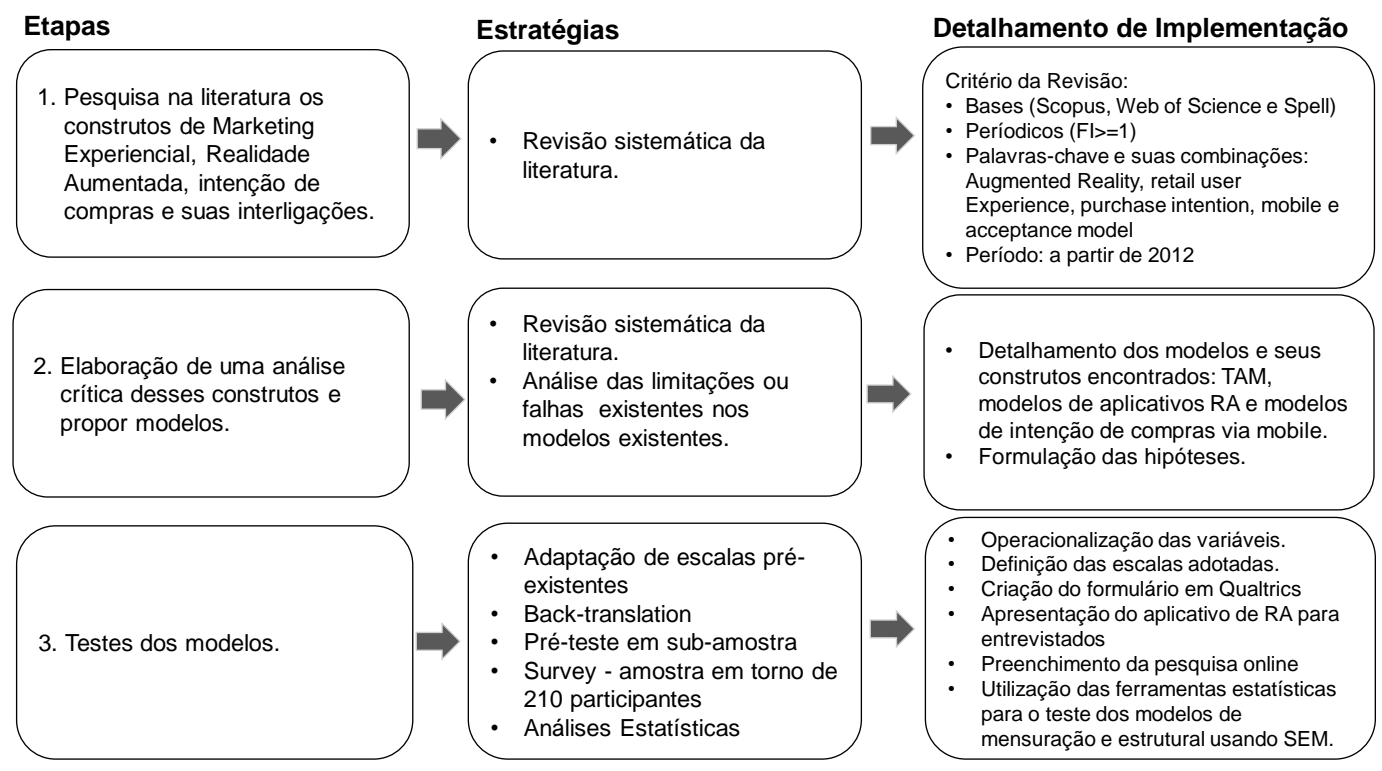

Figura 3.1 - Diagrama Metodológico 


\section{1 Tipo de Pesquisa}

A pesquisa utilizou o método survey. Foi feito um questionário estruturado aplicado a uma amostra não probabilística de consumidores, permitindo testar as hipóteses do estudo. Em relação à abordagem temporal, realizou-se um corte transversal (cross-sectional). Para garantir a padronização da experiência com a Realidade Aumentada, a pesquisa foi conduzida utilizando um mesmo dispositivo móvel (um tablet), que permitia a visualização mais elaborada dos elementos em questão e a vivência da Realidade Aumentada por todos os participantes.

Visando a homogeneidade da pesquisa, foi elaborado um roteiro de navegação (vídeo) para o uso do aplicativo escolhido para realizar a experiência planejada de Realidade Aumentada com os participantes. As imagens do vídeo e o passo-a-passo estão no apêndice B. O estudo utilizou o aplicativo da Ray-Ban que usa a tecnologia de Realidade Aumentada para venda de óculos. Este aplicativo da Ray-Ban foi instalado nos dispositivos móveis usados na pesquisa. Com o objetivo de homogeneizar a Experiência de Realidade Aumentada dos participantes, todos utilizaram, individualmente, o mesmo dispositivo móvel para fazer a experimentação virtual.

Após a experimentação virtual de óculos, o participante preencheu o questionário online autoadministrado (AAKER; KUMAR; DAY, 2006). Este questionário foi implementado na plataforma online Qualtrics. As escalas utilizadas no questionário foram obtidas de estudos publicados em língua inglesa e adaptadas e traduzidas para a língua portuguesa.

\section{2}

\section{Operacionalização das Variáveis}

As variáveis operacionais constituem as escalas utilizadas no instrumento de pesquisa. A definição da operacionalização das variáveis, os procedimentos de adaptação das escalas utilizadas e as informações sobre o pré-testes do questionário são apresentados a segu 


\subsection{1}

\section{Definição Operacional das Variáveis}

A tabela 3.1 contém as variáveis presentes no modelo conceitual proposto e suas definições. Todas as escalas utilizadas para a medição destes construtos já foram testadas anteriormente e foram retiradas da literatura. Uma vantagem de se utilizar as escalas de outros estudos, já padronizadas, consiste em facilitar a comparação com os resultados obtidos dos modelos existentes. O apêndice A contém o questionário apresentado ao entrevistado.

Tabela 3.1 - Definição dos Construtos

\begin{tabular}{|c|c|}
\hline Construto & Definição \\
\hline Fruição percebida (Perceived Enjoyment - PE) & $\begin{array}{l}\text { Relacionado com o prazer ou fruição percebida } \\
\text { pelos consumidores no uso da tecnologia } \\
\text { inteligente do varejo. }\end{array}$ \\
\hline Vantagem Relativa (Relative Advantage - RA) & $\begin{array}{l}\text { Refere-se ao grau em que a tecnologia de } \\
\text { varejo inteligente é percebida como melhor do } \\
\text { que outras tecnologias em termos de } \\
\text { tecnologia, conveniência, qualidade e função. }\end{array}$ \\
\hline Controle Percebido (Perceived Control-PC) & $\begin{array}{l}\text { Refere-se ao grau de controle percebido, } \\
\text { facilidade ou dificuldade, em realizar uma } \\
\text { escolha pelo uso da tecnologia. }\end{array}$ \\
\hline $\begin{array}{l}\text { Realidade Aumentada Percebida (Perceived } \\
\text { Augmented-PA) }\end{array}$ & $\begin{array}{l}\text { Refere-se à avaliação subjetiva e geral dos } \\
\text { recursos exclusivos da tecnologia de Realidade } \\
\text { Aumentada. }\end{array}$ \\
\hline Personalização (Personalization - P) & $\begin{array}{l}\text { Refere-se à capacidade de oferecer serviços } \\
\text { personalizados ou customizados ao } \\
\text { consumidor na experiência com a tecnologia de } \\
\text { Realidade Aumentada. }\end{array}$ \\
\hline Certeza na escolha (choice confidance - CC) & $\begin{array}{l}\text { Determina o quanto um indivíduo se sente } \\
\text { firme para escolher um produto com auxílio da } \\
\text { tecnologia Realidade Aumentada. }\end{array}$ \\
\hline Satisfação do usuário (User Satisfaction - US) & $\begin{array}{l}\text { É condicionada aos resultados da avaliação e } \\
\text { impressão do consumidor no desempenho da } \\
\text { tecnologia inteligente de Realidade } \\
\text { Aumentada. }\end{array}$ \\
\hline Emoção Positiva (Positive Emotion - POE) & $\begin{array}{l}\text { Percepções e comportamentos individuais } \\
\text { ocasionado pela experiência de Realidade } \\
\text { Aumentada que resultam em estados } \\
\text { emocionais. }\end{array}$ \\
\hline Intenção de Compra (Purchase Intention - PI) & $\begin{array}{l}\text { Refere-se à intenção de compra do produto no } \\
\text { varejo online via dispositivo móvel. }\end{array}$ \\
\hline
\end{tabular}

Fonte: elaboração própria 
Um construto de segunda ordem é um construto de ordem superior refletido por fatores (construtos) de primeira ordem. Neste modelo o construto Experiência de Realidade Aumentada é um construto de segunda ordem que é composto pelos fatores (dimensões) de primeira ordem. São eles: Realidade Aumentada Percebida, Controle Percebido, Fruição Percebida, Vantagem Relativa e Personalização. A tabela 3.2 apresenta os itens operacionais e as escalas de cada construto do modelo proposto.

Tabela 3.2 - Operacionalização das Variáveis

(continua)

\begin{tabular}{|c|c|c|c|}
\hline $\begin{array}{l}\text { Construtos } \\
\text { Indicador - }\end{array}$ & $\begin{array}{l}\text { Dimensões } \\
\text { /Indicador }\end{array}$ & Itens Operacionais & $\begin{array}{l}\text { Tipo de Escala } \\
\text { (adaptada de) }\end{array}$ \\
\hline $\begin{array}{l}\text { Experiência } \\
\text { de } \\
\text { Realidade } \\
\text { Aumentada } \\
\text { - EXP_RA } \\
\text { (construto } \\
\text { de segunda } \\
\text { ordem) }\end{array}$ & $\begin{array}{l}\text { Fruição } \\
\text { Percebida } \\
\text { (Perceived } \\
\text { Enjoyment-PE) }\end{array}$ & $\begin{array}{l}\text { PE1. Eu me diverti interagindo com o } \\
\text { aplicativo Ray-Ban usando a tecnologia de } \\
\text { Realidade Aumentada. } \\
\text { PE2. O uso do aplicativo Ray-Ban com a } \\
\text { tecnologia de Realidade Aumentada me } \\
\text { proporcionou prazer. } \\
\text { PE3. Eu gostei de usar o aplicativo Ray- } \\
\text { Ban com a tecnologia de Realidade } \\
\text { Aumentada. }\end{array}$ & $\begin{array}{l}\text { Escala Likert } \\
\text { de } 5 \text { pontos - } \\
\text { Roy et al. } \\
\text { (2017), } \\
\text { adaptado de } \\
\text { estudos } \\
\text { anteriores com } \\
\text { TAM (DAVIS, } \\
\text { 1993). }\end{array}$ \\
\hline $\begin{array}{l}\text { Experiência } \\
\text { de } \\
\text { Realidade } \\
\text { Aumentada } \\
\text { - EXP_RA } \\
\text { (construto } \\
\text { de segunda } \\
\text { ordem) }\end{array}$ & $\begin{array}{l}\text { Vantagem } \\
\text { Relativa } \\
\text { (Relative } \\
\text { Advantage - RA) }\end{array}$ & $\begin{array}{l}\text { RA1. Usar o aplicativo da Ray-Ban com a } \\
\text { tecnologia de Realidade Aumentada foi } \\
\text { mais conveniente do que sem esta } \\
\text { tecnologia. } \\
\text { RA2. Foi mais fácil usar o aplicativo da } \\
\text { Ray-Ban com a tecnologia de Realidade } \\
\text { Aumentada do que sem esta tecnologia. } \\
\text { RA3. Usar o aplicativo da Ray-Ban com a } \\
\text { tecnologia de Realidade Aumentada me } \\
\text { permitiu uma melhor experiência de } \\
\text { compra online. } \\
\text { RA4. O aplicativo da Ray-Ban com a } \\
\text { tecnologia de Realidade Aumentada } \\
\text { apresentou resultados consistentes. }\end{array}$ & $\begin{array}{l}\text { Escala Likert } \\
\text { de } 5 \text { pontos - } \\
\text { Roy et al. } \\
\text { (2017), } \\
\text { adaptado de } \\
\text { estudos } \\
\text { anteriores de } \\
\text { Difusão da } \\
\text { Inovação } \\
\text { Rogers (2003) }\end{array}$ \\
\hline $\begin{array}{l}\text { Experiência } \\
\text { de } \\
\text { Realidade } \\
\text { Aumentada } \\
\text { - EXP_RA } \\
\text { (construto } \\
\text { de segunda } \\
\text { ordem) }\end{array}$ & $\begin{array}{l}\text { Controle } \\
\text { Percebido } \\
\text { (Perceived } \\
\text { Control-PC) }\end{array}$ & $\begin{array}{l}\text { PC1. Ao usar o aplicativo da Ray-Ban } \\
\text { com a tecnologia de Realidade } \\
\text { Aumentada, eu me senti no controle da } \\
\text { experiência. } \\
\text { PC2. Ao usar o aplicativo da Ray-Ban } \\
\text { com a tecnologia de Realidade } \\
\text { Aumentada, a minha atenção ficou focada } \\
\text { nisto. } \\
\text { PC3. Eu tive as condições necessárias para } \\
\text { usar o aplicativo da Ray-Ban com a } \\
\text { tecnologia de Realidade Aumentada. }\end{array}$ & $\begin{array}{l}\text { Escala Likert } \\
\text { de } 5 \text { pontos - } \\
\text { Roy et al. } \\
\text { (2017), original } \\
\text { de Ajzen } \\
(1991)\end{array}$ \\
\hline $\begin{array}{l}\text { Experiência } \\
\text { de }\end{array}$ & $\begin{array}{l}\text { Realidade } \\
\text { Aumentada }\end{array}$ & $\begin{array}{l}\text { PA1. Eu percebi os óculos virtuais } \\
\text { acrescentados no meu rosto na aplicação }\end{array}$ & $\begin{array}{l}\text { Escala Likert } \\
\text { de } 5 \text { pontos - }\end{array}$ \\
\hline
\end{tabular}




\begin{tabular}{|c|c|c|c|}
\hline $\begin{array}{l}\text { Construtos } \\
\text { Indicador - }\end{array}$ & $\begin{array}{l}\text { Dimensões } \\
\text { /Indicador }\end{array}$ & Itens Operacionais & $\begin{array}{l}\text { Tipo de Escala } \\
\text { (adaptada de) }\end{array}$ \\
\hline $\begin{array}{l}\text { Realidade } \\
\text { Aumentada } \\
\text { - EXP_RA } \\
\text { (construto } \\
\text { de segunda } \\
\text { ordem) }\end{array}$ & $\begin{array}{l}\text { Percebida } \\
\text { (Perceived } \\
\text { Augmented - } \\
\text { PA) }\end{array}$ & $\begin{array}{l}\text { da Ray-Ban com a tecnologia de Realidade } \\
\text { Aumentada. } \\
\text { PA2. Ao terminar o uso do aplicativo da } \\
\text { Ray-Ban com a tecnologia de Realidade } \\
\text { Aumentada, eu ainda conseguia imaginar } \\
\text { os óculos virtuais no meu rosto. } \\
\text { PA3. Os óculos virtuais da Ray-Ban no } \\
\text { aplicativo me pareceram reais. } \\
\text { PA4. Eu achei que os óculos virtuais do } \\
\text { aplicativo da Ray-Ban nada acrescentaram } \\
\text { à experiência de compra online. } \\
\text { PA5. A realidade pareceu mais rica com o } \\
\text { aplicativo da Ray-Ban com a tecnologia de } \\
\text { Realidade Aumentada. }\end{array}$ & $\begin{array}{l}\text { Rese et al. } \\
(2017)\end{array}$ \\
\hline $\begin{array}{l}\text { Experiência } \\
\text { de } \\
\text { Realidade } \\
\text { Aumentada } \\
\text { - EXP_RA } \\
\text { (construto } \\
\text { de segunda } \\
\text { ordem) }\end{array}$ & $\begin{array}{l}\text { Personalização } \\
\text { (Personalization } \\
\text { - P) }\end{array}$ & $\begin{array}{l}\text { P1. O aplicativo da Ray-Ban com a } \\
\text { tecnologia de Realidade Aumentada me } \\
\text { ofereceu opções personalizadas. } \\
\text { P2. O aplicativo da Ray-Ban com a } \\
\text { tecnologia de Realidade Aumentada } \\
\text { identificou as minhas necessidades } \\
\text { específicas. } \\
\text { P3. O aplicativo da Ray-Ban com a } \\
\text { tecnologia de Realidade Aumentada } \\
\text { ofereceu recomendações } \\
\text { correspondem às minhas necessidades } \\
\text { para a situação. } \\
\text { P4. O aplicativo da Ray-Ban com a } \\
\text { tecnologia de Realidade Aumentada é } \\
\text { personalizado de acordo com minhas } \\
\text { necessidades. }\end{array}$ & $\begin{array}{l}\text { Escala Likert } \\
\text { de } 5 \text { pontos - } \\
\text { Roy et al. } \\
(2017)\end{array}$ \\
\hline $\begin{array}{l}\text { Certeza na } \\
\text { escolha } \\
\text { (choice } \\
\text { confidance - } \\
\text { CC) }\end{array}$ & - & $\begin{array}{l}\text { CC1. Eu me senti confiante para escolher } \\
\text { os óculos quando usei o aplicativo da Ray- } \\
\text { Ban com Realidade Aumentada. } \\
\text { CC2. Eu me senti à vontade para escolher } \\
\text { os óculos quando usei o aplicativo da Ray- } \\
\text { Ban com Realidade Aumentada. } \\
\text { CC3. Eu me senti no controle para } \\
\text { escolher os óculos quando usei o } \\
\text { aplicativo da Ray-Ban com Realidade } \\
\text { Aumentada. }\end{array}$ & $\begin{array}{l}\text { Escala Likert } \\
\text { de } 5 \text { pontos - } \\
\text { Zhu, Wang e } \\
\text { Chang (2018) }\end{array}$ \\
\hline $\begin{array}{l}\text { Satisfação } \\
\text { do usuário } \\
\text { (User } \\
\text { Satisfaction } \\
\text { - US) }\end{array}$ & - & $\begin{array}{l}\text { US1 Estou satisfeito(a) com aplicativo da } \\
\text { Ray-Ban com Realidade Aumentada. } \\
\text { US2. O aplicativo da Ray-Ban com } \\
\text { Realidade Aumentada superou as minhas } \\
\text { expectativas. } \\
\text { US3. O aplicativo da Ray-Ban com } \\
\text { Realidade Aumentada está próximo do } \\
\text { que considero um aplicativo ideal para } \\
\text { compra online. }\end{array}$ & $\begin{array}{l}\text { Escala Likert } \\
\text { de } 5 \text { pontos - } \\
\text { Roy et al. } \\
(2017)\end{array}$ \\
\hline
\end{tabular}




\begin{tabular}{|c|c|c|c|}
\hline $\begin{array}{l}\text { Construtos } \\
\text { Indicador - }\end{array}$ & $\begin{array}{l}\text { Dimensões } \\
\text { /Indicador }\end{array}$ & Itens Operacionais & $\begin{array}{l}\text { Tipo de Escala } \\
\text { (adaptada de) }\end{array}$ \\
\hline $\begin{array}{l}\text { Emoção } \\
\text { Positiva } \\
\text { (Positive } \\
\text { Emotion - } \\
\text { POE) }\end{array}$ & - & $\begin{array}{l}\text { POE1. Eu fiquei estimulado(a) quando } \\
\text { usei o aplicativo da Ray-Ban com } \\
\text { Realidade Aumentada. } \\
\text { POE2. Eu fiquei empolgado(a) quando } \\
\text { usei o aplicativo da Ray-Ban com } \\
\text { Realidade Aumentada. } \\
\text { POE3. Eu fiquei agitado(a) quando usei o } \\
\text { aplicativo de da Ray-Ban com Realidade } \\
\text { Aumentada. } \\
\text { POE4. Eu fiquei tenso(a) quando usei o } \\
\text { aplicativo de aplicativo da Ray-Ban com } \\
\text { Realidade Aumentada. } \\
\text { POE5. Eu fiquei animado(a) quando usei } \\
\text { o aplicativo de aplicativo da Ray-Ban com } \\
\text { Realidade Aumentada. } \\
\text { POE6. Eu fiquei esperto(a) quando usei o } \\
\text { aplicativo de aplicativo da Ray-Ban com } \\
\text { Realidade Aumentada. } \\
\text { POE7. Eu fiquei ativo(a) quando usei o } \\
\text { aplicativo de aplicativo da Ray-Ban com } \\
\text { Realidade Aumentada. } \\
\text { POE8. Eu fiquei entusiasmado(a) } \\
\text { quando usei o aplicativo de aplicativo da } \\
\text { Ray-Ban com Realidade Aumentada }\end{array}$ & $\begin{array}{l}\text { Adaptação da } \\
\text { Escala } \\
\text { diferencial } \\
\text { semântica de } 5 \\
\text { pontos - Brito, } \\
\text { Stayanova e } \\
\text { Coelho (2018), } \\
\text { original de } \\
\text { Mehrabian e } \\
\text { Russell (1974) } \\
\text { para a escala } \\
\text { likert de } 5 \\
\text { pontos }\end{array}$ \\
\hline $\begin{array}{l}\text { Intenção de } \\
\text { Compra } \\
\text { (Purchase } \\
\text { Intention- } \\
\text { PI) }\end{array}$ & - & $\begin{array}{l}\text { PI1. Eu poderia me imaginar comprando } \\
\text { produtos por meio deste aplicativo da Ray- } \\
\text { Ban com Realidade Aumentada. } \\
\text { PI2. Da próxima vez que for comprar } \\
\text { óculos, levarei em consideração este } \\
\text { aplicativo da Ray-Ban com Realidade } \\
\text { Aumentada. } \\
\text { PI3. Eu tenho interesse em comprar óculos } \\
\text { pelo aplicativo Ray-Ban com Realidade } \\
\text { Aumentada. }\end{array}$ & $\begin{array}{l}\text { Escala Likert de } \\
5 \text { pontos - } \\
\text { Merle, Senecal } \\
\text { e St-Onge } \\
(2012)\end{array}$ \\
\hline
\end{tabular}

Fonte: própria

concluída

A tabela 3.3 contém as variáveis demográficas e as escalas utilizadas na coleta dos dados para auxiliar nas análises dos dados. 
Tabela 3.3 - Variáveis Demográficas

\begin{tabular}{|l|l|}
\hline Variável & Escala \\
\hline Idade & Contínua:Ex:20 \\
\hline Sexo & Categórica: Feminino ou Masculino \\
\hline Estado Civil & $\begin{array}{l}\text { Categórica: solteiro, casado, relacionamento } \\
\text { fixo e outros }\end{array}$ \\
\hline Renda Familiar (mensal?) & $\begin{array}{l}\text { Categórica: "Abaixo de } 1000 \text { reais", "de } 1000 \\
\text { a } 2000 \text { reais" "de } 2000 \text { a 3500 reais", "de 3500 } \\
\text { a } 6000 \text { reais", "de } 6000 \text { a 10000 reais", "Acima } \\
\text { de 10000 reais" }\end{array}$ \\
\hline Grau de Escolaridade & $\begin{array}{l}\text { Categórica: graduação incompleta, graduação } \\
\text { completa, pós-graduação Lato Sensu } \\
\text { incompleta, pós-graduação Lato Sensu } \\
\text { completa, mestrado incompleto, mestrado } \\
\text { completo, doutorado incompleto e doutorado } \\
\text { completo. }\end{array}$ \\
\hline
\end{tabular}

Fonte: elaboração própria

A tabela 3.4 contém as perguntas complementares incluídas no instrumento de coleta de dados que foram utilizadas para entender o uso de smartphones ou tablets pelo consumidor em compra online. Estas perguntas foram feitas no início do questionário (questão 1).

Tabela 3.4 - Perguntas Complementares para Análise dos Dados

\begin{tabular}{|c|c|}
\hline Perguntas Complementares para Análise & Escala \\
\hline $\begin{array}{l}\text { 1. Você tem hábito de fazer compras online } \\
\text { via dispositivo móvel (smartphones ou } \\
\text { tablets)? }\end{array}$ & Categórica_-Sim ou Não \\
\hline $\begin{array}{l}\text { 2. Você já tinha conhecimento sobre a } \\
\text { tecnologia de Realidade Aumentada antes } \\
\text { desta experiência com o aplicativo da Ray- } \\
\text { Ban? }\end{array}$ & Categórica_-Sim ou Não \\
\hline $\begin{array}{l}\text { 3. Você já tinha usado algum aplicativo com } \\
\text { Realidade Aumentada antes desta } \\
\text { experiência com o aplicativo da Ray-Ban? }\end{array}$ & Categórica - Sim ou Não \\
\hline $\begin{array}{l}\text { 4. Qual é, em geral, a frequência de busca de } \\
\text { informações para compra de produtos via } \\
\text { smartphone ou tablets? }\end{array}$ & $\begin{array}{l}\text { Ordinal - diária, semanal, quinzenal, mensal, } \\
\text { bimestral, semestral ou nunca }\end{array}$ \\
\hline $\begin{array}{l}\text { 5. Qual é, em geral, a frequência de compra } \\
\text { de produtos via smartphone ou tablets? }\end{array}$ & $\begin{array}{l}\text { Ordinal- diária, semanal, quinzenal, mensal, } \\
\text { bimestral, semestral ou nunca }\end{array}$ \\
\hline
\end{tabular}


A tabela 3.5 contém os construtos e os itens do questionário correspondentes (Apêndice A).

Tabela 3.5 - Construtos e Itens do Questionário Correspondentes

\begin{tabular}{|l|l|}
\hline Construto & Itens do Questionário \\
\hline Fruição percebida (Perceived Enjoyment - PE) & $\begin{array}{l}\text { Apêndice A, questão 2, itens 1 até 3, PE1, PE2, } \\
\text { PE3 }\end{array}$ \\
\hline Vantagem Relativa (Relative Advantage - RA) & $\begin{array}{l}\text { Apêndice A, questão 2, itens } 4 \text { até 7, RA1, } \\
\text { RA2, RA3, RA4 }\end{array}$ \\
\hline Controle Percebido (Perceived Control-PC) & $\begin{array}{l}\text { Apêndice A, questão 2, itens } 8 \text { até 10, PC1, } \\
\text { PC2, PC3 }\end{array}$ \\
\hline $\begin{array}{l}\text { Realidade Aumentada percebida (Perceived } \\
\text { Augmented - PA) }\end{array}$ & $\begin{array}{l}\text { Apêndice A, questão 2, itens 11 até 15, PA1, } \\
\text { PA2, PA3, PA4, PA5 }\end{array}$ \\
\hline Personalização (Personalization - P) & $\begin{array}{l}\text { Apêndice A, questão 2, itens 16 até 19, P1, P2, } \\
\text { P3, P4 }\end{array}$ \\
\hline Certeza na escolha (choice confidance - CC) & $\begin{array}{l}\text { Apêndice A, questão 3, itens 1 até 3, CC1, } \\
\text { CC2, CC3 }\end{array}$ \\
\hline Satisfação do usuário (User Satisfaction-US) & $\begin{array}{l}\text { Apêndice A, questão 3, itens 4 até 6, US1, } \\
\text { US2, US3 }\end{array}$ \\
\hline Emoção Positiva (Positive Emotion - POE) & $\begin{array}{l}\text { Apêndice A, questão 3, itens 7 até 14, POE1, } \\
\text { POE2, POE3, POE4, POE5, POE6, POE7, } \\
\text { POE8 }\end{array}$ \\
\hline Intenção de Compra (Purchase Intention - PI) & $\begin{array}{l}\text { Apêndice A, questão 3, itens 15 até 17, PI1, } \\
\text { PI2, PI3 }\end{array}$ \\
\hline
\end{tabular}

Fonte: elaboração própria

\subsection{2}

\section{Procedimento de Adaptação das Escalas Utilizadas}

As escalas utilizadas são oriundas de estudos elaborados em inglês. O uso de escalas já utilizadas pode facilitar a comparação de estudos realizados em grupos sociais ou culturas diferentes, além delas já terem sido validadas. Para adaptar e traduzir estas escalas já definidas em estudos anteriores, foi adotado o método de back-translation sugerido por Sperber (2004). Para o presente estudo, seguindo os critérios deste método, foi feita uma tradução inicial para o idioma português por 3 tradutores profissionais fluentes em língua inglesa e 2 especialistas no tema marketing. A partir desta tradução, outros 3 tradutores diferentes com o mesmo 
perfil dos anteriores, voltaram a versão em português para o idioma em inglês. Em seguida, as duas versões em inglês, original e retraduzida, foram comparadas para garantir que as traduções preservassem os significados das escalas originais. Além da comparabilidade de linguagem, foi validada a similaridade na interpretação dos itens por experts, para que o documento retraduzido ficasse com o conteúdo mais próximo do documento original.

\subsection{3}

\section{Pré-teste do Instrumento de Pesquisa}

Após a verificação das escalas traduzidas, foi elaborado um questionário e aplicado um pré-teste em duas etapas com uma amostra de 12 respondentes em cada etapa. Este pré-teste serviu para avaliar o entendimento dos respondentes sobre a pesquisa em uma versão preliminar, permitindo que ajustes fossem feitos antes da realização da pesquisa de campo. Os respondentes foram incentivados a colaborar com feedbacks sobre o tamanho e o tempo do instrumento da pesquisa, assim como dificuldades de compreensão ou dúvidas sobre algum item ou instrução de preenchimento. O pré-teste inicial utilizou o questionário impresso para avaliar a compreensão por parte dos participantes sobre os itens elaborados. O segundo préteste foi realizado online para avaliar a duração da execução do questionário, o número de perguntas e a sua compreensão. Vale ressaltar que os participantes da primeira etapa não foram os mesmos da segunda etapa. Como resultado deste préteste, foram alteradas 9 perguntas de escalas já existentes e foram acrescentadas 2 perguntas iniciais sobre o comportamento dos participantes em relação à compra online. O tipo de escala de Emoção Positiva foi alterado de diferencial semântica para escala tipo Likert para uma melhor compreensão dos participantes por sugestão de uma especialista do assunto. Estes feedbacks serviram para aprimorar o instrumento da pesquisa, contribuindo para a obtenção da validade de face.

\section{3}

\section{População e Amostra}

A definição da população e da amostra utilizadas é apresentada a seguir. 


\subsection{1 \\ População}

A população de interesse deste estudo foi de consumidores, de modo geral, que fazem compras online de ambos os sexos, estudantes ou não, sem distinção de classe social e acima de 17 anos. Vários trabalhos pesquisados (LEE; FIORE; KIM, 2006; LEE; CHUNG, 2008; OH; YOON; SHYU, 2008; DOMINA; LEE; MACGILLIVRAY, 2012; PANTANO; SERVIDIO, 2012; HUANG; LIAO, 2015; STOYANOVA et al., 2015; JAVORNICK, 2016a; KIM; HYUN, 2016) usaram apenas estudantes em seus testes conforme apresentado na tabela 2.3 sobre os estudos realizados de Realidade Aumentada. Para obter uma visão mais ampla dos efeitos dos aplicativos de Realidade Aumentada sobre o comportamento de compra, o questionário foi aplicado fora e dentro de universidades, permitindo ampliar a faixa etária e o grau de escolaridade dos participantes. Para Pantano et al. (2017), apesar de os jovens fazerem uso extensivo da tecnologia de Realidade Aumentada, pode haver limitação ao sucesso da pesquisa ao se utilizar apenas jovens estudantes.

\subsection{2 Amostra}

A amostra é não probabilística por conveniência. A amostra contém estudantes de duas universidades definidas, amigos e familiares que podem ser estudantes ou não estudantes. Além destes, a amostra também contém participantes que são amigos dos meus amigos e seus familiares (efeito "bola de neve").

Na meta-análise de Rese et al. (2017) sobre os estudos realizados a respeito da aceitação de aplicativos de Realidade Aumentada no varejo, foi identificada que a maioria das pesquisas utilizou modelagem de equações estruturais (SEM) para testar as hipóteses. Isto contribuiu para decisão de empregar SEM no presente estudo. 
Para calcular o tamanho mínimo necessário da amostra para este tipo de modelo, segundo Hair et al. (2010), deve-se aplicar a fórmula $\frac{N *(N+1)}{2}$, onde N é o número de variáveis observáveis no modelo. É importante ressaltar que o tamanho da amostra não pode ser inferior à 200 observações. Para este estudo, como $N=$ 42, o mínimo seria de 903 observações. Porém como foi utilizado o método de estimação por máxima verossimilhança (ML), o número de observações pode ser reduzido para o mínimo de 200 pela orientação de Hair et al. (2010).

\section{4}

\section{Coleta de Dados}

A coleta de dados foi realizada por meio de questionário elaborado na ferramenta Qualtrics. Mais detalhes sobre o instrumento e a forma da coleta de dados são apresentados a seguir.

\subsection{1 Instrumento de Coleta de Dados}

O modelo proposto contém o construto Experiência de Realidade Aumentada do consumidor de segunda ordem composto por 5 dimensões, totalizando 19 itens. Além destes, há também os 3 construtos associados às avaliações dos consumidores em relação à intenção da compra online do produto com 14 itens e mais 3 itens do construto intenção de compras. No total, o instrumento de pesquisa proposto possui 36 itens referentes às escalas de medição dos construtos utilizados. Além destes, o questionário tem mais 5 itens para as variáveis demográficas dos respondentes (AAKER; KUMAR; DAY, 2006). Em relação ao layout do instrumento de coleta de dados, primeiro são feitas as perguntas complementares para a análise dos dados e logo em seguida são solicitados o preenchimento dos itens que avaliam a experiência de Realidade Aumentada e a intenção de compra. No fim do instrumento de pesquisa foi solicitado o 
preenchimento dos dados demográficos. O instrumento de pesquisa completo é apresentado no Apêndice A.

\subsection{2 \\ Coleta de Dados}

A coleta dos dados do presente estudo foi realizada em bairros da Zona Sul do Rio de Janeiro e no bairro de Icaraí em Niterói, entre junho e agosto de 2019. As pesquisas foram realizadas nas casas dos participantes, restaurantes, lanchonetes e em duas universidades (PUC- Pontifícia Universidade Católica no Rio de Janeiro e UFF - Universidade Federal Fluminense em Niterói).

Por se tratar de uma tecnologia nova e pouco usada, houve a necessidade de garantir a experimentação prévia do aplicativo de Realidade Aumentada via dispositivo móvel antes do preenchimento do formulário online pelos participantes. Para a coleta de dados, foram organizados encontros individuais e em grupo, dentro e fora de universidades, para experimentação do aplicativo e preenchimento do questionário.

Mesmo nos encontros em grupo, as experimentações no aplicativo da RayBan foram feitas de forma individual. Foram utilizados 3 tablets, do mesmo padrão, com configuração adequada para a experiência. A opção do tablet, em vez do smartphone, se deve à diferença no tamanho da tela que, por ser maior, proporciona melhor visão e experiência do usuário na observação dos elementos virtuais proporcionados por esta tecnologia. Como os participantes desconheciam, ou conheciam muito pouco, as aplicações de RA, todos foram orientados e monitorados presencialmente pelo pesquisador na realização da pesquisa. Segundo Javornik et al. (2016), a imprevisibilidade e a novidade de um aplicativo de Realidade Aumentada podem causar um sentimento de desconfiança no usuário ao usá-lo sozinho. Ter uma pessoa para orientar no uso do aplicativo pode fazer com que os consumidores se sintam mais à vontade.

A experimentação virtual em Realidade Aumentada deste estudo utilizou o aplicativo de vendas de óculos da Ray-Ban disponível para dispositivos móveis. Este aplicativo apresenta um bom exemplo de implementação da tecnologia de RA 
para experiências de compra online. Diversos estudos de Realidade Aumentada fizeram uso deste aplicativo (por exemplo, PANTANO; RESE; BAIER, 2017; POUSHNEH; VASQUEZ-PARRAGA, 2017). O provador virtual da Ray-Ban usa a câmera do dispositivo móvel para filmar e mapear o rosto do consumidor. Baseado no mapeamento do rosto, o aplicativo pode colocar, virtualmente, 95 pares de óculos diferentes no rosto filmado do participante da pesquisa. $\mathrm{O}$ consumidor pode então, escolher os óculos de sua preferência entre os óculos disponíveis. Caso o consumidor goste do resultado dos óculos virtuais na sua face e deseje comprá-lo logo após a experimentação virtual, ele pode prosseguir com a compra efetiva no mesmo aplicativo.

Após esta etapa, o pesquisador solicitou aos participantes o preenchimento do questionário da pesquisa. Grande parte dos participantes preencheu o questionário no próprio tablet onde foi realizada a experiência. Os demais participantes preencheram nos seus celulares. Para agilizar o processo de acesso à pesquisa, foi utilizado o recurso da tecnologia QR Code, que. em conjunto com o uso do celular, obtém, digitalmente, o endereço do questionário elaborado. Este processo agiliza o início do processo de preenchimento do questionário. $\mathrm{O}$ instrumento de pesquisa foi autoadministrado, ou seja, o próprio participante foi o responsável pelo seu preenchimento.

\section{5}

\section{Análise de Dados}

Os dados obtidos da aplicação da pesquisa online feita na ferramenta Qualtrics foram exportados para os softwares SPSS (versão 23). Utilizou-se a ferramenta AMOS (versão 22) para a construção dos modelos de mensuração e estrutural propostos neste estudo. As ferramentas SPSS e AMOS foram usadas para a aplicação das análises estatísticas univariadas e multivariadas dos dados. Na etapa preliminar da análise, foi realizada a limpeza dos dados com objetivo de eliminar os possíveis erros de preenchimento ou dados ausentes. Foram eliminados 7 respondentes que não concluíram o questionário. Com a eliminação destes dados incompletos, a base de dados final ficou com 201 respondentes. Em seguida, foi 
feita uma análise descritiva dos dados demográficos com o objetivo de conhecer o perfil da amostra estudada. Logo após isto, foram realizadas validações, com o intuito de garantir a qualidade dos resultados da pesquisa.

\subsection{1 \\ Validação e Confiabilidade}

O modelo de mensuração foi estimado e avaliado pela aplicação da análise fatorial confirmatória (CFA) nos dados. Por meio desta técnica, foi possível verificar a unidimensionalidade, validade e confiabilidade dos construtos presentes no modelo. Conforme Hair et al. (2010), a validade dos construtos avalia o quanto um conjunto de itens de medição de um conceito teórico não observável representa realmente este construto. Para avaliar esta validade, foram examinadas as cargas fatoriais dentro de cada construto e as correlações entre os construtos resultantes da análise fatorial confirmatória (CFA) nos dados. A confiabilidade, também considerada como um indicador de validade convergente, avalia se há consistência entre as variáveis e o que eles desejam medir. Para avaliar a validade convergente, é necessário obter a confiabilidade dos construtos e extrair as variâncias extraídas médias (Average Variance Extracted - AVE) que devem apresentar valores superiores a 0,5. Foi utilizado também o Alfa de Cronbach e a confiabilidade composta para medir a confiabilidade dos construtos (NUNNALLY; BERNSTEIN, 1978). Os valores do Alfa de Cronbach e da confiabilidade devem ser maiores que 0,8, porém acima de 0,7 já são considerados aceitáveis (Hair et al., 2010).

A validade discriminante avalia a distinção de cada construto em relação aos demais. Para esta validação, utilizam-se as cargas fatoriais dos itens. Estas cargas fatoriais devem apresentar valores maiores nos construtos relacionados do que nos demais construtos do modelo. O significado e a importância relativa das cargas fatoriais dos itens foram avaliados de acordo com as indicações de Hair et al. (2010). Os autores apontam que cargas fatoriais acima de 0,3 podem ser consideradas como significativas, acima de 0,4 podem ser importantes e acima de 0,5 podem ser consideradas muito significativas. Para que a validade discriminante seja aceita, é necessário que a variância média extraída (Average Variance 
Extracted - AVE) do construto seja maior do que a variância compartilhada entre construtos. De acordo com Hair et al (2010), além das avaliações das cargas fatoriais, deve-se avaliar a validade discriminante pela comparação da AVE dos construtos com o quadrado das correlações entres eles. O valor da AVE deve ser superior ao da estimativa da correlação ao quadrado. Esta validação foi realizada neste estudo.

\subsection{2}

\section{Análise Estatística}

O teste das hipóteses do modelo proposto foi feito via modelagem de equações estruturais (SEM), utilizando o software AMOS 22.0. Em sintonia com as definições de uso do SEM feitas por Bagozzi e Phillips (1982), o emprego de SEM neste estudo é apropriado pelas questões levantadas e pelos testes necessários para avaliar as hipóteses definidas no estudo. A modelagem de equações estruturais (SEM) permite estimar simultaneamente as relações entre várias variáveis independentes e dependentes e, com isto, testar as hipóteses. Com a utilização desta técnica, é possível examinar os efeitos de todos os construtos do modelo proposto em conjunto e avaliar as características de mensuração dos construtos não observáveis. Sendo assim, foi estimado um modelo de equações estruturais adequado que permitisse operacionalizar o modelo conceitual e testar as relações entre os construtos do modelo proposto.

Foi utilizado o método de estimação por ML (Maximum Likelihood) para a estimação do modelo de equações estruturais. Olsson et al. (2000) afirmam que estimações via ML produzem resultados confiáveis e similares comparados aos usados com outras técnicas. A amostra de 201 coletada é considerada adequada quando se usa a estimação por ML.

De acordo com Anderson e Gerbing (1988), a modelagem de equações estruturais deve ser realizada em duas etapas. Na primeira etapa, realiza-se a análise fatorial confirmatória (CFA) que gera o modelo de mensuração. Este modelo permite verificar se as escalas estão medindo apenas o seu respectivo construto. Para o aprimoramento do modelo, os itens que não apresentarem boa confiabilidade 
são excluídos. Após esta etapa, deve-se estimar o modelo de equações estruturais, realizando-se o teste das hipóteses. As duas etapas foram realizadas para o modelo proposto e para os modelos alternativos. Os desempenhos dos modelos foram comparados e analisados. Por orientação de Hair et al. (2010), foram utilizados os índices Tucker-Lewis Index (TLI ou NFFI), o comparative fit index (CFI), o root mean squared approximation error (RMSEA) e a estatística qui-quadrada com os graus de liberdade para ajustes dos modelos. Os índices Standardized Root Mean Square Residual (SRMR) dos modelos também foram avaliados e comparados.

\section{6}

\section{Limitações do Método}

As limitações do método apresentadas a seguir estão relacionadas com a amostra e a coleta de dados.

\section{6}

\section{Limitações Relacionadas à Amostra}

A amostra por conveniência permite que a coleta de dados seja feita de forma mais rápida, porém pode gerar uma amostra mais uniforme, assim como a delimitação geográfica pode gerar uma amostra mais homogênea. Sendo assim, a amostra coletada presencialmente somente nos bairros da Zona Sul do Rio de Janeiro e no bairro de Icaraí em Niterói poderia prejudicar a representatividade dos dados. Como o propósito da pesquisa é examinar as relações contidas no modelo proposto e não a validade externa de seus resultados, a representatividade da amostra não é um aspecto fundamental neste estudo. Neste caso, uma amostra mais homogênea pode até ser desejável, como forma de evitar efeitos moderadores imprevisíveis, que poderiam prejudicar a investigação das relações estudadas de consumidores do varejo online. 


\subsection{2}

\section{Limitações Relacionadas à Coleta de Dados}

A coleta de dados em grupo foi limitada à experimentação simultânea por três pessoas, uma vez que foram utilizados três tablets. Em média, cada participante levou 15 minutos no total para experimentar o aplicativo da Ray-Ban e a seguir responder o questionário. Dada a curiosidade de alguns participantes, ao ficar experimentando diversos óculos virtuais, estes excederam o tempo planejado no roteiro para cada participante. Isto reduziu o tempo disponível para os demais participantes. Com isto, tanto o tempo de experimentação, como o tempo de preenchimento do questionário foram prejudicados para alguns participantes. Esta circunstância pode ter afetado a qualidade de algumas respostas.

Esta forma de coleta, com a apresentação e teste de uma tecnologia pelos respondentes, tornou o processo de obtenção de dados mais demorado, porém garantiu que todos os respondentes já tivessem utilizado a tecnologia e estivessem capacitados a responder o questionário.

A partir de setembro de 2019, o aplicativo da Ray-Ban apresentou um problema na atualização do catálogo de óculos. Apenas mostrava um modelo de óculos. Por esta razão, a coleta de dados foi suspensa, limitando o número de respondentes em 208 .

Outro ponto de atenção relacionado à coleta de dados foi a possível dificuldade na compreensão das perguntas do questionário pelos respondentes pelo fato de ser autoadministrado. 


\section{4 \\ Modelagem e Análise dos Dados}

Este capítulo contém as análises estatísticas e psicométricas dos dados da amostra, assim como os resultados obtidos nos testes das hipóteses formuladas e os ajustes realizados nos modelos.

\section{1}

\section{Caracterização da Amostra}

As características da amostra final contendo 201 respondentes, apresentadas na tabela 4.1, revelaram que a maioria dos participantes é do sexo feminino (66\%). Em relação a renda familiar, 44\% deles possuem renda maior que 10.000 reais. Em termos de grau de escolaridade, $31 \%$ dos respondentes têm graduação incompleta. No que diz respeito à idade, $52 \%$ dos participantes têm até 28 anos. Apesar de a base conter muitos jovens, a média de idade foi de 34,2 anos com desvio padrão de 1,04. Isto foi ocasionado pela base de dados conter 50 respondentes com idade acima de 50 anos $(25 \%)$. 
Tabela 4.1 - Característica da Amostra

\begin{tabular}{|c|c|}
\hline Característica & Porcentagem dos respondentes (n) \\
\hline \multicolumn{2}{|l|}{ Sexo } \\
\hline Feminino & $65,7 \%(\mathrm{n}=132)$ \\
\hline Masculino & $34,3 \%(\mathrm{n}=69)$ \\
\hline \multicolumn{2}{|l|}{ Estado Civil } \\
\hline Casado & $51,7 \%(\mathrm{n}=104)$ \\
\hline Solteiro & $31,8 \%(n=64)$ \\
\hline Relacionamento sério & $12,4 \%(\mathrm{n}=25)$ \\
\hline Outros & $4,0 \%(\mathrm{n}=8)$ \\
\hline \multicolumn{2}{|l|}{ Renda Familiar } \\
\hline Acima de $\mathrm{R} \$ 10.000$ & $43,8 \%(\mathrm{n}=88)$ \\
\hline Entre $\mathrm{R} \$ 6.000$ e $\mathrm{R} \$ 10.000$ & $17,4 \%(\mathrm{n}=35)$ \\
\hline Entre $\mathrm{R} \$ 3.500$ e $\mathrm{R} \$ 6.000$ & $11,9 \%(\mathrm{n}=24)$ \\
\hline Entre $\mathrm{R} \$ 2.000$ e $\mathrm{R} \$ 3.500$ & $12,4 \%(\mathrm{n}=25)$ \\
\hline Entre $\mathrm{R} \$ 1.000$ e $\mathrm{R} \$ 2.000$ & $4,0 \%(\mathrm{n}=8)$ \\
\hline Abaixo de $\mathrm{R} \$ 1.000$ & $1,0 \%(\mathrm{n}=2)$ \\
\hline Prefiro não informar & $9,5 \%(\mathrm{n}=19)$ \\
\hline \multicolumn{2}{|l|}{ Escolaridade } \\
\hline Graduação incompleta & $31,3 \%(\mathrm{n}=63)$ \\
\hline Graduação completa & $31,3 \%(\mathrm{n}=63)$ \\
\hline Pós-graduação Lato Sensu incompleta & $4,5 \%(\mathrm{n}=9)$ \\
\hline Pós-graduação Lato Sensu completa & $13,4 \%(\mathrm{n}=27)$ \\
\hline Mestrado incompleto & $5,0 \%(\mathrm{n}=10)$ \\
\hline Mestrado completo & $4,5 \%(\mathrm{n}=9)$ \\
\hline Doutorado incompleto & $6,0 \%(\mathrm{n}=12)$ \\
\hline Doutorado completo & $4,0 \%(\mathrm{n}=8)$ \\
\hline \multicolumn{2}{|l|}{ Idade } \\
\hline$<28$ anos & $52,2 \%(\mathrm{n}=105)$ \\
\hline Média & 34,2 anos \\
\hline Desvio Padrão & 1,04 \\
\hline Mediana & 28 anos \\
\hline Moda & 20 anos \\
\hline Mínimo & 17 anos \\
\hline Máximo & 63 anos \\
\hline
\end{tabular}

Fonte própria

Além das informações demográficas, algumas perguntas complementares foram feitas, apresentadas na tabela 4.2, para permitir análises sobre o perfil dos respondentes da amostra. A maioria dos entrevistados (120) respondeu que não tinha conhecimento da tecnologia de Realidade Aumentada (60\%) e 143 respondentes não tinham usado aplicativos com este recurso (71\%). Sobre o hábito de fazer compras online com aplicativos móvel, 132 respondentes afirmaram que têm este hábito (65\%), enquanto 69 não têm (35\%). Para 150 respondentes (76\%), a busca por informações de produtos para compra online ocorre diariamente, semanalmente ou quinzenalmente, porém as frequências para compras online não acontecem da mesma forma. Somente 52 respondentes (27\%) fazem compras online com frequência diária, semanal ou quinzenal. 
Alguns participantes relataram que conheciam a tecnologia RA pelo jogo Pokémon Go, mas não sabiam da possibilidade de seu uso na experimentação virtual em compras. Muitos participantes acharam a experiência inovadora, interessante e atraente. Estas informações foram coletadas durante a realização da experiência em conversas informais com os participantes.

Tabela 4.2 - Perguntas Complementares

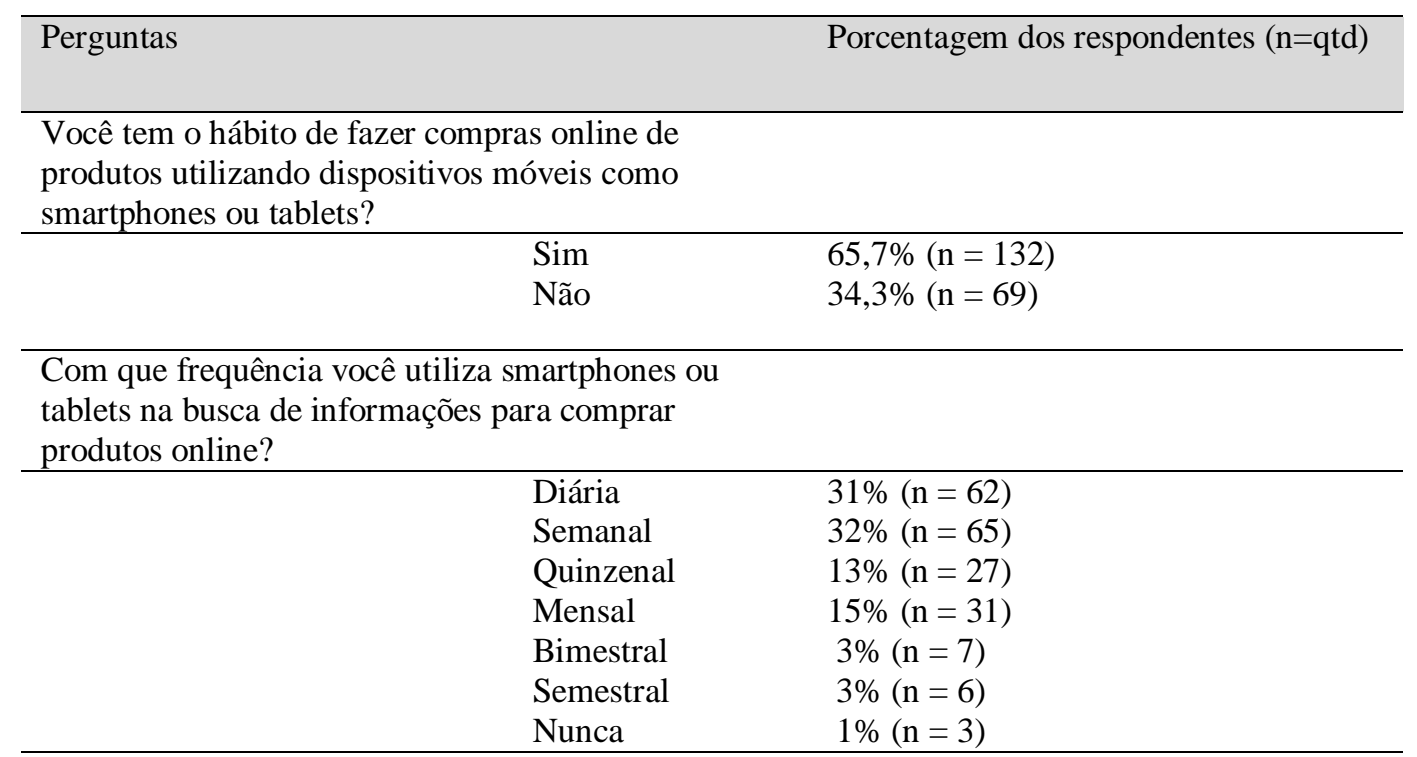

Com que frequência você utiliza smartphones ou tablets para comprar produtos online?

$\begin{array}{lc}\text { Diária } & 2 \%(\mathrm{n}=5) \\ \text { Semanal } & 13 \%(\mathrm{n}=27) \\ \text { Quinzenal } & 12 \%(\mathrm{n}=25) \\ \text { Mensal } & 34 \%(\mathrm{n}=68) \\ \text { Bimestral } & 15 \%(\mathrm{n}=30) \\ \text { Semestral } & 13 \%(\mathrm{n}=27) \\ \text { Nunca } & 9 \%(\mathrm{n}=19)\end{array}$

Você já tinha conhecimento sobre a tecnologia de

Realidade Aumentada antes desta experiência com o aplicativo da Ray-Ban?

$\begin{array}{ll}\text { Sim } & 40 \%(\mathrm{n}=81) \\ \text { Não } & 60 \%(\mathrm{n}=120)\end{array}$

Você já tinha usado algum aplicativo com Realidade Aumentada antes desta experiência com o aplicativo da Ray-Ban?

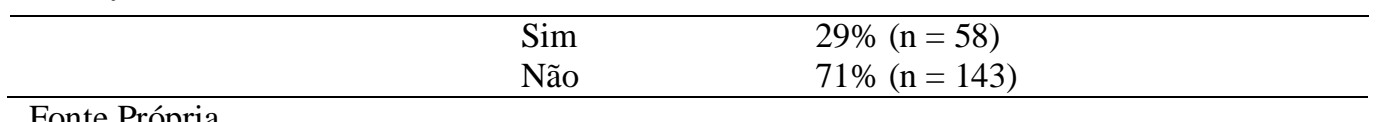




\section{2 \\ Análises e Resultados}

Apresentam-se a seguir os resultados apurados nas etapas das análises estatísticas realizadas neste estudo.

\subsection{1}

\section{Avaliação do Modelo de Mensuração}

O modelo de mensuração apresenta a relação entre as variáveis observáveis e as latentes (não observáveis). Pela análise fatorial confirmatória (CFA), foi verificado se as escalas do modelo de mensuração mediam somente os seus respectivos construtos relacionados. Os itens que não apresentaram boa confiabilidade foram eliminados com o intuito de se obter um modelo mais aprimorado. O modelo inicial proposto contém a Experiência de Realidade Aumentada que é um construto de segunda ordem contendo cinco dimensões (Realidade Aumentada percebida, Controle Percebido, Fruição Percebida, Vantagem Relativa e Personalização). Este construto se relacionou com três construtos que avaliaram a experiência (Certeza na Escolha, Emoção Positiva e Satisfação do Usuário).

Diversos índices de ajustes, incrementais e absolutos, foram usados para avaliar o modelo de mensuração proposto. Isto porque não há consenso sobre qual índice ou conjunto de índices deve ser usado para verificar o ajuste do modelo desta natureza (HU; BENTLER, 1999, SIVO; FAN; WITTA; WILLSE, 2006, SCHREIBER; NORA; STAGE; BARLOW; KING, 2006).

O modelo inicial testado contendo os 36 itens do instrumento de pesquisa não apresentou bons índices de ajuste. Pela análise da matriz de covariância dos resíduos padronizados da CFA, foram identificados 5 itens (PA1 e PA4 - itens 1 e 4 do construto Realidade Aumentada Percebida e POE3, POE4 e POE6 - itens 3, 4 e 6 do construto Emoção Positiva) que não se encaixavam com a estrutura proposta, contribuindo para o ajuste fraco do modelo. Estes itens foram eliminados, resultando em 31 itens de escala. Após este refinamento, os índices de ajustes do modelo melhoram. O modelo de mensuração final, contendo 31 itens e 5 construtos 
(um deles de segunda ordem com 5 dimensões), apresentou bons índices de ajuste com melhoria significativa em relação ao modelo inicial. Estes índices avaliados conjuntamente sugerem um ajuste satisfatório dos dados para o modelo proposto (HU; BENTLER, 1999; SCHREIBER et al., 2006). Os valores encontrados para os índices estão apresentados na tabela 4.3 de Avaliação dos Índices de Ajustes do Modelo de Mensuração Final.

Tabela 4.3 - Avaliação dos Índices de Ajustes do Modelo Mensuração Final

\begin{tabular}{c|c|c}
\hline $\begin{array}{c}\text { Índice de } \\
\text { ajuste }\end{array}$ & $\begin{array}{c}\text { Valores sugeridos na } \\
\text { literatura }\end{array}$ & Modelo de Mensuração \\
\hline$\chi^{\mathbf{2}}$ & & 729,320 \\
\hline $\boldsymbol{2} \mathbf{2}$ d.f. & $\leq 3$ & 1,753 \\
\hline CFI & $\geq 0,9$ & 0,92 \\
\hline TLI & $\geq 0,9$ & 0,91 \\
\hline IFI & $\geq 0,9$ & 0,92 \\
\hline RMSEA & $\leq 0,08$ & 0,061 \\
\hline SRMR & $\leq 0,08$ & 0,064 \\
\hline
\end{tabular}

Fonte Própria

\subsection{2 \\ Validade e Confiabilidade dos Construtos}

Para confirmar um modelo de mensuração é necessário avaliar a validade dos construtos utilizados, que inclui a validades de face, convergente, discriminante e nomológica (HAIR et al., 2010). A validade de um construto avalia o quanto um conjunto de itens de medição de um conceito teórico não observável representa realmente este construto.

A validade de face, que avalia a consistência do conteúdo de cada escala em relação ao construto que ela mede, foi garantida pelo uso de escalas já testadas em estudos anteriores na literatura, aliada à tradução feita dessas escalas para português usando o processo minucioso de back-transalation e também pela realização de pré-testes com uma amostra pequena da população de interesse. 
A validade nomológica avalia se as correlações entre os construtos na teoria de mensuração são coerentes, ou seja, avalia se a relação entre os construtos está consistente com a teoria (HAIR et al., 2010). São esperadas relações positivas entre a Experiência de Realidade Aumentada e os construtos Certeza na Escolha (BECK; CRIÉ, 2016; JAVORNIK, 2016a; POUSHNEH, 2018; POUSHNEH; VASQUEZPARRAGA, 2017; YIM; CHU; SAUER, 2017), Emoção Positiva (OLSSON et al., 2013) e Satisfação do Usuário (ROY et al., 2017). Da mesma forma, são esperadas relações positivas entre Certeza na Escolha, Emoção Positiva, Satisfação do Usuário e a Intenção de Compras (ROY et al., 2017, PONCIN; MIMUN, 2014; HILKEN et al, 2017).

O quadro 4.1 contém a matriz de correlação dos construtos utilizados no modelo de estudo.

Quadro 4.1- Matriz de Correlação dos Construtos Estudados

\begin{tabular}{|c|c|c|c|c|c|}
\hline & $\begin{array}{l}\text { Experiência } \\
\text { de Realidade } \\
\text { Aumentada } \\
\text { EXP_RA }\end{array}$ & $\begin{array}{l}\text { Certeza na } \\
\text { Escolha } \\
\text { CC }\end{array}$ & $\begin{array}{l}\text { Emoção } \\
\text { Positiva } \\
\text { POE }\end{array}$ & $\begin{array}{l}\text { Satisfação } \\
\text { do Usuário } \\
\text { US }\end{array}$ & $\begin{array}{l}\text { Intenção de } \\
\text { Compra } \\
\text { PI }\end{array}$ \\
\hline $\begin{array}{l}\text { Experiência de } \\
\text { Realidade Aumentada } \\
\text { EXP_RA }\end{array}$ & 1 & $\begin{array}{l}0,831 \\
* * *\end{array}$ & $\begin{array}{l}0,760 \\
* * *\end{array}$ & $\begin{array}{l}0,953 \\
* * *\end{array}$ & $\begin{array}{c}0,752 \\
* * *\end{array}$ \\
\hline $\begin{array}{l}\text { Certeza na Escolha } \\
\text { CC }\end{array}$ & $\begin{array}{c}0,831 \\
* * *\end{array}$ & 1 & $\begin{array}{l}0,655 \\
* * *\end{array}$ & $\begin{array}{c}0,806 \\
* * *\end{array}$ & $\begin{array}{c}0,847 \\
* * *\end{array}$ \\
\hline $\begin{array}{l}\text { Emoção Positiva } \\
\text { POE }\end{array}$ & $\begin{array}{c}0,760 \\
* * *\end{array}$ & $\begin{array}{c}0,655 \\
* * *\end{array}$ & 1 & $\begin{array}{c}0,729 \\
* * *\end{array}$ & $\begin{array}{c}0,659 \\
* * *\end{array}$ \\
\hline $\begin{array}{l}\text { Satisfação do Usuário } \\
\text { US }\end{array}$ & $\begin{array}{l}0,953 \\
* * *\end{array}$ & $\begin{array}{c}0,806 \\
* * *\end{array}$ & $\begin{array}{c}0,729 \\
* * *\end{array}$ & 1 & $\begin{array}{l}0,756 \\
* * *\end{array}$ \\
\hline $\begin{array}{l}\text { Intenção de Compra } \\
\text { PI }\end{array}$ & $\begin{array}{c}0,752 \\
* * *\end{array}$ & $\begin{array}{c}0,847 \\
* * *\end{array}$ & $\begin{array}{l}0,659 \\
* * *\end{array}$ & $\begin{array}{c}0,756 \\
* * *\end{array}$ & 1 \\
\hline
\end{tabular}

Correlações significativas: $* * * \mathrm{p}<0,001$

Todas as correlações apresentadas no quadro 4.1 foram significativas com o nível de significância de 0,001 ( $p$-value <0,001). Observa-se também que todas as correlações foram positivas e consistentes como eram esperadas na teoria. Sendo assim, pode-se concluir que a validade nomológica foi atendida neste modelo. 
A confiabilidade e a consistência interna das escalas utilizadas foram verificadas pelo coeficiente Alfa de Cronbach calculado para as escalas revisadas (contendo apenas os itens presentes no modelo de mensuração final), pela confiabilidade composta e a Variância Extraída Média (average variance extracted - AVE) para cada construto. Os coeficientes Alfa de Cronbach maiores do que 0,8 são considerados bons e entre 0,7 e 0,8 são considerados aceitáveis (NUNNALLY; BERNSTEIN,1994, FORNELL; LARCKER, 1981; HAIR et al., 2010). Para a confiabilidade composta, que reflete a consistência interna de indicadores que medem um mesmo fator (FORNELL; LARCKER,1981), são recomendados valores acima de 0,7 .

$\mathrm{Na}$ tabela 4.4, que apresenta a confiabilidade, confiabilidade composta e variância extraída média (AVE), verifica-se que todas as escalas utilizadas no modelo revisado estão com valores acima de 0,7, tanto para o coeficiente Alfa (confiabilidade), quanto para a confiabilidade composta. Estes valores atendem aos níveis mínimos de confiabilidade considerados adequados pela literatura. (FORNELL; LARCKER,1981; HAIR et al., 2010).

Tabela 4.4 - Confiabilidade, Confiabilidade Composta e Variância Extraída Média

\begin{tabular}{l|c|c|c}
\hline Escala & $\begin{array}{c}\text { Confiabilidade } \\
(\boldsymbol{\alpha})\end{array}$ & $\begin{array}{c}\text { Confiabilidade } \\
\text { Composta (CR) }\end{array}$ & $\begin{array}{c}\text { Variância } \\
\text { extraída da } \\
\text { média (AVE) }\end{array}$ \\
\hline $\begin{array}{l}\text { Experiência de Realidade } \\
\text { Aumentada (EXP_RA) }\end{array}$ & 0,882 & 0,88 & 0,61 \\
\hline Certeza na Escolha (CC) & 0,866 & 0,89 & 0,73 \\
\hline Satisfação do Usuário (US) & 0,829 & 0,85 & 0,66 \\
\hline Emoção Positiva (POE) & 0,875 & 0,88 & 0,60 \\
\hline Intenção de Compras (PI) & 0,821 & 0,83 & 0,62 \\
\hline
\end{tabular}

Os resultados da variância extraída média (average variance extracted AVE) calculados para os construtos estão apresentados na tabela 4.4. Esses valores de AVE calculados estão acima de 0,60. Fornell e Larcker (1981) afirmam que quando as estimativas de AVE estão acima de 0,50, isto indica validade convergente adequada. Para corroborar a validação convergente, foram também examinadas as cargas fatoriais padronizadas e as significâncias das variáveis 
observáveis nos construtos (variáveis latentes não observáveis). Quanto mais alto os valores, mais forte é a representatividade destas variáveis medidas em relação aos seus construtos e isto indica a validade convergente e unidimensionalidade. As estimativas de parâmetros maiores do que 0,70 , significativas e na direção esperada pela teoria indicam a unidimensionalidade e validade convergente de um construto (GARVER; MENTZER,1999).

A tabela 4.5 apresenta as cargas fatoriais padronizadas e as significâncias (p-values) dos indicadores no modelo de mensuração estimado.

Tabela 4.5 - Cargas Fatoriais Padronizadas

\begin{tabular}{|c|c|c|}
\hline Construto/Indicador & Carga Fatorial Padronizada & p-value \\
\hline \multicolumn{3}{|l|}{$\begin{array}{l}\text { Experiência de Realidade Aumentada } \\
\text { (EXP_RA) }\end{array}$} \\
\hline - Realidade Aumentada Percebida (PA) & 0,68 & $<0.001$ \\
\hline - $\quad$ Controle Percebido (PC) & 0,76 & $<0.001$ \\
\hline - Fruição Percebida (PE) & 0,82 & $<0.001$ \\
\hline - Vantagem Relativa (RA) & 0,93 & $<0.001$ \\
\hline - Personalização $(\mathrm{P})$ & 0,66 & $<0.001$ \\
\hline \multicolumn{3}{|l|}{ Certeza na Escolha (CC) } \\
\hline - $\mathrm{CC} 1$ & 0,82 & $<0.001$ \\
\hline - $\quad \mathrm{CC} 2$ & 0,93 & $<0.001$ \\
\hline - $\quad \mathrm{CC} 3$ & 0,76 & $<0.001$ \\
\hline \multicolumn{3}{|l|}{ Satisfacão do Usuário (US) } \\
\hline - US1 & 0,77 & $<0.001$ \\
\hline - US2 & 0,78 & $<0.001$ \\
\hline - US3 & 0,82 & $<0.001$ \\
\hline \multicolumn{3}{|l|}{ Emoção Positiva (POE) } \\
\hline - $\quad$ POE1 & 0,69 & $<0.001$ \\
\hline - $\quad$ POE2 & 0,83 & $<0.001$ \\
\hline - $\quad$ POE5 & 0,81 & $<0.001$ \\
\hline - $\quad$ POE7 & 0,62 & $<0.001$ \\
\hline - $\quad$ POE8 & 0,90 & $<0.001$ \\
\hline \multicolumn{3}{|l|}{ Intenção de Compras (PI) } \\
\hline - $\quad$ PI1 & 0,86 & $<0.001$ \\
\hline - $\quad$ PI2 & 0,81 & $<0.001$ \\
\hline - $\mathrm{PI} 3$ & 0,69 & $<0.001$ \\
\hline
\end{tabular}

Pela análise feita com auxílio da tabela 4.5, verificou-se que as cargas fatoriais dos indicadores são significativas e indicam a direção esperada. Pela magnitude das cargas estimadas, foi observado que a grande maioria é acima de 0,70, conforme sugestão dada por Garver e Mentzer (1999). Contudo, cinco variáveis apresentam valores menores que 0,70 , porém maiores que 0,60. Apesar disto, uma vez que todas as cargas estimadas são significativas e apresentam 
magnitude boa ou razoável, foram consideradas a unidimensionalidade e a validade convergente dos construtos verificadas.

No que diz respeito à validade discriminante, as variáveis observáveis (itens da escala) devem se relacionar mais fortemente com os construtos a que se referem do que com os demais construtos do modelo. A variância compartilhada entre os itens de cada construto deve ser maior do que a variância compartilhada entre este construto e os demais construtos. Fornell e Larcker (1981) sugerem a comparação entre a variância extraída média (AVE) de cada construto e a variância compartilhada (o quadrado do coeficiente de correlação) de todos os pares de construtos. A validade discriminante ocorre quando todos os construtos apresentam variâncias extraídas maiores do que as respectivas variâncias compartilhadas.

O quadro 4.2 contém uma matriz para a análise da validade discriminante, com a diagonal principal contendo a AVE para cada construto e as demais células apresentando o quadrado dos coeficientes de correlação entre cada par de construtos.

Quadro 4.2 - Matriz de Validade Discriminante

\begin{tabular}{|l|c|c|c|c|c|}
\cline { 2 - 6 } \multicolumn{1}{c|}{} & $\begin{array}{l}\text { Experiência de } \\
\text { Realidade } \\
\text { Aumentada }\end{array}$ & $\begin{array}{l}\text { Certeza } \\
\text { na } \\
\text { Escolha }\end{array}$ & $\begin{array}{l}\text { Emoçã } \\
\text { o } \\
\text { Positiva }\end{array}$ & $\begin{array}{l}\text { Satisfação } \\
\text { do Usuário }\end{array}$ & $\begin{array}{l}\text { Intenç } \\
\text { ão de } \\
\text { Compr } \\
\text { a }\end{array}$ \\
\hline $\begin{array}{l}\text { Experiência de Realidade } \\
\text { Aumentada - EXP_RA }\end{array}$ & 0,61 & 0,69 & 0,58 & 0,91 & 0,57 \\
\hline Certeza na Escolha - CC & 0,69 & 0,73 & 0,43 & 0,65 & 0,72 \\
\hline Emoção Positiva - POE & 0,58 & 0,43 & 0,60 & 0,53 & 0,43 \\
\hline Satisfação do Usuário - US & 0,91 & 0,65 & 0,53 & 0,66 & 0,57 \\
\hline Intenção de Compra - PI & 0,57 & 0,72 & 0,43 & 0,57 & 0,62 \\
\hline
\end{tabular}

Pela análise do quadro 4.2, observa-se que a maioria das variâncias compartilhadas é inferior à variância extraída pelos itens que medem os construtos, exceto para os pares a seguir: (Experiência de Realidade Aumentada, Certeza na Escolha), (Experiência de Realidade Aumentada, Satisfação do Usuário), (Satisfação do Usuário, Experiência de Realidade Aumentada) e (Intenção de Compra, Certeza na Escolha). Por este método, a validade discriminante do modelo 
não seria obtida. Uma outra forma de verificar a validade discriminante foi proposta por Brambilla (2011). Ele sugere que os valores de variâncias compartilhadas maiores do que os de AVE sejam calculados pelo teste de Bagozzi e Phillips (1982).

Em Bagozzi e Phillips (1982), os pares de construtos que não obtiveram validade discriminante pelo critério de Fornell e Larcker (1981) devem ser testados comparando o modelo livre com parâmetros não fixados com um modelo fixo com o caminho entre os construtos fixado em 1. Este método também é sugerido por Anderson e Gerbing (1988). A tabela 4.6 apresenta o comparativo entre modelo livre e o modelo fixo.

Tabela 4.6 - Comparativo entre Modelo Livre e Modelo Fixo

\begin{tabular}{|l|l|l|l|l|}
\hline Pares & $\begin{array}{l}\boldsymbol{\chi 2} \text { - Modelo } \\
\text { Livre }\end{array}$ & $\begin{array}{l}\boldsymbol{\chi} \mathbf{2} \text { - Modelo } \\
\text { Fixo }\end{array}$ & Diferença & $\boldsymbol{p}$-value \\
\hline $\begin{array}{l}\text { Experiência de Realidade } \\
\text { Aumentada } \leftrightarrow \text { Certeza na Escolha } \\
\text { (EXP_RA } \leftrightarrow \text { CC) }\end{array}$ & 729,320 & 815,597 & 86,277 & $<0.001$ \\
\hline $\begin{array}{l}\text { Experiência de Realidade } \\
\text { Aumentada } \leftrightarrow \text { Satisfação do } \\
\text { Usuário (EXP_RA } \leftrightarrow \text { US) }\end{array}$ & 729,320 & 784,137 & 53,817 & $<0.001$ \\
\hline $\begin{array}{l}\text { Intenção de Compra } \leftrightarrow \text { Certeza na } \\
\text { Escolha (EXP_RA } \leftrightarrow \text { US) }\end{array}$ & 729,320 & 756,424 & 26,843 & $<0.001$ \\
\hline
\end{tabular}

Todos os pares testados por este método apresentaram significância, indicando que a validade discriminante foi atendida no pressuposto de Bagozzi e Phillips (1982). Sendo assim, pela análise dos resultados obtidos na análise fatorial confirmatória (CFA), julga-se que o modelo de mensuração proposto atende os requisitos desejados de confiabilidade, unidimensionalidade, validade de face, validade nomológica, validade convergente e validade discriminante. Após estas validações, pode-se investigar a relação entre os construtos latentes por meio de um modelo estrutural. 


\subsection{3}

\section{Análise do Modelo Estrutural}

A técnica de modelagem de equações estruturais (SEM) foi usada com auxílio do software AMOS (versão 22) para testar o modelo proposto e hipóteses de pesquisa. Em modelagem de equações estruturais (SEM), a verificação das hipóteses formuladas para as relações entre construtos é verificada ou não em função da significância dos coeficientes estimados para estas relações do modelo proposto (BYRNE, 2013).

Por sugestão de Anderson e Gerbing (1988), o modelo proposto foi comparado com os modelos alternativos (ou rivais). Os índices de ajustes dos modelos, proposto e alternativos, foram comparados, permitindo a avaliação das forças e relevâncias de diferentes relações entre os construtos.

O modelo de mensuração final com as modificações feitas serviu de base para o teste do modelo estrutural.

\subsubsection{1 \\ Normalidade dos Dados}

Para a elaboração de modelos de equações estruturais por meio de estimação por Máxima Verossimilhança (ML) há uma premissa importante de que os dados apresentem uma distribuição multivariada normal. Olsson et al. (2000) afirmam que estimações via ML são robustas contra violações da premissa de normalidade, sendo até mais precisas e estáveis do que outras técnicas de estimação que não possuem essa premissa.

Mesmo assim, antes da análise dos resultados, foi verificada se a condição de normalidade multivariada foi satisfeita. O principal problema para SEM é a curtose multivariada dos dados, que existe quando a distribuição multivariada das variáveis observadas possui tanto caudas quanto picos que diferem das características de uma distribuição normal multivariada (RAYKOV; MARCOULIDES, 2000). A tabela 4.6 apresenta os valores da curtose para cada item. Analisando os resultados para a avaliação de normalidade disponibilizados pelo AMOS 22, observa-se que os valores da curtose univariada na maioria dos 
itens usados no modelo foram inferiores a 3,7, porém 5 itens apresentam valores acima de 7,0. Bryne (2010) sugere que somente valores de curtose maiores que 7,0 são preocupantes. Por outro lado, a curtose multivariada apresentada pelos dados foi de 383,085, com razão crítica (critical ratio - C. R.) de 60,03. O valor do C. R. representa a estimativa normalizada de Mardia (1970) para a curtose multivariada e, na prática, deve ser menor do que 5,0 para indicar normalidade multivariada (BYRNE, 2010). Sendo assim, o valor de 60,03 observado indica fortemente que os dados da pesquisa não apresentam normalidade multivariada. Apesar desse resultado, foi utilizada a estimação via ML, baseado nos resultados de Roy et al. (2017), Javornik (2016a), Poushneh e Vasquez-Parraga (2017) e na impossibilidade do uso de outros métodos de estimação devido ao tamanho da amostra. A tabela 4.7 apresenta a curtose dos itens medidos dos construtos.

Tabela 4.7: Curtose dos Itens

\begin{tabular}{c|c}
\hline Item & Curtose \\
\hline PI1 & 3,108 \\
\hline PI2 & 1,683 \\
\hline PI3 & 0,16 \\
\hline POE1 & 2,293 \\
\hline POE2 & 3,006 \\
\hline POE5 & 1,977 \\
\hline POE7 & $-0,21$ \\
\hline POE8 & 1,532 \\
\hline P1 & 2,232 \\
\hline P2 & $-0,287$ \\
\hline P3 & 0,602 \\
\hline P4 & $-0,131$ \\
\hline PA2 & 0,253 \\
\hline PA3 & 2,695 \\
\hline PA5 & 3,632 \\
\hline US1 & 7,406 \\
\hline &
\end{tabular}

\begin{tabular}{c|c}
\hline Item & Curtose \\
\hline US2 & 7,406 \\
\hline US3 & 3,965 \\
\hline CC1 & 2,11 \\
\hline CC2 & 4,441 \\
\hline CC3 & 3,778 \\
\hline RA1 & 3,09 \\
\hline RA2 & 6,949 \\
\hline RA3 & 8,823 \\
\hline RA4 & 2,246 \\
\hline PE1 & 11,997 \\
\hline PE2 & 7,965 \\
\hline PE3 & 20,09 \\
\hline PC1 & 1,946 \\
\hline PC2 & 2,106 \\
\hline PC3 & \\
\hline Multivariate & 383,085 \\
\hline
\end{tabular}

\subsubsection{2}

\section{Ajuste do Modelo Proposto - Modelo \#1}

O ajuste do modelo proposto foi examinado com o uso de vários índices de ajuste (GARVER; MENTZER, 1999; HAIR et al., 2009). A figura 4.1 apresenta o modelo proposto (modelo \#1). 


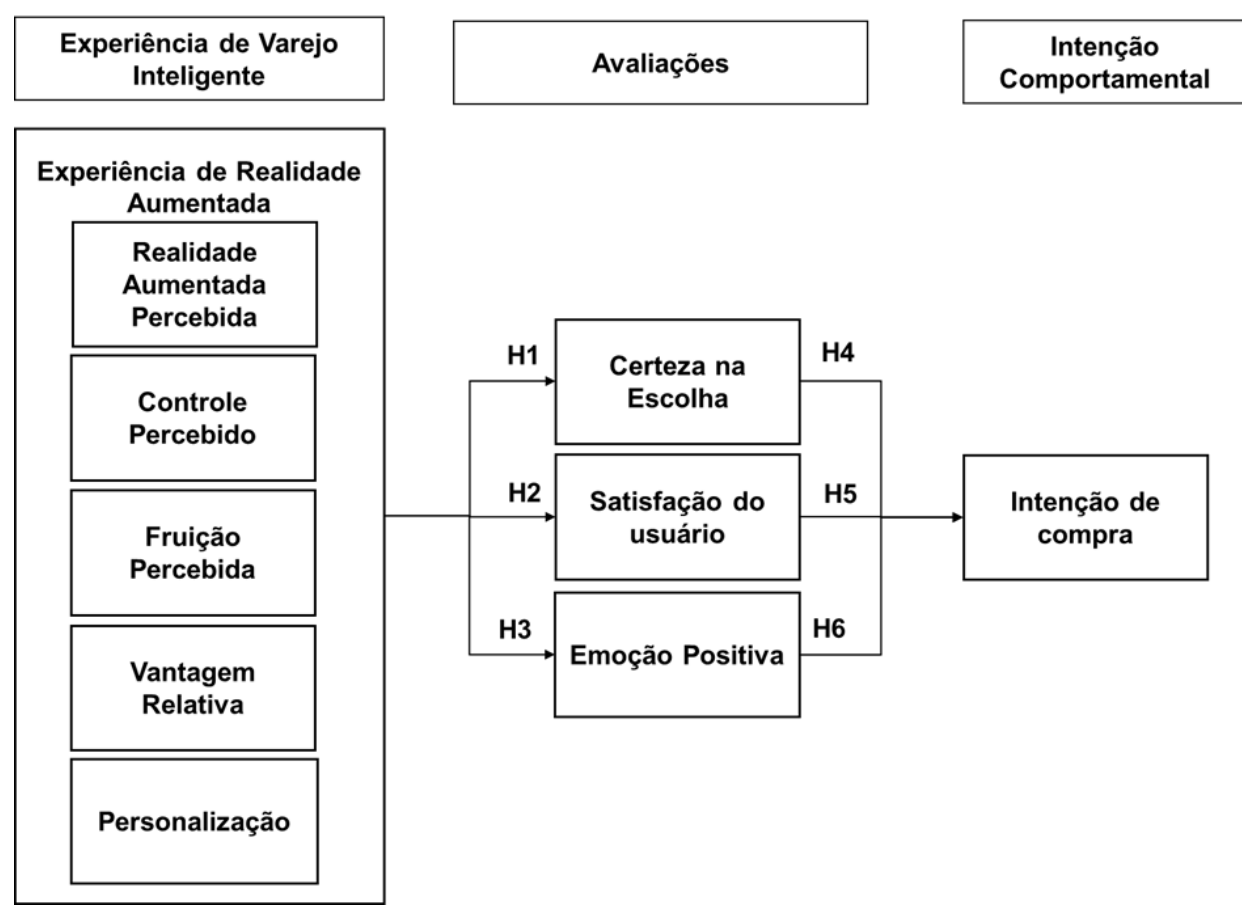

Figura 4.1 - Modelo Proposto do ARORM (Modelo \#1)

A estatística qui-quadrado obtida para o modelo foi estatisticamente significativa $(\chi 2=$

742,008, d.f. $=421, p$-value $<0,001)$. Este índice deve ser interpretado com cautela, pois é sensível ao tamanho da amostra e a violações da premissa de normalidade (BENTLER, 1990). Todos os outros índices indicaram um bom ajuste do modelo aos dados. A razão $\chi 2 /$ d.f. foi de 1,762, abaixo do valor de 3,0 sugerido por Byrne (2013). Os índices de ajuste incrementais foram acima de 0,90, com um CFI (comparative fit index) de 0,92 um TLI (Tucker-Lewis index) de 0,91 e um IFI (incremental fit index) de 0,92. Em relação aos índices de ajuste absoluto, estes apresentaram valores inferior ao limite de 0,08 estabelecido pela literatura (HU; BENTLER, 1999; BYRNE, 2013; HAIR et al., 2010), indicando também um bom ajuste do modelo. O RMSEA (Root-Mean-Square Error of Approximation) foi de 0,062 (C. I. de 0,054 a 0,069) e o SRMR (standardized root meansquare residual) foi de 0,063 . Estes resultados estão apresentados na tabela 4.8. Os valores de todos estes índices indicam que o ajuste do modelo proposto é satisfatório. 
Tabela 4.8 - Avaliação dos Índices de Ajustes do Modelo Estrutural Proposto (Modelo \#1)

\begin{tabular}{c|c|c}
\hline $\begin{array}{c}\text { Índice de } \\
\text { ajuste }\end{array}$ & $\begin{array}{c}\text { Valores sugeridos na } \\
\text { literatura }\end{array}$ & $\begin{array}{c}\text { Modelo \#1 (com os mediadores US/CC/POE } \\
\text { entre EXP_RA e IP) }\end{array}$ \\
\hline $\boldsymbol{\chi 2}$ & & 742,008 \\
\hline $\boldsymbol{2}$ /d.f. & $\leq 3$ & 1,762 \\
\hline CFI & $\geq 0,9$ & 0,92 \\
\hline TLI & $\geq 0,9$ & 0,91 \\
\hline IFI & $\geq 0,9$ & 0,92 \\
\hline RMSEA & $\leq 0,08$ & 0,062 \\
\hline SRMR & $\leq 0,08$ & 0,063 \\
\hline
\end{tabular}

Os coeficientes estimados para as relações causais entre os construtos foram avaliados logo após a verificação dos ajustes dos modelos de mensuração e estrutural propostos (Figura 4.1). O exame de cada uma das hipóteses da pesquisa foi feito com a análise da magnitude, direção e significância dos coeficientes padronizados estimados do modelo estrutural (BYRNE, 2013; KULVIWAT et al., 2007). A relação foi considerada significativa quando o p-value para o teste $t$ associado ao coeficiente estimado foi abaixo de um nível de significância de 0,05 (BYRNE, 2013; HAIR et al., 2010). Os coeficientes estimados para o modelo proposto, assim como, as hipóteses de pesquisa e suas significâncias estão apresentados na tabela 4.9 e ilustrados na figura 4.2.

Tabela 4.9- Coeficientes Padronizados Estimados, Hipóteses e Significâncias para o Modelo Estrutural Proposto (Modelo \#1)

\begin{tabular}{l|c|c|c}
\hline Relação Proposta & $\begin{array}{l}\text { Coeficiente } \\
\text { Padronizado }\end{array}$ & P-Value & $\begin{array}{l}\text { Hipótese } \\
\text { Verificada }\end{array}$ \\
\hline $\begin{array}{l}\text { H1: Experiência de Realidade Aumentada } \rightarrow \\
\text { Certeza na Escolha }\end{array}$ & 0,85 & $<0,001$ & Sim \\
\hline $\begin{array}{l}\text { H2: Experiência de Realidade Aumentada } \rightarrow \\
\text { Satisfação do Usuário }\end{array}$ & 0,95 & $<0,001$ & Sim \\
\hline $\begin{array}{l}\text { H3: Experiência de Realidade Aumentada } \rightarrow \\
\text { Emoção Positiva }\end{array}$ & 0,76 & $<0,001$ & Sim \\
\hline H4: Certeza na Escolha $\rightarrow$ Intenção de Compra & 0,67 & $<0,001$ & Sim \\
\hline H5: Satisfação do Usuário $\rightarrow$ Intenção de Compra & 0,11 & 0,394 & Não \\
\hline H6: Emoção Positiva $\rightarrow$ Intenção de Compra & 0,15 & 0,078 & Não \\
\hline
\end{tabular}

Pelos resultados apresentados na tabela 4.9 e na figura 4.2, verifica-se pela significância das relações entre os construtos, que das 6 hipóteses formuladas, 4 delas foram significativas, com nível abaixo de 0,001, obtendo assim, o suporte empírico. A relação entre Satisfação do Usuário e Intenção de compra (H5 - 
Hipótese 5) e relações entre Emoção Positiva e Intenção de Compra (H6 - Hipótese 6) não foram significantes.

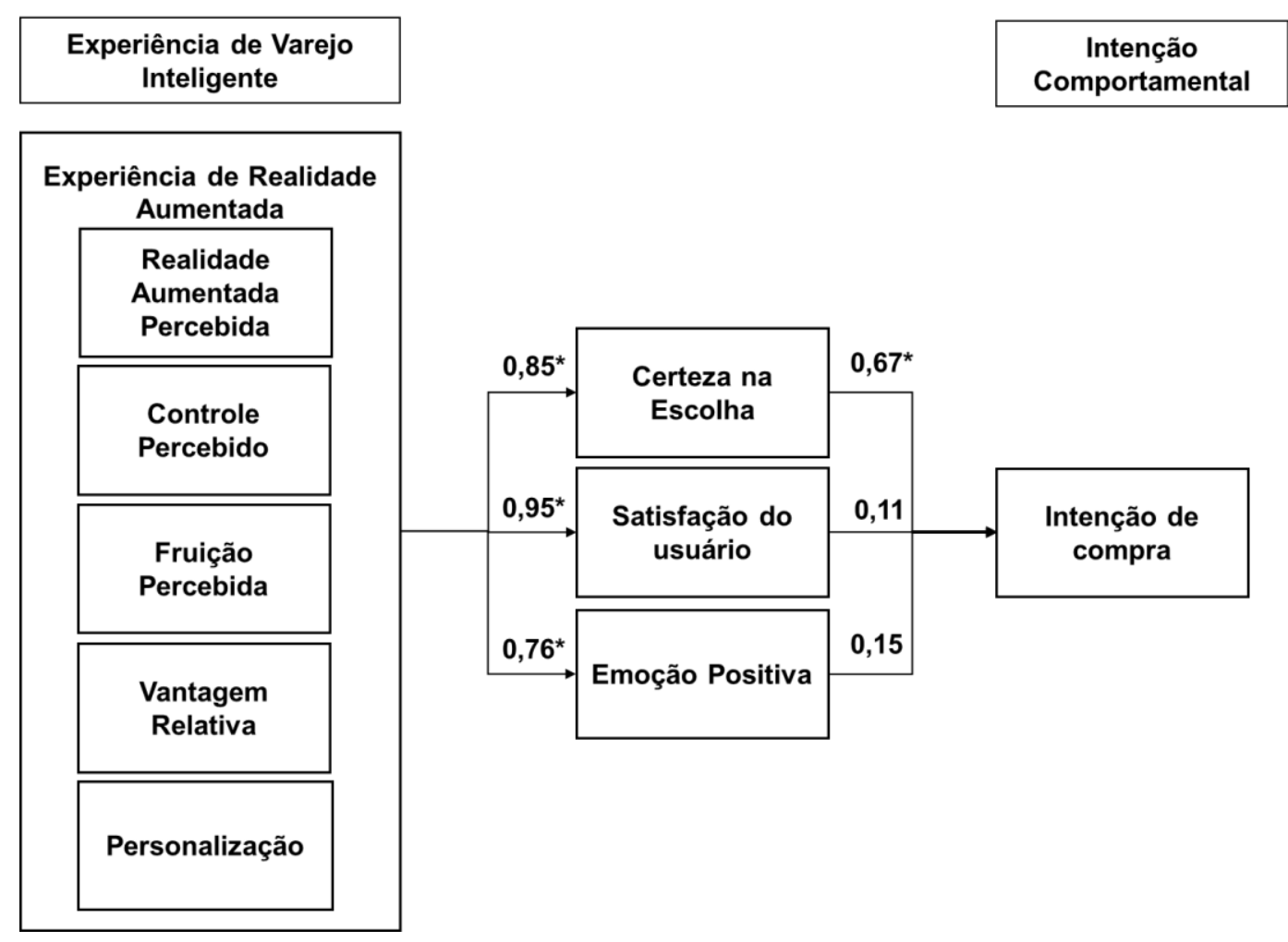

Figura 4.2 - Coeficientes Padronizados Estimados para o ARORM (Modelo \#1)

$(*$ indica p-value $<0,001)$

As hipóteses H1 até H3 representam os efeitos da Experiência de Realidade Aumentada nos construtos Certeza na Escolha, Satisfação do Usuário e Emoção Positiva, refletindo as avaliações dos consumidores nas experiências de Realidade Aumentada em compra online de produtos. Os efeitos em todas estas hipóteses foram significativos com $p$-value $<0,001$. Sendo assim, foi verificado que a Experiência de Realidade Aumentada tem efeito direto e positivo (todas apresentam coeficientes com sinal positivo) sobre a Certeza na Escolha, Satisfação do Usuário e Emoção Positiva pelo consumidor durante a compra no varejo online via dispositivo móvel. Estes resultados estão de acordo com os estudos de Yim, Chu e Sauer (2017), Roy et al. (2017) e Hilken et al. (2017). 
No que diz respeito às hipóteses H4 até H6 que representam os efeitos da Certeza na Escolha, Satisfação do Usuário e Emoção Positiva sobre a Intenção de Compra online de produtos pelo consumidor, apenas $\mathrm{H} 4$ avaliada pela relação entre Certeza na Escolha e Intenção de Compra apresentou significância, com p-value < 0,001, indicando que a Certeza na Escolha apresentou efeito direto e positivo sobre a Intenção de Compra. Estes resultados estão de acordo com as evidências apontadas nos estudos de Beck e Crié (2016), Javornik (2016a) e Poushneh (2018). Isto fortalece a noção de que a Certeza na Escolha influencia a Intenção de Compra. Em contrapartida, era esperado que a Satisfação do Usuário e a Emoção Positiva afetassem a Intenção de Compra, porém as respectivas relações não foram significantes. Sendo assim, o modelo proposto mostrou que a Experiência de Realidade Aumentada afetou a Certeza de Escolha, Satisfação de Usuário e Emoção Positiva e que a Certeza na Escolha, uma avaliação do aspecto utilitário, influenciou a Intenção de Compra. Pela magnitude dos coeficientes estimados, nota-se que os efeitos entre a Experiência de Realidade Aumentada e a Certeza de escolha, Satisfação de Usuário e Emoção Positiva são muito fortes. O efeito da Experiência de Realidade Aumentada sobre a Satisfação do Usuário apresentou coeficiente padronizado de 0,95 , sendo este coeficiente mais pronunciado do que os obtidos nos efeitos sobre a Certeza da Escolha e a Emoção Positiva (coeficientes padronizados de 0,85 e 0,76 respectivamente).

No que diz respeito às magnitudes dos coeficientes estimados das relações Certeza na Escolha, Emoção Positiva e Satisfação do Usuário com a Intenção de Compra, apenas a Certeza na Escolha teve efeito na Intenção de Compra (coeficiente padronizado de 0,67). A relação entre Satisfação do Usuário e a Intenção de Compra (H5) apresentou coeficiente padronizado de 0,11 ( $p$-value = 0,394). Já a relação entre Emoção Positiva e a Intenção de Compra (H6) apresentou coeficiente padronizado de 0,15 ( $p$-value $=0,078)$. Ambas as hipóteses (H5 e H6) não foram confirmadas no modelo estrutural principal proposto. Estes resultados diferiram de estudos anteriores (ROY et al., 2017, YU, 2009; ZHOU; DAI; ZHANG, 2007). Como o construto mediador Certeza na Escolha se revelou nesta pesquisa como um preditor forte para a Intenção de Compra e este construto não foi considerado nos estudos que apresentaram resultados diferentes (ROY et al., 2017, YU, 2009; ZHOU; DAI; ZHANG, 2007), isto pode indicar o motivo das 
divergências. Um outro ponto a considerar sobre H5 e H6 não terem sido confirmadas, pode estar relacionado a esta Experiência de Realidade Aumentada ter sido feita com um único produto, que poderia não ser de interesse de compra para alguns participantes. Apesar da Experiência de Realidade Aumentada ter efeito direto na Satisfação do Usuário e na Emoção Positiva dos participantes, isto não foi suficiente para que esta Satisfação do Usuário e Emoção Positiva produzissem efeitos diretos na Intenção de Compra.

\subsubsection{3}

\section{Comparação com os Modelos Alternativos}

Segundo Anderson e Gerbing (1988), a comparação do modelo proposto com os modelos alternativos visa examinar a força e a relevância para diferentes relações entre construtos. Do mesmo modo como foi feito para o modelo proposto, foi utilizada a técnica de modelagem de equações estruturais (SEM) com auxílio do software AMOS (versão 22) para realizar os testes dos modelos alternativos propostos (modelos rivais) e das hipóteses de pesquisa. Para isto, foram examinados os índices de ajuste e as relações estimadas entre construtos de dois modelos rivais (modelo \#2 e modelo \#3) e comparados com o modelo estrutural proposto do ARORM (modelo \#1).

\subsubsection{1}

\section{Análise do Modelo Alternativo 1 - Modelo \#2}

O modelo alternativo 1 (modelo \#2) avalia a relevância para o modelo ARORM dos mediadores Certeza na Escolha, Satisfação do Usuário e Emoção Positiva na relação entre a Experiência de Realidade Aumentada e a Intenção de Compra. Com base em estudos que examinaram as relações entre eventos experienciais e intenção de compra mas que não utilizaram construtos mediadores (JAVORNIK, 2016a; POUSHNEH; VASQUEZ-PARRAGA, 2017) foi proposto o modelo alternativo 1 (modelo \#2) que acrescenta uma relação direta entre a Experiência de Realidade Aumentada e a Intenção de Compra. Sendo assim, a 
hipótese 7 (H7) que avalia se a Experiência de Realidade Aumentada tem efeito direto e positivo sobre a Intenção de Compra no varejo online via dispositivo móvel foi incluída no modelo.

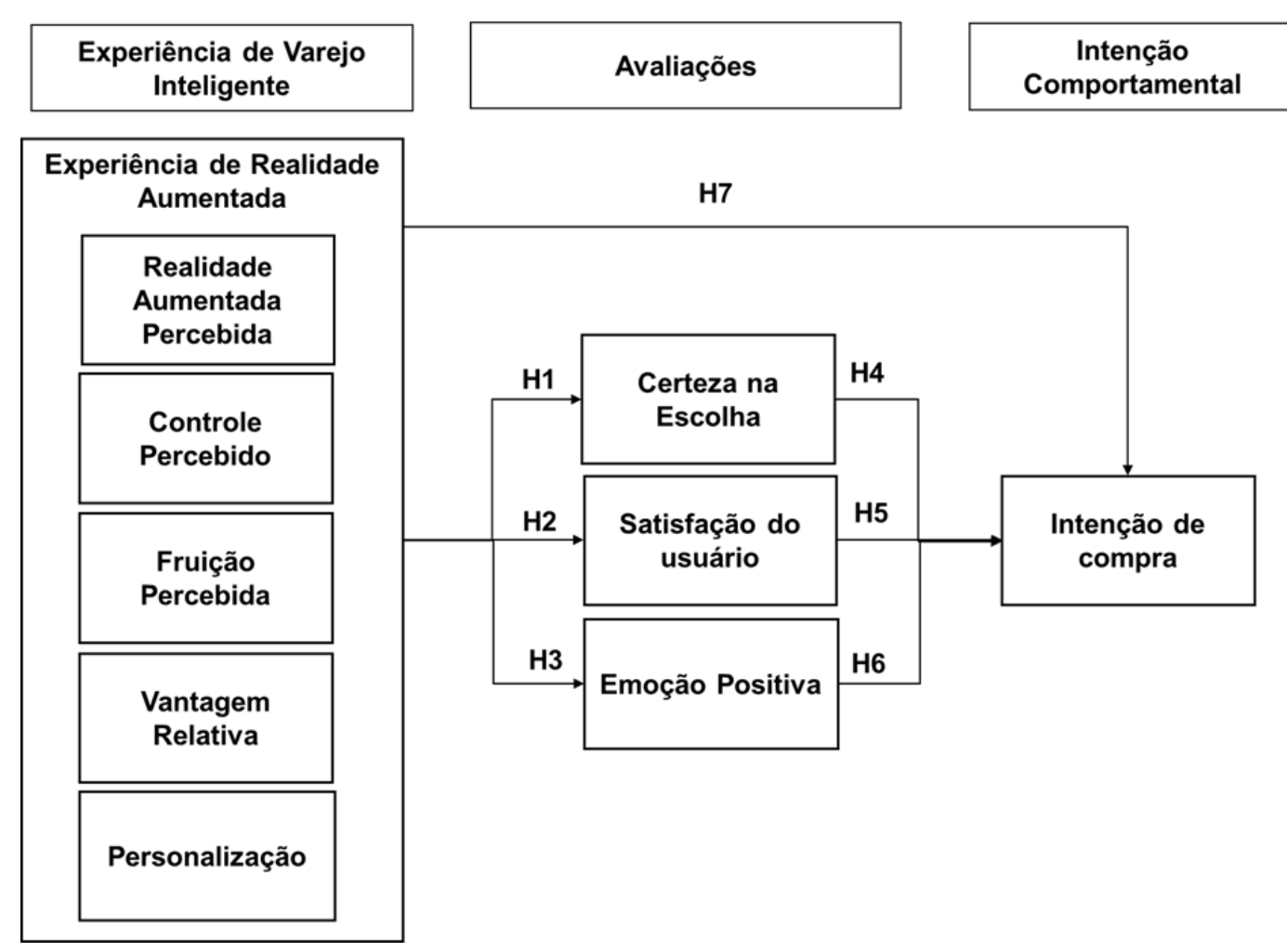

Figura 4.3 - Modelo Alternativo 1 (Modelo \#2)

O modelo \#2 estimado apresentou valor significativo para o índice quiquadrado $(\chi 2=741,682 ;$ d.f. $=420, p$-value $<0,001)$, visto que a razão $\chi 2 /$ d.f. foi de 1,744, inferior ao valor de 3,0 recomendado por Byrne (2013). Os indicadores de ajuste incrementais obtiveram índices satisfatórios, sendo acima de 0,90, com CFI (índice de ajuste comparativo) de 0,92 TLI (índice de Tucker Lewis) de 0,91, e IFI (índice de ajuste incremental) de 0,92. Assim como, os índices de ajuste absoluto também apontaram para um bom fit do modelo com RMSEA (raiz do erro quadrático médio de aproximação) de 0,062 (com intervalo de confiança de 0,055 até 0,069 ) e SRMR (raiz padronizada do resíduo médio) de 0,0631, ambos com valores inferiores à 0,08 estabelecido pela literatura (HU; BENTLER, 1999; BYRNE, 2013; HAIR et al., 2010). Esses resultados indicam ajuste satisfatório geral do modelo \#2 (ver tabela 4.10). 
Tabela 4.10- Avaliação dos Índices de Ajustes do Modelo \#2

\begin{tabular}{c|c|c}
\hline Índice de ajuste & $\begin{array}{c}\text { Valores sugeridos } \\
\text { na literatura }\end{array}$ & Modelo \#2 \\
\hline $\boldsymbol{\chi 2}$ & & 741,682 \\
\hline $\boldsymbol{2} \mathbf{2}$ d.f. & $\leq 3$ & 1,744 \\
\hline CFI & $\geq 0,9$ & 0,92 \\
\hline TLI & $\geq 0,9$ & 0,91 \\
\hline IFI & $\geq 0,9$ & 0,92 \\
\hline RMSEA & $\leq 0,08$ & 0,062 \\
\hline SRMR & $\leq 0,08$ & 0,063 \\
\hline
\end{tabular}

\subsubsection{2}

\section{Análise do Modelo Alternativo 2 - Modelo \#3}

O modelo alternativo 2 (modelo \#3) avalia a relevância de dois mediadores (Certeza na Escolha e Emoção Positiva) na relação entre a Experiência de Realidade Aumentada e a Intenção de Compra no modelo ARORM. Este modelo, mais parcimonioso que o modelo \#1, avaliou tanto um aspecto utilitário como um hedônico. Neste estudo, optou-se por retirar do modelo o construto Satisfação do Usuário e manter os construtos Certeza na Escolha e Emoção Positiva. A escolha dos dois construtos foi baseada em estudos anteriores que apontaram efeitos significativos nas relações destes dois construtos com Experiências de Realidade Aumentada e Intenção de Compra (LEMOINE; NOTEBAERT, 2011; MURRAY; HÄUBL, 2008; SENECAL; NANTEL, 2004). Já a retirada da Satisfação do Usuário foi baseada em que o resultado da satisfação do usuário é obtido pela avaliação detalhada do desempenho da experiência de compra (HOMBURG; KOSCHATE; HOYER, 2006). Como a constatação desta expectativa satisfatória da compra ocorre geralmente numa etapa posterior à Intenção de Compra, optou-se por testar este modelo sem a mediação Satisfação do Usuário. 


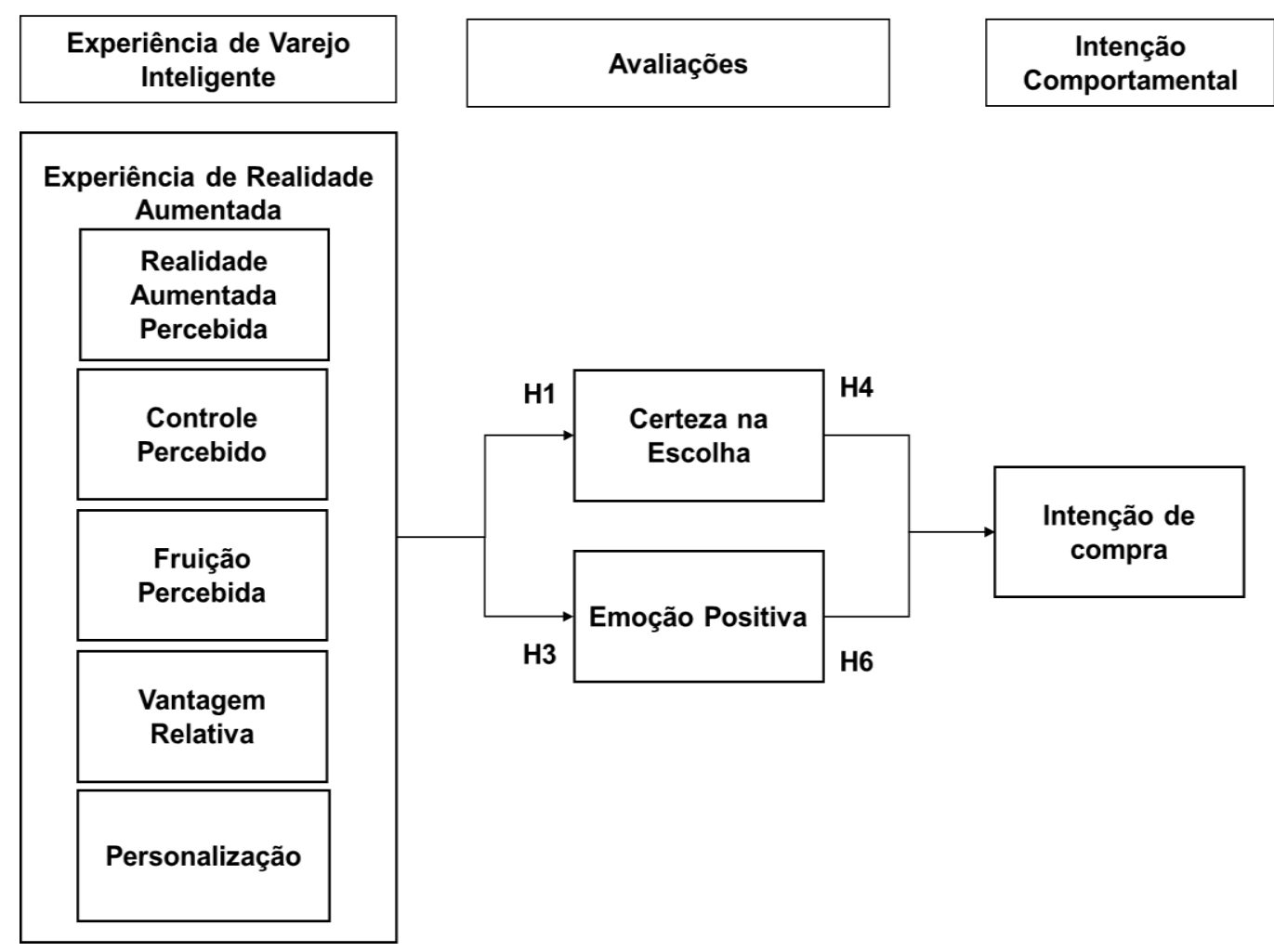

Figura 4.4 - Modelo Alternativo 2 (Modelo \#3)

Em relação à estimação do modelo \#3, este obteve valor significativo para o índice qui-quadrado $(\chi 2=568,388$; d.f. $=340, p$-value $<0,001)$ com razão $\chi 2 /$ d.f. de 1,672, inferior ao valor de 3,0 recomendado por Byrne (2013). Os indicadores de ajuste incrementais apresentaram índices satisfatórios, inferiores à 0,90, com CFI (índice de ajuste comparativo) de 0,93, TLI (índice de Tucker Lewis) de 0,92, e IFI (índice de ajuste incremental) de 0,93. De mesma forma, os índices de ajuste absoluto também apontaram para um bom modelo, com RMSEA (raiz do erro quadrático médio de aproximação) de 0,058 (com intervalo de confiança de 0,050 até 0,066 ) e SRMR (raiz padronizada do resíduo médio) de 0,0631, com valores inferiores à 0,08 (HU; BENTLER, 1999; BYRNE, 2013; HAIR et al., 2010). Esses resultados indicam ajuste satisfatório geral do modelo \#3 (ver tabela 4.11). 
Tabela 4.11 - Avaliação dos Índices de Ajustes do Modelo \#3

\begin{tabular}{c|c|c}
\hline Índice de ajuste & $\begin{array}{c}\text { Valores sugeridos } \\
\text { na literatura }\end{array}$ & Modelo \#3 \\
\hline $\boldsymbol{\chi 2}$ & & 568,388 \\
\hline $\boldsymbol{2} \mathbf{2}$ d.f. & $\leq 3$ & 1,672 \\
\hline CFI & $\geq 0,9$ & 0,93 \\
\hline TLI & $\geq 0,9$ & 0,92 \\
\hline IFI & $\geq 0,9$ & 0,93 \\
\hline RMSEA & $\leq 0,08$ & 0,058 \\
\hline SRMR & $\leq 0,08$ & 0,063 \\
\hline
\end{tabular}

\subsubsection{3}

\section{Comparação dos Modelo \#1, \#2 e \#3}

Para facilitar a comparação dos índices de ajuste dos modelos \#1, \#2 e \#3, a tabela 4.12 reúne os índices dos três modelos testados para modelo ARORM.

Tabela 4.12 - Comparação dos Índices de Ajustes dos Modelos \#1, \#2 e \#3

\begin{tabular}{|c|c|c|c|c|}
\hline $\begin{array}{c}\text { Índice de } \\
\text { Ajuste }\end{array}$ & $\begin{array}{c}\text { Valores } \\
\text { Sugeridos na } \\
\text { literatura }\end{array}$ & $\begin{array}{c}\text { Modelo \#1 - } \\
\text { com mediadores } \\
\text { Satisfação do } \\
\text { Usuário, Certeza } \\
\text { na Escolha e } \\
\text { Emoção Positiva }\end{array}$ & $\begin{array}{c}\text { Modelo \#2 - } \\
\text { Avaliação da } \\
\text { mediação - } \\
\text { parcial ou total }\end{array}$ & $\begin{array}{c}\text { Modelo \#3 - } \\
\text { com os } \\
\text { mediadores } \\
\text { Certeza na } \\
\text { Escolha e } \\
\text { Emoção Positiva }\end{array}$ \\
\hline $\boldsymbol{\chi 2}$ & $\leq 3$ & 742,008 & 741,682 & 568,388 \\
\hline $\boldsymbol{\chi 2}$ /d.f. & $\geq 0,9$ & 0,962 & 1,744 & 1,672 \\
\hline CFI & $\geq 0,9$ & 0,91 & 0,92 & 0,93 \\
\hline TLI & $\geq 0,9$ & 0,92 & 0,91 & 0,92 \\
\hline IFI & $\leq 0,08$ & 0,062 & 0,92 & 0,93 \\
\hline RMSEA & $\leq 0,08$ & 0,063 & 0,063 & 0,058 \\
\hline SRMR & & \multicolumn{2}{|c|}{} \\
\hline
\end{tabular}

Todos os modelos alternativos para ARORM apresentaram índices de ajustes satisfatórios. O modelo \#3 apresentou índices de ajustes melhores do que os demais modelos, principalmente quando comparado com o modelo \#1. O teste quiquadrado para diferença de ajuste entre o modelo \#1 e o modelo \#2 não foi significativo para $\left(\Delta \chi^{2}=0,32, p\right.$-value $\left.=0,57\right)$, indicando que este dois modelos são similares. Já em relação a comparação entre o modelo \#1 e o modelo \#3, a diferença de ajuste apresentou significância $(\Delta \chi 2=173,62, p$-value $<0,001)$, indicando que o modelo \#3 apresenta de fato melhorias em relação ao Modelo \#1. Estes resultados confirmam que o modelo \#3, mais parcimonioso e com menos 
construtos mediadores, apresenta efeitos significativos nas relações envolvendo a Intenção de Compra online com o uso da tecnologia de RA. Desta forma, o modelo \#3 foi selecionado como o modelo final ARORM.

Na tabela 4.13, são comparados os coeficientes do modelo \#1, modelo \#2 e modelo \#3. A relação entre a Experiência de Realidade Aumentada e a Certeza na Escolha foi significativa nos três modelos ( $p$-value $<0,001)$, indicando que houve efeito direto e positivo entre a Experiência de Realidade Aumentada e a Certeza na Escolha. Do mesmo modo, a relação entre a Experiência de Realidade Aumentada e a Emoção Positiva foi significativa ( $p$-value < 0,001) com efeito direto e positivo para todos os modelos. A relação entre a Experiência de Realidade Aumentada e a Satisfação do Usuário encontrada nos modelos \#1 e \#2 foi significativa ( $p$-value < 0,001), indicando efeito direto e positivo. No entanto, a relação entre Satisfação do Usuário e Intenção de Compra não foi significativa nos modelos \#1 e \#2. Vale relembrar que o modelo \#3 não possui o mediador Satisfação do Usuário. A relação entre Experiência de Realidade Aumentada e Intenção de Compra encontrada somente no modelo \#2 não foi significativa, apontando que não houve efeito direto e positivo entre os dois construtos. Além disto, como o efeito indireto, utilizando o mediador Certeza na Escolha entre estes dois construtos, foi significante, isto pode indicar que a mediação parcial não foi encontrada. É importante destacar que a relação entre Emoção Positiva e a Intenção de Compra só foi considerada significativa no modelo \#3 ( $p$-value $<0,05)$. 
Tabela 4.13 - Coeficientes Padronizados Estimados e Significâncias para os Modelos \#1, \#2 e \#3

\begin{tabular}{|c|c|c|c|c|c|c|c|c|c|}
\hline $\begin{array}{l}\text { Relações } \\
\text { Propostas }\end{array}$ & Mod. \#1 & $\begin{array}{l}\text { P- } \\
\text { Value }\end{array}$ & Verif & $\begin{array}{l}\text { Mod. } \\
\# 2\end{array}$ & $\begin{array}{l}\text { P- } \\
\text { Value }\end{array}$ & Verif & $\begin{array}{l}\text { Mod } \\
\# 3\end{array}$ & $\begin{array}{l}\text { P- } \\
\text { Value }\end{array}$ & Verif \\
\hline $\begin{array}{l}\text { H1: Experiência } \\
\text { de Realidade } \\
\text { Aumentada } \rightarrow \\
\text { Certeza na } \\
\text { Escolha }\end{array}$ & 0,85 & $\begin{array}{l}< \\
0,001\end{array}$ & Sim & 0,85 & $\begin{array}{l}< \\
0,001\end{array}$ & Sim & 0,85 & $\begin{array}{l}< \\
0,001\end{array}$ & Sim \\
\hline $\begin{array}{l}\text { H2: Experiência } \\
\text { de Realidade } \\
\text { Aumentada } \rightarrow \\
\text { Satisfação do } \\
\text { Usuário }\end{array}$ & 0,95 & $\begin{array}{l}< \\
0,001\end{array}$ & Sim & 0,95 & $\begin{array}{l}< \\
0,001\end{array}$ & Sim & $\begin{array}{l}\text { n.a. } \\
(*)\end{array}$ & & \\
\hline $\begin{array}{l}\text { H3: Experiência } \\
\text { de Realidade } \\
\text { Aumentada } \rightarrow \\
\text { Emoção } \\
\text { Positiva }\end{array}$ & 0,76 & $\begin{array}{l}< \\
0,001\end{array}$ & Sim & 0,76 & $\begin{array}{l}< \\
0,001\end{array}$ & Sim & 0,76 & $\begin{array}{l}< \\
0,001\end{array}$ & Sim \\
\hline $\begin{array}{l}\text { H4: Certeza na } \\
\text { Escolha } \rightarrow \\
\text { Intenção de } \\
\text { Compra }\end{array}$ & 0,67 & $\begin{array}{l}< \\
0,001\end{array}$ & Sim & 0,71 & $\begin{array}{l}< \\
0,001\end{array}$ & Sim & 0,72 & $\begin{array}{l}< \\
0,001\end{array}$ & Sim \\
\hline $\begin{array}{l}\text { H5: Satisfação } \\
\text { do Usuário } \rightarrow \\
\text { Intenção de } \\
\text { Compra }\end{array}$ & 0,11 & 0,394 & Não & 0,30 & 0,416 & Não & $\begin{array}{l}\text { n.a.( } \\
*)\end{array}$ & & \\
\hline $\begin{array}{l}\text { H6: Emoção } \\
\text { Positiva } \rightarrow \\
\text { Intenção de } \\
\text { Compra }\end{array}$ & 0,15 & 0,078 & Não & 0,17 & 0,069 & Não & 0,19 & $\begin{array}{l}0,009 \\
< \\
0,005\end{array}$ & Sim \\
\hline $\begin{array}{l}\text { H7:Experiência } \\
\text { de Realidade } \\
\text { Aumentada } \rightarrow \\
\text { Intenção de } \\
\text { Compra }\end{array}$ & n.a. $(*)$ & & & $-0,25$ & 0,573 & Não & $\begin{array}{l}\text { n.a. } \\
(*)\end{array}$ & & \\
\hline
\end{tabular}

(*) n.a. - não se aplica

Nota-se que as magnitudes dos coeficientes padronizados em todos os modelos apresentaram variações pequenas para as mesmas relações. A magnitude dos coeficientes padronizados das relações com a Experiência de Realidade Aumentada e a Certeza na Escolha foram iguais nos 3 modelos $(0,85)$. Da mesma forma, a relação entre a Experiência de Realidade Aumentada e a Emoção Positiva apresenta valores iguais em todos os modelos $(0,76)$. 


\section{3 \\ Discussão dos Resultados}

O modelo investigou os efeitos afetivos e cognitivos observados na Experiência de Realidade Aumentada, tanto relacionados à aceitação da tecnologia, quanto ligados ao seu uso no marketing experiencial do varejo online.

Os resultados da pesquisa evidenciam que o modelo proposto apresenta índices de ajuste satisfatórios, indicando um modelo adequado. Os resultados também sugerem a influência das relações propostas entre Experiência de Realidade Aumentada e os construtos cognitivo (Certeza na Escolha) e afetivo (Emoção Positiva) e por sua vez, a influência das relações destes construtos com a intenção de compra. A figura 4.5 apresenta o modelo ARORM proposto em sua versão final (modelo \#3).

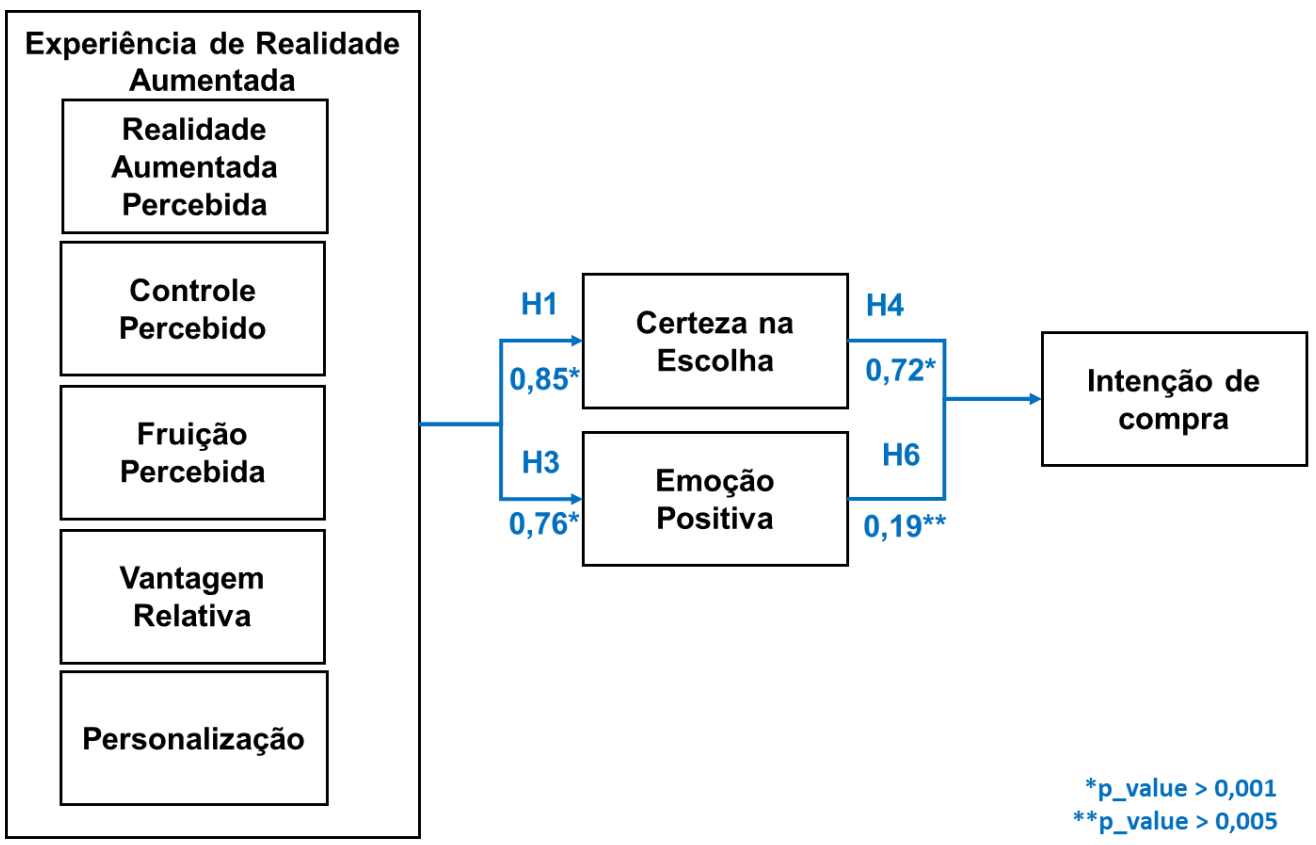

Figura 4.5 - Modelo ARORM Final

No que diz respeito às hipóteses avaliadas, 5 das 7 hipóteses formuladas inicialmente para os modelos testados foram verificadas. A tabela 4.14, a seguir, apresenta os resultados das verificações destas hipóteses examinadas. A H6 foi a única hipótese que não apresentou o mesmo resultado em todos modelos, sendo 
somente confirmada no modelo \#3. Na seção 4.3.5, que avalia a influência da emoção positiva sobre a intenção de compra serão apresentadas as análises sobre os resultados da $\mathrm{H} 6$.

Tabela 4.14 -Resumo dos Resultados dos Testes de Hipóteses

\begin{tabular}{ll}
\hline Hipótese de Pesquisa & Hipótese Verificada \\
\hline Hipóteses Relacionadas com a Experiência de Realidade & \\
Aumentada e as Avaliações & \\
\hline H1: A Experiência de Realidade Aumentada tem efeito direto e positivo & \\
sobre a certeza na escolha percebida pelo consumidor durante a & Sim \\
compra no varejo online via dispositivo móvel. & \\
- Todos os modelos & \\
\hline
\end{tabular}

H2: A Experiência de Realidade Aumentada tem efeito direto e positivo sobre a satisfação do usuário.

- Todos os modelos Sim

H3: A Experiência de Realidade Aumentada tem efeito direto e positivo sobre a emoção positiva percebidas pelo consumidor para a compra no varejo online via dispositivo móvel.

Sim

- Todos os modelos

\begin{tabular}{ll}
\hline Hipóteses Relacionadas com as Avaliações e Intenção de Compras & \\
\hline $\begin{array}{l}\text { H4: A certeza na escolha percebida tem efeito direto e positivo sobre a } \\
\text { intenção de compra no varejo online via dispositivo móvel. } \\
\text { • Todos os modelos }\end{array}$ & Sim \\
\hline $\begin{array}{l}\text { H5: A satisfação tem efeito direto e positivo sobre a intenção de compra } \\
\text { pelo consumidor no varejo online via dispositivo móvel } \\
\text { • Todos os modelos }\end{array}$ & Não \\
\hline $\begin{array}{l}\text { H6: A emoção positiva tem efeito direto e positivo sobre a intenção de } \\
\text { compra no varejo online via dispositivo móvel. }\end{array}$ & Não \\
- Modelos \#1 e \#2 & Sim \\
- Modelo \#3 & \\
\hline $\begin{array}{l}\text { Hipóteses relacionada com a Experiência de Realidade Aumentada } \\
\text { e a Intenção de Compra }\end{array}$ & \\
\hline $\begin{array}{l}\text { H7: A Experiência de Realidade Aumentada tem efeito direto e positivo } \\
\text { sobre a intenção de compra no varejo online via dispositivo móvel. } \\
\text { - Modelo \#2 }\end{array}$ & $\mathbf{N a ̃ o}$ \\
\end{tabular}

\subsection{1}

\section{Influência da Experiência de Realidade Aumentada nos Construtos Mediadores}

Os dados obtidos indicam que a Experiência de Realidade Aumentada é um importante antecedente das avaliações cognitivas e afetivas dos usuários durante 
uma experiência de compra. Isto foi evidenciado pelos resultados das relações entre a Experiência de Realidade Aumentada e os construtos Certeza na Escolha, Emoção Positiva e Satisfação do Usuário. Todas estas relações apresentaram efeitos diretos, positivos e significativos. Vale relembrar que apesar da retirada do construto Satisfação do Usuário do modelo final, a relação da Experiência de Realidade Aumentada com este construto foi significativa. No que concerne às magnitudes desses efeitos, verificou-se que todos apresentaram valor maior do que 0,3 (efeito na Certeza na Escolha de 0,85, na Satisfação do Usuário de 0,95 e na Emoção Positiva de 0,76). Os resultados indicam que após uma Experiência de Realidade Aumentada, o indivíduo está mais apto para avaliar os benefícios e a importância do uso de um produto durante o processo decisório de compra online. Assim sendo, estes indivíduos puderam ter mais certeza na escolha em comprar ou não, além de se sentirem satisfeitos, estimulados, animados, ativos e entusiasmados por vivenciarem a experiência. $\mathrm{O}$ efeito mais forte foi observado na relação com a Satisfação do Usuário. Este efeito está de acordo com o observado no modelo de varejo inteligente de Roy et al. (2017). Vale relembrar que o construto Experiência do modelo de Roy et al. (2017) difere deste modelo pela substituição da dimensão Interatividade pela Realidade Aumentada Percebida. Esta substituição foi objeto de consideração nas seções 2.4.3.1 Experiência de Realidade Aumentada e 2.4.3.6 Realidade Aumentada do Modelo Proposto. O efeito encontrado neste estudo para a relação entre Experiência de Realidade Aumentada e Emoção Positiva também foi apontado no estudo de Olsson et al. (2013), que indicava que as experiências de Realidade Aumentada via dispositivo móvel (MAR) podem gerar emoções positivas. De acordo com Porter e Heppelmann (2017), a experiência reduz significativamente a incerteza que os indivíduos possam sentir sobre suas escolhas e pode acarretar maior rapidez no ciclo de compras. Esta consideração foi observada no resultado da relação entre Experiência de Realidade Aumentada e Certeza na Escolha. Sendo assim, os resultados obtidos corroboram as hipóteses formuladas em relação à Experiência de Realidade Aumentada.

Desta forma, estes resultados sugerem que o uso de novas tecnologias, como o uso da tecnologia de RA, pode transformar a jornada de compra em experiências mais interessantes e prazerosas para os consumidores, estimulando novas possibilidades de compra online. 


\subsection{2 Influência dos Mediadores}

Todos os modelos, principal e alternativos, avaliaram a influência dos mediadores entre Experiência de Realidade Aumentada e Intenção de Compra. Estes modelos apresentaram índices de ajustes satisfatórios. Segundo Hair et al. (2010), quando um modelo com mediação apresenta um bom resultado, isto sustenta o papel do mediador.

No modelo alternativo \#2 foi acrescentada a relação direta entre Experiência de Realidade Aumentada e Intenção de Compra para testar a hipótese (H7) do efeito direto entre estes dois construtos. Esta hipótese serviu para testar se a mediação é parcial ou total. A mediação total ocorre quando o efeito direto se apresenta não significativo e o efeito indireto se apresenta significativo. Já a mediação parcial ocorre quando o efeito direto é significativo, mesmo que pequeno (HAIR et al., 2010).

Conforme mencionado na seção 4.2 Modelo Proposto, os construtos de avaliação de uma Experiência de Realidade Aumentada foram incluídos como mediadores entre a Experiência de Realidade Aumentada e Intenção de Compra. No modelo final, onde foi retirado o mediador Satisfação do Usuário, os resultados mostraram que a relação entre Experiência de Realidade Aumentada e a Certeza na Escolha, hipótese H1, e a relação entre este construto e a Intenção de Compra, hipótese H4, foram significativas. Assim como, também, foram significativas a relação entre Experiência de Realidade Aumentada e a Emoção Positiva, hipótese H3, e a relação entre este construto e a Intenção de Compra, hipótese H6.

Nos modelos \#1 e \#2, os mediadores Satisfação de Usuário e Emoção Positiva não apresentaram efeitos diretos na Intenção de Compra, hipóteses H5 e H6 respectivamente, apesar de apresentarem significância nas relações com a Experiência de Realidade Aumentada (hipóteses H2 e H3). Pelos resultados dos dados, estes construtos não são antecedentes da Intenção de Compra, porém são consequentes da Experiência de Realidade Aumentada. Isto pode indicar que após a Experiência de Realidade Aumentada, o indivíduo se sente satisfeito, animado e 
entusiasmado, porém estes sentimentos não influenciam a sua intenção de compra. Estes resultados constam na tabela 4.13 que contém os coeficientes padronizados estimados e as suas significâncias.

O resultado do modelo \#2, que avalia se a mediação é total ou parcial, pode indicar que a mediação é total, pois o efeito indireto, testado nas hipóteses H1 e H3, do mediador Certeza na Escolha foi significativo enquanto que o efeito direto, verificado na hipótese H7, entre a Experiência de Realidade Aumentada e a Intenção de Compra não foi significativo. No modelo de varejo inteligente de Roy et al. (2017), os efeitos dos mediadores Satisfação do Usuário e Risco Percebido entre a Experiência de Varejo Inteligente e a Intenção Comportamental de Compra foram significativos. Assim também neste estudo, foram confirmados os efeitos de mediadores entre a Experiência de Realidade Aumentada e a Intenção de compra.

Por outro lado, os resultados do presente estudo contradizem os verificados nos estudos de Javornik (2016a) e Poushneh e Vasquez-Parraga (2017) que não possuíam mediadores entre Experiência e Intenção de Compra. As magnitudes das relações do mediador Certeza na Escolha com Experiência de Realidade Aumentada, hipótese H1, e Intenção de Compra, hipótese H4, apresentaram valores superiores a 0,3 , indicando fortes efeitos. No que diz respeito a magnitude do efeito da Experiência de Realidade Aumentada sobre a Emoção Positiva no modelo final (modelo \#3), a magnitude foi alta (valor superior a 0,3 ). No entanto, o efeito da Emoção Positiva sobre a Intenção de Compra apresentou magnitude significativa, porém fraca (valor inferior à 0,3 ). Isto pode indicar que o aspecto cognitivo da Certeza na Escolha é mais importante na Intenção de Compra do que os aspectos afetivos, ou seja, isto sugere que após uma experiência de simulação virtual de um produto, a certeza na escolha tem predominância sobre as emoções positivas de um indivíduo.

Os resultados significativos dos mediadores podem indicar que após uma Experiência de Realidade Aumentada, os indivíduos tendem a avaliar a experiência - papel da inclusão dos mediadores no modelo - para depois decidir sobre a sua intenção de compra. 


\subsection{3 Influência da Satisfação do Usuário sobre a Intenção de Compra}

Embora estudos de Realidade Aumentada mostrem que quanto maior a satisfação do cliente, maior é sua a intenção de compra (ROY et al., 2017; YU, 2009; ZHOU; DAI; ZHANG, 2007), a influência da Satisfação do Usuário sobre a Intenção de Compra, H5, não foi significativa nos modelos \#1 e \#2 testados neste estudo. Estes modelos contêm três mediadores entre Experiência de Realidade Aumentada e Intenção de Compra: Certeza na Escolha, Emoção Positiva e Satisfação do Usuário. É possível que este resultado tenha diferido dos estudos de Roy et al. (2017), Yu (2009) e Zhou, Dai e Zhang (2007) pela ausência do construto Certeza na Escolha nos modelos anteriores, e pela revelação neste estudo de que a Certeza na Escolha foi um forte preditor da Intenção de Compra. Outra diferença entre o presente estudo e o estudo de Roy et al. (2017), a utilização, por Roy et al. (2017), de várias tecnologias de varejo inteligente testadas em conjunto, como a Radio-Frequency Identification (RFI) usado em etiquetas, tecnologias de autoatendimento e Realidade Aumentada.

Uma das sugestões para estudos futuros dadas por Roy et al. (2017) seria testar o modelo utilizando uma única tecnologia de varejo inteligente. Isto porque em seus achados, a Satisfação do Usuário tende a ser seletiva entre as diversas tecnologias utilizadas nas experiências inteligentes do cliente. $\mathrm{O}$ fato deste resultado da relação entre Satisfação do Usuário e Intenção de Compra ter diferido do estudo presente nos modelos \#1 e \#2 em relação ao estudo de Roy et al. (2017) pode estar associado ao número de tecnologias envolvidas nos testes dos modelos. O estudo presente cingiu-se a uma única tecnologia de varejo inteligente (Realidade Aumentada). Segundo Homburg, Koschate e Hoyer (2006), o resultado da satisfação do usuário é obtido pela avaliação e impressão do desempenho de uma única tecnologia inteligente.

O estudo de Poushneh e Vasquez-Parraga (2017), que também serviu como base para o presente estudo, apresentou no modelo o construto Experiência do Usuário como sendo o antecessor da Intenção de Compra (variável dependente) e da Satisfação do Usuário (uma outra variável dependente no modelo). Este modelo apresentou resultados satisfatórios nas duas relações. Isto pode indicar que a 
Experiência do Usuário tem uma relação direta com a Intenção de Compra, não havendo necessidade da existência da Satisfação do Usuário como mediadora da relação entre elas. O resultado significativo da relação entre a Experiência do Usuário e a Satisfação do Usuário (variável dependente) neste estudo mencionado, indicou que as avaliações e impressões dos usuários foram satisfatórias logo após a Experiência.

Já nos modelos \#1 e \#2, testado no presente estudo, a razão da Satisfação do Usuário não ser determinante na Intenção de Compra pode ser devido ao fato da experiência ter sido rápida e reduzida na coleta de dados. Com isto, os respondentes não tiveram tempo suficiente para experimentar virtualmente os vários óculos disponíveis no catálogo de óculos do aplicativo da Ray-Ban. Além disto, eles não dispuseram do tempo necessário para usufruir de todos os recursos disponíveis no aplicativo da Ray-Ban. Isto resultou em prejuízo na avaliação da satisfação do usuário com essa experiência de Realidade Aumentada, o que pode ter gerado uma diminuição dos seus efeitos no modelo. Um outro fato a considerar na coleta de dados, refere-se ao tempo reduzido para o preenchimento do questionário por alguns participantes. Esta limitação que ocorreu na coleta de dados foi mencionada na seção 3.6.2 sobre limitações relacionadas à coleta de dados. Isto pode ter influenciado no resultado inesperado na relação entre Satisfação do Usuário e Intenção de Compra. Outro fator que poderia ter influenciado no resultado desta relação, pode estar relacionado com número limitado de participantes. Como houve problema no aplicativo, a experiência contou com menos participantes do que o planejado.

No modelo final (modelo \#3), o construto Satisfação do Usuário foi retirado do modelo e então, o resultado da relação entre a Emoção Positiva e Intenção de Compra ficou significativo, enquanto que nos modelos \#1 e \#2, que contêm a Satisfação do Usuário, a relação entre Emoção Positiva e Intenção de Compra não foi significativa. 


\subsection{4 Influência da Certeza na Escolha sobre a Intenção de Compra}

No modelo final e nos demais modelos testados neste estudo, a relação entre a Certeza na Escolha e a Intenção de Compra apresentou efeito direto, positivo e significativo. A magnitude desse efeito no modelo final teve valor igual a 0,72 (valor maior do que 0,3), indicando uma forte relação entre eles. De acordo com Porter e Heppelmann (2017), com a experimentação virtual dos produtos em um ambiente online para avaliar a aparência do produto ou seu funcionamento antes da compra, os clientes poderão esperar que as suas decisões de compra do produto sejam mais precisas e confiantes.

Esta influência forte entre Certeza na Escolha e Intenção de Compra também foi examinada por Dacko (2017). Ele observou que os usuários de aplicativo de Realidade Aumentada Móvel valorizam a importância deste aplicativo no Varejo para reduzir as incertezas de compra. Dacko (2017) acrescenta que a percepção do usuário sobre o aumento da certeza é de que o comprado é o que se deseja.

Como descrito na seção 2.3.3 sobre provador virtual, esta nova tecnologia de Realidade Aumentada permite experimentação virtual dos produtos antes da compra, proporcionando experiências envolventes e persuasivas que aproximam mais o cliente dos produtos oferecidos. Em especial, esta tecnologia é muito útil no Marketing Experiencial voltado para produtos de vestuário pela facilidade de visualizar o produto virtual no corpo do cliente. Isto permite ao cliente verificar a adequação do produto ao seu físico e ao seu gosto. No caso deste estudo, foi particularizado o uso dos óculos da Ray-Ban, que permite experimentar os modelos, cores e tamanhos na face dos clientes.

O construto Certeza na Escolha utilizado com sucesso em outros estudos (LEMOINE; NOTEBAERT, 2011; OH; YOON; SHYU, 2008) que envolveram experimentação virtual, apresentou nesta pesquisa um resultado muito expressivo e consistente. A relação forte entre a Experiência de Realidade Aumentada e a Certeza na Escolha, indicada pelo coeficiente encontrado, foi um achado relevante desta pesquisa. Isto sugere que essa prova virtual dos óculos Ray-Ban, proporcionada pela Experiência de Realidade Aumentada antes da decisão de 
compra, aumentou a Certeza na Escolha. Além disso, o resultado encontrado para a relação entre a Certeza na Escolha e a Intenção de Compra também foi forte, indicando que o participante ao escolher o produto com mais certeza aumentou a sua Intenção de Compra.

Estes resultados sobre a Certeza na Escolha eram esperados diante de estudos anteriores (LEMOINE; NOTEBAERT, 2011; OH; YOON; SHYU, 2008), pois uma experimentação virtual de produtos de vestuário proporciona maior aproximação do cliente com o produto antes da compra. Isto porque os participantes puderam ter a convicção da maior adequação do produto em suas escolhas após a Experiência de Realidade Aumentada e isto aumentou a intenção de compra. Por outro lado, sem a possibilidade deste recurso de RA, os clientes tomariam a decisão baseada unicamente na suposição da adequação do produto no seu corpo, valendose dos formatos, tamanhos e das medidas exclusivamente informadas na apresentação do produto no varejo online.

Desta forma, considerando o resultado relevante encontrado na pesquisa sobre a relação forte entre Certeza na Escolha e Intenção de Compra, é sugerido que, em estudos futuros sobre Realidade Aumentada aplicada ao varejo online, este achado seja levado em consideração. Esta sugestão visa obter mais aprofundamento sobre os efeitos da Certeza na Escolha no processo decisório de compra.

\subsection{5 Influência da Emoção Positiva sobre a Intenção de Compra}

O resultado no modelo final da relação entre Emoção Positiva e Intenção de Compra foi significante, indicando uma influência direta e positiva com magnitude de 0,19 (inferior ao valor de 0,3). Esta magnitude pode indicar uma relação fraca entre estes dois construtos. Uma das razões para isto pode ser a dificuldade que um indivíduo tem em expressar os seus sentimentos com exatidão.

Outra razão para relação fraca, pode estar associada ao construto Certeza na Escolha, um construto antecedente da Intenção de Compra, que apresentou uma relação forte com a Intenção de Compra. As pesquisas anteriores sobre Realidade Aumentada de Brito, Stoyanova e Coelho (2018) e Poncin e Mimoun (2014) 
reconhecem que as emoções influenciam positivamente na intenção de compra e isto está em conformidade com os resultados encontrados. A relação fraca entre Emoção Positiva e Intenção de Compra encontrada neste estudo difere de estudos anteriores sobre este assunto (CILLEY, 2016; LIM et al., 2016; NOORDIN; ASHAARI; WOOK, 2017; OVERMARS; POELS, 2015; TANNER; RAYMOND, 2012; WALLACE, 2015). Nestes estudos anteriores, foi evidenciada uma relação forte entre Emoção Positiva e Intenção de Compra, indicando que os sentimentos são fatores relevantes envolvidos no processo de decisão de compra dos clientes.

Pelo potencial que os aplicativos de MAR têm de fornecer sensibilidade ao contexto e as emoções, estudos futuros deveriam investir na avaliação do construto Emoção Positiva para explorar melhor esta influência sobre a Intenção de Compra, principalmente pela diferença encontrada na magnitude da relação nesta pesquisa em relação aos outros estudos (CILLEY, 2016; LIM et al., 2016; NOORDIN; ASHAARI; WOOK, 2017; OVERMARS; POELS, 2015; TANNER; RAYMOND, 2012; WALLACE, 2015).

Vale aprofundar em estudos futuros mais sobre as avaliações dos usuários em relação às suas emoções durante o Marketing Experiencial com uso de RA. Isto porque as experiências com RA, permitem explorar, além da percepção de usabilidade da tecnologia, a capacidade de envolver emocionalmente os consumidores, permitindo criar relações atraentes entre o usuário e o produto (DESMET; PORCELIJN; VAN DIJK, 2007). Outro ponto a considerar para estudos futuros seria investigar os efeitos observados com a retirada do construto Satisfação do Usuário do modelo e a consequente alteração no resultado obtido na relação entre Emoção Positiva e Intenção de Compra. 


\section{5 CONCLUSÕES E RECOMENDAÇÕES}

Este capítulo apresenta inicialmente um resumo da pesquisa realizada e após isto são discutidas as contribuições e impactos do resultado do estudo para a teoria e para prática gerencial. Por fim, são retratadas as limitações do estudo e sugeridas contribuições para estudos futuros.

\section{1 Resumo dos Resultados}

Esta pesquisa investigou de que forma a Experiência de Realidade Aumentada afetou a Intenção de Compra no varejo online via dispositivo móvel. Desta forma, foi avaliado como os efeitos da Experiência de Realidade Aumentada mediada por fatores de avaliação do consumidor durante o processo de compra online - como certeza na escolha, emoção positiva e satisfação do usuário - afetam a intenção de compra no varejo online via dispositivo móvel.

Para o cumprimento das etapas necessárias para alcançar o objetivo definido do estudo, foi utilizada uma metodologia para o planejamento das atividades. As principais atividades planejadas foram a revisão de literatura sobre os principais assuntos envolvidos nesta pesquisa, a análise crítica dos construtos e modelos encontrados, e proposta e teste de modelos. No detalhamento das principais atividades foram realizadas a revisão bibliográfica minuciosa, análises das limitações e falhas existentes nos modelos encontrados, propostas de modelos, formulação de hipóteses, adaptação de escalas, pré-teste de amostras, pesquisa com participantes, análises estatísticas e avaliação dos resultados dos modelos.

As hipóteses formuladas foram baseadas nas questões definidas na investigação do estudo. Elas procuram responder se a experiência da Realidade Aumentada no varejo online via dispositivo móvel tem efeito significativo sobre a certeza na escolha, emoção positiva e satisfação do usuário, e também, se a certeza na escolha, emoção positiva e satisfação do usuário têm efeitos significativos sobre a intenção de compra no varejo online via dispositivo móvel dos consumidores, em 
um contexto de experiência da Realidade Aumentada. Outra questão do estudo foi investigar se a certeza na escolha, a emoção positiva e a satisfação do usuário são mediadores dos efeitos da experiência da Realidade Aumentada sobre a intenção de compra no varejo online via dispositivo móvel.

$\mathrm{Na}$ revisão bibliográfica feita para compreender as teorias e os modelos existentes sobre Realidade Aumentada, Realidade Aumentada Móvel (MAR), Provador Virtual, Varejo Inteligente e Marketing Experiencial, foram encontrados vários modelos e teorias em destaques que foram apresentados no capítulo 2 Revisão de Literatura.

Um estudo sobre varejo inteligente encontrado na revisão bibliográfica foi feito por Roy et al. (2017). Eles avaliaram o uso de novas tecnologias, dentre elas a de Realidade Aumentada, aplicadas ao varejo para melhorar a qualidade das experiências de compras, porém este estudo não avaliou de forma específica a experiência de Realidade Aumentada.

Outros modelos importantes de estudos de Realidade Aumentada foram os de Javornik (2016a) e Poushneh e Vasquez-Parraga (2017). Eles introduziram um novo construto - Realidade Aumentada Percebida - que permite avaliar especificamente as experiências de Realidade Aumentada dos consumidores.

As pesquisas de Beck e Crié (2016) e Yim, Chu e Sauer (2017) apontaram que a inclusão de informações e objetos virtuais nas experiências de compra online utilizando a Realidade Aumentada pode levar à redução da incerteza sobre uma compra potencial.

Vale destacar também as teorias das pesquisas de Lim et al. (2016) e Noordin, Ashaari e Wook (2017) que indicaram os sentimentos como fatores relevantes envolvidos no processo decisório de compra.

Com base nos estudos identificados no referencial teórico, o modelo ARORM (Augmented Reality in the Online Retail Model) foi desenvolvido nesta pesquisa para avaliar não somente os aspectos técnicos da ferramenta numa Experiência de Realidade Aumentada, mas também avaliar os efeitos dos aspectos cognitivos e afetivos percebidos pelo consumidor sobre sua intenção de compra. Este modelo permitiu avaliar os efeitos da Experiência de Realidade Aumentada 
sobre a Intenção de Compra, conforme o objetivo definido na pesquisa. De acordo com o objetivo traçado, o modelo ARORM foi elaborado contendo o construto de segunda ordem Experiência de Realidade Aumentada com quatro dimensões que avaliam os aspectos técnicos da ferramenta, a saber, Realidade Aumentada Percebida, Personalização, Vantagem Relativa e Controle. Além dos aspectos técnicos avaliados, os participantes avaliaram um aspecto afetivo pela dimensão Fruição Percebida existente neste construto de segundo ordem. A Experiência de Realidade Aumentada é um construto novo adaptado do construto de segunda ordem de Experiência de Varejo Inteligente de Roy et al. (2017). A diferença entre os dois construtos está na substituição da dimensão Interatividade existente no construto Experiência de Varejo Inteligente pela dimensão Realidade Aumentada Percebida (uma dimensão nova e específica para avaliar aspectos técnicos da tecnologia de Realidade Aumentada). As razões apontadas para esta substituição foram esclarecidas nas seções 2.4.3.1 Experiência de Realidade Aumentada e 2.4.3.6 Realidade Aumentada do Modelo proposto.

Ainda sobre o modelo ARORM, foram incluídos os construtos Certeza na Escolha, Emoção Positiva e Satisfação do Usuário, após a Experiência de Realidade Aumentada, permitindo a avaliação dos aspectos cognitivos e afetivos da experiência pelos participantes da pesquisa. O construto Intenção de Compra (variável dependente do modelo) foi incluído logo após estes construtos, permitindo avaliar se estes construtos afetam a Intenção de Compra. Os construtos Certeza na Escolha, Emoção Positiva e Satisfação do Usuário foram incluídos para avaliar os efeitos de mediadores entre Experiência de Realidade Aumentada e a Intenção de Compra.

Após a construção do modelo, foi elaborado um instrumento de pesquisa para testar e validar o modelo. Este instrumento utilizou nove escalas já desenvolvidas em estudos acadêmicos anteriores (ROY et al., 2017; RESE et al., 2017; ZHU; WANG; CHANG, 2018; MEHRABIAN; RUSSEL, 1974; MERLE; SENECAL; ST-ONGE, 2012). Foi realizado o processo de back-transalation para a tradução das escalas para o idioma em português. Em seguida foi feito um préteste com uma amostra reduzida da população de interesse para validar o entendimento do questionário. A amostra dos dados da pesquisa contém 201 
respondentes que são consumidores que fazem compras online, de ambos os sexos, estudantes ou não, sem distinção de classe social e acima de 17 anos. $\mathrm{O}$ processo de coleta de dados estabelecia que todos os respondentes experimentassem, antes de responder o questionário, o aplicativo online de óculos da Ray-Ban que utiliza a tecnologia de Realidade Aumentada para experimentação virtual. Esta experimentação possibilitou a avaliação concreta, cognitiva e afetiva, da tecnologia. Pela análise fatorial confirmatória (CFA), foram verificadas a confiabilidade e a validade dos construtos medidos com as escalas utilizadas.

Pela modelagem de equações estruturais (KULVIWAT et al., 2007; HAIR et al., 2010; BYRNE, 2013) foram verificadas as hipóteses da pesquisa (tabela 4.14). Os dois modelos alternativos e o principal foram testados, sendo comparados os seus índices de ajustes, de acordo com orientações de Anderson e Gerbing (1988). Todos os modelos apresentaram índices de ajustes satisfatórios e a maioria das hipóteses foram confirmadas. As hipóteses não confirmadas nos modelos \#1 e \#2 foram a H5 que avaliou se a satisfação tem efeito direto e positivo sobre a intenção de compra pelo consumidor no varejo online via dispositivo móvel, H6 que avaliou se a emoção positiva tem efeito direto e positivo sobre a intenção de compra pelo consumidor no varejo online via dispositivo móvel. A hipótese H7, existente somente no modelo \#2, que avaliou se a Experiência de Realidade Aumentada tem efeito direto e positivo sobre a intenção de compra no varejo online via dispositivo móvel também não foi confirmada. No modelo final (modelo \#3), que não incluiu o construto Satisfação do Usuário, todas as hipóteses do modelo foram confirmadas, inclusive a hipótese H6 que avalia o efeito da Emoção Positiva sobre a Intenção de Compra. Como as hipóteses relacionadas com o mediador Certeza na Escolha entre Experiência de Realidade Aumentada e a Intenção de Compra foram confirmadas no modelo \#2 e a hipótese (H7), que avaliou o efeito direto entre estes dois construtos não foi confirmada, isto indica uma mediação total. Outros aspectos relevantes do estudo estão nas relações significativas entre Certeza na Escolha e Intenção de Compra e entre Emoção Positiva e Intenção de Compra. Foram encontradas diferenças consideráveis dos efeitos observados para estas relações. A relação entre Certeza na Escolha e Intenção de Compra apresentou um efeito bem forte, enquanto a relação entre Emoção Positiva e Intenção de Compra apresentou um efeito bem fraco. Este resultado de efeito forte entre a Certeza na Escolha e 
Intenção de Compra, pode estar relacionado com a experiência vivida pelos respondentes. Esta experiência com a tecnologia de Realidade Aumentada permitiu aos respondentes experimentar vários óculos utilizando o aplicativo da Ray-Ban via tablets. Esta experiência tem um significado especial para o usuário, considerando que ela permite a visualização dos óculos em seu rosto antes de sua decisão pela compra. É importante enfatizar que sem esta tecnologia no ambiente de compra online, isto seria impossível de ser feito antes de uma compra de óculos.

Para concluir, destaca-se a Certeza na Escolha e Emoção Positiva como mediadores entre Experiência de Realidade Aumentada e Intenção de Compras. Os outros estudos relevantes de Realidade Aumentada aplicados em Marketing como o de Javornik (2016a) e Poushneh e Vasquez-Parraga (2017) não apresentaram mediadores, confirmando a relação direta entre estes dois construtos. Esta descoberta pode indicar que o indivíduo tem uma etapa intermediária na avaliação dos benefícios da Experiência de Realidade Aumentada antes da intenção de compra.

\section{2 \\ Implicações Teóricas}

As relações verificadas no estudo contribuem de forma relevante para a teoria do uso da tecnologia de Realidade Aumentada Móvel (MAR) aplicada ao varejo online. Como esta tecnologia é nova, a contribuição deste estudo serve para um melhor entendimento nas áreas de inovação tecnológica e de marketing. O estudo examinou dois aspectos: a avaliação da tecnologia de Realidade Aumentada e seu uso aplicado no marketing experiencial. Sendo assim, este estudo considerou não só a avaliação da experiência com a tecnologia, mas também a avaliação do produto desejado para a compra. Desta forma, o objetivo do trabalho foi alcançado pela investigação dos efeitos do uso da Realidade Aumentada, avaliando os aspectos técnicos desta nova tecnologia no contexto da Experiência do Consumidor no Varejo e os efeitos cognitivos e afetivos desta experiência sobre a Intenção de Compra. O uso da tecnologia de Realidade Aumentada na experiência permitiu a aplicação de uma estratégia eficaz para um Marketing Experiencial dinâmico e 
inovador. O resultado do uso da tecnologia de Realidade Aumentada no marketing experiencial permitiu que os participantes testassem positivamente o produto em foco (óculos), levando a uma maior certeza na sua intenção de compra e aprimorando as informações para o seu processo de tomada de decisão.

A pesquisa permitiu investigar, em conjunto, os efeitos afetivos e cognitivos desta nova tecnologia numa Experiência de Realidade Aumentada realizadas com os participantes. Esta Experiência de Realidade Aumentada, um construto de segunda ordem, contém as dimensões Realidade Aumentada Percebida, Controle Percebido, Fruição Percebida, Vantagem Relativa e Personalização que permitiram avaliar esses efeitos afetivos e cognitivos. Durante o estudo, verificou-se que estas dimensões representam, de forma satisfatória, a Experiência de Realidade Aumentada. Dentre estas dimensões, a Realidade Aumentada Percebida mostrou a sua importância na contribuição para a teoria no contexto da Experiência de Realidade Aumentada. Esta importância decorre do fato de que estudos anteriores encontrados na revisão bibliográfica não utilizaram esta dimensão dentro da Experiência de Realidade Aumentada.

O primeiro resultado da pesquisa indicou que os consumidores ao experimentarem o produto virtual - óculos da Ray-Ban - usando a tecnologia de Realidade Aumentada ficaram com mais certeza na escolha do produto, alcançando o objetivo traçado de avaliar aspectos cognitivos presentes na experiência. O estudo também confirmou que, após uma Experiência de Realidade Aumentada via dispositivo móvel aplicada no varejo online, os indivíduos se sentem satisfeitos, entusiasmados, estimulados e emocionalmente animados com a experiência, alcançando também o objetivo definido de avaliar os aspectos afetivos e cognitivos após a Experiência de Realidade Aumentada. A Experiência de Realidade Aumentada afetou fortemente a Certeza na Escolha, Emoção Positiva e Satisfação do Usuário.

O segundo resultado do estudo reforça a importância das avaliações dos consumidores após uma experiência RA, levando em consideração aspectos afetivos e cognitivos que podem influenciar na intenção de compra. A forte influência da Certeza na Escolha na Intenção de Compra foi evidenciada no estudo e isto pode estar relacionado aos efeitos persuasivos que esta tecnologia tem em 
aproximar o produto do consumidor, afetando de forma positiva na Intenção de Compra. O estímulo, o entusiasmo e a animação do consumidor após a Experiência de Realidade Aumentada afetaram de certa forma a Intenção de Compra, embora com menos intensidade que a Certeza na Escolha. O objetivo de avaliar os efeitos cognitivos e afetivos da Experiência de Realidade Aumentada sobre a Intenção de Compra foi alcançado com estes resultados. Embora a Experiência de Realidade Aumentada tenha afetado fortemente a Satisfação do Usuário, isto não foi suficiente para influenciar a sua Intenção de Compra.

O terceiro resultado do estudo evidencia a importância dos mediadores Certeza na Escolha e Emoção Positiva entre Experiência de Realidade Aumentada e a Intenção de Compra. Os resultados indicaram que houve uma mediação total entre Experiência de Realidade Aumentada e Intenção de Compra. Isto se deve ao fato de que a relação direta entre Experiência de Realidade Aumentada e Intenção de Compra não foi encontrada e que as relações indiretas, utilizando os mediadores, foram verificadas. Sendo assim, o objetivo de avaliar os mediadores entre Experiência de Realidade Aumentada e Intenção de Compra foram alcançados com estes resultados. Estes resultados podem indicar a necessidade de uma reflexão pelos consumidores sobre avaliação dos aspectos afetivos e cognitivo antes da Intenção de Compra.

Esta pesquisa sugere que os aspectos afetivos e cognitivos podem motivar o uso da tecnologia de Realidade Aumentada em aplicativos de varejo online via dispositivo móvel, sendo a consideração cognitiva Certeza na Escolha a mais dominante para os consumidores. Estes achados estão de acordo e corroboram os resultados de outras pesquisas (RESE et al., 2017; DACKO, 2017; OLSSON et al., 2013) que examinaram o uso de aplicativos de varejo online com a tecnologia de Realidade Aumentada em situações reais. Estas pesquisas anteriores indicaram que os aspectos utilitários, tais como tomar decisões confiáveis e eficazes, eram considerados os benefícios mais importantes que os consumidores buscavam ao utilizar um aplicativo de varejo online com Realidade Aumentada.

Estas conclusões ampliam-se as possibilidades de uso dos resultados obtidos na construção do conhecimento acadêmico mais aprimorado sobre os efeitos da tecnologia de Realidade Aumentada nas compras online. 


\section{3 \\ Implicações Gerenciais}

O estudo fornece informações que podem ser utilizadas no gerenciamento do varejo online. A Experiência de Realidade Aumentada no varejo online mede as percepções do indivíduo ao usarem a tecnologia. Estas percepções estão relacionadas com as características funcionais e hedônicas decorrentes do uso da Realidade Aumentada, levando a avaliações cognitiva e afetiva sobre uso desta tecnologia aplicado ao varejo. Além destas avaliações, o consumidor avalia o produto em função da sua predisposição para a compra.

De fato, pelos resultados do estudo, a Experiência de Realidade Aumentada é um antecedente forte da avaliação do consumidor e por sua vez, esta avaliação é um antecedente significativo da intenção de compra. Os gerentes de varejo online podem fazer uso destes resultados para criar Experiências de Realidade Aumentada mais prazerosas e eficazes para obter bons resultados no marketing experiencial. Conforme Pantano e Timmermans (2014), o uso de tecnologias inteligentes pode reinventar a economia de serviços, melhorando a qualidade das experiências de compras. Esta tecnologia inteligente de Realidade Aumentada é um recurso de grande valor que deve compor as estratégias de marketing a serem adotadas para o varejo online.

Com relação à construção de novos aplicativos para o varejo online com uso da Realidade Aumentada Móvel, as empresas devem explorar os estímulos sensoriais e visuais oferecidos pela tecnologia para incrementar os contextos de compras, tornando-as mais envolventes. Como a experimentação virtual pode criar uma familiaridade com o produto, podendo causar um efeito persuasivo e uma motivação para o consumidor na predisposição a compra, esta tecnologia pode ser um recurso poderoso e diferenciado para os varejistas. Além disto, o uso da tecnologia de Realidade Aumentada pode ter impacto na redução da taxa de devolução de produtos em compras online.

$\mathrm{Na}$ fase de construção dos testes do estudo, foram encontrados poucos aplicativos no varejo online utilizando Realidade Aumentada Móvel. Por fim, 
considerando o potencial intrínseco da tecnologia e a pouca exploração do seu uso e dos seus recursos disponíveis, sugere-se aos gerentes das empresas o investimento na construção de novos aplicativos com uso de Realidade Aumentada.

Desta forma, espera-se que a construção de aplicativos de Realidade Aumentada para varejo online possa fazer uso dos resultados obtidos neste estudo para criar experiências envolventes e benéficas tanto para o consumidor quanto para o varejista.

\section{4}

\section{Limitações}

Uma limitação importante na realização da pesquisa está relacionada com a coleta de dados, pois o aplicativo da Ray-Ban usado na pesquisa apresentou problema com a atualização do catálogo de óculos. Este problema não foi resolvido durante a etapa da pesquisa no campo, impedindo a continuidade da coleta. Por esta razão, o tamanho da amostra ficou reduzido a 201 respondentes. Não obstante, ao rodar o modelo, os índices foram satisfatórios. Outros estudos de RA também obtiveram bons resultados com tamanhos de amostra similares ao utilizado neste estudo (HILKEN et al., 2017; DOMINA; LEE; MACGILLIVRAY, 2012; JAVORNIK et al., 2016; POUSHNEH; VASQUEZ-PARRAGA, 2017). Apesar disto, uma amostra maior seria aconselhável para que melhor fosse apurado os resultados da pesquisa.

Outra limitação da tese refere-se a escolha do aplicativo de Realidade Aumentada. O número de aplicativos disponíveis no varejo online no mercado brasileiro é muito reduzido e os existentes no Brasil não eram elaborados o suficiente para permitir uma pesquisa sobre experiência de varejo via Realidade Aumentada. Assim sendo, optou-se por usar o aplicativo internacional da Ray-Ban, que apresentava as características desejadas para a experiência.

Mais uma limitação da pesquisa é verificada pelo uso de um único aplicativo para a experimentação virtual via Realidade Aumentada. Como esta tecnologia é nova e diversos participantes não tinham ainda usado este tipo de aplicativo, é possível que os resultados utilizando outros aplicativos sejam diferentes. 
Na realização da coleta de dados, alguns participantes excederam o tempo planejado no roteiro para sua experiência individual. Esta circunstância reduziu o tempo disponível para os para os participantes que fizeram a experimentação a seguir. Isto pode ter influenciado e prejudicado as respostas destes participantes no questionário sobre emoção positiva e a satisfação. Esta circunstância pode ter causado, por exemplo, a não significância da relação entre Satisfação do Usuário e a Intenção de Compra.

Mesmo diante destas limitações, considera-se que esta pesquisa contribuiu para um maior entendimento sobre as relações dos consumidores com a tecnologia de Realidade Aumentada em compras online.

\section{5 \\ Sugestões de Pesquisas Futuras}

Diante das limitações constatadas, a primeira sugestão seria que em estudos futuros sejam utilizados outros aplicativos de Realidade Aumentada ligados ao varejo online para testar o modelo proposto. Da mesma forma, deve-se aplicar o modelo para outros consumidores com perfis diferentes dos encontrados neste estudo. Isto vai permitir avaliar se o modelo é adequado para outros aplicativos e para diferentes públicos. Por fim, verificará se os resultados obtidos podem ser generalizados.

Uma outra sugestão de estudo está em procurar compreender a influência do comportamento do consumidor, em relação ao conceito do "eu estendido" no ambiente digital de Belk (2014) usando a tecnologia de Realidade Aumentada. A abordagem do "eu aumentado" (SCHOLZ; DUFFY, 2018), obtida pela fusão do uso da tecnologia de Realidade Aumentada pelo consumidor com as marcas, necessita de estudos futuros.

Em relação ao modelo, a sugestão seria expandi-lo para verificar se outros aspectos avaliados pelos consumidores após uma Experiência de Realidade Aumentada, tais como, a sua percepção de conveniência ou de risco podem afetar intenção de compra. Esta sugestão de modelo poderia avaliar se a economia de tempo, como por exemplo, por uma experimentação de produto mais rápida e 
personalizada, poderia levar a percepção do consumidor de que a experiência inteligente de Realidade Aumentada pode ser uma conveniência e se isto pode se traduzir em maior disposição ou atitude para uma compra futura. Quanto ao risco percebido, estudos futuros poderiam avaliar se a tecnologia de Realidade Aumentada pode contribuir para a redução do risco percebido para a compra.

Por fim, questões relacionadas com a segurança e a privacidade poderiam ser examinadas em estudos futuros, diante do receio e incertezas que os consumidores possam sentir em relação à tecnologia ao fazer uso de escaneamento de suas faces e corpos. Os dados biométricos são considerados dados pessoais sensíveis. 


\section{Referências}

AAKER, D. A.; KUMAR, V. e DAY, G. S. Marketing Research. Wiley, 9 ed., 2006.

ABI GHANEM, D., MANDER, S., Designing consumer engagement with the smart grids of the future: bringing active demand technology to everyday life. Tech. Anal. Strat. Manag. V.26 n.10, p. 1163-1175. http://dx.doi.org/10.1080/09537325.2014.974531.2014.

ADHANI, Nur Intan; RAMBLI, Dayang Rohaya Awang. A survey of mobile augmented reality applications. In: 1st International Conference on Future Trends in Computing and Communication Technologies. 2012. p. 89-96.

AGARWAL, Ritu; KARAHANNA, Elena. Time flies when you're having fun: Cognitive absorption and beliefs about information technology usage. MIS quarterly, p. 665-694, 2000.

AHN, Tony; RYU, Seewon; HAN, Ingoo. The impact of the online and offline features on the user acceptance of Internet shopping malls. Electronic commerce research and applications, v. 3, n. 4, p. 405-420, 2004.

AJZEN, Icek. The theory of planned behavior. Organizational behavior and human decision processes, v. 50, n. 2, p. 179-211, 1991.

AJZEN, I. e FISHBEIN, M. Understanding Attitudes and Predicting Social Behaviour. Prentice-Hall, Englewood Cliffs, NJ, 1980.

ALBEN, Lauralee. Defining the criteria for effective interaction design. interactions, v. 3, n. 3, p. 11-15, 1996.

ALVAREZ-MARIN, Alejandro; CASTILLO-VERGARA, Mauricio; GELDESGONZÁLEZ, Cristian. Análisis Bibliométrico de la Realidad Aumentada y su Relación con la Administración de Negocios. Información tecnológica, v. 28, n. 4, p. 57-66, 2017.

ANDERSON, James C.; GERBING, David W. Structural equation modeling in practice: A review and recommended two-step approach. Psychological bulletin, v. 103 , n. 3, p. 411, 1988. 
ANDREWS, Demetra. The interplay of information diagnosticity and need for cognitive closure in determining choice confidence. Psychology \& Marketing, v. 30, n. 9, p. 749-764, 2013.

ANITAWATI, M. L.; LAILA, MN Nor; NAGAMUCHI, M. Kansei Engineering: a study on perception of online clothing websites. In: 10th QMOD Conference. Quality Management and Organiqatinal Development. Our Dreams of Excellence; 18-20 June; 2007 in Helsingborg; Sweden. Linköping University Electronic Press, 2008.

AZUMA, Ronald et al. Recent advances in augmented reality. Naval Research Lab Washington DC, 2001.

AZUMA Ronald et al. Developing augmented reality applications. ACM Siggraph 2004 Course Notes, 2004.

AZUMA, Ronald. Making Augmented Reality a Reality. In: Applied Industrial Optics: Spectroscopy, Imaging and Metrology. Optical Society of America, 2017. p. JTu1F. 1.

BABIN, B. J. et al. Modeling consumer satisfaction and word-of-mouth: Restaurant patronage in Korea. Journal of Services Marketing, v. 19 n. 3, p. 133-139 2005

BÄCKSTRÖM, Kristina; JOHANSSON, Ulf. Creating and consuming experiences in retail store environments: Comparing retailer and consumer perspectives. Journal of Retailing and Consumer Services, v. 13, n. 6, p. 417430, 2006.

BAGOZZI, Richard P.; PHILLIPS, Lynn W. Representing and testing organizational theories: A holistic construal. Administrative science quarterly, p. 459-489, 1982.

BAIER, Daniel; RESE, Alexandra; SCHREIBER, Stefanie. Analyzing online reviews to measure augmented reality acceptance at the point of sale: the case of IKEA. In: Mobile Computing and Wireless Networks: Concepts, Methodologies, Tools, and Applications. IGI Global, 2016. p. 1714-1736.

BAUER, Raymond A. Consumer behavior as risk taking. In: Proceedings of the 43rd National Conference of the American Marketing Association, June 15, 16, 17, Chicago, Illinois, 1960. American Marketing Association, 1960. 
BAUER, Raymond A.; COX, Donald F. Risk taking and information handling in consumer behavior. Boston: Harvard University, p. 469-486, 1967.

BAUER, H. H. et al. eTransQual: A transaction process-based approach for capturing service quality in online shopping. Journal of Business Research, v.59 n.7, p. 866-875 2006.

BARUTÇU, Süleyman. Attitudes towards mobile marketing tools: A study of Turkish consumers. Journal of Targeting, Measurement and Analysis for Marketing, v. 16, n. 1, p. 26-38, 2007.

BARNES, Stuart J.; SCORNAVACCA, Eusebio. Mobile marketing: the role of permission and acceptance. International Journal of Mobile Communications, v. 2, n. 2, p. 128-139, 2004.

BECK, Marie; CRIÉ, Dominique. I virtually try it... I want it! Virtual Fitting Room: A tool to increase on-line and off-line exploratory behavior, patronage and purchase intentions. Journal of Retailing and Consumer Services, 2016.

BELK, Russell. Digital consumption and the extended self. Journal of Marketing Management, v. 30, n. 11-12, p. 1101-1118, 2014.

BENBASAT, Izak; BARKI, Henri. Quo vadis TAM? Journal of the association for information systems, v. 8, n. 4, p. 7, 2007.

BENOU, Poulcheria; VASSILAKIS, Costas. The conceptual model of context for mobile commerce applications. Electronic Commerce Research, v. 10, n. 2, p. 139-165, 2010.

BENTLER, P. M. Comparative Fit Indices in Structural Models. Psychological Bulletin, v. 107, pp. 238-246, 1990.

BERNARDO, Merce; MARIMON, Frederic; DEL MAR ALONSO-ALMEIDA, María. Functional quality and hedonic quality: A study of the dimensions of eservice quality in online travel agencies. Information \& Management, v. 49, n. 78, p. 342-347, 2012.

BHARADWAJ, Neeraj; NAYLOR, Rebecca Walker; TER HOFSTEDE, Frenkel. Consumer response to and choice of customized versus standardized 
systems. International Journal of Research in Marketing, v. 26, n. 3, p. 216227, 2009.

BHATNAGAR, Amit; GHOSE, Sanjoy. Segmenting consumers based on the benefits and risks of Internet shopping. Journal of Business Research, v. 57, n. 12, p. 1352-1360, 2004.

BHATNAGAR, Amit; MISRA, Sanjog; RAO, H. Raghav. On risk, convenience, and Internet shopping behavior. Communications of the ACM, v. 43, n. 11, p. 98$105,2000$.

BHATTACHARYA, Mithu. A conceptual framework of RFID adoption in retail using Rogers stage model. Business Process Management Journal, v. 21, n. 3, p. 517-540, 2015.

BILLINGHURST, Mark et al. A survey of augmented reality. Foundations and Trends® in Human-Computer Interaction, v. 8, n. 2-3, p. 73-272, 2015.

BLÁZQUEZ, Marta. Compras de moda no varejo multicanal: O papel da tecnologia no aprimoramento da experiência do cliente. Revista Internacional de Comércio Eletrônico, v. 18, n. 4, p. 97-116, 2014.

BLOCH, Peter H.; RICHINS, Marsha L. A theoretical model for the study of product importance perceptions. The Journal of Marketing, p. 69-81, 1983.

BODHANI, Aasha. Shops offer the e-tail experience. Engineering and Technology, v. 7, n. 5, p. 46-49, 2012.

BODHANI, Aasha. Getting a purchase on AR. Engineering \& Technology, v. 8, n. 4, p. 46-49, 2013.

BRAMBILLA, Flávio Régio. Modelagem de equações estruturais: exemplo comentado da aplicação mediante a utilização do software AMOS. INGEPROInovação, Gestão e Produção, v. 3, n. 4, p. 1-12, 2011.

BRYNE, B. M. Structural Equation Modeling with AMOS: Basic Concepts, Applications and Programming. 2nd ed. Routledge, NY, 2010.

BRITO, Pedro Quelhas; STOYANOVA, Jasmina; COELHO, António. Augmented reality versus conventional interface: Is there any difference in 
effectiveness? Multimedia Tools and Applications, v. 77, n. 6, p. 7487-7516, 2018.

BRYANT, Jennings; OLIVER, Mary Beth (Ed.). Media effects: Advances in theory and research. Routledge, 2009.

BROOKS, Anthony L.; BROOKS, EvaPetersson. Towards an inclusive virtual dressing room for wheelchair-bound customers. In: Collaboration Technologies and Systems (CTS), 2014 International Conference on. IEEE, 2014. p. 582-589.

BURKE, Raymond R. Technology and the customer interface: what consumers want in the physical and virtual store. Journal of the academy of Marketing Science, v. 30, n. 4, p. 411-432, 2002.

BYRNE, Barbara M. Structural equation modeling with LISREL, PRELIS, and SIMPLIS: Basic concepts, applications, and programming. Psychology Press, 2013.

CARMIGNIANI, Julie et al. Augmented reality technologies, systems and applications. Multimedia tools and applications, v. 51, n. 1, p. 341-377, 2011.

CARPENTER, Jason M.; MOORE, Marguerite. Utilitarian and hedonic shopping value in the US discount sector. Journal of Retailing and Consumer Services, v. 16, n. 1, p. 68-74, 2009.

CASSEL, Claes; EKLÖF, Jan A. Modelling customer satisfaction and loyalty on aggregate levels: Experience from the ECSI pilot study. Total quality management, v. 12, n. 7-8, p. 834-841, 2001.

CENTRIC DIGITAL, How Augmented Reality Could Help Retailers Increase Revenue. March 20th, 2017 [online] accessed on 2018, available at: 〈https:// centricdigital.com/blog/augmented-reality/how-augmented-reality-couldhelpretailers-increase-revenue/>.

CHAUVEL, Marie Agnes. A satisfação do consumidor no pensamento de marketing: revisão de literatura. Encontro Nacional da ANPAD, v. 23, 1999.

CHEN, Alfred et al. Applying augmented reality to consumer garment try-on experience. In: Transactions on computational science XIII. Springer, Berlin, Heidelberg, 2011. p. 169-190. 
CHEN, Lei-Da; TAN, Justin. Technology Adaptation in E-commerce: Key Determinants of Virtual Stores Acceptance. European Management Journal, v. 22, n. 1, p. 74-86, 2004.

CHEN, Qimei; WELLS, William D. Attitude toward the site. Journal of advertising research, v. 39, n. 5, p. 27-38, 1999.

CHILDERS, Terry L. et al. Hedonic and utilitarian motivations for online retail shopping behavior. Journal of retailing, v. 77, n. 4, p. 511-535, 2001.

CHIOU, Jyh-Shen; SHEN, Chung-Chi. The antecedents of online financial service adoption: the impact of physical banking services on Internet banking acceptance. Behaviour \& Information Technology, v. 31, n. 9, p. 859-871, 2012.

CHONG, Alain Yee-Loong. Mobile commerce usage activities: The roles of demographic and motivation variables. Technological Forecasting and Social Change, v. 80, n. 7, p. 1350-1359, 2013.

CHUNG, Namho; HAN, Heejeong; JOUN, Youhee. Tourists' intention to visit a destination: The role of augmented reality (AR) application for a heritage site. Computers in Human Behavior, v. 50, p. 588-599, 2015.

CHURCHILL, G. A., IACOBUCCI, D. Marketing Research: Methodological Foundations. 10 ed., South-Western College Pub, 2009.

CILLEY, J. Apparel \& Footwear Retail Survey Report. Body Labs Inc, New York, 2016.

CLODFELTER, Richard. Biometric technology in retailing: Will consumers accept fingerprint authentication? . Journal of Retailing and Consumer Services, v. 17, n. 3, p. 181-188, 2010.

COX, Donald F. Risk taking and information handling in consumer behavior. 1967.

CSIKSZENTMIHALYI, Mihaly. Flow: The psychology of optimal performance. 1990. 
CSIKSZENTMIHALYI, Mihaly; CSIKSZENTMIHALYI, Isabella. Beyond boredom and anxiety. San Francisco: Jossey-Bass, 1975.

DACKO, Scott G. Enabling smart retail settings via mobile augmented reality shopping apps. Technological Forecasting and Social Change, v. 124, p. 243256, 2017.

DAPONTE, Pasquale et al. State of the art and future developments of the augmented reality for measurement applications. Measurement, v. 57, p. 53-70, 2014.

D'ASTOUS, Alain; JACOB, Isabelle. Understanding consumer reactions to premium-based promotional offers. European Journal of Marketing, v. 36, n. 11/12, p. 1270-1286, 2002.

DAVIS, Fred D. Perceived usefulness, perceived ease of use, and user acceptance of information technology. MIS quarterly, p. 319-340, 1989.

DAVIS, Fred D. User acceptance of information technology: system characteristics, user perceptions and behavioral impacts. International journal of man-machine studies, v. 38, n. 3, p. 475-487, 1993.

DAVIS, Fred D.; BAGOZZI, Richard P.; WARSHAW, Paul R. User acceptance of computer technology: a comparison of two theoretical models. Management science, v. 35, n. 8, p. 982-1003, 1989.

DAVIS, Fred D.; BAGOZZI, Richard P.; WARSHAW, Paul R. Extrinsic and intrinsic motivation to use computers in the workplace 1. Journal of applied social psychology, v. 22, n. 14, p. 1111-1132, 1992.

DELONE, William H.; MCLEAN, Ephraim R. The DeLone and McLean model of information systems success: a ten-year update. Journal of management information systems, v. 19, n. 4, p. 9-30, 2003.

DESMET, Pieter MA; PORCELIJN, Rick; VAN DIJK, M. B. Emotional design; application of a research-based design approach. Knowledge, Technology \& Policy, v. 20, n. 3, p. 141, 2007.

DI RIENZO, Antonella et al. Towards a smart retail environment. In: Adjunct Proceedings of the 2015 ACM International Joint Conference on Pervasive and 
Ubiquitous Computing and Proceedings of the 2015 ACM International Symposium on Wearable Computers. ACM, 2015. p. 779-782.

DIELS, Jana Luisa; WIEBACH, Nicole; HILDEBRANDT, Lutz. The impact of promotions on consumer choices and preferences in out-of-stock situations. Journal of Retailing and Consumer Services, v. 20, n. 6, p. 587-598, 2013.

DOMINA T., LEE S.E, MACGILLIVRAY M. Understanding factors affecting consumer intention to shop in a virtual world. Journal of Retailing and Consumer Services. v 19, i. 6, p 613-620, 2012.

DUCOFFE, Robert H. advertising value and advertising on the web-Blog@ management. Journal of advertising research, p. 21, 1996.

EXTRAGLOBO, Trocas e devolução de produtos em compras online viram pesadelo para consumidor from https://extra.globo.com/noticias/economia/trocasdevolucao-de-produtos-em-compras-online-viram-pesadelo-para-consumidor23947641.html, accessed April, 2020, 2019.

EVELAND JR, William P. A "mix of attributes" approach to the study of media effects and new communication technologies. Journal of Communication, v. 53, n. 3, p. 395-410, 2003.

FAIOLA, Anthony et al. Correlating the effects of flow and telepresence in virtual worlds: Enhancing our understanding of user behavior in game-based learning. Computers in Human Behavior, v. 29, n. 3, p. 1113-1121, 2013.

FOGG, Brian J. Persuasive technology: using computers to change what we think and do. Ubiquity, v. 2002, n. December, p. 5, 2002.

FORNELL, Claes; LARCKER, David F. Structural equation models with unobservable variables and measurement error: Algebra and statistics. Journal of marketing research, p. 382-388, 1981.

FORTIN, David R.; DHOLAKIA, Ruby Roy. Interactivity and vividness effects on social presence and involvement with a web-based advertisement. Journal of business research, v. 58, n. 3, p. 387-396, 2005. 
FOROUDI, Pantea et al. Investigating the effects of smart technology on customer dynamics and customer experience. Computers in Human Behavior, v. 80, p. 271-282, 2018.

GAIOSHKO, Dariia. How Augmented Reality Can Help Retailers. mobileommercedaily.com (29 January, accessed 23 February 2016, 2014.

GAO, Qin; RAU, Pei-Luen Patrick; SALVENDY, Gavriel. Perception of interactivity: Effects of four key variables in mobile advertising. International Journal of Human-Computer Interaction, v. 25, n. 6, p. 479-505, 2009.

GAO, Tao Tony et al. Consumers un-tethered: A three-market empirical study of consumers' mobile marketing acceptance. Journal of Business Research, v. 66, n. 12, p. 2536-2544, 2013.

GARRETT, Jesse James. Elements of user experience, the: user-centered design for the web and beyond. Pearson Education, 2010.

GARVER, Michael S.; MENTZER, John T. Logistics research methods: employing structural equation modeling to test for construct validity. Journal of business logistics, v. 20, n. 1, p. 33, 1999.

GIOVANNINI, Cristiane Junqueira et al. The effects of trust transference, mobile attributes and enjoyment on mobile trust. BAR-Brazilian Administration Review, v. 12, n. 1, p. 88-108, 2015.

GRANT, Ian; O'DONOHOE, Stephanie. Why young consumers are not open to mobile marketing communication. International journal of advertising, v. 26, n. 2, p. 223-246, 2007.

GRETZEL, Ulrike et al. Smart tourism: foundations and developments. Electronic Markets, v. 25, n. 3, p. 179-188, 2015a.

GRETZEL, Ulrike et al. Conceptual foundations for understanding smart tourism ecosystems. Computers in Human Behavior, v. 50, p. 558-563, 2015b

GREWAL, Dhruv; LEVY, Michael; KUMAR, Vijay. Customer experience management in retailing: An organizing framework. Journal of retailing, v. 85, n. 1, p. 1-14, 2009. 
GUO, Yue; BARNES, Stuart , Virtual item purchase behavior in virtual worlds: an exploratory investigation. Electronic Commerce Research, v. 9, n. 1-2, p. 77-96, 2009.

GUPTA S., KIM H-W., Value-Driven Internet Shopping: The Mental Accounting Theory Perspective, Psychology and Marketing, v. 27, n. 1, p. 13-35, 2010.

GUPTA, S; VAJIC, M. The contextual and dialectical nature of experience, new service development, creating memorable experiences. Ed. J. A. Fitzsimmons; M. J. Fitzsimmons. Thousand Oaks: Sage, 2000.

GURTNER, Sebastian; REINHARDT, Ronny; SOYEZ, Katja. Designing mobile business applications for different age groups. Technological Forecasting and Social Change, v. 88, p. 177-188, 2014.

HAIR, Joseph F. et al. Multivariate Data Analysis (ed.): Pearson Prentice Hall. 2010 .

HASSENZAHL, Marc; TRACTINSKY, Noam. User experience-a research agenda. Behaviour \& information technology, v. 25, n. 2, p. 91-97, 2006.

HASSENZAHL, Marc; ULLRICH, Daniel. To do or not to do: Differences in user experience and retrospective judgments depending on the presence or absence of instrumental goals. Interacting with computers, v. 19, n. 4, p. 429-437, 2007.

HAVLENA, William J.; HOLBROOK, Morris B. The varieties of consumption experience: comparing two typologies of emotion in consumer behavior. Journal of consumer research, v. 13, n. 3, p. 394-404, 1986.

HAUSMAN, Angela V.; SIEKPE, Jeffrey Sam. The effect of web interface features on consumer online purchase intentions. Journal of Business Research, v. 62, n. 1, p. 5-13, 2009.

HE, Zeya; WU, Laurie; LI, Xiang Robert. When art meets tech: The role of augmented reality in enhancing museum experiences and purchase intentions. Tourism Management, v. 68, p. 127-139, 2018.

HILKEN, Tim et al. Augmenting the eye of the beholder: exploring the strategic potential of augmented reality to enhance online service experiences. Journal of the Academy of Marketing Science, v. 45, n. 6, p. 884-905, 2017. 
HIRSCHMAN, Elizabeth C.; HOLBROOK, Morris B. Hedonic consumption: emerging concepts, methods and propositions. The Journal of Marketing, p. 92$101,1982$.

HO CHEONG, Je; PARK, Myeong-Cheol. Mobile internet acceptance in Korea. Internet research, v. 15, n. 2, p. 125-140, 2005.

HOEHLE, Hartmut; VENKATESH, Viswanath. Mobile Application Usability: Conceptualization and Instrument Development. Mis Quarterly, v. 39, n. 2, 2015.

HOFFMAN, Donna L.; NOVAK, Thomas P. Marketing in hypermedia computermediated environments: Conceptual foundations. The Journal of Marketing, $p$. 50-68, 1996.

HOFFMAN, Donna L.; NOVAK, Thomas P. Flow online: lessons learned and prospects. Journal of interactive marketing, v. 23, n. 1, p. 23-34, 2009.

HOFFMAN, Donna L.; NOVAK, Thomas. Emergent experience and the connected consumer in the smart home assemblage and the internet of things. 2015.

HOFSTEDE, Geert; MCCRAE, Robert R. Personality and culture revisited: Linking traits and dimensions of culture. Cross-cultural research, v. 38, n. 1, p. 52-88, 2004.

HOLBROOK, Morris B. The nature of customer value: an axiology of services in the consumption experience. Service quality: New directions in theory and practice, v. 21, p. 21-71, 1994.

HOLBROOK, Morris B. (Ed.). Consumer value: a framework for analysis and research. Psychology Press, 1999.

HOMBURG, Christian; KOSCHATE, Nicole; HOYER, Wayne D. The role of cognition and affect in the formation of customer satisfaction: a dynamic perspective. Journal of marketing, 70.3: 21-31, 2006.

HOOKER, Robert; WASKO, Molly; PARADICE, David. Linking flow, brand attitudes and purchase intent in virtual worlds. ICIS 2009 Proceedings, p. 106, 2009. 
HOPP, Toby; GANGADHARBATLA, Harsha. Novelty effects in augmented reality advertising environments: The influence of exposure time and selfefficacy. Journal of Current Issues \& Research in Advertising, v. 37, n. 2, p. 113-130, 2016.

HOYER, Wayne D.; STOKBURGER-SAUER, Nicola E. The role of aesthetic taste in consumer behavior. Journal of the Academy of Marketing Science, v. 40, n. 1, p. 167-180, 2012.

HU, Li-tze; BENTLER, Peter M. Cutoff criteria for fit indexes in covariance structure analysis: Conventional criteria versus new alternatives. Structural equation modeling: a multidisciplinary journal, v. 6, n. 1, p. 1-55, 1999.

HUA, Guangying; HAUGHTON, Dominique. An investigation of virtual worlds adoption: A research framework and empirical study. In: Service Systems and Service Management, 2008 International Conference on. IEEE, 2008. p. 1-5.

HUANG, Echo. Online experiences and virtual goods purchase intention. Internet Research, v. 22, n. 3, p. 252-274, 2012.

HUANG, Ming-Hui. Modeling virtual exploratory and shopping dynamics: an environmental psychology approach. Information \& Management, v. 41, n. 1, p. 39-47, 2003

HUANG, Niexi; QIN, Guifeng. A study of online virtual fitting room adoption based on UTAUT. In: E-Business and E-Government (ICEE), 2011 International Conference on. IEEE, 2011. p. 1-4.

HUANG, Tseng-Lung. Creating a commercially compelling smart service encounter. Service Business, v. 12, n. 2, p. 357-377, 2018.

HUANG, Tseng-Lung; HSU LIU, Feng. Formation of augmented-reality interactive technology's persuasive effects from the perspective of experiential value. Internet Research, v. 24, n. 1, p. 82-109, 2014.

HUANG, Tseng-Lung; LIAO, Shuling. A model of acceptance of augmentedreality interactive technology: the moderating role of cognitive innovativeness. Electronic Commerce Research, v. 15, n. 2, p. 269-295, 2015. 
HUANG, Tseng-Lung; TSENG, Chung-Hui. Using augmented reality to reinforce vivid memories and produce a digital interactive experience. Journal of Electronic Commerce Research, v. 16, n. 4, p. 307, 2015.

HUANG, Zhanpeng et al. Mobile augmented reality survey: a bottom-up approach. arXiv preprint arXiv:1309.4413, 2013.

IPSOS RETAIL PERFORMANCE. Mirror, mirror on the wall - who's the smartest of all? Retrieved from https://www.ipsos-retailperformance.com/resources/blog/mirrormirror-on-the-wallwhos-the-smartest-of-them-all/ , 2014

JACKSON, Cynthia M.; CHOW, Simeon; LEITCH, Robert A. Toward an understanding of the behavioral intention to use an information system. Decision sciences, v. 28, n. 2, p. 357-389, 1997.

JAMALI, Siti Salmi et al. Utilizing mobile-augmented reality for learning human anatomy. Procedia-Social and Behavioral Sciences, v. 197, p. 659-668, 2015.

JAVORNIK, Ana. 'It's an illusion, but it looks real!'Consumer affective, cognitive and behavioural responses to augmented reality applications. Journal of Marketing Management, v. 32, n. 9-10, p. 987-1011, 2016a.

JAVORNIK, Ana. Augmented reality: Research agenda for studying the impact of its media characteristics on consumer behavior. Journal of Retailing and Consumer Services, v. 30, p. 252-261, $2016 b$.

JAVORNIK, Ana et al. Revealing the Shopper Experience of Using a "Magic Mirror" Augmented Reality Make-Up Application. In: Conference on Designing Interactive Systems. Association for Computing Machinery (ACM), p. 871-882. 2016.

JONSTRÖMER, H.; RENTZHOG, M.; ANÉR, E., "E-commerce - New Opportunities, New Barriers," Kommerskollegium, The National Board of Trade, Retrieved from http://www.kommers.se/InEnglish/Publications/2012/Ecommerce--New-Opportunities-NewBarriers/,2012.

JUNG, Timothy; CHUNG, Namho; LEUE, M. Claudia. The determinants of recommendations to use augmented reality technologies: The case of a Korean theme park. Tourism management, v. 49, p. 75-86, 2015. 
KAMIS, Arnold; STERN, Tziporah; LADIK, Daniel M. A flow-based model of web site intentions when users customize products in business-to-consumer electronic commerce. Information Systems Frontiers, v. 12, n. 2, p. 157-168, 2010 .

KANG, Ju-Young. M. Augmented reality and motion capture apparel e-shopping values and usage intention. International Journal of Clothing Science and Technology, v. 26, n. 6, p. 486-499, 2014.

KANG, Ju-Young M.; MUN, Jung Mee; JOHNSON, Kim KP. In-store mobile usage: Downloading and usage intention toward mobile location-based retail apps. Computers in Human Behavior, v. 46, p. 210-217, 2015.

KANNAN, P. K. et al. Digital marketing: A framework, review and research agenda. International Journal of Research in Marketing, v. 34, n. 1, p. 22-45, 2017.

KAO, Danny Tengti. The impact of transaction trust on consumers' intentions to adopt M-commerce: A cross-cultural investigation. CyberPsychology \& Behavior, v. 12, n. 2, p. 225-229, 2009.

KAYNAMA, Shohreh A.; BLACK, Christine I. A proposal to assess the service quality of online travel agencies: An exploratory study. Journal of professional services marketing, v. 21, n. 1, p. 63-88, 2000.

KENT, Anthony et al. Branding, marketing, and design: experiential in-store digital environments. In: Fashion and Textiles: Breakthroughs in Research and Practice. IGI Global, 2018. p. 275-298.

KIM, Eun Young; YOON, Namhee. Perceived QR code technological attributes in the smart shopping context. Journal of Global Fashion Marketing, v. 5, n. 4, p. 297-307, 2014.

KIM, Jihyun; FIORE, Ann Marie; LEE, Hyun-Hwa. Influences of online store perception, shopping enjoyment, and shopping involvement on consumer patronage behavior towards an online retailer. Journal of retailing and Consumer Services, v. 14, n. 2, p. 95-107, 2007.

KIM, Jiyeon; FORSYTHE, Sandra. Adoption of Virtual Try-on technology for online apparel shopping. Journal of Interactive Marketing, v. 22, n. 2, p. 45-59, 2008a. 
KIM, Jiyeon; FORSYTHE, Sandra. Sensory enabling technology acceptance model (SE-TAM): A multiple-group structural model comparison. Psychology \& Marketing, v. 25, n. 9, p. 901-922, 2008 b.

KIM, Sora; HALEY, Eric; KOO, Gi-Yong. Comparison of the paths from consumer involvement types to ad responses between corporate advertising and product advertising. Journal of Advertising, v. 38, n. 3, p. 67-80, 2009.

KIM, Hyeon-Cheol; HYUN, Martin Yongho. Predicting the use of smartphonebased Augmented Reality (AR): Does telepresence really help? Computers in Human Behavior, v. 59, p. 28-38, 2016.

KOUFARIS, Marios. Applying the technology acceptance model and flow theory to online consumer behavior. Information systems research, v. 13, n. 2, p. 205-223, 2002.

KULVIWAT, Songpol, et al. Toward a unified theory of consumer acceptance technology. Psychology and Marketing, 2007, 24.12: 1059-1084.

KUMAR, V., PANSARI, A. Competitive advantage through engagement. Journal of Marketing Research, v. 53 n. 4, p. 497-514. 2016.

LAW, Effie Lai-Chong et al. Understanding, scoping and defining user experience: a survey approach. In: Proceedings of the SIGCHI conference on human factors in computing systems. ACM, 2009. p. 719-728.

LEE, Eun-Jung; PARK, Jihye. Enhancing virtual presence in e-tail: Dynamics of cue multiplicity. International Journal of Electronic Commerce, v. 18, n. 4, p. 117-146, 2014.

LEE, Hyun-Hwa; FIORE, Ann Marie; KIM, Jihyun. The role of the technology acceptance model in explaining effects of image interactivity technology on consumer responses. International Journal of Retail \& Distribution Management, v. 34, n. 8, p. 621-644, 2006.

LEE, Hyunae; CHUNG, Namho; JUNG, Timothy. Examining the cultural differences in acceptance of mobile augmented reality: Comparison of South Korea and Ireland. In: Information and communication technologies in tourism 2015. Springer, Cham, 2015. p. 477-491. 
LEE, Kun Chang; CHUNG, Namho. Empirical analysis of consumer reaction to the virtual reality shopping mall. Computers in Human Behavior, v. 24, n. 1, p. 88104, 2008.

LEE, Younghwa; KOZAR, Kenneth A.; LARSEN, Kai RT. The technology acceptance model: Past, present, and future. Communications of the Association for information systems, v. 12, n. 1, p. 50, 2003.

LEGRIS, Paul; INGHAM, John; COLLERETTE, Pierre. Why do people use information technology? A critical review of the technology acceptance model. Information \& management, v. 40, n. 3, p. 191-204, 2003.

LEMOINE, J.F., NOTEBAERT, J.F. Agent virtuel et confiance des internautes visà-vis d'un site Web. Déci. Mark. V. 61, p. 47-53, 2011.

LI, Yung-Ming; YEH, Yung-Shao. Increasing trust in mobile commerce through design aesthetics. Computers in Human Behavior, v. 26, n. 4, p. 673-684, 2010.

LILJANDER, Veronica et al. Technology readiness and the evaluation and adoption of self-service technologies. Journal of Retailing and Consumer Services, v. 13, n. 3, p. 177-191, 2006.

LIM, Yi Jin et al. Factors influencing online shopping behavior: the mediating role of purchase intention. Procedia Economics and Finance, v. 35, p. 401-410, 2016.

LIN, Hsiu-Fen. An empirical investigation of mobile banking adoption: The effect of innovation attributes and knowledge-based trust. International journal of information management, v. 31, n. 3, p. 252-260, 2011.

LINDGAARD, Gitte; DUDEK, Cathy. What is this evasive beast we call user satisfaction? Interacting with computers, v. 15, n. 3, p. 429-452, 2003.

LIU, Yuping; SHRUM, L. J. What is interactivity and is it always such a good thing? Implications of definition, person, and situation for the influence of interactivity on advertising effectiveness. Journal of advertising, v. 31, n. 4, p. 5364, 2002.

LU, Jiaying et al. Goodbye maps, hello apps? Exploring the influential determinants of travel app adoption. Current issues in Tourism, v. 18, n. 11, p. 1059-1079, 2015. 
LU, Yuzhu; SMITH, Shana. Augmented reality e-commerce assistant system: trying while shopping. In: International Conference on Human-Computer Interaction. Springer, Berlin, Heidelberg, 2007. p. 643-652.

MAGNI, Massimo; TAYLOR, M. Susan; VENKATESH, Viswanath. 'To play or not to play': A cross-temporal investigation using hedonic and instrumental perspectives to explain user intentions to explore a technology. International journal of human-computer studies, v. 68, n. 9, p. 572-588, 2010.

MANTRALA, Murali K.; KRAFFT, Manfred. Entrepreneurship in Retailing: Leopold Stiefel's "Big Idea" and the Growth of Media Market and Saturn. In: Retailing in the 21st Century. Springer, Berlin, Heidelberg, 2010. p. 43-60.

MARDIA, K. V. Measures of Multivariate Skewness and Kurtosis with Applications. Biometrika, v. 57, pp. 519-530, 1970.

MARKETSANDMARKETS. Augmented Reality and Virtual Reality Market by Offering (Hardware \& Software), Device Type (HMD, HUD, Handheld Device, Gesture Tracking), Application (Enterprise, Consumer, Commercial, Healthcare, Automotive), and Geography - Global Forecast to 2023, https://www.marketsandmarkets.com/search.asp?search=Augmented+Reality ， accessed June 2018, 2018.

MARTÍNEZ, Héctor et al. Drivers and bottlenecks in the adoption of augmented reality applications. Journal ISSN, v. 2368, p. 5956, 2014.

MATHWICK, Charla; MALHOTRA, Naresh; RIGDON, Edward. Experiential value: conceptualization, measurement and application in the catalog and Internet shopping environment is 1. Journal of retailing, v. 77, n. 1, p. 39-56, 2001.

MATHWICK, Charla; RIGDON, Edward. Play, flow, and the online search experience. Journal of consumer research, v. 31, n. 2, p. 324-332, 2004.

MCCARTHY, John; WRIGHT, Peter. Technology as experience. interactions, v. 11, n. 5, p. 42-43, 2004.

MEHRABIAN, A., RUSSELL, J. An Approach to Environmental Psychology, MIT Press, Cambridge, MA. 1974. 
MERLE, Aurélie; SENECAL, Sylvain; ST-ONGE, Anik. Whether and how virtual try-on influences consumer responses to an apparel web site. International Journal of Electronic Commerce, v. 16, n. 3, p. 41-64, 2012.

MICHAELIS, Dicionário Escolar da Língua Portuguesa, Editora Melhoramento, 2008.

MILGRAM, Paul; KISHINO, Fumio. A taxonomy of mixed reality visual displays. IEICE TRANSACTIONS on Information and Systems, v. 77, n. 12, p. 1321-1329, 1994.

MORRISON, Donald G. Purchase intentions and purchase behavior. Journal of marketing, v. 43, n. 2, p. 65-74, 1979.

MÜLLER-SEITZ, Gordon et al. Customer acceptance of RFID technology: Evidence from the German electronic retail sector. Journal of retailing and consumer services, v. 16, n. 1, p. 31-39, 2009.

MURRAY, Kyle B.; HÄUBL, Gerald. Interactive consumer decision aids. In: Handbook of marketing decision models. Springer, Boston, MA, 2008. p. 5577.

MURRAY, Kyle B.; LIANG, Jianping; HÄUBL, Gerald. ACT 2.0: the next generation of assistive consumer technology research. Internet Research, v. 20, n. 3, p. 232-254, 2010.

NAH, F.F. H et al., Impact of flow and brand equity in 3D virtual worlds, Journal of Database Management, v. 21, n. 3, p. 69-89, 2010.

NEL, Deon et al. Going with the flow: Web sites and customer involvement. Internet research, v. 9, n. 2, p. 109-116, 1999.

NEUHOFER, Barbara; BUHALIS, Dimitrios; LADKIN, Adele. Smart technologies for personalized experiences: a case study in the hospitality domain. Electronic Markets, v. 25, n. 3, p. 243-254, 2015.

NEWSOM, Mi Kyong; COLLIER, David A.; OLSEN, Eric O. Using "biztainment" to gain competitive advantage. Business Horizons, v. 52, n. 2, p. 167-176, 2009. 
NOORDIN, Syazwan; ASHAARI, Noraidah Sahari; WOOK, Tengku Siti Meriam Tengku. Virtual fitting room: The needs for usability and profound emotional elements. In: Electrical Engineering and Informatics (ICEEI), 2017 6th International Conference on. IEEE, 2017. p. 1-6.

NUNNALLY, Jum C.; BERNSTEIN, Ira H. Psychometric theory. 1978.

OH, Hyunjoo; YOON, So-Yeon; SHYU, Chi-Ren. How can virtual reality reshape furniture retailing? Clothing and Textiles Research Journal, v. 26, n. 2, p. 143$163,2008$.

OLIVER, Richard L. Effect of expectation and disconfirmation on postexposure product evaluations: An alternative interpretation. Journal of applied psychology, v. 62, n. 4, p. 480, 1977.

OLIVER, Richard L. A cognitive model of the antecedents and consequences of satisfaction decisions. Journal of marketing research, p. 460-469, 1980.

OLIVER, Richard L.; LINDA, Gerald. Effect of satisfaction and its antecedents on consumer preference and intention. ACR North American Advances, 1981.

OLSSON, Ulf Henning et al. The performance of ML, GLS, and WLS estimation in structural equation modeling under conditions of misspecification and nonnormality. Structural equation modeling, v. 7, n. 4, p. 557-595, 2000.

OLSSON, Thomas et al. Expected user experience of mobile augmented reality services: a user study in the context of shopping centres. Personal and ubiquitous computing, v. 17, n. 2, p. 287-304, 2013.

OVERMARS, Suzanne; POELS, Karolien. A touching experience: Designing for touch sensations in online retail environments. International journal of design. Taipei, 2007, currens, v. 9, n. 3, p. 17-31, 2015.

PALMER, Adrian. Customer experience management: a critical review of an emerging idea. Journal of Services marketing, 2010.

PANTANO, Eleonora. Augmented reality in retailing of local products of Magna Grcia: consumer's response. International Journal of Management Cases, v. 11, n. 2, p. 206-213, 2009. 
PANTANO, Eleonora. Innovation management in retailing: From consumer perspective to corporate strategy. Call for paper Special Issue of Journal of Retailing and Consumer Services, 2014.

PANTANO, Eleonora; NACCARATO, Giuseppe. Entertainment in retailing: The influences of advanced technologies. Journal of Retailing and Consumer Services, v. 17, n. 3, p. 200-204, 2010.

PANTANO, Eleonora; PRIPORAS, Constantinos-Vasilios. The effect of mobile retailing on consumers' purchasing experiences: A dynamic perspective. Computers in Human Behavior, v. 61, p. 548-555, 2016.

PANTANO, Eleonora; RESE, Alexandra; BAIER, Daniel. Enhancing the online decision-making process by using augmented reality: A two country comparison of youth markets. Journal of Retailing and Consumer Services, v. 38, p. 81-95, 2017.

PANTANO, Eleonora; SERVIDIO, Rocco. Modeling innovative points of sales through virtual and immersive technologies. Journal of Retailing and Consumer Services, v. 19, n. 3, p. 279-286, 2012.

PANTANO, Eleonora; VIASSONE, Milena. Demand pull and technology push perspective in technology-based innovations for the points of sale: The retailer's evaluation. Journal of Retailing and Consumer Services, v. 21, n. 1, p. 43-47, 2014.

PANTANO, Eleonora; TIMMERMANS, Harry. What is smart for retailing?. Procedia Environmental Sciences, v. 22, p. 101-107, 2014.

PEREIRA, Francisco; SILVA, Catarina; ALVES, Mário. Virtual fitting room augmented reality techniques for e-commerce. In: International conference on Enterprise information systems. Springer, Berlin, Heidelberg, 2011. p. 62-71.

PERSAUD, Ajax; AZHAR, Irfan. Innovative mobile marketing via smartphones: Are consumers ready? Marketing Intelligence \& Planning, v. 30, n. 4, p. 418443, 2012.

PIRES, Guilherme; STANTON, John; ECKFORD, Andrew. Influences on the perceived risk of purchasing online. Journal of Consumer Behaviour: An International Research Review, v. 4, n. 2, p. 118-131, 2004. 
PREECE, Jenny; ROGERS, Yvonne; SHARP, Helen. Interaction design: beyond human-computer interaction. John Wiley \& Sons, 2015.

PONCIN, Ingrid; MIMOUN, Mohamed Slim Ben. The impact of "e-atmospherics" on physical stores. Journal of Retailing and Consumer Services, v. 21, n. 5, p. 851-859, 2014.

PORTER, Constance Elise; DONTHU, Naveen. Using the technology acceptance model to explain how attitudes determine Internet usage: The role of perceived access barriers and demographics. Journal of business research, v. 59, n. 9, p. 999-1007, 2006.

PORTER, Michael E.; HEPPELMANN, James E. Why every organization needs an augmented reality strategy. Harvard Business Review, v. 6, p. 46-57, 2017.

POUSHNEH, Atieh. Augmented reality in retail: A trade-off between user's control of access to personal information and augmentation quality. Journal of Retailing and Consumer Services, v. 41, p. 169-176, 2018.

POUSHNEH, Atieh; VASQUEZ-PARRAGA, Arturo Z. Discernible impact of augmented reality on retail customer's experience, satisfaction and willingness to buy. Journal of Retailing and Consumer Services, v. 34, p. 229-234, 2017.

POUSTTCHI, Key et al. Introduction to the special issue on mobile commerce: mobile commerce research yesterday, today, tomorrow — what remains to be done? 2015.

POUSTTCHI, Key; HUFENBACH, Yvonne. Engineering the value network of the customer interface and marketing in the data-rich retail environment. International Journal of Electronic Commerce, v. 18, n. 4, p. 17-42, 2014.

RAYKOV, Tenko; MARCOULIDES, George A. A method for comparing completely standardized solutions in multiple groups. Structural equation modeling, v. 7, n. 2, p. 292-308, 2000.

RAMAKRISHNA, Venkatraman et al. An un-tethered mobile shopping experience. In: International Conference on Mobile and Ubiquitous Systems: Computing, Networking, and Services. Springer, Cham, 2013. p. 409-421.

RAUSCHNABEL, Philipp A.; BREM, Alexander; IVENS, Bjoern S. Who will buy smart glasses? Empirical results of two pre-market-entry studies on the role of 
personality in individual awareness and intended adoption of Google Glass wearables. Computers in Human Behavior, v. 49, p. 635-647, 2015.

RAUSCHNABEL, Philipp A.; RO, Young K. Augmented reality smart glasses: An investigation of technology acceptance drivers. International Journal of Technology Marketing, v. 11, n. 2, p. 123-148, 2016.

RESE, Alexandra et al. How augmented reality apps are accepted by consumers: A comparative analysis using scales and opinions. Technological Forecasting and Social Change, v. 124, p. 306-319, 2017.

RESE, Alexandra; SCHREIBER, Stefanie; BAIER, Daniel. Technology acceptance modeling of augmented reality at the point of sale: Can surveys be replaced by an analysis of online reviews? Journal of Retailing and Consumer Services, v. 21, n. 5, p. 869-876, 2014.

ROACH, Gemma. Consumer perceptions of mobile phone marketing: a direct marketing innovation. Direct marketing: an international journal, v. 3, n. 2, p. 124-138, 2009.

ROGERS, Everett M. Diffusion of Innovations. 5ed.New York: Free Press, 2003.

ROSE, Susan et al. Online customer experience in e-retailing: an empirical model of antecedents and outcomes. Journal of Retailing, v. 88, n. 2, p. 308-322, 2012.

ROSS, Heather F.; HARRISON, Tina. Augmented reality apparel: An appraisal of consumer knowledge, attitude and behavioral intentions. In: System Sciences (HICSS), 2016 49th Hawaii International Conference on. IEEE, 2016. p. 39193927.

ROY, Sanjit Kumar et al. Constituents and consequences of smart customer experience in retailing. Technological Forecasting and Social Change, v. 124, p. 257-270, 2017.

SAARIJÄRVI, Hannu; MITRONEN, Lasse; YRJÖLÄ, Mika. From selling to supporting-Leveraging mobile services in the context of food retailing. Journal of Retailing and consumer services, v. 21, n. 1, p. 26-36, 2014.

SALO, Markus et al. Consumer value of camera-based mobile interaction with the real world. Pervasive and Mobile Computing, v. 9, n. 2, p. 258-268, 2013. 
SCARDAMALIA, M., BEREITER, C. Smart technology for self-organizing processes. Smart Learn. Environ. v.1, n. 1, p. 1-13. http://dx.doi.org/10.1186/s40561-014-00018, 2014.

SCHARL, Arno; DICKINGER, Astrid; MURPHY, Jamie. Diffusion and success factors of mobile marketing. Electronic commerce research and applications, v. 4, n. 2, p. 159-173, 2005.

SCHMALSTIEG, Dieter; HOLLERER, Tobias. Augmented reality: principles and practice. Addison-Wesley Professional, 2016.

SCHMITT, Bernd H. Experiential marketing: How to get customers to sense, feel, think, act, relate. Simon and Schuster, 2000.

SCHOLZ, Joachim; DUFFY, Katherine. We ARe at home: How augmented reality reshapes mobile marketing and consumer-brand relationships. Journal of Retailing and Consumer Services, v. 44, p. 11-23, 2018.

SCHOLZ, Joachim; SMITH, Andrew N. Augmented reality: Designing immersive experiences that maximize consumer engagement. Business Horizons, v. 59, n. 2, p. 149-161, 2016.

SCHREIBER, James B.; NORA, A.; STAGE, F. K.; BARLOW, E. A.; KING, J. Reporting structural equation modeling and confirmatory factor analysis results: A review. The Journal of educational research, v. 99, n. 6, p. 323-338, 2006.

SCHWARTZ, Amanda Michelle. Augmenting Purchase Intent: An Empirical Study on the Effects of Utilizing Augmented Reality in Online Shopping. 2011.

SENECAL, S., NANTEL, J. The influence of online product recommendations on consumers' online choices. J. Retail. V.80 n.2, p. 159-169. 2004.

SHANKAR, Venkatesh et al. Mobile marketing in the retailing environment: current insights and future research avenues. Journal of interactive marketing, v. 24, n. 2, p. 111-120, 2010.

SHANKAR, Venkatesh et al. Innovations in shopper marketing: current insights and future research issues. Journal of Retailing, v. 87, p. S29-S42, 2011. 
SHANKAR, Venkatesh et al. Mobile shopper marketing: Key issues, current insights, and future research avenues. Journal of Interactive Marketing, v. 34, p. 37-48, 2016.

SIMON, Françoise; USUNIER, Jean-Claude. Cognitive, demographic, and situational determinants of service customer preference for personnel-in-contact over self-service technology. International Journal of Research in Marketing, v. 24, n. 2, p. 163-173, 2007.

SIMONSON, Itamar; CARMON, Ziv; O'CURRY, Suzanne. Experimental evidence on the negative effect of product features and sales promotions on brand choice. Marketing Science, v. 13, n. 1, p. 23-40, 1994.

SINGH, Mona; SINGH, Munindar P. Augmented reality interfaces. IEEE Internet Computing, v. 17, n. 6, p. 66-70, 2013.

SIVO, Stephen A.; FAN, X.; WITTA, E. L.; WILLSE, J. T. The search for" optimal" cutoff properties: Fit index criteria in structural equation modeling. The Journal of Experimental Education, v. 74, n. 3, p. 267-288, 2006.

SPAKE, D.F. et al. Consumer comfort in service relationships measurement and importance. Journal of Service Research, v.5 n. 4, p. 316-332. 2003.

SPERBER, Ami D. Translation and validation of study instruments for crosscultural research. Gastroenterology, v. 126, p. S124-S128, 2004.

SPIEGELMAN, Paul. Live Customer Interaction and the Internet Join in'Internaction'. Direct Marketing, v. 63, n. 4, p. 38-39, 2000.

SPREER, Philipp; KALLWEIT, Katrin. Augmented reality in retail: assessing the acceptance and potential for multimedia product presentation at the PoS. Transactions on Marketing Research, v. 1, n. 1, p. 20-35, 2014.

STOYANOVA, Jasmina et al. Comparison of consumer purchase intention between interactive and augmented reality shopping platforms through statistical analyses. In: Innovations in Intelligent SysTems and Applications (INISTA), 2015 International Symposium on. IEEE, 2015. p. 1-8.

SUNDAR, S. Shyam et al. Toward a theory of interactive media effects (TIME). The handbook of the psychology of communication technology, p. 4786, 2015. 
SWAMINATHAN, Vanitha. The impact of recommendation agents on consumer evaluation and choice: the moderating role of category risk, product complexity, and consumer knowledge. Journal of Consumer Psychology, v. 13, n. 1-2, p. 93$101,2003$.

TANNER, Jeff; RAYMOND, M. A. Marketing principles. Irvington, NY: Flat World Knowledge, 2012.

TECMUNDO, Douglas V. Um ano depois nenhum App superou o sucesso inicial do Pokemón Go. Cultura Geek. Tecmundo, 21 jul 2017.

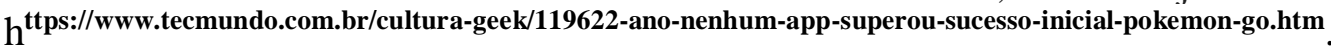
2017

TO, P., LIAO, C., LIN, T. Shopping motivations on Internet: a study based on utilitarian and hedonic value. Technovation. v. 27, n.12, p. 774-784. 2007

TRUMAN, G.E., SANDOE, K., RIFKIN, T. An Empirical Study of Smart Card Technology. Inf. Manag. 40 (6), 591-606. http://dx.doi.org/10.1016/S03787206(02)00046-0. 2003.

VAN KREVELEN, D. W. F.; POELMAN, Ronald. A survey of augmented reality technologies, applications and limitations. International journal of virtual reality, v. 9, n. 2, p. 1, 2010.

VAN NOORT, Guda; VOORVELD, Hilde AM; VAN REIJMERSDAL, Eva A. Interactivity in brand web sites: cognitive, affective, and behavioral responses explained by consumers' online flow experience. Journal of Interactive Marketing, v. 26, n. 4, p. 223-234, 2012.

VARADARAJAN, Rajan et al. Interactive technologies and retailing strategy: A review, conceptual framework and future research directions. Journal of Interactive Marketing, v. 24, n. 2, p. 96-110, 2010.

VENKATESH, Viswanath. Determinants of perceived ease of use: Integrating control, intrinsic motivation, and emotion into the technology acceptance model. Information systems research, v. 11, n. 4, p. 342-365, 2000.

VENKATESH, Viswanath; BALA, Hillol. Technology acceptance model 3 and a research agenda on interventions. Decision sciences, v. 39, n. 2, p. 273-315, 2008. 
VENKATESH, Viswanath; DAVIS, Fred D. A theoretical extension of the technology acceptance model: Four longitudinal field studies. Management science, v. 46, n. 2, p. 186-204, 2000.

VENKATESH, Viswanath et al. User acceptance of information technology: Toward a unified view. MIS quarterly, p. 425-478, 2003.

VENKATESH, Viswanath; THONG, James YL; XU, Xin. Consumer acceptance and use of information technology: extending the unified theory of acceptance and use of technology. MIS quarterly, p. 157-178, 2012.

VIOT, C., BRESSOLLES, G. Les agents virtuels intelligents quels atouts pour la relation client? Décis. Mark. V. 65, p. 45-56, 2012

WALLACE, S. The State of Retail. Online Shopping Survey, 2015.

WANG, L.C. et al. Can a retail web site be social? J. Mark. V. 71, p. 143-157. 2007

WANG, Wei-Tsong; LI, Hui-Min. Factors influencing mobile services adoption: a brand-equity perspective. Internet Research, v. 22, n. 2, p. 142-179, 2012.

WEBSTER, Jane; TREVINO, Linda Klebe; RYAN, Lisa. The dimensionality and correlates of flow in human-computer interactions. Computers in human behavior, v. 9, n. 4, p. 411-426, 1993.

WEI, Jie; LOWRY, Paul Benjamin; SEEDORF, Stefan. The assimilation of RFID technology by Chinese companies: A technology diffusion perspective. Information \& Management, v. 52, n. 6, p. 628-642, 2015.

WILLEMS, Kim et al. The path-to-purchase is paved with digital opportunities: An inventory of shopper-oriented retail technologies. Technological Forecasting and Social Change, v. 124, p. 228-242, 2017.

WIXOM, Barbara H.; TODD, Peter A. A theoretical integration of user satisfaction and technology acceptance. Information systems research, v. 16, n. 1, p. 85-102, 2005 .

WON JEONG, So et al. The role of experiential value in online shopping: The impacts of product presentation on consumer responses towards an apparel web site. Internet Research, v. 19, n. 1, p. 105-124, 2009. 
WU, Kewen et al. A meta-analysis of the impact of trust on technology acceptance model: Investigation of moderating influence of subject and context type. International Journal of Information Management, v. 31, n. 6, p. 572-581, 2011.

WÜNDERLICH, Nancy V.; WANGENHEIM, Florian V.; BITNER, Mary Jo. High tech and high touch: a framework for understanding user attitudes and behaviors related to smart interactive services. Journal of Service Research, v. 16, n. 1, p. $3-20,2013$

WUENDERLICH et al. Futurizing smart service: implications for service researchers and managers. J. Serv. Mark. 29 (6/7), 442-447. http://dx.doi.org/10.1108/JSM01-2015-0040 2015

YADAV, Manjit S.; PAVLOU, Paul A. Marketing in computer-mediated environments: Research synthesis and new directions. Journal of Marketing, v. 78, n. 1, p. 20-40, 2014.

YAOYUNEYONG, Gallayanee et al. Augmented reality marketing: Consumer preferences and attitudes toward hypermedia print ads. Journal of Interactive Advertising, v. 16, n. 1, p. 16-30, 2016.

YIM, Mark Yi-Cheon; CHU, Shu-Chuan; SAUER, Paul L. Is augmented reality technology an effective tool for e-commerce? An interactivity and vividness perspective. Journal of Interactive Marketing, v. 39, p. 89-103, 2017.

YOUSAFZAI, Shumaila Y.; FOXALL, Gordon R.; PALLISTER, John G. Technology acceptance: a meta-analysis of the TAM: Part 1. Journal of Modelling in Management, v. 2, n. 3, p. 251-280, 2007.

YOON, Song-Oh; SIMONSON, Itamar. Choice set configuration as a determinant of preference attribution and strength. Journal of Consumer Research, v. 35, n. 2, p. 324-336, 2008.

YU, Ui-jeen. Relationship of body satisfaction to virtual product experience and perceived risk of product performance in online and multi-channel apparel shopping. 2009. 
YUAN, Yi-Hua "Erin"; WU, Chihkang "Kenny". Relationships among experiential marketing, experiential value, and customer satisfaction. Journal of Hospitality \& Tourism Research, v. 32, n. 3, p. 387-410, 2008.

ZHOU, Lina; DAI, Liwei; ZHANG, Dongsong. Online shopping acceptance model-A critical survey of consumer factors in online shopping. Journal of Electronic commerce research, v. 8, n. 1, 2007.

ZHU, Dong Hong; WANG, Ya Wei; CHANG, Ya Ping. The influence of online cross-recommendation on consumers' instant cross-buying intention: the moderating role of decision-making difficulty. Internet Research, v. 28, n. 3, p. 604-622, 2018. 


\section{APÊNDICES}

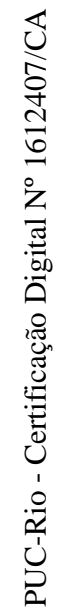


Apêndice A - Questionário

Prezado(a) entrevistado(a),

Por favor, responda a todas as perguntas deste questionário com atenção.

SÓ RESPONDA APÓS TER EXPERIMENTADO O APLICATIVO DA RAY-BAN COM A TECNOLOGIA DE REALIDADE AUMENTADA.

AGRADEÇO DESDE JÁ SUA COLABORAÇÃO.

1. Responda as perguntas a seguir sobre compras online via dispositivo móvel e sobre o seu conhecimento sobre Realidade Aumentada.

1. Você tem hábito de fazer compras online via dispositivo móvel (smartphones ou tablets)?

$\operatorname{Sim}$

Não

2. Você já tinha conhecimento sobre a tecnologia de Realidade Aumentada antes desta experiência com o aplicativo da Ray-Ban?

Sim

Não

3. Você já tinha usado algum aplicativo com Realidade Aumentada antes desta experiência com o aplicativo da Ray-Ban?

$\operatorname{Sim}$

Não 
4. Qual é, em geral, a sua frequência de busca de informações para compra de produtos via smartphone e tablets?

Diária

Semanal

Quinzenal

Mensal

Bimestral

Semestral

Nunca

5. Qual é, em geral, a sua frequência de compra de produtos via smartphone e tablets?

Diária

Semanal

Quinzenal

Mensal

Bimestral

Semestral

Nunca 
2. Marque o seu grau de concordância ou discordância com cada uma das afirmativas abaixo. Estas afirmativas referem-se a sua experiência com uso do aplicativo da Ray-Ban com tecnologia de Realidade Aumentada via dispositivo

móvel.

\begin{tabular}{|c|c|c|c|c|c|c|}
\hline & & \begin{tabular}{|c|} 
Discordo \\
totalmente
\end{tabular} & \begin{tabular}{|l} 
Discordo \\
em parte
\end{tabular} & \begin{tabular}{|c|} 
Nem \\
concordo, \\
nem \\
discordo \\
\end{tabular} & $\begin{array}{l}\text { Concordo } \\
\text { em parte }\end{array}$ & $\begin{array}{l}\text { Concordo } \\
\text { Totalmente }\end{array}$ \\
\hline PE1 & Eu me diverti interagindo com o aplicativo Ray-Ban que usa a tecnologia de Realidade Aumentada. & & & & & \\
\hline PE2 & O uso do aplicativo Ray-Ban com a tecnologia de Realidade Aumentada me proporcionou prazer. & & & & & \\
\hline PE3 & Eu gostei de usar o aplicativo Ray-Ban com a tecnologia de Realidade Aumentada. & & & & & \\
\hline RA1 & $\begin{array}{l}\text { Usar o aplicativo da Ray-Ban com a tecnologia de Realidade Aumentada foi mais conveniente do } \\
\text { que sem esta tecnologia. }\end{array}$ & & & & & \\
\hline RA2 & $\begin{array}{l}\text { Foi mais fácil usar o aplicativo da Ray-Ban com a tecnologia de Realidade Aumentada do que sem } \\
\text { esta tecnologia. }\end{array}$ & & & & & \\
\hline RA3 & $\begin{array}{l}\text { Usar o aplicativo da Ray-Ban com a tecnologia de Realidade Aumentada me permitiu uma melhor } \\
\text { experiência de compra online. }\end{array}$ & & & & & \\
\hline RA4 & $\begin{array}{l}\text { O aplicativo da Ray-Ban com a tecnologia de Realidade Aumentada apresentou resultados } \\
\text { consistentes. }\end{array}$ & & & & & \\
\hline $\mathrm{PC} 1$ & $\begin{array}{l}\text { Ao usar o aplicativo da Ray-Ban com a tecnologia de Realidade Aumentada, eu me senti no controle } \\
\text { da experiência. }\end{array}$ & & & & & \\
\hline $\mathrm{PC2}$ & $\begin{array}{l}\text { Ao usar o aplicativo da Ray-Ban com a tecnologia de Realidade Aumentada, a minha atenção ficou } \\
\text { focada nisto. }\end{array}$ & & & & & \\
\hline $\mathrm{PC} 3$ & $\begin{array}{l}\text { Eu tive as condiçöes necessárias para usar o aplicativo da Ray-Ban com a tecnologia de Realidade } \\
\text { Aumentada. }\end{array}$ & & & & & \\
\hline PA1 & $\begin{array}{l}\text { Eu percebi os óculos virtuais acrescentados no meu rosto no aplicativo da Ray-Ban com a tecnologia } \\
\text { de Realidade Aumentada. }\end{array}$ & & & & & \\
\hline $\mathrm{PA} 2$ & $\begin{array}{l}\text { Ao terminar o uso do aplicativo da Ray-Ban com a tecnologia de Realidade Aumentada, eu ainda } \\
\text { conseguia imaginar os óculos virtuais no meu rosto. }\end{array}$ & & & & & \\
\hline PA3 & Os óculos virtuais da Ray-Ban no aplicativo me pareceram reais. & & & & & \\
\hline PA4 & $\begin{array}{l}\text { Eu achei que os óculos virtuais do aplicativo da Ray-Ban nada acrescentaram à experiência de } \\
\text { compra online. }\end{array}$ & & & & & \\
\hline PA5 & A realidade pareceu mais rica com o aplicativo da Ray-ban com a tecnologia Realidade Aumentada. & & & & & \\
\hline$\left.\mathbf{P 1}\right|_{\mathrm{F}} ^{\mathrm{C}}$ & $\begin{array}{l}\text { O aplicativo da Ray-Ban com a tecnologia de Realidade Aumentada me ofereceu opçöes } \\
\text { personalizadas. }\end{array}$ & & & & & \\
\hline $\mathbf{P 2} 2 \begin{array}{lll}\mathrm{c} \\
\mathrm{r}\end{array}$ & $\begin{array}{l}\text { O aplicativo da Ray-Ban com a tecnologia de Realidade Aumentada identificou as minhas } \\
\text { necessidades específicas. }\end{array}$ & & & & & \\
\hline P3 3 & $\begin{array}{l}\text { O aplicativo da Ray-Ban com a tecnologia de Realidade Aumentada ofereceu recomendaçōes que } \\
\text { correspondem às minhas necessidades para a situação. }\end{array}$ & & & & & \\
\hline & $\begin{array}{l}\text { O aplicativo da Ray-Ban com a tecnologia de Realidade Aumentada é personalizado de acordo com } \\
\text { minhas necessidades. }\end{array}$ & & & & & \\
\hline
\end{tabular}


3. Marque o seu grau de concordância ou discordância com cada uma das afirmativas abaixo. Estas afirmativas referem-se as suas avaliações e percepções após a experiência usando o aplicativo de óculos da Ray-Ban com Realidade Aumentada relacionada a sua intenção de compra.

\begin{tabular}{|c|c|c|c|c|c|}
\hline & & $\begin{array}{c}\text { Discordo } \\
\text { totalmente }\end{array}$ & $\begin{array}{l}\text { Discordo } \\
\text { em parte }\end{array}$ & $\begin{array}{c}\text { Nem } \\
\text { concordo, } \\
\text { nem } \\
\text { discordo }\end{array}$ & $\begin{array}{l}\text { Concordo } \\
\text { em parte }\end{array}$ \\
\hline Cc1 & $\begin{array}{l}\text { Eu me senti confiante para escolher os óculos quando usei o aplicativo da Ray-Ban com } \\
\text { Realidade Aumentada. }\end{array}$ & & & & \\
\hline $\mathrm{CC} 2$ & $\begin{array}{l}\text { Eu me senti à vontade para escolher os óculos quando usei o aplicativo da Ray-Ban com } \\
\text { Realidade Aumentada. }\end{array}$ & & & & \\
\hline $\mathrm{CC} 3$ & $\begin{array}{l}\text { Eu me senti no controle para escolher os óculos quando usei o aplicativo da Ray-Ban com } \\
\text { Realidade Aumentada. }\end{array}$ & & & & \\
\hline US1 & Estou satisfeito(a) com aplicativo da Ray-Ban com Realidade Aumentada. & & & & \\
\hline US2 & O aplicativo da Ray-Ban com Realidade Aumentada superou as minhas expectativas. & & & & \\
\hline US3 & $\begin{array}{l}\text { O aplicativo da Ray-Ban com Realidade Aumentada está próximo do que considero um } \\
\text { aplicativo ideal para compra online. }\end{array}$ & & & & \\
\hline POE1 & Eu fiquei estimulado(a) quando usei o aplicativo da Ray-Ban com Realidade Aumentada. & & & & \\
\hline POE2 & Eu fiquei empolgado(a) quando usei o aplicativo da Ray-Ban com Realidade Aumentada. & & & & \\
\hline POE3 & Eu fiquei agitado(a) quando usei o aplicativo de da Ray-Ban com Realidade Aumentada. & & & & \\
\hline POE4 & $\begin{array}{l}\text { Eu fiquei tenso(a) quando usei o aplicativo de aplicativo da Ray-Ban com Realidade } \\
\text { Aumentada. }\end{array}$ & & & & \\
\hline POE5 & $\begin{array}{l}\text { Eu fiquei animado(a) quando usei o aplicativo de aplicativo da Ray-Ban com Realidade } \\
\text { Aumentada. }\end{array}$ & & & & \\
\hline POE6 & $\begin{array}{l}\text { Eu fiquei esperto(a) quando usei o aplicativo de aplicativo da Ray-Ban com Realidade } \\
\text { Aumentada. }\end{array}$ & & & & \\
\hline POE7 & $\begin{array}{l}\text { Eu fiquei ativo(a) quando usei o aplicativo de aplicativo da Ray-Ban com Realidade } \\
\text { Aumentada. }\end{array}$ & & & & \\
\hline POE8 & $\begin{array}{l}\text { Eu fiquei entusiasmado(a) quando usei o aplicativo de aplicativo da Ray-Ban com Realidade } \\
\text { Aumentada. }\end{array}$ & & & & \\
\hline PI1 & $\begin{array}{l}\text { Eu poderia me imaginar comprando produtos por meio deste aplicativo da Ray-Ban com } \\
\text { Realidade Aumentada. }\end{array}$ & & & & \\
\hline PI2 & $\begin{array}{l}\text { Da próxima vez que for comprar óculos, levarei em consideração este aplicativo da Ray-Ban } \\
\text { com Realidade Aumentada. }\end{array}$ & & & & \\
\hline PI3 & Eu tenho interesse em comprar óculos pelo aplicativo Ray-Ban com Realidade Aumentada. & & & & \\
\hline
\end{tabular}

\section{Informe os seus dados Pessoais}

1. Idade

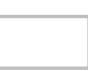

2. Sexo

Feminino

Masculino 


\section{Estado Civil}

Solteiro

Casado

Relacionamento Fixo

Outros

4. Faixa de renda familiar estimada.

Abaixo de 1000 reais

Entre 1000 e 3500 reais

Entre 3500 e 6000 reais

Entre 6000 e 10000 reais

Acima de 10000 reais

Prefiro não informar

5. - Grau de Escolaridade:

Graduação incompleta

Graduação completa

Pós-graduação Lato Sensu incompleta

Pós-graduação Lato Sensu completa

Mestrado incompleto

Mestrado completo

Doutorado incompleto

Doutorado completo 
Apêndice B - Fotos da Experiência no Aplicativo da Ray-ban

Neste aplicativo você pode fazer a experimentação

Virtual de óculos da Ray-

Ban preferidos e depois

compartilhar com

amigos para obter feedback

seus oculos favoritos.
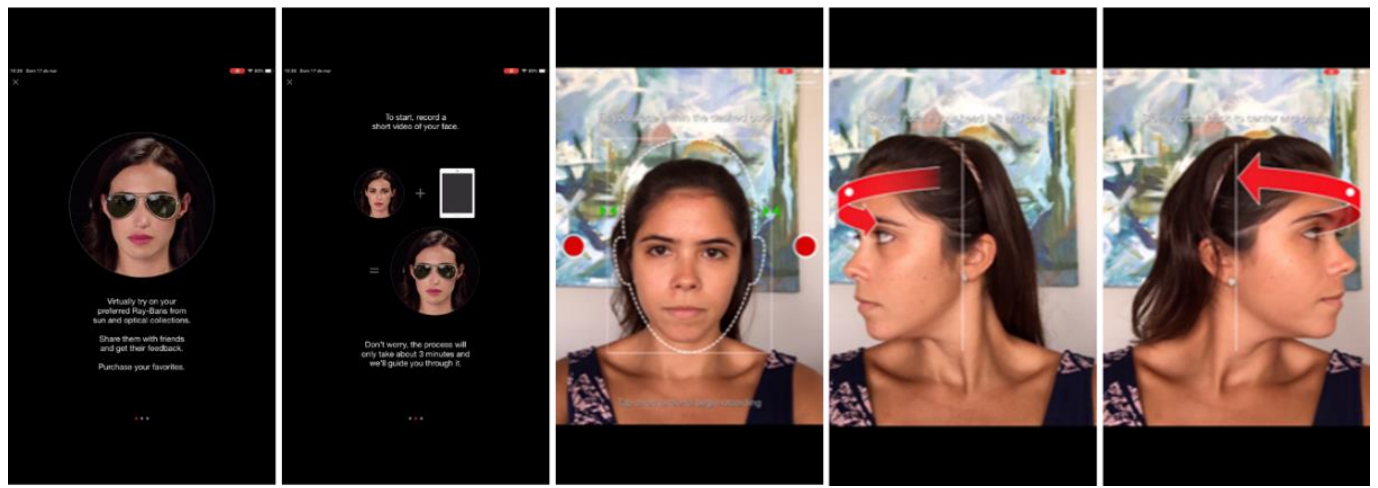

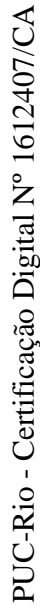

Passo 4-Qual tipo de armação de óculos você procura?

Masculino ou Feminino

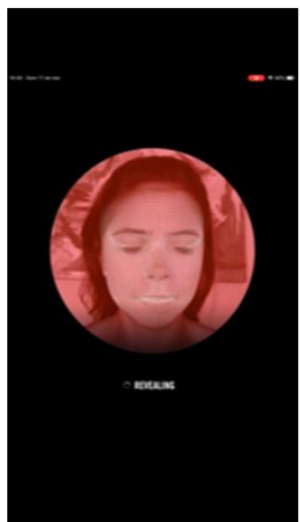

Passo 1 - Coloque a sua face na região delineada Passo 2 - Gire devagar a face para direita $\mathrm{e}$ pause. Depors retorn pause. Depois retorne para o centro e pause. a face para esquerda $\mathrm{e}$

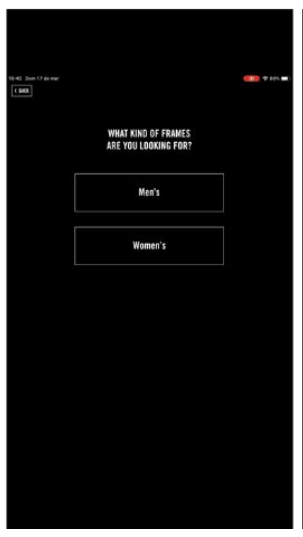

Passo 5 - Qual tipo de óculos normalmente você prefere? Grande, pequeno ou normal

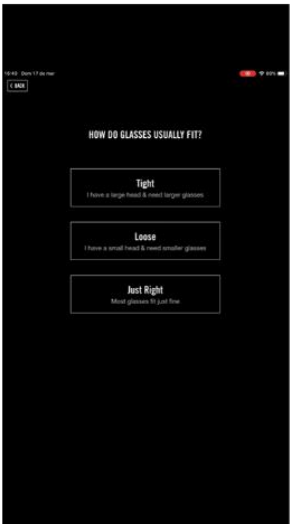

Passo 6 - Selecione óculos e veja como eles ficam na sua face.

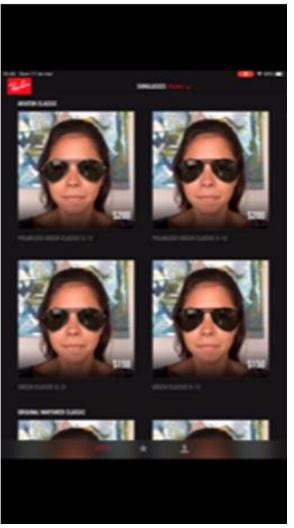

